Cochrane Database of Systematic Reviews

\title{
Rivastigmine for Alzheimer's disease (Review)
}

Birks JS, Chong LY, Grimley Evans J

Birks JS, Chong LY, Grimley Evans J.

Rivastigmine for Alzheimer's disease.

Cochrane Database of Systematic Reviews 2015, Issue 9. Art. No.: CD001191.

DOI: 10.1002/14651858.CD001191.pub4.

www.cochranelibrary.com 
TABLE OF CONTENTS

HEADER

ABSTRACT

PLAIN LANGUAGE SUMMARY

SUMMARY OF FINDINGS

BACKGROUND

OBJECTIVES

METHODS

RESULTS

Figure 1.

Figure 2.

DISCUSSION

AUTHORS' CONCLUSIONS

ACKNOWLEDGEMENTS

REFERENCES

CHARACTERISTICS OF STUDIES

DATA AND ANALYSES

Analysis 1.1. Comparison 1 Rivastigmine (capsules 6 to $12 \mathrm{mg}$ /day in two divided doses or $10 \mathrm{~cm} 2$ (9.5 mg/day) patch) versus placebo, Outcome 1 ADAS-Cog (change from baseline at 24-26 weeks) ITT.

Analysis 1.2. Comparison 1 Rivastigmine (capsules 6 to $12 \mathrm{mg} /$ day in two divided doses or $10 \mathrm{~cm} 2$ (9.5 mg/day) patch) versus placebo, Outcome 2 MMSE (change from baseline at 24-26 weeks) ITT.

Analysis 1.3. Comparison 1 Rivastigmine (capsules 6 to $12 \mathrm{mg} /$ day in two divided doses or $10 \mathrm{~cm} 2$ (9.5 mg/day) patch) versus placebo, Outcome 3 Activities of daily living (change from baseline at 24-26 weeks ) ITT.

Analysis 1.4. Comparison 1 Rivastigmine (capsules 6 to $12 \mathrm{mg}$ /day in two divided doses or $10 \mathrm{~cm} 2$ (9.5 mg/day) patch) versus placebo, Outcome 4 Clinical Global Impression (no change or worse at 24-26 weeks) ITT.

Analysis 1.5. Comparison 1 Rivastigmine (capsules 6 to $12 \mathrm{mg} /$ day in two divided doses or $10 \mathrm{~cm} 2$ (9.5 mg/day) patch) versus placebo, Outcome 5 Behavioural symptoms (change from baseline at 24-26 weeks) ITT.

Analysis 1.6. Comparison 1 Rivastigmine (capsules 6 to $12 \mathrm{mg}$ /day in two divided doses or $10 \mathrm{~cm} 2$ (9.5 mg/day) patch) versus placebo, Outcome 6 Withdrawals before end of treatment at 24-26 weeks.

Analysis 1.7. Comparison 1 Rivastigmine (capsules 6 to $12 \mathrm{mg} /$ day in two divided doses or $10 \mathrm{~cm} 2$ (9.5 mg/day) patch) versus placebo, Outcome 7 at least one adverse event by 24-26 weeks.

Analysis 1.8. Comparison 1 Rivastigmine (capsules 6 to $12 \mathrm{mg}$ /day in two divided doses or $10 \mathrm{~cm} 2$ (9.5 mg/day) patch) versus placebo, Outcome 8 NPI-D carer distress scale (change from baseline at 24-26 weeks) ITT.

Analysis 2.1. Comparison 2 Rivastigmine oral capsules (1 to $4 \mathrm{mg}$ /day or 6 to $12 \mathrm{mg} /$ day in two divided doses) versus placebo, Outcome 1 ADAS-Cog (change from baseline at 12 weeks) ITT.

Analysis 2.2. Comparison 2 Rivastigmine oral capsules (1 to $4 \mathrm{mg}$ /day or 6 to $12 \mathrm{mg} /$ day in two divided doses) versus placebo, Outcome 2 ADAS-Cog (change from baseline at 26 weeks) ITT.

Analysis 2.3. Comparison 2 Rivastigmine oral capsules ( 1 to $4 \mathrm{mg}$ /day or 6 to $12 \mathrm{mg} /$ day in two divided doses) versus placebo, Outcome 3 MMSE (change from baseline at 26 weeks) ITT.

Analysis 2.4. Comparison 2 Rivastigmine oral capsules ( 1 to $4 \mathrm{mg}$ /day or 6 to $12 \mathrm{mg} /$ day in two divided doses) versus placebo, Outcome 4 SIB (change from baseline at 26 weeks).

Analysis 2.5. Comparison 2 Rivastigmine oral capsules ( 1 to $4 \mathrm{mg} /$ day or 6 to $12 \mathrm{mg} /$ day in two divided doses) versus placebo, Outcome 5 ADCS-ADL (change from baseline at 26 weeks) ITT.

Analysis 2.6. Comparison 2 Rivastigmine oral capsules ( 1 to $4 \mathrm{mg} /$ day or 6 to $12 \mathrm{mg} /$ day in two divided doses) versus placebo, Outcome 6 PDS (change from baseline at 12 weeks ) ITT.

Analysis 2.7. Comparison 2 Rivastigmine oral capsules ( 1 to $4 \mathrm{mg}$ /day or 6 to $12 \mathrm{mg} /$ day in two divided doses) versus placebo, Outcome 7 PDS (change from baseline at 26 weeks) ITT.

Analysis 2.8. Comparison 2 Rivastigmine oral capsules (1 to $4 \mathrm{mg}$ /day or 6 to $12 \mathrm{mg} /$ day in two divided doses) versus placebo, Outcome 8 Clinical Global Impression (no change or worse at 12 weeks) ITT.

Analysis 2.9. Comparison 2 Rivastigmine oral capsules ( 1 to $4 \mathrm{mg} /$ day or 6 to $12 \mathrm{mg} /$ day in two divided doses) versus placebo, Outcome 9 Clinical Global Impression (no change or worse at 26 weeks) ITT.

Analysis 2.10. Comparison 2 Rivastigmine oral capsules ( 1 to $4 \mathrm{mg}$ /day or 6 to $12 \mathrm{mg} /$ day in two divided doses) versus placebo, Outcome $10 \mathrm{GDS}$ ( moderately severe, severe, or very severe dementia at 26 weeks) ITT.

Analysis 2.11. Comparison 2 Rivastigmine oral capsules ( 1 to $4 \mathrm{mg} /$ day or 6 to $12 \mathrm{mg} /$ day in two divided doses) versus placebo, Outcome 11 CGIC (little or no improvement, or worse at 12 weeks) ITT. 
Analysis 2.12. Comparison 2 Rivastigmine oral capsules ( 1 to $4 \mathrm{mg}$ /day or 6 to $12 \mathrm{mg} /$ day in two divided doses) versus placebo, Outcome 12 Behavioural disturbance NPI-10 or NPI-12 (change from baseline at 26 weeks) ITT.

Analysis 2.13. Comparison 2 Rivastigmine oral capsules ( 1 to $4 \mathrm{mg} /$ day or 6 to $12 \mathrm{mg} /$ day in two divided doses) versus placebo, Outcome 13 withdrawals before end of treatment at 12 weeks.

Analysis 2.14. Comparison 2 Rivastigmine oral capsules ( 1 to $4 \mathrm{mg} /$ day or 6 to $12 \mathrm{mg} /$ day in two divided doses) versus placebo, Outcome 14 withdrawals before end of treatment at 26 weeks.

Analysis 2.15. Comparison 2 Rivastigmine oral capsules ( 1 to $4 \mathrm{mg} /$ day or 6 to $12 \mathrm{mg} /$ day in two divided doses) versus placebo, Outcome 15 at least one adverse event by the end of titration period.

Analysis 2.16. Comparison 2 Rivastigmine oral capsules ( 1 to $4 \mathrm{mg} /$ day or 6 to $12 \mathrm{mg} /$ day in two divided doses) versus placebo, Outcome 16 at least one adverse event by 26 weeks.

Analysis 2.17. Comparison 2 Rivastigmine oral capsules ( 1 to $4 \mathrm{mg}$ /day or 6 to $12 \mathrm{mg} /$ day in two divided doses) versus placebo, Outcome 17 dropouts due to adverse events by 12 weeks.

Analysis 2.18. Comparison 2 Rivastigmine oral capsules ( 1 to $4 \mathrm{mg} /$ day or 6 to $12 \mathrm{mg} /$ day in two divided doses) versus placebo, Outcome 18 dropouts due to adverse events by 26 weeks.

Analysis 2.19. Comparison 2 Rivastigmine oral capsules ( 1 to $4 \mathrm{mg} /$ day or 6 to $12 \mathrm{mg} /$ day in two divided doses) versus placebo, Outcome 19 at least one adverse event of decreased appetite by 26 weeks.

Analysis 2.20. Comparison 2 Rivastigmine oral capsules ( 1 to $4 \mathrm{mg}$ /day or 6 to $12 \mathrm{mg} /$ day in two divided doses) versus placebo, Outcome 20 at least one adverse event of weight decrease by 26 weeks.

Analysis 2.21. Comparison 2 Rivastigmine oral capsules ( 1 to $4 \mathrm{mg} /$ day or 6 to $12 \mathrm{mg} /$ day in two divided doses) versus placebo, Outcome 21 at least one adverse event of nausea by the end of titration period.

Analysis 2.22. Comparison 2 Rivastigmine oral capsules ( 1 to $4 \mathrm{mg} /$ day or 6 to $12 \mathrm{mg} /$ day in two divided doses) versus placebo, Outcome 22 at least one adverse event of nausea by 26 weeks.

Analysis 2.23. Comparison 2 Rivastigmine oral capsules ( 1 to $4 \mathrm{mg}$ /day or 6 to $12 \mathrm{mg} /$ day in two divided doses) versus placebo, Outcome 23 at least one adverse event of vomiting by the end of titration period.

Analysis 2.24. Comparison 2 Rivastigmine oral capsules ( 1 to $4 \mathrm{mg}$ /day or 6 to $12 \mathrm{mg} /$ day in two divided doses) versus placebo, Outcome 24 at least one adverse event of vomiting by 26 weeks.

Analysis 2.25. Comparison 2 Rivastigmine oral capsules ( 1 to $4 \mathrm{mg}$ /day or 6 to $12 \mathrm{mg} /$ day in two divided doses) versus placebo, Outcome 25 at least one adverse event of diarrhoea by the end of titration period.

Analysis 2.26. Comparison 2 Rivastigmine oral capsules ( 1 to $4 \mathrm{mg} /$ day or 6 to $12 \mathrm{mg} /$ day in two divided doses) versus placebo, Outcome 26 at least one adverse event of diarrhoea by 26 weeks.

Analysis 2.27. Comparison 2 Rivastigmine oral capsules ( 1 to $4 \mathrm{mg} /$ day or 6 to $12 \mathrm{mg} /$ day in two divided doses) versus placebo, Outcome 27 at least one adverse event of anorexia by the end of titration period.

Analysis 2.28. Comparison 2 Rivastigmine oral capsules (1 to $4 \mathrm{mg} /$ day or 6 to $12 \mathrm{mg} /$ day in two divided doses) versus placebo, Outcome 28 at least one adverse event of anorexia by 26 weeks.

Analysis 2.29. Comparison 2 Rivastigmine oral capsules ( 1 to $4 \mathrm{mg} /$ day or 6 to $12 \mathrm{mg} /$ day in two divided doses) versus placebo, Outcome 29 at least one adverse event of headache by the end of titration period.

Analysis 2.30. Comparison 2 Rivastigmine oral capsules ( 1 to $4 \mathrm{mg}$ /day or 6 to $12 \mathrm{mg} /$ day in two divided doses) versus placebo, Outcome 30 at least one adverse event of headache by 26 weeks.

Analysis 2.31. Comparison 2 Rivastigmine oral capsules ( 1 to $4 \mathrm{mg}$ /day or 6 to $12 \mathrm{mg} /$ day in two divided doses) versus placebo, Outcome 31 at least one adverse event of insomnia by the end of titration period.

Analysis 2.32. Comparison 2 Rivastigmine oral capsules ( 1 to $4 \mathrm{mg} /$ day or 6 to $12 \mathrm{mg} /$ day in two divided doses) versus placebo, Outcome 32 at least one adverse event of insomnia by 26 weeks.

Analysis 2.33. Comparison 2 Rivastigmine oral capsules ( 1 to $4 \mathrm{mg} /$ day or 6 to $12 \mathrm{mg} /$ day in two divided doses) versus placebo, Outcome 33 at least one adverse event of syncope by the end of titration period.

Analysis 2.34. Comparison 2 Rivastigmine oral capsules ( 1 to $4 \mathrm{mg}$ /day or 6 to $12 \mathrm{mg} /$ day in two divided doses) versus placebo, Outcome 34 at least one adverse event of syncope by 26 weeks.

Analysis 2.35. Comparison 2 Rivastigmine oral capsules ( 1 to $4 \mathrm{mg} /$ day or 6 to $12 \mathrm{mg} /$ day in two divided doses) versus placebo, Outcome 35 at least one adverse event of abdominal pain by the end of titration period.

Analysis 2.36. Comparison 2 Rivastigmine oral capsules ( 1 to $4 \mathrm{mg}$ /day or 6 to $12 \mathrm{mg} /$ day in two divided doses) versus placebo, Outcome 36 at least one adverse event of abdominal pain by 26 weeks.

Analysis 2.37. Comparison 2 Rivastigmine oral capsules ( 1 to $4 \mathrm{mg} /$ day or 6 to $12 \mathrm{mg} /$ day in two divided doses) versus placebo, Outcome 37 at least one adverse event of dizziness by the end of titration period.

Analysis 2.38. Comparison 2 Rivastigmine oral capsules ( 1 to $4 \mathrm{mg}$ /day or 6 to $12 \mathrm{mg} /$ day in two divided doses) versus placebo, Outcome 38 at least one adverse event of dizziness by 26 weeks.

Analysis 2.39. Comparison 2 Rivastigmine oral capsules ( 1 to $4 \mathrm{mg} /$ day or 6 to $12 \mathrm{mg} /$ day in two divided doses) versus placebo, Outcome 39 at least one adverse event of bone fracture by the end of titration period. 
Analysis 2.40. Comparison 2 Rivastigmine oral capsules ( 1 to $4 \mathrm{mg}$ /day or 6 to $12 \mathrm{mg} /$ day in two divided doses) versus placebo, Outcome 40 at least one adverse event of bone fracture by 26 weeks.

Analysis 2.41. Comparison 2 Rivastigmine oral capsules (1 to $4 \mathrm{mg} /$ day or 6 to $12 \mathrm{mg} /$ day in two divided doses) versus placebo, Outcome 41 at least one adverse event of asthenia by 26 weeks.

Analysis 2.42. Comparison 2 Rivastigmine oral capsules ( 1 to $4 \mathrm{mg}$ /day or 6 to $12 \mathrm{mg} /$ day in two divided doses) versus placebo, Outcome 42 at least one severe adverse event by the end of titration period.

Analysis 2.43. Comparison 2 Rivastigmine oral capsules (1 to $4 \mathrm{mg} /$ day or 6 to $12 \mathrm{mg} /$ day in two divided doses) versus placebo, Outcome 43 at least one serious adverse event by 26 weeks.

Analysis 2.44. Comparison 2 Rivastigmine oral capsules ( 1 to $4 \mathrm{mg} /$ day or 6 to $12 \mathrm{mg} /$ day in two divided doses) versus placebo, Outcome 44 deaths before end of treatment at 12 weeks.

Analysis 2.45. Comparison 2 Rivastigmine oral capsules (1 to $4 \mathrm{mg} /$ day or 6 to $12 \mathrm{mg} /$ day in two divided doses) versus placebo, Outcome 45 deaths before end of treatment at 26 weeks.

Analysis 2.46. Comparison 2 Rivastigmine oral capsules (1 to $4 \mathrm{mg} /$ day or 6 to $12 \mathrm{mg} /$ day in two divided doses) versus placebo, Outcome 46 CIBIC-Plus (no change or worse at 12 weeks) OC.

Analysis 2.47. Comparison 2 Rivastigmine oral capsules ( 1 to $4 \mathrm{mg} /$ day or 6 to $12 \mathrm{mg} /$ day in two divided doses) versus placebo, Outcome 47 CIBIC-Plus (no change or worse at 26 weeks) OC.

Analysis 2.48. Comparison 2 Rivastigmine oral capsules ( 1 to $4 \mathrm{mg}$ /day or 6 to $12 \mathrm{mg} /$ day in two divided doses) versus placebo, Outcome $48 \mathrm{CIBIC}$-Plus (no change or worse at 12 weeks) OC+RDO.

Analysis 2.49. Comparison 2 Rivastigmine oral capsules ( 1 to $4 \mathrm{mg}$ /day or 6 to $12 \mathrm{mg} /$ day in two divided doses) versus placebo, Outcome 49 CIBIC-Plus (no change or worse at 26 weeks)OC+RDO.

Analysis 2.50. Comparison 2 Rivastigmine oral capsules ( 1 to $4 \mathrm{mg} /$ day or 6 to $12 \mathrm{mg} /$ day in two divided doses) versus placebo, Outcome $50 \mathrm{CIBIC}$-Plus (no change or worse at 12 weeks) ALL+OC.

Analysis 2.51. Comparison 2 Rivastigmine oral capsules ( 1 to $4 \mathrm{mg} /$ day or 6 to $12 \mathrm{mg} /$ day in two divided doses) versus placebo, Outcome 51 CIBIC-Plus (no change or worse at 26 weeks) ALL+OC.

Analysis 2.52. Comparison 2 Rivastigmine oral capsules ( 1 to $4 \mathrm{mg}$ /day or 6 to $12 \mathrm{mg} /$ day in two divided doses) versus placebo, Outcome 52 ADAS-Cog (change from baseline at 12 weeks) OC.

Analysis 2.53. Comparison 2 Rivastigmine oral capsules ( 1 to $4 \mathrm{mg}$ /day or 6 to $12 \mathrm{mg} /$ day in two divided doses) versus placebo, Outcome 53 ADAS-Cog (change from baseline at 26 weeks) OC.

Analysis 2.54. Comparison 2 Rivastigmine oral capsules ( 1 to $4 \mathrm{mg} /$ day or 6 to $12 \mathrm{mg} /$ day in two divided doses) versus placebo, Outcome 54 ADAS-Cog (change from baseline at 12 weeks) OC+RDO.

Analysis 2.55. Comparison 2 Rivastigmine oral capsules ( 1 to $4 \mathrm{mg}$ /day or 6 to $12 \mathrm{mg} /$ day in two divided doses) versus placebo, Outcome 55 ADAS-Cog (change from baseline at 26 weeks) OC+RDO.

Analysis 3.1. Comparison 3 Rivastigmine $20 \mathrm{~cm} 2$ patch $(17.4 \mathrm{mg} /$ day) versus placebo, Outcome 1 ADAS-Cog (change from baseline at 24 weeks) ITT.

Analysis 3.2. Comparison 3 Rivastigmine $20 \mathrm{~cm} 2$ patch $(17.4 \mathrm{mg} /$ day) versus placebo, Outcome 2 TMT-A (change from baseline at 24 weeks) ITT.

Analysis 3.3. Comparison 3 Rivastigmine $20 \mathrm{~cm} 2$ patch (17.4 mg/day) versus placebo, Outcome 3 clock drawing (change from baseline at 24 weeks) ITT.

Analysis 3.4. Comparison 3 Rivastigmine $20 \mathrm{~cm} 2$ patch $(17.4 \mathrm{mg} /$ day) versus placebo, Outcome 4 MMSE (change from baseline at 24 weeks) ITT.

Analysis 3.5. Comparison 3 Rivastigmine $20 \mathrm{~cm} 2$ patch $(17.4 \mathrm{mg} /$ day) versus placebo, Outcome 5 ADCS-ADL (change from baseline at 24 weeks) ITT.

Analysis 3.6. Comparison 3 Rivastigmine $20 \mathrm{~cm} 2$ patch (17.4 mg/day) versus placebo, Outcome $6 \mathrm{NPI}-12$ (change from baseline at 24 weeks) ITT.

Analysis 3.7. Comparison 3 Rivastigmine $20 \mathrm{~cm} 2$ patch $(17.4 \mathrm{mg} /$ day) versus placebo, Outcome 7 withdrawals before end of treatment at 24 weeks.

Analysis 3.8. Comparison 3 Rivastigmine $20 \mathrm{~cm} 2$ patch $(17.4 \mathrm{mg} /$ day $)$ versus placebo, Outcome 8 at least one adverse event by 24 weeks.

Analysis 3.9. Comparison 3 Rivastigmine $20 \mathrm{~cm} 2$ patch $(17.4 \mathrm{mg} /$ day $)$ versus placebo, Outcome 9 withdrawals due to an adverse event before end of treatment at 24 weeks.

Analysis 3.10. Comparison 3 Rivastigmine $20 \mathrm{~cm} 2$ patch $(17.4 \mathrm{mg} /$ day) versus placebo, Outcome 10 at least one adverse event of dizziness by 24 weeks.

Analysis 3.11. Comparison 3 Rivastigmine $20 \mathrm{~cm} 2$ patch $(17.4 \mathrm{mg} /$ day) versus placebo, Outcome 11 at least one adverse event of nausea by 24 weeks.

Analysis 3.12. Comparison 3 Rivastigmine $20 \mathrm{~cm} 2$ patch $(17.4 \mathrm{mg} /$ day) versus placebo, Outcome 12 at least one adverse event of vomiting by 24 weeks. 
Analysis 3.13. Comparison 3 Rivastigmine $20 \mathrm{~cm} 2$ patch $(17.4 \mathrm{mg} /$ day) versus placebo, Outcome 13 at least one adverse event of weight decrease by 24 weeks.

Analysis 3.14. Comparison 3 Rivastigmine $20 \mathrm{~cm} 2$ patch $(17.4 \mathrm{mg} /$ day) versus placebo, Outcome 14 at least one adverse event of decreased appetite by 24 weeks.

Analysis 3.15. Comparison 3 Rivastigmine $20 \mathrm{~cm} 2$ patch $(17.4 \mathrm{mg} /$ day) versus placebo, Outcome 15 at least one adverse event of headache by 24 weeks.

Analysis 3.16. Comparison 3 Rivastigmine $20 \mathrm{~cm} 2$ patch $(17.4 \mathrm{mg} /$ day) versus placebo, Outcome 16 at least one adverse event of asthenia by 24 weeks.

Analysis 3.17. Comparison 3 Rivastigmine $20 \mathrm{~cm} 2$ patch $(17.4 \mathrm{mg} /$ day) versus placebo, Outcome 17 deaths before end of treatment at 24 weeks.

Analysis 3.18. Comparison 3 Rivastigmine $20 \mathrm{~cm} 2$ patch $(17.4 \mathrm{mg} /$ day) versus placebo, Outcome $18 \mathrm{NPI}-\mathrm{D}$ carer distress scale (change from baseline at 24 weeks) ITT.

Analysis 4.1. Comparison 4 Rivastigmine $10 \mathrm{~cm} 2$ patch $(9.5 \mathrm{mg} /$ day) versus placebo, Outcome 1 ADAS-Cog (change from baseline at 24 weeks) ITT.

Analysis 4.2. Comparison 4 Rivastigmine $10 \mathrm{~cm} 2$ patch $(9.5 \mathrm{mg} /$ day) versus placebo, Outcome 2 MMSE (change from baseline at 24 weeks) ITT.

Analysis 4.3. Comparison 4 Rivastigmine $10 \mathrm{~cm} 2$ patch $(9.5 \mathrm{mg} /$ day) versus placebo, Outcome 3 clock drawing (change from baseline at 24 weeks) ITT.

Analysis 4.4. Comparison 4 Rivastigmine $10 \mathrm{~cm} 2$ patch $(9.5 \mathrm{mg} /$ day) versus placebo, Outcome 4 TMT-A (change from baseline at 24 weeks) ITT.

Analysis 4.5. Comparison 4 Rivastigmine $10 \mathrm{~cm} 2$ patch $(9.5 \mathrm{mg} /$ day) versus placebo, Outcome 5 Mental Function Impairment MENFIS (change from baseline at 24 weeks) ITT.

Analysis 4.6. Comparison 4 Rivastigmine $10 \mathrm{~cm} 2$ patch $(9.5 \mathrm{mg} /$ day) versus placebo, Outcome 6 ADCS-ADL (change from baseline at 24 weeks) ITT.

Analysis 4.7. Comparison 4 Rivastigmine $10 \mathrm{~cm} 2$ patch $(9.5 \mathrm{mg} /$ day) versus placebo, Outcome 7 Disability Assessment for Dementia (DAD) (change from baseline at 24 weeks) ITT.

Analysis 4.8. Comparison 4 Rivastigmine $10 \mathrm{~cm} 2$ patch $(9.5 \mathrm{mg} /$ day) versus placebo, Outcome 8 BEHAVE-AD (change from baseline at 24 weeks) ITT.

Analysis 4.9. Comparison 4 Rivastigmine $10 \mathrm{~cm} 2$ patch $(9.5 \mathrm{mg} /$ day) versus placebo, Outcome $9 \mathrm{NPI}-12$ (change from baseline at 24 weeks) ITT.

Analysis 4.10. Comparison 4 Rivastigmine $10 \mathrm{~cm} 2$ patch $(9.5 \mathrm{mg} /$ day $)$ versus placebo, Outcome 10 Clinical Global Impression (no change or worse at 24 weeks).

Analysis 4.11. Comparison 4 Rivastigmine $10 \mathrm{~cm} 2$ patch $(9.5 \mathrm{mg} /$ day) versus placebo, Outcome 11 withdrawals before end of treatment at 24 weeks.

Analysis 4.12. Comparison 4 Rivastigmine $10 \mathrm{~cm} 2$ patch $(9.5 \mathrm{mg} /$ day) versus placebo, Outcome 12 at least one adverse event by 24 weeks.

Analysis 4.13. Comparison 4 Rivastigmine $10 \mathrm{~cm} 2$ patch $(9.5 \mathrm{mg} /$ day) versus placebo, Outcome 13 withdrawals due to an adverse event before end of treatment at 24 weeks.

Analysis 4.14. Comparison 4 Rivastigmine $10 \mathrm{~cm} 2$ patch $(9.5 \mathrm{mg} /$ day) versus placebo, Outcome 14 at least one adverse event of application site erythema by 24 weeks.

Analysis 4.15. Comparison 4 Rivastigmine $10 \mathrm{~cm} 2$ patch $(9.5 \mathrm{mg} /$ day) versus placebo, Outcome 15 at least one adverse event of application site pruritis by 24 weeks.

Analysis 4.16. Comparison 4 Rivastigmine $10 \mathrm{~cm} 2$ patch $(9.5 \mathrm{mg} /$ day) versus placebo, Outcome 16 at least one adverse event of application site edema by 24 weeks.

Analysis 4.17. Comparison 4 Rivastigmine $10 \mathrm{~cm} 2$ patch $(9.5 \mathrm{mg} /$ day) versus placebo, Outcome 17 at least one adverse event application site exfoliation by 24 weeks.

Analysis 4.18. Comparison 4 Rivastigmine $10 \mathrm{~cm} 2$ patch $(9.5 \mathrm{mg} /$ day) versus placebo, Outcome 18 at least one adverse event of dermatitis contact by 24 weeks.

Analysis 4.19. Comparison 4 Rivastigmine $10 \mathrm{~cm} 2$ patch $(9.5 \mathrm{mg} /$ day) versus placebo, Outcome 19 at least one adverse event of nasopharyngitis by 24 weeks.

Analysis 4.20. Comparison 4 Rivastigmine $10 \mathrm{~cm} 2$ patch $(9.5 \mathrm{mg} /$ day) versus placebo, Outcome 20 at least one adverse event of nausea by 24 weeks.

Analysis 4.21. Comparison 4 Rivastigmine $10 \mathrm{~cm} 2$ patch $(9.5 \mathrm{mg} /$ day) versus placebo, Outcome 21 at least one adverse event of vomiting by 24 weeks.

Analysis 4.22. Comparison 4 Rivastigmine $10 \mathrm{~cm} 2$ patch $(9.5 \mathrm{mg} /$ day $)$ versus placebo, Outcome 22 at least one adverse event of diarrhoea by 24 weeks. 
Analysis 4.23. Comparison 4 Rivastigmine $10 \mathrm{~cm} 2$ patch $(9.5 \mathrm{mg} /$ day) versus placebo, Outcome 23 at least one adverse event of weight decrease by 24 weeks.

Analysis 4.24. Comparison 4 Rivastigmine $10 \mathrm{~cm} 2$ patch $(9.5 \mathrm{mg} /$ day) versus placebo, Outcome 24 at least one adverse event of dizziness by 24 weeks.

Analysis 4.25. Comparison 4 Rivastigmine $10 \mathrm{~cm} 2$ patch $(9.5 \mathrm{mg} /$ day) versus placebo, Outcome 25 at least one adverse event of decreased appetite by 24 weeks.

Analysis 4.26. Comparison 4 Rivastigmine $10 \mathrm{~cm} 2$ patch $(9.5 \mathrm{mg} /$ day $)$ versus placebo, Outcome 26 at least one adverse event of headache by 24 weeks.

Analysis 4.27. Comparison 4 Rivastigmine $10 \mathrm{~cm} 2$ patch $(9.5 \mathrm{mg} /$ day) versus placebo, Outcome 27 at least one adverse event of asthenia by 24 weeks.

Analysis 4.28. Comparison 4 Rivastigmine $10 \mathrm{~cm} 2$ patch $(9.5 \mathrm{mg} /$ day $)$ versus placebo, Outcome 28 deaths before end of treatment at 24 weeks.

Analysis 4.29. Comparison 4 Rivastigmine $10 \mathrm{~cm} 2$ patch $(9.5 \mathrm{mg} /$ day $)$ versus placebo, Outcome 29 NPI-D carer distress scale (change from baseline at 24 weeks) ITT.

Analysis 5.1. Comparison 5 Rivastigmine $5 \mathrm{~cm} 2$ patch $(4.6 \mathrm{mg} /$ day) versus placebo, Outcome 1 ADAS-J Cog (change from baseline at 24 weeks) ITT.

Analysis 5.2. Comparison 5 Rivastigmine $5 \mathrm{~cm} 2$ patch $(4.6 \mathrm{mg} /$ day) versus placebo, Outcome 2 MMSE (change from baseline at 24 weeks) ITT.

Analysis 5.3. Comparison 5 Rivastigmine $5 \mathrm{~cm} 2$ patch $(4.6 \mathrm{mg} /$ day) versus placebo, Outcome 3 Mental Function Impairment MENFIS (change from baseline at 24 weeks) ITT.

Analysis 5.4. Comparison 5 Rivastigmine $5 \mathrm{~cm} 2$ patch $(4.6 \mathrm{mg} /$ day) versus placebo, Outcome 4 Disability Assessment for Dementia (DAD) (change from baseline at 24 weeks) ITT.

Analysis 5.5. Comparison 5 Rivastigmine $5 \mathrm{~cm} 2$ patch ( $4.6 \mathrm{mg} /$ day) versus placebo, Outcome 5 CIBIC-Plus J (no change or worse at 24 weeks) ITT.

Analysis 5.6. Comparison 5 Rivastigmine $5 \mathrm{~cm} 2$ patch $(4.6 \mathrm{mg}$ /day) versus placebo, Outcome 6 BEHAVE-AD (change from baseline at 24 weeks) ITT.

Analysis 5.7. Comparison 5 Rivastigmine $5 \mathrm{~cm} 2$ patch $(4.6 \mathrm{mg} /$ day) versus placebo, Outcome 7 withdrawals before end of treatment at 24 weeks.

Analysis 5.8. Comparison 5 Rivastigmine $5 \mathrm{~cm} 2$ patch ( $4.6 \mathrm{mg} /$ day) versus placebo, Outcome 8 at least one adverse event by 24 weeks.

Analysis 5.9. Comparison 5 Rivastigmine $5 \mathrm{~cm} 2$ patch $(4.6 \mathrm{mg} /$ day) versus placebo, Outcome 9 withdrawals due to an adverse event before end of treatment at 24 weeks.

Analysis 5.10. Comparison 5 Rivastigmine $5 \mathrm{~cm} 2$ patch $(4.6 \mathrm{mg} /$ day) versus placebo, Outcome 10 at least one adverse event of application site erythema by 24 weeks.

Analysis 5.11. Comparison 5 Rivastigmine $5 \mathrm{~cm} 2$ patch $(4.6 \mathrm{mg} /$ day) versus placebo, Outcome 11 at least one adverse event of application site pruritis by 24 weeks.

Analysis 5.12. Comparison 5 Rivastigmine $5 \mathrm{~cm} 2$ patch ( $4.6 \mathrm{mg} /$ day) versus placebo, Outcome 12 at least one adverse event of application site edema by 24 weeks.

Analysis 5.13. Comparison 5 Rivastigmine $5 \mathrm{~cm} 2$ patch $(4.6 \mathrm{mg} /$ day) versus placebo, Outcome 13 at least one adverse event application site exfoliation by 24 weeks.

Analysis 5.14. Comparison 5 Rivastigmine $5 \mathrm{~cm} 2$ patch $(4.6 \mathrm{mg} /$ day) versus placebo, Outcome 14 at least one adverse event of dermatitis contact by 24 weeks.

Analysis 5.15. Comparison 5 Rivastigmine $5 \mathrm{~cm} 2$ patch $(4.6 \mathrm{mg} /$ day) versus placebo, Outcome 15 at least one adverse event of nasopharyngitis by 24 weeks.

Analysis 5.16. Comparison 5 Rivastigmine $5 \mathrm{~cm} 2$ patch $(4.6 \mathrm{mg} /$ day) versus placebo, Outcome 16 at least one adverse event of nausea by 24 weeks.

Analysis 5.17. Comparison 5 Rivastigmine $5 \mathrm{~cm} 2$ patch $(4.6 \mathrm{mg} /$ day) versus placebo, Outcome 17 at least one adverse event of vomiting by 24 weeks.

Analysis 5.18. Comparison 5 Rivastigmine $5 \mathrm{~cm} 2$ patch $(4.6 \mathrm{mg} /$ day $)$ versus placebo, Outcome 18 deaths before end of treatment at 24 weeks.

Analysis 6.1. Comparison 6 Rivastigmine $10 \mathrm{~cm} 2$ patch $(9.5 \mathrm{mg} /$ day) versus rivastigmine capsules (6 to $12 \mathrm{mg} /$ day in two divided doses), Outcome 1 ADAS-Cog (change from baseline at 24 weeks) ITT.

Analysis 6.2. Comparison 6 Rivastigmine $10 \mathrm{~cm} 2$ patch $(9.5 \mathrm{mg} /$ day) versus rivastigmine capsules ( 6 to $12 \mathrm{mg} /$ day in two divided doses), Outcome 2 MMSE (change from baseline at 24 weeks) ITT.

Analysis 6.3. Comparison 6 Rivastigmine $10 \mathrm{~cm} 2$ patch $(9.5 \mathrm{mg} /$ day) versus rivastigmine capsules ( 6 to $12 \mathrm{mg} /$ day in two divided doses), Outcome 3 clock drawing (change from baseline at 24 weeks) ITT. 
Analysis 6.4. Comparison 6 Rivastigmine $10 \mathrm{~cm} 2$ patch ( $9.5 \mathrm{mg} /$ day) versus rivastigmine capsules (6 to $12 \mathrm{mg} /$ day in two divided doses), Outcome 4 TMT-A (change from baseline at 24 weeks) ITT.

Analysis 6.5. Comparison 6 Rivastigmine $10 \mathrm{~cm} 2$ patch ( $9.5 \mathrm{mg} /$ day) versus rivastigmine capsules (6 to $12 \mathrm{mg} /$ day in two divided doses), Outcome 5 ADCS-ADL (change from baseline at 24 weeks) ITT.

Analysis 6.6. Comparison 6 Rivastigmine $10 \mathrm{~cm} 2$ patch $(9.5 \mathrm{mg} /$ day) versus rivastigmine capsules ( 6 to $12 \mathrm{mg} /$ day in two divided doses), Outcome 6 Clinical Global Impression (no change or worse at 24 weeks).

Analysis 6.7. Comparison 6 Rivastigmine $10 \mathrm{~cm} 2$ patch $(9.5 \mathrm{mg} /$ day) versus rivastigmine capsules (6 to $12 \mathrm{mg} /$ day in two divided doses), Outcome $7 \mathrm{NPI}-12$ (change from baseline at 24 weeks) ITT.

Analysis 6.8. Comparison 6 Rivastigmine $10 \mathrm{~cm} 2$ patch ( $9.5 \mathrm{mg} /$ day) versus rivastigmine capsules (6 to $12 \mathrm{mg} /$ day in two divided doses), Outcome 8 withdrawals before end of treatment at 24 weeks.

Analysis 6.9. Comparison 6 Rivastigmine $10 \mathrm{~cm} 2$ patch $(9.5 \mathrm{mg} /$ day) versus rivastigmine capsules ( 6 to $12 \mathrm{mg} /$ day in two divided doses), Outcome 9 at least one adverse event by 24 weeks.

Analysis 6.10. Comparison 6 Rivastigmine $10 \mathrm{~cm} 2$ patch $(9.5 \mathrm{mg} /$ day) versus rivastigmine capsules (6 to $12 \mathrm{mg} / \mathrm{day}$ in two divided doses), Outcome 10 withdrawals due to an adverse event before end of treatment at 24 weeks.

Analysis 6.11 . Comparison 6 Rivastigmine $10 \mathrm{~cm} 2$ patch $(9.5 \mathrm{mg} /$ day) versus rivastigmine capsules (6 to $12 \mathrm{mg} / \mathrm{day}$ in two divided doses), Outcome 11 at least one adverse event of nausea by 24 weeks.

Analysis 6.12. Comparison 6 Rivastigmine $10 \mathrm{~cm} 2$ patch $(9.5 \mathrm{mg} /$ day) versus rivastigmine capsules (6 to $12 \mathrm{mg} /$ day in two divided doses), Outcome 12 at least one adverse event of vomiting by 24 weeks.

Analysis 6.13 . Comparison 6 Rivastigmine $10 \mathrm{~cm} 2$ patch $(9.5 \mathrm{mg} /$ day) versus rivastigmine capsules (6 to $12 \mathrm{mg} /$ day in two divided doses), Outcome 13 at least one adverse event of diarrhoea by 24 weeks.

Analysis 6.14. Comparison 6 Rivastigmine $10 \mathrm{~cm} 2$ patch $(9.5 \mathrm{mg} /$ day) versus rivastigmine capsules (6 to $12 \mathrm{mg} /$ day in two divided doses), Outcome 14 at least one adverse event of weight decrease by 24 weeks.

Analysis 6.15. Comparison 6 Rivastigmine $10 \mathrm{~cm} 2$ patch $(9.5 \mathrm{mg} /$ day) versus rivastigmine capsules (6 to $12 \mathrm{mg} /$ day in two divided doses), Outcome 15 at least one adverse event of dizziness by 24 weeks.

Analysis 6.16. Comparison 6 Rivastigmine $10 \mathrm{~cm} 2$ patch $(9.5 \mathrm{mg} /$ day) versus rivastigmine capsules (6 to $12 \mathrm{mg} / \mathrm{day}$ in two divided doses), Outcome 16 at least one adverse event of decreased appetite by 24 weeks.

Analysis 6.17 . Comparison 6 Rivastigmine $10 \mathrm{~cm} 2$ patch $(9.5 \mathrm{mg} /$ day) versus rivastigmine capsules (6 to $12 \mathrm{mg} / \mathrm{day}$ in two divided doses), Outcome 17 at least one adverse event of headache by 24 weeks.

Analysis 6.18. Comparison 6 Rivastigmine $10 \mathrm{~cm} 2$ patch $(9.5 \mathrm{mg} /$ day) versus rivastigmine capsules (6 to $12 \mathrm{mg} / \mathrm{day}$ in two divided doses), Outcome 18 at least one adverse event of asthenia by 24 weeks.

Analysis 6.19. Comparison 6 Rivastigmine $10 \mathrm{~cm} 2$ patch $(9.5 \mathrm{mg} /$ day) versus rivastigmine capsules (6 to $12 \mathrm{mg} / \mathrm{day}$ in two divided doses), Outcome 19 deaths before end of treatment at 24 weeks +30 days.

Analysis 6.20. Comparison 6 Rivastigmine $10 \mathrm{~cm} 2$ patch $(9.5 \mathrm{mg} /$ day) versus rivastigmine capsules (6 to $12 \mathrm{mg} /$ day in two divided doses), Outcome 20 NPI-D carer distress scale (change from baseline at 24 weeks) ITT.

ADDITIONAL TABLES

APPENDICES

WHAT'S NEW

HISTORY

CONTRIBUTIONS OF AUTHORS 
[Intervention Review]

\section{Rivastigmine for Alzheimer's disease}

Jacqueline S Birks ${ }^{1}$, Lee-Yee Chong ${ }^{2}$, John Grimley Evans ${ }^{3 a}$

${ }^{1}$ Centre for Statistics in Medicine, Nuffield Department of Orthopaedics, Rheumatology and Musculoskeletal Sciences, University of Oxford, Oxford, UK. 2UK Cochrane Centre, Oxford, UK. 3Division of Clinical Geratology, Nuffield Department of Clinical Medicine, University of Oxford, Oxford, UK

a Deceased

Contact address: Jacqueline S Birks, Centre for Statistics in Medicine, Nuffield Department of Orthopaedics, Rheumatology and Musculoskeletal Sciences, University of Oxford, Botnar Research Centre, Windmill Road, Oxford, OX3 7LD, UK.

jacqueline.birks@csm.ox.ac.uk.

Editorial group: Cochrane Dementia and Cognitive Improvement Group.

Publication status and date: Edited (no change to conclusions), published in Issue 3, 2020.

Citation: Birks JS, Chong LY, Grimley Evans J. Rivastigmine for Alzheimer's disease. Cochrane Database of Systematic Reviews 2015, Issue 9. Art. No.: CD001191. DOI: 10.1002/14651858.CD001191.pub4.

Copyright ( 2020 The Cochrane Collaboration. Published by John Wiley \& Sons, Ltd.

\section{A B S T R A C T}

\section{Background}

Alzheimer's disease is the commonest cause of dementia affecting older people. One of the therapeutic strategies aimed at ameliorating the clinical manifestations of Alzheimer's disease is to enhance cholinergic neurotransmission in the brain by the use of cholinesterase inhibitors to delay the breakdown of acetylcholine released into synaptic clefts. Tacrine, the first of the cholinesterase inhibitors to undergo extensive trials for this purpose, was associated with significant adverse effects including hepatotoxicity. Other cholinesterase inhibitors, including rivastigmine, with superior properties in terms of specificity of action and lower risk of adverse effects have since been introduced. Rivastigmine has received approval for use in 60 countries including all member states of the European Union and the USA.

\section{Objectives}

To determine the clinical efficacy and safety of rivastigmine for patients with dementia of Alzheimer's type.

\section{Search methods}

We searched ALOIS, the Cochrane Dementia and Cognitive Improvement Group Specialized Register, on 2 March 2015 using the terms: Rivastigmine OR exelon OR ENA OR "SDZ ENA 713". ALOIS contains records of clinical trials identified from monthly searches of a number of major healthcare databases (Cochrane Library, MEDLINE, EMBASE, PsycINFO, CINAHL, LILACS), numerous trial registries and grey literature sources.

\section{Selection criteria}

We included all unconfounded, double-blind, randomised, controlled trials in which treatment with rivastigmine was administered to patients with dementia of the Alzheimer's type for 12 weeks or more and its effects compared with those of placebo in a parallel group of patients, or where two formulations of rivastigmine were compared.

\section{Data collection and analysis}

One review author (JSB) applied the study selection criteria, assessed the quality of studies and extracted data.

\section{Main results}

A total of 13 trials met the inclusion criteria of the review. The trials had a duration of between 12 and 52 weeks. The older trials tested a capsule form with a dose of up to $12 \mathrm{mg} /$ day. Trials reported since 2007 have tested continuous dose transdermal patch formulations delivering 4.6, 9.5 and $17.7 \mathrm{mg} /$ day. 
Our main analysis compared the safety and efficacy of rivastigmine 6 to $12 \mathrm{mg} /$ day orally or $9.5 \mathrm{mg} /$ day transdermally with placebo.

Seven trials contributed data from 3450 patients to this analysis. Data from another two studies were not included because of a lack of information and methodological concerns. All the included trials were multicentre trials and recruited patients with mild to moderate Alzheimer's disease with a mean age of about 75 years. All had low risk of bias for randomisation and allocation but the risk of bias due to attrition was unclear in four studies, low in one study and high in two studies.

After 26 weeks of treatment rivastigmine compared to placebo was associated with better outcomes for cognitive function measured with the Alzheimer's Disease Assessment Scale-Cognitive (ADAS-Cog) score (mean difference (MD) -1.79; 95\% confidence interval (CI) -2.21 to -1.37, $\mathrm{n}=3232,6$ studies) and the Mini-Mental State Examination (MMSE) score (MD 0.74; 95\% Cl 0.52 to $0.97, \mathrm{n}=3205,6$ studies), activities of daily living (SMD $0.20 ; 95 \% \mathrm{Cl} 0.13$ to $0.27, \mathrm{n}=3230,6$ studies) and clinician rated global impression of changes, with a smaller proportion of patients treated with rivastigmine experiencing no change or a deterioration (OR $0.68 ; 95 \% \mathrm{Cl} 0.58$ to $0.80, \mathrm{n}=3338,7$ studies).

Three studies reported behavioural change, and there were no differences compared to placebo (standardised mean difference (SMD) $-0.04 ; 95 \% \mathrm{Cl}-0.14$ to $0.06, \mathrm{n}=1529,3$ studies). Only one study measured the impact on caregivers using the Neuropsychiatric InventoryCaregiver Distress (NPI-D) scale and this found no difference between the groups (MD 0.10; $95 \% \mathrm{Cl}-0.91$ to $1.11, \mathrm{n}=529,1$ study). Overall, participants who received rivastigmine were about twice as likely to withdraw from the trials (odds ratio $(\mathrm{OR}) 2.01,95 \% \mathrm{Cl} 1.71$ to $2.37, \mathrm{n}=$ 3569,7 studies) or to experience an adverse event during the trials (OR $2.16,95 \% \mathrm{Cl} 1.82$ to $2.57, \mathrm{n}=3587,7$ studies).

\section{Authors' conclusions}

Rivastigmine ( 6 to $12 \mathrm{mg}$ daily orally or $9.5 \mathrm{mg}$ daily transdermally) appears to be beneficial for people with mild to moderate Alzheimer's disease. In comparisons with placebo, better outcomes were observed for rate of decline of cognitive function and activities of daily living, although the effects were small and of uncertain clinical importance. There was also a benefit from rivastigmine on the outcome of clinician's global assessment. There were no differences between the rivastigmine group and placebo group in behavioural change or impact on carers. At these doses the transdermal patch may have fewer side effects than the capsules but has comparable efficacy. The quality of evidence is only moderate for all of the outcomes reviewed because of a risk of bias due to dropouts. All the studies with usable data were industry funded or sponsored. This review has not examined economic data.

\section{PLAIN LANGUAGE SUMMARY}

\section{Rivastigmine for people with Alzheimer's disease}

\section{Review question}

We reviewed evidence comparing the effectiveness and safety of rivastigmine with placebo in people with Alzheimer's disease.

\section{Background}

Alzheimer's disease is the commonest cause of dementia affecting older people. As the disease progresses, people lose the ability to remember, communicate, think clearly and perform the usual daily activities. Their behaviour or personality may also change. In severe Alzheimer's disease, the patients lose the ability to care for themselves and require full time care.

Currently, there is no cure available for Alzheimer's disease, but a few pharmacological interventions are available to alleviate symptoms.

The symptoms are caused by the loss of a type of nerve cell in the brain called cholinergic neurons. Rivastigmine, an acetylcholinesterase inhibitor, works by increasing the levels of a brain chemical called acetylcholine which allows the nerve cells to communicate. This may improve the symptoms of dementia. Rivastigmine can be taken orally, either as capsules or a liquid, or by applying a patch on the skin. Its effectiveness in improving the symptoms of Alzheimer's disease and safety were evaluated in this review.

\section{Study characteristics}

This review included double-blinded randomised controlled trials, and the evidence was searched for up to March 2015 using the standard Cochrane methods. The review included studies conducted for at least 12 weeks that compared the safety and effectiveness of rivastigmine compared with placebo. Thirteen studies that met these criteria were found. Most of these studies involved people with mild to moderate Alzheimer's disease with an average age of around 75 years.

\section{Key results}

Results from seven trials showed that patients on rivastigmine ( 6 to $12 \mathrm{mg} /$ day by mouth, or $9.5 \mathrm{mg} /$ day by skin patch) were better for three outcomes than those on placebo, after six months of treatment. The differences were quite small for cognitive function ( 2 points, using the ADAS-Cog which has a range of 70 points) and activities of daily living (standardised mean difference (SMD) of 0.20 , which is considered a small effect). Patients on rivastigmine were more likely to show overall improvement compared with those on placebo (odds ratio of 1.47 , $95 \%$ confidence interval ( $\mathrm{Cl}$ ) of 1.25 to 1.72 ). However, there was no difference for behavioural changes (reported by three trials) or impact on carers (reported by one trial). Patients on rivastigmine were also about twice as likely to experience adverse events, although this risk 
might have been slightly less for patients using patches compared with capsules. It was possible that certain types of adverse events were less in people using patches than taking capsules (nausea, vomiting, weight loss, dizziness).

In summary, rivastigmine may be of benefit to people with Alzheimer's disease. It is possible that the using a patch is associated with reduced side effects compared to using oral capsules.

\section{Quality of evidence}

The quality of the evidence for most of the outcomes reviewed was moderate. The main factors affecting our confidence in the results included relatively high number of patients dropping out in some of the trials (the rates of dropout in the rivastigmine arms were higher). There were also concerns about the applicability of the evidence for the long term treatment of Alzheimer's disease since data from doubleblinded randomised controlled trials were only available for up to 12 months. All the data included in the main analysis of this review came from studies either sponsored or funded by the drug manufacturer (Novartis Pharma). 


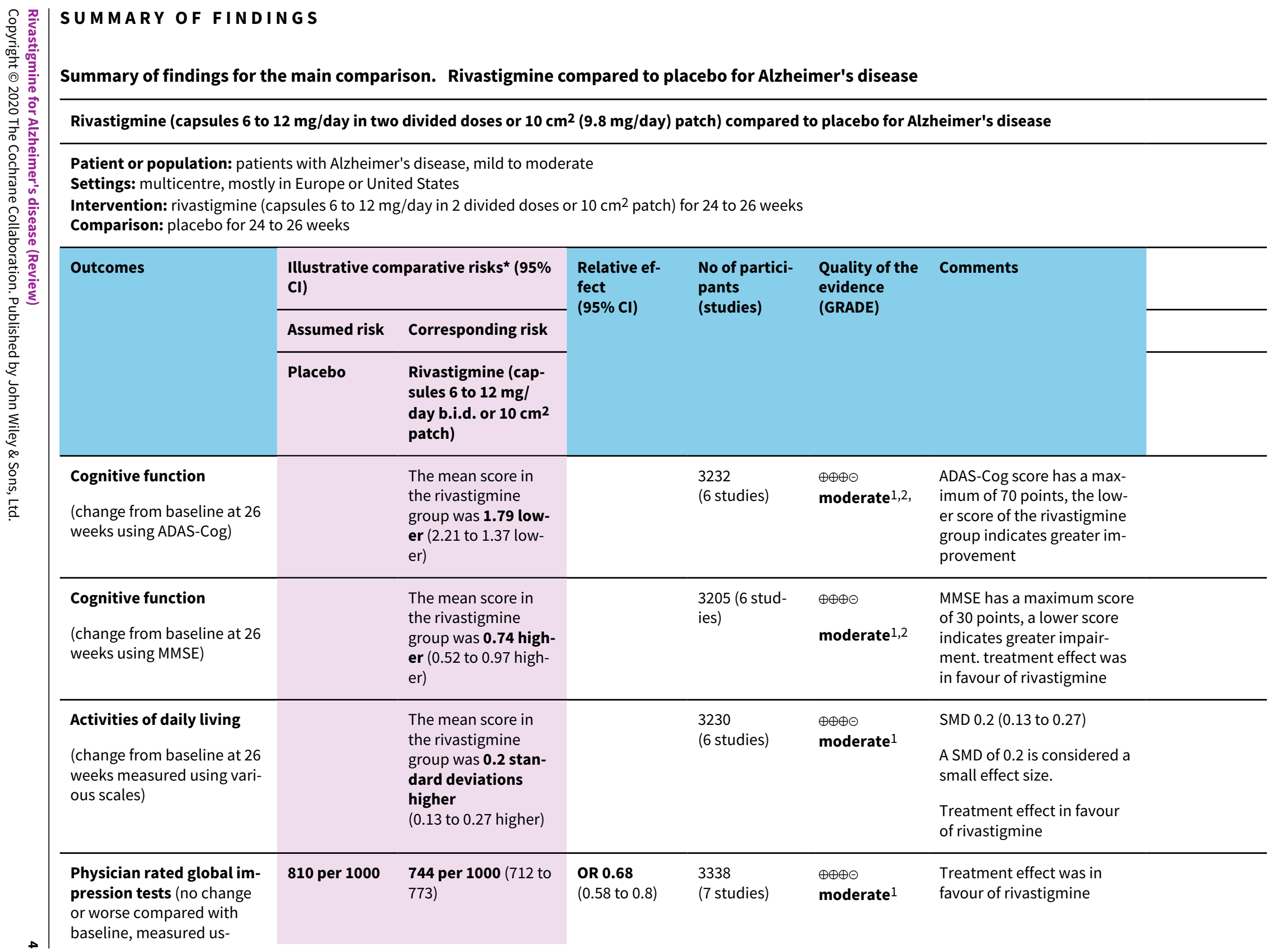

Intervention: rivastigmine (capsules 6 to $12 \mathrm{mg}$ /day in 2 divided doses or $10 \mathrm{~cm}^{2}$ patch) for 24 to 26 weeks

Comparison: placebo for 24 to 26 weeks 
Behavioural symptoms

The mean score in

the rivastigmine

1529

group was

(3 studies)

$\oplus \oplus \oplus \Theta$

moderate $\mathrm{m}^{1,3}$

(change from baseline at 26 weeks measured using vari-

0.04 standard de-

viations lower $(0.14$

lower to 0.06 higher)
SMD $-0.04(-0.14$ to 0.06$)$

A SMD of 0.2 is considered a small effect size. The size of this SMD and its small confidence interval suggests that there is no difference between the two groups

Withdrawals significantly

\section{Acceptability of treat-}

ment (as measured by

withdrawals from trials be-

149 per 1000260 per 1000 (230 to

293)

OR $2.01(1.71, \quad 3569$

2.37)

(7 studies)

$\oplus \oplus \oplus \ominus$

moderate ${ }^{1}$

Withdrawals significantly more frequent in rivastigmine group compared with placebo group

weeks)

\section{Incidence of adverse}

events (at least one adverse

event by 26 weeks)
761 per $1000 \quad 870$ per 1000 (850 to

888)

\section{OR 2.14}

(1.80 to 2.53 )

\section{7}

(7 studies)

\section{$\oplus \oplus \oplus \odot$}

moderate
Adverse events significant-

ly more frequent in rivastig-

mine group compared with

placebo group

\begin{tabular}{|c|c|c|c|c|}
\hline $\begin{array}{l}\text { Quality of life of patients } \\
\text { or carers (measured using } \\
\text { NPI-D carer distress scale } \\
\text { (change from baseline at } 24 \\
\text { weeks) }\end{array}$ & $\begin{array}{l}\text { The mean score in } \\
\text { the rivastigmine } \\
\text { group was } 0.1 \text { high- } \\
\text { er }(0.91 \text { lower to } 1.11 \\
\text { higher) }\end{array}$ & $\begin{array}{l}529 \\
\text { (1 study) }\end{array}$ & $\begin{array}{l}\oplus \oplus \oplus \ominus \\
\text { moderate }{ }^{1}\end{array}$ & $\begin{array}{l}\text { The size of this MD and its } \\
\text { small confidence interval } \\
\text { suggests that there is no dif- } \\
\text { ference between the two } \\
\text { groups }\end{array}$ \\
\hline
\end{tabular}

*The assumed risk used the median control group risk across studies. The corresponding risk (and its 95\% confidence interval) is based on the assumed risk in the comparison group and the relative effect of the intervention (and its $95 \% \mathrm{Cl}$ ).

CI: Confidence interval; OR: Odds ratio.

${ }^{1}$ Confidence in estimate of effect lowered due to relatively high dropout rates across studies, which are higher in the treatment group. The ITT analysis in these studies used LOCF (last observed carried forward) imputations. In addition, results are available up to only 26 weeks, longer term data would be more applicable.

2 There was high heterogeneity the ADAS-Cog outcome due to B352, which had high dropout rates and showed a difference of 3.8 points, compared to 1.2 to 1.6 points for the other studies. However, evidence not further downgraded; removal of this study from the analysis will only result in a small change of estimate by about 0.35 points.

3 Three studies (IDEAL; Lopez-Pousa 2005; Nakamura 2011) reported a scale measuring behavioural disturbance.

4 The protocol for most studies had some measures related to quality of life or impact on carers, but only one study reported this (IDEAL). 


\section{B A C K G R O U N D}

\section{Description of the condition}

Alzheimer's disease (AD), alone or in combination with other brain conditions, is the commonest cause of dementia affecting older people. It is associated with the loss of cholinergic neurons in parts of the brain subserving aspects of memory. As the disease progresses, people lose the ability to remember, communicate, think clearly and perform their usual daily activities. Their behaviour or personality may also change. In severe AD, people lose the ability to care for themselves and require full time care.

Currently there is no cure available for $A D$, but a few pharmacological interventions are available to alleviate symptoms.

\section{Description of the intervention}

Acetylcholinesterase inhibitors, such as rivastigmine, delay the breakdown of acetylcholine released into synaptic clefts and may enhance cholinergic neurotransmission.

Tacrine, the first of the acetylcholinesterase inhibitors to undergo extensive trials for this purpose, was associated with significant disadvantages, including low oral bioavailability and metabolism involving hepatic microsomal enzymes with a consequent risk of interactions with other drugs. Tacrine was also associated with adverse effects including hepatotoxicity. Several other acetylcholinesterase inhibitors, including rivastigmine, galantamine, and donepezil, have now been introduced. They are believed to have superior properties in terms of specificity of action and low incidence of adverse effects.

Rivastigmine is a 'pseudo-irreversible' inhibitor of acetyl and butyrylcholinesterases with a phenylcarbamate structure, the metabolism of which is almost totally independent of the hepatic cytochrome P450 system. After binding to cholinesterase, the carbamate portion of rivastigmine is slowly hydrolysed, cleaved, conjugated to a sulphate and excreted. Rivastigmine has an oral bioavailability of 0.355 and low (40\%) binding to plasma proteins. Its elimination half-life is around two hours. Its disposition is essentially unaltered in patients with renal or hepatic impairment (Jann 2000) and the risk of interactions with other drugs is low (Grossberg 2000). This is of particular relevance for elderly patients with $A D$, some of whom may also need medications for other conditions. The drug is selective both to the central nervous system (CNS) and within it. In studies in human volunteers the inhibition of central acetylcholinesterase was substantially greater than the inhibition of peripheral acetylcholinesterase or butyrylcholinesterase (Kennedy 1999). Evidence from animal studies suggests that rivastigmine is a more potent inhibitor of acetylcholinesterase in the cortex and hippocampus, the brain regions most affected by $A D$ (Polinsky 1998). Rivastigmine also preferentially inhibits the $G 1$ enzymatic form of acetylcholinesterase, which predominates in the brains of patients with AD (Polinsky 1998). Rivastigmine is long-acting and readily penetrates the CNS after parenteral or oral administration. The duration of cholinesterase inhibition by rivastigmine is approximately 10 hours.

Rivastigmine can be administered orally as capsules or liquid or from a transdermal patch, which has been developed more recently. Based on pharmacokinetic principles, the transdermal patch form was postulated to have advantages over the oral form.
Adherence was expected to be improved by once daily dosing. Tolerance was also expected to be improved as the patch delivers a more steady concentration of rivastigmine to the body and has a lower equivalent dose to the oral form $(9.5 \mathrm{mg}$ as a transdermal patch is equivalent to $12 \mathrm{mg}$ daily in the oral form).

\section{Why it is important to do this review}

Large multicentre trials have been completed in the USA, Canada, Europe, Australia and South Africa. Rivastigmine has received approval for use in 60 countries including all the member states of the European Union and in the USA, where it received approval from the Food and Drugs Administration (FDA) in April 2000. It is important to assess the safety and efficacy of this intervention in a systematic review.

\section{O B JECTIVES}

1. To determine the clinical efficacy and safety of rivastigmine for patients with dementia of Alzheimer's type

2. To compare the efficacy and safety of the oral and transdermal formulations of rivastigmine

\section{METHO D S}

\section{Criteria for considering studies for this review}

\section{Types of studies}

We included double-blind, randomised controlled trials in which rivastigmine was administered for 12 weeks or longer and compared with placebo; or rivastigmine patches were compared with rivastigmine capsules. Trials in which the allocation to treatment was not randomised, or in which treatment allocation was not concealed, were excluded. This was because prior knowledge of treatment allocation may lead to biased allocation of patients (Schulz 1995).

\section{Types of participants}

The patients in trials to be included were diagnosed with probable $A D$ according to internationally accepted criteria such as the Diagnostic and Statistical Manual of Mental Disorders DSM-IV (DSM IV) and National Institute of Neurological and Communicative Disorders and Stroke-Alzheimer's Disease and Related Disorders Association (NINCDS-ADRDA) criteria (McKhann 1984).

\section{Types of interventions}

\section{Objective 1}

Intervention: rivastigmine given at any dose, using any method of administration

Comparison: placebo

\section{Objective 2}

Intervention: rivastigmine patches at the manufacturer's recommended dose

Comparison: rivastigmine capsules at the manufacturer's recommended dose 


\section{Types of outcome measures}

In the original protocol and during the review, we looked for all the following outcomes:

1. cognitive function (as measured by psychometric tests);

2. functional performance;

3. global impression;

4. behavioural disturbance;

5. acceptability of treatment as measured by withdrawal from trials;

6. incidence of adverse effects;

7. effect on carers;

8. death;

9. institutionalisation rates;

10.quality of life;

11.dependency.

\section{Search methods for identification of studies}

\section{Electronic searches}

We searched ALOIS (www.medicine.ox.ac.uk/alois), the Cochrane Dementia and Cognitive Improvement Group Specialized Register, on 2 March 2015. The search terms used were: Rivastigmine OR exelon OR ENA OR "SDZ ENA 713".

ALOIS is maintained by the Trials Search Co-ordinator of the Cochrane Dementia and Cognitive Improvement Group and contains studies in the areas of dementia prevention, dementia treatment and cognitive enhancement in healthy people. The studies are identified from:

1. monthly searches of a number of the major healthcare databases, MEDLINE, EMBASE, CINAHL, PsycINFO and LILACS;

2. monthly searches of a number of the trial registers, ISRCTN, UMIN (Japan's Trial Register), the World Health Organization (WHO) Clinical Trials Registry Platform portal (which covers ClinicalTrials.gov, ISRCTN, the Chinese Clinical Trials Register, the German Clinical Trials Register, the Iranian Registry of Clinical Trials, and the Netherlands National Trials Register, plus others);

3. quarterly searches of the Cochrane Central Register of Controlled Trials (CENTRAL) in the Cochrane Library;

4. six-monthly searches of a number of grey literature sources, ISI Web of Knowledge Conference Proceedings, Index to Theses, Australasian Digital Theses.

To view a list of all sources searched for ALOIS see About ALOIS on the ALOIS website.

Details of the search strategies used for the retrieval of reports of trials from the healthcare databases, CENTRAL and conference proceedings can be viewed in the 'methods used in reviews' section within the editorial information about the Dementia and Cognitive Improvement Group.

Additional searches were performed in many of the sources listed above to cover the timeframe from the last searches performed for ALOIS to ensure that the search for the review was as up-to-date and as comprehensive as possible. The search strategies used can be seen in Appendix 1.
The latest search for this review (March 2015) retrieved a total of 17 results for consideration.

\section{Searching other resources}

In addition, the search engines Copernic and Google were used to find evidence of unreported or unpublished trials using the word rivastigmine and its synonyms. Novartis websites, the Food and Drug Administration (FDA), European Medicines Agency (EMEA) and National Institute for Health and Care Excellence (NICE) websites were searched for data and evidence of trials.

1. Reference searching

The references of all identified studies were inspected for more studies.

\section{Pharmaceutical companies}

Novartis, the developer of rivastigmine, was contacted for information about any unpublished and published trials.

\section{Data collection and analysis}

\section{Selection of studies}

Irrelevant citations were discarded by a review of the title of the publication and its abstract. In the presence of any suggestion that the article could possibly be relevant, it was retrieved in full for further assessment. In the later versions of the review, one review author (JSB) selected the trials for inclusion in the review from the culled citation list.

There were multiple publications for most of the industry sponsored trials, often reporting different aspects (outcomes) of the studies or different lengths of follow up.

\section{Data extraction and management}

Data were extracted from the published reports in journals and unpublished company reports using data collection forms. One review author (JSB) extracted information from the reports of each study.

In addition to extracting pre-specified information about study characteristics and aspects of methodology relevant to risk of bias, the following summary statistics, required for each trial and each outcome, were extracted.

- For continuous data, mean change from baseline, the standard deviation, and the number of patients for each treatment group at each assessment. Where changes from baseline were not reported, the mean, standard deviation and number of patients for each treatment group at each time point were extracted, if available.

- For binary data, the numbers in each treatment group and the numbers experiencing the outcome of interest were sought.

- For ordinal variables which can be approximated to continuous variables, the main outcomes of interest were the assessment score at the time point being considered and the change from baseline (i.e. pre-randomisation or at randomisation) at this time point. For some binary and ordinal outcomes the endpoint category relative to the baseline category was the outcome of interest. For other categorical outcomes, such as the Clinical Global Impression of Change (CIBIC-Plus), the endpoint itself was of clinical relevance as all patients had begun, by definition, at the same baseline score. 
The baseline assessment score was the latest available score, no longer than two months prior to the randomisation. Studies may have included a titration period prior to the randomisation phase of the study. Data from any open follow-on phase, after the randomised phase, were not used to assess safety or efficacy.

For each outcome measure, data were sought on every patient assessed. To allow an intention-to-treat analysis (ITT), the data were sought irrespective of compliance and whether or not the patient was subsequently deemed ineligible or otherwise excluded from treatment or follow up. If ITT data were not available, an analysis of patients who completed treatment was conducted.

\section{Assessment of risk of bias in included studies}

The risk of bias assessment was conducted using the standard recommended approach for assessing the risk of bias in studies included in Cochrane reviews. The Cochrane Collaboration risk of bias tool is available in RevMan 5.2 and assesses the following domains:

- sequence generation;

- allocation concealment;

- blinding of participants and personnel;

- blinding of outcomes assessment;

- incomplete outcome data;

- selective outcome reporting;

- 'other bias'.

We made a judgement about the risk of bias in each domain, assigning it to one of three categories: 'high', 'low' or 'unclear' risk of bias. These assessments were based on the criteria for making judgements that are listed in section 8.5 of the Cochrane Handbook for Systematic Reviews of Interventions. The criteria focus on whether the risk is of importance (that is whether the presence of the risk could have an important impact on the results or the outcomes of the trial) rather than whether a risk of bias is present or not (Higgins 2011). The levels of risk may be different for different outcomes and this was considered during the assessment.

If insufficient detail was reported to make a judgement, this was usually considered as an 'unclear' risk of bias. An 'unclear' judgement was also used in situations where it was clear what happened in the study but its likely impact on the study results was not known.

\section{Measures of treatment effect}

For dichotomous outcomes (where the outcome of interest was either present or absent), the estimate of treatment effect of the intervention was expressed as the Peto odds ratio (OR) together with the $95 \%$ confidence interval $(\mathrm{Cl})$.

For continuous data the measure of treatment effect was the mean difference (MD) or the standardised mean difference (SMD).

\section{Unit of analysis issues}

The review only included parallel-group, double-blinded randomised controlled trials (RCTs), with individual patients randomised. No unit of analysis issues were expected or encountered.

\section{Dealing with missing data}

Where data were missing from the published report of a trial, the authors or the study sponsors were contacted to obtain the data and to clarify any uncertainty.

We made no attempts at data imputation, except for the estimation of standard deviations for continuous data using the methods detailed in section 7.7.3 of the Cochrane Handbook for Systematic Reviews of Interventions (Higgins 2011).

Where possible we reported ITT analyses. We conducted sensitivity analyses to compare methods of dealing with missing data.

\section{Assessment of heterogeneity}

Potential differences between the included studies in the types of participants, interventions or control used were assessed before pooling data. No subgroup analyses were planned.

We assessed heterogeneity between studies using the $\mathrm{Chi}^{2}$ test (with a significance level set at $\mathrm{P}<0.10$ ) and the $\mathrm{I} 2$ statistic, which calculates the percentage of variability due to heterogeneity rather than to chance, with 12 values over $50 \%$ suggesting substantial heterogeneity (Higgins 2011).

\section{Assessment of reporting biases}

Outcomes reported in a trial were compared with the protocol, whenever possible, to examine whether all of the study's prespecified outcomes that were of interest to the review had been reported.

\section{Data synthesis}

For ordinal variables, such as psychometric test scores, functional and quality of life scales, where there are a large number of possible scores, the measure was treated as continuous and the mean difference or the SMD was calculated.

For ordinal variables with only a small number of possible values, such as the Clinical Global Impression of Change, the data were reduced to a binary variable. The two classes were improvement compared with no change or worse. For all binary variables the Peto method of the typical OR was used.

The duration of the trials varied between 12 weeks and 1 year. Separate meta-analyses were conducted for endpoints of 12 weeks, 24 to 26 weeks and 52 weeks. Some trials contributed data to more than one meta-analysis if multiple assessments had been done.

A weighted estimate of the typical treatment effect across trials was calculated. Overall estimates of the treatment difference are presented. In all cases the overall estimate from a fixed-effect model was presented.

\section{Subgroup analysis and investigation of heterogeneity}

Heterogeneity were examined both visually and using the $1^{2}$ statistic. Where there was evidence of heterogeneity of the treatment effect between trials then sensitivity analyses were conducted, where only homogeneous results were pooled.

There were no pre-identified subgroups for subgroup analysis. 


\section{Sensitivity analysis}

This review sought to analyse data using ITT data whenever possible. Some studies reported both an ITT analysis that included all patients randomised and a per protocol analysis. The ITT analysis results reported in studies often involved data imputation techniques such as the last observation carried forward (LOCF) for patients who did not complete the study. The impact of different ways of dealing with missing data were investigated using a sensitivity analysis of as observed, ITT and per protocol analyses. These results were tabulated and any important discrepancies discussed.

\section{Summary of findings table}

We summarised the data on the efficacy and safety of the currently recommended dose of rivastigmine (6 to $12 \mathrm{mg}$ /day orally or 9.5 $\mathrm{mg}$ /day transdermally) in the summary of findings table using GRADE methods (Guyatt 2008) to assess the overall quality of the evidence.

\section{RES U L T S}

\section{Description of studies}

\section{Results of the search}

The updated searches performed in 2011, 2013, 2014 and 2015 retrieved a total of 112 references. The full texts of 42 references were read and, of these, 10 were of studies that could be included or additional reports of studies already included, and 32 were of studies that were excluded.

\section{Included studies}

The characteristics of the 13 included trials are summarised in Characteristics of included studies.

\section{Design, participants, samples sizes and setting}

Important details of study design (number of participants, duration of follow up, mean Mini-Mental State Examination (MMSE) of participants at baseline and description of interventions) are summarised in Table 1 and the objectives of the trials in Table 2.

Only randomised, double-blinded placebo controlled trials or studies comparing different formulations were included in this review. Thirteen studies met the inclusion criteria of the review.

Six trials, phase II and III, were all supported by Novartis Pharmaceuticals Corporation and were completed by 1996. They are identified by their Novartis or ADENA code (ADENA was the name given by Novartis to the Exelon Phase III clinical trials programme). The two phase II trials were designed to assess the tolerability, efficacy and safety of rivastigmine over three to four months. The four phase III trials were designed to assess the efficacy and safety of rivastigmine in patients with mild to moderately severe AD over six months. The trials had many features in common. They were all multicentre, randomised, double-blind, parallel-group trials. All trials compared rivastigmine with placebo, with at least two treatment groups of different rivastigmine regimens.

Of the seven later trials, three were also sponsored by Novartis (IDEAL; Lopez-Pousa 2005; Nakamura 2011). The key information about these seven trials is summarised as follows.
- There is limited information available about Tai 2000, which has been published only as an abstract. This trial appeared to be an independent trial carried out in Taiwan. Eighty participants with mild to moderate $A D$ were treated with rivastigmine or placebo for 26 weeks. No data were available to include in the metaanalyses.

- Ballard 2005 was a small 26 week trial $(n=93)$ with three treatment arms, rivastigmine, quetiapine and placebo, of equal size. The objective was to compare the efficacy of rivastigmine and quetiapine for agitation in people with possible or probable $A D$ who were living in institutions. We did not include any data from this trial in the meta-analyses because of concerns about a high risk of attrition bias and exclusion of the most severely impaired patients from the analyses.

Karaman 2005 and Lopez-Pousa 2005 aimed to investigate the efficacy of rivastigmine for patients with more advanced disease than those previously tested.

- Karaman 2005 was a small 12 month trial ( $n=44$, mean baseline MMSE = 12.2). We did not include data from this trial in our metaanalyses due to concern about a high risk of bias.

- Lopez-Pousa 2005 was a 6 month trial $(n=218$, mean baseline MMSE = 8.8). In addition to the outcomes of cognitive function, activities of daily living and global clinical change, LopezPousa 2005 was the earliest included trial to assess behavioural symptoms.

- Mowla 2007 was a 12 week trial in mild to moderate $A D$ with three treatment groups, rivastigmine, rivastigmine plus fluoxetine and placebo. The rivastigmine plus fluoxetine group was not included in this review. There were 82 participants in total in the rivastigmine and placebo groups. We were not able to include any data from this trial in the meta-analyses due to incomplete reporting of results.

IDEAL and Nakamura 2011 were the only trials to include transdermal rivastigmine.

- IDEAL was a 6 month study $(n=1195)$ in mild to moderate $\mathrm{AD}$, with 4 treatments arms, rivastigmine capsules, 2 doses of transdermal rivastigmine and placebo.

- Nakamura 2011 was a 24 week dose finding trial in mild to moderate $A D(n=859)$ with 3 treatment arms, 2 doses of transdermal rivastigmine and placebo..

All studies used current diagnostic criteria for dementia (DSM-IV) and probable AD (NINCDS-ADRDA) (McKhann 1984) except Tai 2000, which did not give its diagnostic criteria. The severity of disease was mostly assessed by the MMSE rating scale, and patients that were included had MMSE scores of 10 to 26 inclusive apart from 2 studies (Karaman 2005; Lopez-Pousa 2005), which randomised patients with MMSE scores of 3 to 12 . The list of exclusions was not extensive. Patients with severe and unstable illnesses (cardiovascular or pulmonary disease, unstable diabetes mellitus, peptic ulceration within the preceding five years, evidence of alcohol or substance abuse) were excluded, as were individuals taking medications such as anticholinergic drugs, acetylcholine precursor health food supplements, memory enhancers, insulin and psychotropic drugs. The procedures followed were in accordance with the ethical standards of the relevant institutional committees on human experimentation and with the Declaration of Helsinki (Helsinki declaration). 


\section{Interventions}

Information about treatment groups and actual doses achieved are tabulated in Table 1 and Table 3 respectively.

Twelve studies investigated the oral form of rivastigmine, and one of these studies also included an arm randomised to a rivastigmine patch (IDEAL).

Earlier industry sponsored trials investigated a range of doses, from $2 \mathrm{mg} /$ day to $12 \mathrm{mg}$ /day in two or three divided doses. In later trials (Ballard 2005; Karaman 2005; Lopez-Pousa 2005; Mowla 2007; IDEAL) only the dose range of 6 to $12 \mathrm{mg} /$ day was used to compare against placebo. Tai 2000 investigated doses of 3 to $6 \mathrm{mg} /$ day in two divided doses. All studies with high oral doses achieved a mean daily dose of between 9.3 to $10.7 \mathrm{mg} /$ day, except for Karaman 2005 (8.3 mg/day) and B351 (8.5 mg/day). The mean daily doses achieved for medium doses were between 5.7 and $6 \mathrm{mg} /$ day. Further information on the doses achieved was not available for four trials (B103; Ballard 2005; Mowla 2007; Tai 2000).

Two studies evaluated the safety and efficacy of patches. IDEAL investigated 6 to $12 \mathrm{mg} /$ day capsules in 2 doses and the other 2 arms tested rivastigmine patches, a $10 \mathrm{~cm}^{2}$ patch which delivered $9.5 \mathrm{mg} /$ day and a $20 \mathrm{~cm}^{2}$ patch which delivered $17.4 \mathrm{mg} /$ day. Patients were titrated to their target dose in four week steps. Patients in the patch groups started with a $5 \mathrm{~cm}^{2}$ patch until the target dose was achieved; in the capsule group they began with $3 \mathrm{mg} /$ day, increased by steps of $3 \mathrm{mg} /$ day. All patients had a rivastigmine or placebo patch once a day and a rivastigmine or placebo capsule twice a day. Nakamura 2011 investigateda $10 \mathrm{~cm}^{2}$ patch which delivered $9.5 \mathrm{mg} /$ day, a $5 \mathrm{~cm}^{2}$ patch which delivered $4.6 \mathrm{mg} /$ day and a placebo arm. Patients were titrated to their target patch dose over four week intervals, followed by an eight week maintenance period.

\section{Outcomes}

The trials examined cognitive, functional and global effects, behavioural symptoms, as well as the safety and tolerability of rivastigmine.

Apart from the outcome measures related to safety or adverse effects, all the outcomes for the effectiveness of rivastigmine were measured by questionnaires or psychometric tests. Different types of instruments were utilised to measure each outcome. The details of the outcomes measured and reported in each trial are summarised in Table 4.

\section{Cognitive function}

- Alzheimer's Disease Assessment Scale (ADAS-Cog) (Rosen 1984). ADAS-Cog comprises 11 individual tests: spoken language ability (0 to 5 ), comprehension of spoken language (0 to 5$)$, recall of test instructions ( 0 to 5 ), word finding difficulty ( 0 to 5 ), following commands ( 0 to 5 ), naming object ( 0 to 5 ), construction drawing (0 to 5), ideational praxis ( 0 to 5$)$, orientation (0 to 8), word recall ( 0 to 10 ) and word recognition ( 0 to 12 ). The total score ranges from 0 to 70, the higher the score indicating greater impairment.

- The ADAS-CogA total score is the ADAS-Cog plus the attention item from the ADAS-Noncog.

- The Mini-Mental State Examination (MMSE) (Folstein 1975) evaluates cognition in five areas: orientation, immediate recall, attention and calculation, delayed recall and language. The test takes only 15 minutes to administer and the scores range from 0 (severe impairment) to 30 (normal).

- The Severe Impairment Battery (SIB) (Panisset 1994; Saxton 1990) is a 40-item questionnaire designed to assess the severity of cognitive dysfunction in advanced $A D$ and is divided into 9 domains: memory, language, orientation, attention, praxis, vasospastically, construction, orientation to name and social interaction. The score ranges from 0 (greatest impairment) to 100 (no impairment).

- The Revised Wechsler Memory Scale (WMS-R) (Wechsler 1987) comprises a series of brief subtests, some taken from the WMS and each measuring a different facet of memory, which are summarised into five composite scores and finally two major scores using weights prescribed by Wechsler. Some of the tests were used in B103.

- The Fuld Object-Memory Test (OME) (Fuld 1981) evaluates short term memory and learning by measuring the recall of 10 previously viewed objects.

- The Benton Visual Retention Test (VRT) (Benton 1974) evaluates visual memory by assessing the accuracy of reproduction of each of 10 designs shown briefly to the individual.

- The Trail Making Test (TMT) (Reitan 1958) assesses the time taken to connect a series of 25 numbered dots.

- The Alzheimer's Disease Cooperative Study-Clinical Global Impression of Change (ADCS-CGIC) (Schneider 1997) provides a single global rating of change from baseline, rated by an independent observer who has no access to the other efficacy or safety data.

- The Ten-Point Clock Drawing Test (Watson 1993) assesses visuospatial and executive functions.

- The Mental Function Impairment (MENFIS) (Homma 1991) evaluates core symptoms of dementia including cognitive, motivational and emotional aspects based on an interview with the patient and carer. The score ranges from 0 to 78 (greater functional deficit).

- Digital substitution test (DSST).

\section{Activities of daily living}

- The Progressive Deterioration Scale (PDS) (DeJong 1989) is an instrument with 29 items assessing the activities of daily living as rated by a carer. Each item is scored on a visual analogue scale of 0 to 100 , and the total score is the mean item score. The score of 0 to 100 decreases with severity of dementia.

- The Alzheimer's Disease Cooperative Study activities of daily living inventory for severe Alzheimer's disease (ADCS-ADL) (Galasko 1997). This is a 19-item scale for basic and complex abilities validated in patients with moderate to severe dementia. The total score ranges from 0 to 54 (no impairment). Items include basic activities of daily living (eating, bathing) and complex activities (operating taps, switching lights).

- The Caregiver Activity Survey (CAS) is completed by the caregiver and includes six items for which the caregiver estimates the amount of time spent in the previous 24 hours helping the patient with activities of daily living.

- The Nurses' Observation Scale for Geriatric Patients (NOSGER) (Brunner 1990) is designed to assess various cognitive functions and behaviour as related to activities of daily living and as assessed by a caregiver who sees the patient frequently. The NOSGER contains $6 \times 5=30$ items which were selected to 
assess the following dimensions: (a) memory, (b) self-care, (c) instrumental activities of daily life, (d) mood, (e) disturbing behaviour, (f) social behaviour.The Disability Assessment for Dementia (DAD) is a 46-item structured interview for the carer, scored 0 to 100 (least impairment), to evaluate activities of daily living (Gelinas 1999).

\section{Behavioural symptoms}

- The Neuropsychiatric Instrument (NPI) (Cummings 1994) is a 12-item, carer rated instrument to evaluate behavioural and neuropsychiatric symptoms, including delusions, hallucinations, agitation and aggression, depression or dysphoria, anxiety, elation or euphoria, apathy, disinhibition, irritability, aberrant motor behaviour, night-time behaviour and appetite or eating disorder. The frequency is rated from 1 (occasional, less than once a week) to 4 (very frequent) and severity from 1 (mild) to 3 (severe). The product of frequency and severity ranges from 1 to 12 , with a total score ranging from 12 to 120 for the 10 domains summed. A lower score indicates improvement.

- The Cohen-Mansfield Agitation Inventory (CMAI) (CohenMansfield 1995) scale, range from 29 to 203, is widely used in nursing homes to assess agitation. The scale examines 29 types of agitated behaviour, including pacing, verbal or physical aggression, performing repetitious mannerisms, screaming, and general restlessness. The frequency of these behaviours is measured on a 7-point scale, ranging from 1 (never occurs) to 7 (occurs several times an hour, and includes cluster scores for physical and verbal aggression, and total aggression.

- The Behavioural Pathology in AD (BEHAVE-AD) assesses potentially remediable behavioural problems (agitation, aggression, affect, psychosis) in patients with AD. It consists of 22 symptoms grouped into 7 categories, each scored by a carer on a 4-point scale (Reisberg 1989).

\section{Physician rated global impression tests}

- A Clinician's Interview-Based Impression of Change scale (CIBICPlus) (Reisberg 1994) includes information supplied by the caregiver and patient. It provides a global rating of patient function in four areas: general, cognitive, behaviour and activities of daily living. All patients are scored as 4 at baseline; subsequent assessment on a scale of 1 to 7 is relative to baseline, with 1 showing marked improvement and 7 marked worsening.

- The Global Deterioration Scale (GDS) (Reisberg 1982) is reported as a score from 1 to 7,1 indicating normality to 7 indicating very severe dementia, and is a global assessment carried out by a clinician who has access to all information about a patient.

- The Clinical Global Impression of Change (CGIC) (Guy 1976) is a global rating of all domains of a patient's current condition in comparison with baseline. It is a 7-point scale ranging from 1 (very much improved) to 7 (very much worse), with 4 indicating no change. The assessment is conducted by the same clinician at both time points with input from relatives or carers.

\section{Acceptability of treatment, as measured by withdrawal from trial}

In anticipation of the typical gastrointestinal adverse events associated with cholinesterase inhibitors, which can be dosedependent, the various arms of the older trials compared both different doses and twice or thrice daily dosage schedules. Three fixed doses were tested in B351, but the other trials aimed for a maximum tolerated dose within a prescribed range. The period of titration was longer for larger doses and varied between 3 and 12 weeks. The later trials tested a transdermal patch formulation which provided continuous delivery of the drug with the objective of improving tolerability. The mean daily doses of rivastigmine at different time points are presented in Table 3. Safety and tolerability were evaluated by recording adverse events and serious adverse events. In addition, routine physical examinations with blood and urine analyses were performed and vital signs and electrocardiograms were checked at all clinic visits. Seven trials reported the withdrawal rate at 26 weeks (B303/B305; B304; B351; B352; IDEAL; Lopez-Pousa 2005; Nakamura 2011).

\section{Incidence of adverse events}

The studies reported the types of adverse events reported by patients, and the number of patients experiencing these events, usually focusing on the most commonly experienced adverse events. A wide range of adverse events which were consistent with the anticholinergic properties of rivastigmine were reported, including gastrointestinal adverse events such as nausea, vomiting, abdominal pain or discomfort, and diarrhoea. Other adverse events reported included falls, insomnia, agitation, weight loss, headache, dizziness, and cutaneous adverse events where patches were used.

The same seven studies which reported on withdrawal from the trial before completion of the study also reported the number of patients who experienced at least one adverse event. Most of these studies had defined a safety population which is the basis for the adverse events analyses.

\section{Quality of life of patients and carers}

Only one study reported changes in the NPI-D carer distress scale. This study reported the change from baseline at 24 weeks (IDEAL).

\section{Excluded studies}

Please see Characteristics of excluded studies.

\section{Risk of bias in included studies}

(Figure 1 and Figure 2) 
Figure 1. Risk of bias graph: review authors' judgements about each risk of bias item presented as percentages across all included studies.

Random sequence generation (selection bias)

Allocation concealment (selection bias)

Blinding of participants and personnel (performance bias)

Blinding of outcome assessment (detection bias)

Incomplete outcome data (attrition bias)

Selective reporting (reporting bias)

Other bias

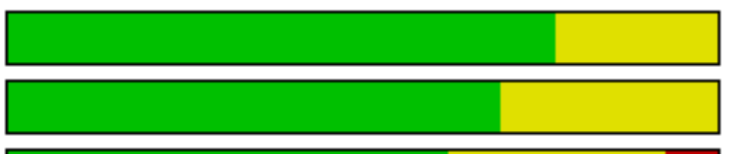

L

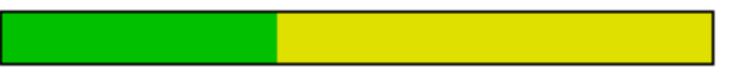

$$
\text { L }
$$
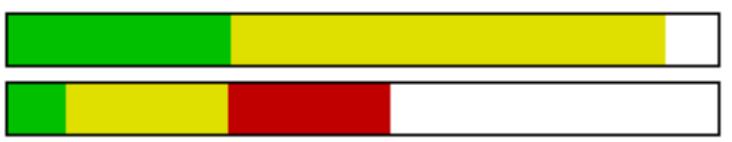

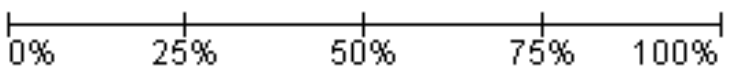

Low risk of bias

Unclear risk of bias

High risk of bias 
Figure 2. Risk of bias summary: review authors' judgements about each risk of bias item for each included study.

\begin{tabular}{|c|c|c|c|c|c|c|c|}
\hline & 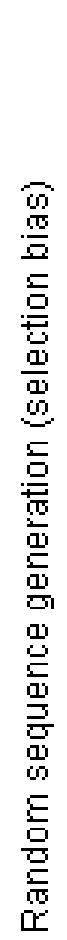 & 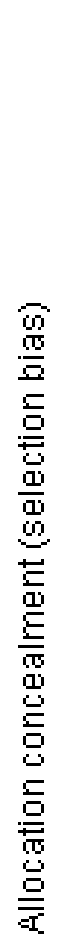 & 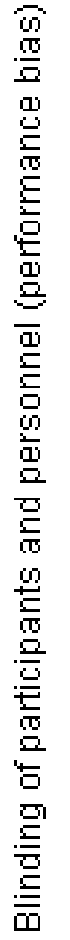 & 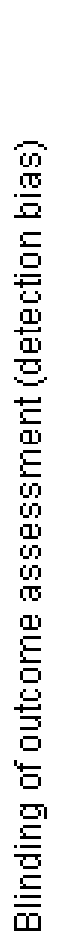 & 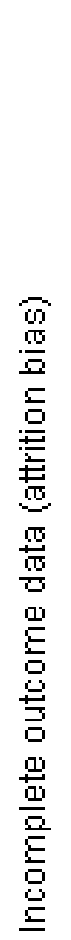 & 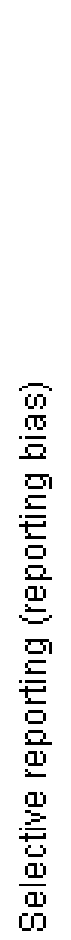 & 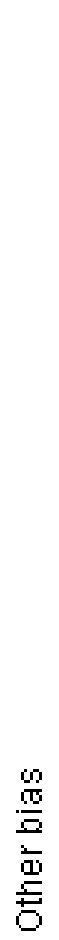 \\
\hline B103 & + & + & + & + & $?$ & + & \\
\hline B104 & + & + & C & $?$ & 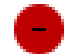 & + & \\
\hline B303/B305 & + & + & + & + & $?$ & $?$ & \\
\hline B304 & + & + & + & $?$ & $?$ & + & \\
\hline B351 & + & + & $?$ & $?$ & & $?$ & \\
\hline B352 & + & + & + & $?$ & & $?$ & \\
\hline Ballard 2005 & + & + & + & $?$ & & $?$ & $?$ \\
\hline IDEAL & + & + & + & $?$ & $?$ & $?$ & $?$ \\
\hline Karaman 2005 & $?$ & $?$ & + & $?$ & & $?$ & \\
\hline Lopez-Pousa 2005 & ) & $?$ & + & + & + & $?$ & \\
\hline Mowla 2007 & $?$ & $?$ & $?$ & + & $?$ & & \\
\hline Nakamura 2011 & + & + & $?$ & + & $?$ & + & + \\
\hline Tai 2000 & $?$ & $?$ & $?$ & $?$ & $?$ & $?$ & $?$ \\
\hline
\end{tabular}




\section{Allocation}

All the trials sponsored by Novartis were considered to be at low risk of bias for randomisation and allocation concealment, other than Lopez-Pousa 2005 where it was difficult to be sure whether allocation was concealed effectively.

Of the independent trials, Ballard 2005 had a low risk of allocation bias, with clearly described procedures. However, the risk of bias in this domain was unclear for Tai 2000 (an abstract), Karaman 2005 and Mowla 2007 because there were no descriptions of methods. Karaman 2005 was of particular concern as only "participants who tolerated the drug well and perceived benefit were invited to continue rivastigmine treatment" after eight weeks.

\section{Blinding}

All trials were double-blinded and placebo controlled, with precautions taken to maintain the blinding such as ensuring the placebo was identical in appearance to the active treatment. However, in B104 the placebo group received the treatment twice daily whereas one of the treatment arms received the intervention three times daily. There were no descriptions of additional steps taken to mask this. The difference in the number of times the capsules were taken could have unmasked the three times per day group. The effectiveness of double-blinding in Mowla 2007 was also unclear because all patients in this study had received the placebo during the six week pre-randomisation run-in period.

Of the two studies testing patches, IDEAL was considered to be at low risk of bias for blinding as a double dummy was used. Nakamura 2011 stated that "patients, investigator staff, persons performing the assessments and data analysts are all blinded", but it was unclear how this was achieved since the study had used different patch sizes $\left(2.5,5,7.5\right.$ and $\left.10 \mathrm{~cm}^{2}\right)$ to achieve the target dose.

\section{Incomplete outcome data}

Attrition bias was a major concern. There were substantial losses from Ballard 2005 where 19\% (6/31) of those randomised to rivastigmine did not start treatment compared with $6 \%$ of those randomised to placebo. Only $18 / 31$ in the rivastigmine group completed the trial compared with $27 / 31$ in the placebo group. Those with a low baseline score on the Severe Impairment Battery (SIB) were not included in the analyses. These concerns led us to exclude data from Ballard 2005 from the meta-analyses.

Karaman 2005, although the longest duration included trial (52 weeks), lost very few patients: only 3 of 24 in the rivastigmine group and none from the placebo group. This was a much lower rate of loss than for any other trial.

For the other 11 studies missing assessments caused major problems in the analysis and interpretation of the results. Approximately $17 \%$ of patients from the 1 to $4 \mathrm{mg}$ daily and placebo groups and 35\% of patients from the 6 to $12 \mathrm{mg}$ daily groups left the trial before completing treatment. If patients dropped out at random from each group, that is the dropout was not associated with the treatment, the comparisons between groups are not biased but estimates of differences are reduced in precision. However, the dropout rates were not random and were related to treatment. Various methods were used in the trials for dealing with missing data.
The older trials (B303/B305; B304; B351; B352) reported in detail the methods using for dealing with missing data. Approximately a third of the patients who dropped out contributed endpoint data (retrieved drop out (RDO)). The ITT analyses included the completers (observed cases (OC)) data and the RDO data, and for the remainder of the patients the last available assessment (last observation carried forward (LOCF)). This remainder comprised approximately $6 \%$ of the patients in the placebo and 1 to $4 \mathrm{mg}$ daily groups, and $24 \%$ for the 6 to $12 \mathrm{mg}$ daily group at 26 weeks. An overestimate of the outcome effect would be expected.

In order to compare the different methods of dealing with missing assessments, for two outcomes (ADAS-Cog and CIBIC-Plus) we conducted meta-analyses on three different groups of patients: $\mathrm{OC}$ only, RDO + OC, and ITT (OC + RDO + LOCF). The results are presented in Table 5. These analyses showed that compared with OC or RDO + OC, the ITT analyses did not produce results favouring rivastigmine, indeed the opposite was true but the differences between results were small. Therefore, the ITT analyses were considered satisfactory and were reported for all other outcomes. Further analysis of the data from the ITT, the OC and RDO + OC analyses to investigate the size and direction of the bias due to differential dropouts from the arms of the rivastigmine trials (Birks 2008) led to the conclusion that the absolute size of the bias was small and the direction could not be ascertained.

\section{Selective reporting}

For most of the studies the risk of reporting bias across all outcomes was difficult to judge. A few of the studies had listed the Caregiver Activities Survey (CAS) as an outcome in their protocols but these were not reported in the study results. In addition B304 and B351, two large randomised trials, were not published. Our data were obtained from information provided by Novartis Ltd.

For three of the studies (B104; B304; Nakamura 2011) sufficient information was available from the study protocols and we considered these as low risk of bias. However, there was insufficient information to assess the risk of reporting bias in the other studies.

\section{Other potential sources of bias}

Out of these 13 studies included in the review, only four (Ballard 2005; Karaman 2005; Mowla 2007; Tai 2000) were conducted without direct sponsorship or funding from the manufacturer, Novartis Pharma, but none provided data that could be included in the review.

Karaman 2005 reported standard deviations for the outcome measures that were an order of magnitude smaller than those seen in any other trial. We have asked the authors for clarification of these unusual findings but have not received a reply.

\section{Effects of interventions}

See: Summary of findings for the main comparison Rivastigmine compared to placebo for Alzheimer's disease

There are 13 included trials but 4 (Ballard 2005; Karaman 2005; Mowla 2007; Tai 2000) did not contribute to the analyses. Data from Ballard 2005 was excluded because of the high attrition rate from the rivastigmine group and concern over the elimination from the analyses of patients with a low baseline score. Data from Mowla 2007 could not be included due to incomplete reporting. No data could be used from Tai 2000 as the trial report provided insufficient 
information. The data from Karaman 2005 were of concern because of the potential for biased results and were omitted from the analyses. Although the longest duration trial, 52 weeks, only 3 of 24 in the rivastigmine group and none from the placebo group were lost. This was a much lower rate of loss than for any other trial. The numbers randomised were not reported but it was stated that patients were excluded at eight weeks if they did not appear to benefit.

In order to meet the objectives of the review we conducted analyses comparing various doses and formulations of rivastigmine with placebo or comparing different formulations of rivastigmine.

The rating scales and cognitive tests used differ in the direction representing improvement. A decrease in score indicates clinical improvement with the ADAS-Cog, the CIBIC-Plus and the GDS, while an increase shows improvement for the PDS and MMSE.

\section{Comparison of rivastigmine (6 to $12 \mathrm{mg}$ /day twice daily capsules or $10 \mathrm{~cm}^{2}(9.5 \mathrm{mg} / \mathrm{day})$ patch) with placebo}

\section{Cognitive function}

The meta-analysis, using weighted mean differences (WMDs), revealed a benefit on cognitive function as measured by the ADASCog test scores for rivastigmine compared with placebo at 26 weeks (ITT analysis, WMD $-1.79 ; 95 \% \mathrm{Cl}-2.21$ to $-1.37, \mathrm{P}<0.00001,6$ studies).

The MMSE showed similar results in favour of rivastigmine at 26 weeks compared with placebo (ITT analysis, WMD 0.74; 95\% Cl 0.52 to $0.97, \mathrm{P}<0.00001,6$ studies).

\section{Activities of daily living}

The meta-analysis, using standardised mean differences (SMDs), showed an improvement associated with rivastigmine compared with placebo at 26 weeks (ITT analysis, WMD $0.20 ; 95 \% \mathrm{Cl} 0.13$ to $0.27, \mathrm{P}<0.00001,6$ studies).

\section{Global assessment}

The seven-point CIBIC-Plus scale, or the ADCS-CGIC scale, measuring global clinical state was dichotomized by counting those showing no change or decline against those showing improvement. There were benefits associated with rivastigmine compared with placebo at 26 weeks (ITT analysis, 1339/1848 rivastigmine, $1197 / 1490$ placebo) (OR $0.68 ; 95 \% \mathrm{Cl} 0.58$ to $0.80, \mathrm{P}<$ $0.00001,7$ studies).

\section{Behavioural symptoms}

Three studies (IDEAL; Lopez-Pousa 2005; Nakamura 2011) assessed behavioural symptoms using the Neuropsychiatric Instrument (NPI-10 and NPI-12). There was no difference between rivastigmine and placebo at 26 weeks.

\section{Withdrawals before the end of treatment}

The meta-analysis of withdrawals before the end of treatment showed a significant difference in favour of placebo compared with rivastigmine 26 weeks (571/2038 rivastigmine, 240/1531 placebo) (OR 2.06; $95 \% \mathrm{Cl} 1.74$ to $2.45, \mathrm{P}<0.00001,7$ studies).

\section{Adverse events}

The meta-analysis of numbers of patients with at least one adverse event showed that at 26 weeks there was a significant difference between the rivastigmine and placebo groups in favour of placebo (1637/2025 rivastigmine, 1123/1562 placebo) (OR 2.16; 95\%Cl 1.82 to $2.57, \mathrm{P}<0.00001,7$ studies).

\section{Quality of life of carers}

One study reported the changes in NPI-D carer distress scale from baseline and this was reported at 24 weeks (IDEAL). No significant difference was detected (MD $0.10 ; 95 \% \mathrm{Cl}-0.91$ to $1.11,1$ study).

\section{Comparison of rivastigmine (1 to $4 \mathrm{mg} /$ day and 6 to $12 \mathrm{mg} /$ day twice daily capsules) with placebo}

\section{Cognitive function}

The meta-analysis, using WMDs, revealed a benefit on cognitive function as measured by ADAS-Cog test scores for the lower dose rivastigmine compared with placebo at 26 weeks, but not at 12 weeks; and for the higher dose at 12 and 26 weeks:

- rivastigmine 1 to $4 \mathrm{mg}$ /day at 12 weeks (ITT analysis, WMD -0.31; $95 \% \mathrm{Cl}-0.87$ to $0.25, \mathrm{P}=0.01,3$ studies);

- rivastigmine 6 to $12 \mathrm{mg} /$ day at 12 weeks (ITT analysis, WMD $-1.49 ; 95 \% \mathrm{Cl}-1.96$ to $-1.01, \mathrm{P}<0.00001$, 4 studies);

- rivastigmine 1 to $4 \mathrm{mg} /$ day at 26 weeks (ITT analysis, WMD -0.84; $95 \% \mathrm{Cl}-1.48$ to $-0.19, \mathrm{P}=0.01,3$ studies);

- rivastigmine 6 to $12 \mathrm{mg} /$ day at 26 weeks (ITT analysis, WMD $-1.99 ; 95 \% \mathrm{Cl}-2.49$ to $-1.50, \mathrm{P}<0.00001,5$ studies).

The MMSE showed similar results in favour of lower dose rivastigmine at 26 weeks and higher dose rivastigmine at 26 weeks, compared with placebo:

- rivastigmine 1 to $4 \mathrm{mg}$ /day at 26 weeks (ITT analysis, WMD 0.43; $95 \% \mathrm{Cl} 0.08$ to $0.78, \mathrm{P}=0.02$, 3 studies);

- rivastigmine 6 to $12 \mathrm{mg}$ /day at 26 weeks (ITT analysis, WMD 0.82; $95 \% \mathrm{Cl} 0.56$ to $1.08, \mathrm{P}<0.00001,5$ studies).

One study (Lopez-Pousa 2005) used the Severe Impairment Battery (SIB), which showed benefit associated with higher dose rivastigmine compared with placebo at 26 weeks (MD 4.53; $95 \% \mathrm{Cl}$ 0.47 to $8.59, \mathrm{P}=0.03$ ).

\section{Activities of daily living}

The PDS (carer assessment of the activities of daily living) showed an improvement associated with higher dose, but not lower dose, rivastigmine compared with placebo at 12 and 26 weeks:

- rivastigmine 1 to $4 \mathrm{mg}$ /day at 12 weeks (WMD $-0.77 ; 95 \% \mathrm{Cl}-1.84$ to $0.30,3$ studies);

- rivastigmine 1 to $4 \mathrm{mg}$ /day at 26 weeks (WMD $-0.38 ; 95 \% \mathrm{Cl}-1.61$ to 0.84 ) (3 studies);

- rivastigmine 6 to $12 \mathrm{mg} /$ day at 12 weeks (WMD 1.08; 95\% Cl 0.19 to $1.98, P=0.02,4$ studies);

- rivastigmine 6 to $12 \mathrm{mg} /$ day at 26 weeks (WMD 2.15; 95\% Cl 1.13 to $3.16, \mathrm{P}<0.0001,4$ studies).

One study (IDEAL) assessing activities of daily living (ADL) using the ADCS-ADL scale showed benefit for 6 to $12 \mathrm{mg}$ /day at 24 weeks (MD $1.80 ; 95 \% \mathrm{Cl} 0.20$ to $3.40, \mathrm{P}=0.03$ ). 


\section{Global assessment}

The seven-point CIBIC-Plus scale, or the ADCS-CGIC scale, measuring global clinical state was dichotomized by counting those showing no change or decline against those showing improvement (as set out in the study protocols by Novartis) and analysed using the Peto OR. There were benefits associated with lower dose rivastigmine compared with placebo at 26 weeks, but not at 12 weeks; and benefits with the higher dose at both 12 and 26 weeks compared with placebo:

- rivastigmine $14 \mathrm{mg} /$ day at 12 weeks (ITT analysis, 456/608 rivastigmine, $466 / 612$ placebo) (OR $0.93 ; 95 \% \mathrm{Cl} 0.72$ to $1.21,3$ studies);

- rivastigmine 6 to $12 \mathrm{mg} /$ day at 12 weeks (ITT analysis, 688/950 rivastigmine, $645 / 825$ placebo) (OR $0.74 ; 95 \% \mathrm{Cl} 0.60$ to $0.92, \mathrm{P}=$ $0.008,4$ studies);

- rivastigmine 1 to $4 \mathrm{mg}$ /day at 26 weeks (ITT analysis, 457/614 rivastigmine, $500 / 623$ placebo) (OR $0.71 ; 95 \% \mathrm{Cl} 0.55$ to $0.93, \mathrm{P}=$ $0.01,3$ studies);

- rivastigmine 6 to $12 \mathrm{mg} /$ day at 26 weeks (ITT analysis, 957/1330 rivastigmine, $971 / 1223$ placebo) (OR $0.66 ; 95 \% \mathrm{Cl} 0.55$ to $0.79, \mathrm{P}$ $<0.00001,6$ studies)

The GDS (global assessment) carried out at 26 weeks by a clinician who had access to all information about a patient was dichotomized by counting those showing moderately severe, severe or very severe dementia against those showing moderate or mild dementia. Using the Peto OR to compare with placebo, there were benefits associated with 6 to $12 \mathrm{mg}$ daily rivastigmine (ITT analysis, 579/1056 on rivastigmine showed the worse condition compared to $511 / 868$ on placebo) $(\mathrm{OR} 0.78 ; 95 \% \mathrm{Cl} 0.64$ to $0.94, \mathrm{P}=$ $0.01,4$ studies) but not with 1 to $4 \mathrm{mg}$ daily rivastigmine.

\section{Behavioural symptoms}

Two studies (IDEAL; Lopez-Pousa 2005) assessed behavioural symptoms using the NPI (NPI-10 and NPI-12). There was no difference between rivastigmine and placebo:

- rivastigmine 6 to $12 \mathrm{mg} /$ day at 26 weeks (ITT analysis, WMD $-0.06 ; 95 \% \mathrm{Cl}-0.20$ to $0.09,2$ studies).

\section{Withdrawals before the end of treatment}

The meta-analyses of withdrawals before the end of treatment showed no significant differences between withdrawals from the 1 to $4 \mathrm{mg}$ daily rivastigmine group and from the placebo group at 12 and 26 weeks. There were significant differences for the higher dose group in favour of placebo at 12 and 26 weeks:

- rivastigmine 1 to $4 \mathrm{mg} /$ day at 12 weeks (17/136 rivastigmine, 8/133 placebo) (OR 2.15; $95 \%$ Cl 0.95 to $4.89,1$ study);

- rivastigmine 1 to $4 \mathrm{mg} /$ day at 26 weeks (113/644 rivastigmine, $113 / 646$ placebo) (OR 1.01; $95 \% \mathrm{Cl} 0.75$ to 1.34 , 3 studies);

- rivastigmine 6 to $12 \mathrm{mg} /$ day at 12 weeks (20/133 rivastigmine, 8/133 placebo) (OR 2.60; $95 \% \mathrm{Cl} 1.19$ to $5.68, \mathrm{P}=0.02$, 1 study);

- rivastigmine 6 to $12 \mathrm{mg} /$ day at 26 weeks (448/1458 rivastigmine, $1194 / 1243$ placebo) (OR 2.19; $95 \% \mathrm{Cl} 1.83$ to 2.63 , $\mathrm{P}<0.00001,6$ studies).

\section{Adverse events}

Most adverse events occurred within the titration period. The meta-analyses of numbers of patients with at least one adverse event showed that by the end of the titration period and at 26 weeks there were no significant differences between the lower dose rivastigmine and placebo groups. There were, however, significant differences between the higher dose rivastigmine and placebo groups in favour of placebo by the end of the titration period and at 26 weeks:

- rivastigmine 1 to $4 \mathrm{mg} /$ day at the end of the titration period (440/644 rivastigmine, $437 / 646$ placebo) (OR $1.04 ; 95 \% \mathrm{Cl} 0.82$ to 1.31, 3 studies);

- rivastigmine 1 to $4 \mathrm{mg} /$ day at 26 weeks (509/644 rivastigmine, 518/646 placebo) (OR 0.93; 95\% Cl 0.71 to 1.23 , 3 studies);

- rivastigmine 6 to $12 \mathrm{mg} /$ day at the end of the titration period (920/1072 rivastigmine, 584/878 placebo) (OR 2.96; 95\% Cl 2.39 to $3.68, \mathrm{P}<0.00001$, 4 studies);

- rivastigmine 6 to $12 \mathrm{mg} /$ day at 26 weeks $(1242 / 1450$ rivastigmine, $901 / 1276$ placebo) (OR $2.49 ; 95 \% \mathrm{Cl} 2.05$ to $3.02, \mathrm{P}$ $<0.00001,6$ studies).

A similar pattern was seen for the number of patients with at least one severe adverse event. The rivastigmine 1 to $4 \mathrm{mg}$ daily group did not differ significantly from the placebo group, but there were significant differences between the rivastigmine 6 to $12 \mathrm{mg}$ daily and placebo groups in favour of the latter for the titration period:

- rivastigmine 1 to $4 \mathrm{mg} /$ day at the end of the titration period (48/644 rivastigmine, 51/646 placebo) (OR $0.94 ; 95 \% \mathrm{Cl} 0.62$ to 1.42, 3 studies);

- rivastigmine 6 to $12 \mathrm{mg} /$ day at the end of the titration period (130/1052 rivastigmine versus $61 / 868$ placebo) (OR $1.88 ; 95 \% \mathrm{CI}$ 1.39 to $2.55, \mathrm{P}<0.0001,4$ studies).

There were many types of adverse events reported and only the significant results are reported here. There were significant differences in favour of placebo for the rivastigmine 6 to $12 \mathrm{mg}$ daily group by the end of the titration period and by 26 weeks for the number of patients suffering nausea, vomiting, diarrhoea, anorexia, headache, syncope, abdominal pain and dizziness. There were significant differences in favour of placebo for the rivastigmine 1 to $4 \mathrm{mg}$ daily group compared to placebo by the end of the titration period and by 26 weeks for the number of patients suffering nausea, vomiting, diarrhoea and anorexia.

\section{Withdrawals before the end of treatment due to adverse events}

The meta-analyses of withdrawals at 26 weeks due to adverse events showed no significant differences in withdrawals from the lower dose rivastigmine and placebo groups. There were, however, significant differences between the rivastigmine 6 to $12 \mathrm{mg}$ daily and placebo groups in favour of placebo (291/1453 versus 94/1276) (OR 2.73, 95\% Cl 2.19 to $3.41, \mathrm{P}<0.00001,6$ studies).

\section{Comparison of rivastigmine $\left(20 \mathrm{~cm}^{2}(17.4 \mathrm{mg} /\right.$ day $)$ patch) with placebo}

\section{Cognitive function}

The meta-analysis, using MDs, showed that rivastigmine had a benefit compared with placebo for cognitive function as measured by the ADAS-Cog at 24 weeks: 
- rivastigmine (ITT analysis, $\mathrm{MD}-2.60 ; 95 \% \mathrm{Cl}-3.72$ to $-1.48, \mathrm{P}<$ $0.00001,1$ study).

The MMSE showed similar results in favour of rivastigmine at 26 weeks, compared with placebo:

- rivastigmine (ITT analysis, MD 0.90; $95 \% \mathrm{Cl} 0.32$ to $1.48, \mathrm{P}=0.002$, 1 study).

The TMT-A showed similar results in favour of rivastigmine at 26 weeks, compared with placebo:

- rivastigmine (ITT analysis, $\mathrm{MD}-14.20 ; 95 \% \mathrm{Cl}-24.11$ to $-4.29, \mathrm{P}=$ $0.005,1$ study).

There was no significant difference between rivastigmine and placebo for the clock drawing test.

\section{Activities of daily living}

The ADCS-ADL showed benefit in favour of rivastigmine compared with placebo at 24 weeks:

- rivastigmine (ITT analysis, $\mathrm{MD} 2.30 ; 95 \% \mathrm{Cl} 0.52$ to $4.08, \mathrm{P}=0.01$, 1 study).

\section{Behavioural symptoms}

One study assessed behavioural symptoms using the NPI (NPI-12). There was no difference between rivastigmine and placebo (ITT analysis, MD $-0.60 ; 95 \% \mathrm{Cl}-2.88$ to $1.68,1$ study).

\section{Withdrawals before the end of treatment}

There was a significant difference between rivastigmine and placebo in favour of placebo for total withdrawals before the end of treatment (62/303 rivastigmine compared with $36 / 302$ placebo) (OR $1.90 ; 95 \% \mathrm{Cl} 1.22$ to $2.97, \mathrm{P}=0.005$ ).

\section{Adverse events}

There was a significant difference between rivastigmine and placebo in favour of placebo for the total number of patients that had at least one adverse event by 24 weeks (200/303 rivastigmine compared with $139 / 302$ placebo) (OR $2.28 ; 95 \% \mathrm{Cl} 1.64$ to $3.16, \mathrm{P}<$ $0.00001)$.

There was a significant difference between rivastigmine and placebo in favour of placebo for the total number of patients that had at least one adverse event of dizziness (21/303 compared with $7 / 302$ ) (ITT analysis, OR $3.14 ; 95 \% \mathrm{Cl} 1.31$ to $7.50, \mathrm{P}=0.01$ ), nausea (64/303 compared with 15/302) (OR 5.12; $95 \% \mathrm{Cl} 2.85$ to 9.22, $\mathrm{P}<$ 0.00001 ), vomiting (57/303 compared with 10/302) (ITT analysis, OR $6.77 ; 95 \% \mathrm{Cl} 3.38$ to $13.53, \mathrm{P}<0.00001)$, weight decrease $(23 / 303$ compared with 4/302) (ITT analysis, OR $6.12 ; 95 \% \mathrm{Cl} 2.09$ to 17.92 , $\mathrm{P}=0.0009)$, and decreased appetite (15/303 compared with $3 / 302)$ (ITT analysis, OR 5.19; $95 \% \mathrm{Cl} 1.49$ to $18.12, \mathrm{P}=0.01$, 1 study).

\section{Withdrawals before the end of treatment due to adverse events}

The meta-analyses of withdrawals at 26 weeks due to adverse events showed no significant differences in withdrawals from the rivastigmine and placebo groups (26/303 rivastigmine compared with $15 / 302$ placebo) (OR $1.80 ; 95 \%$ Cl 0.93 to $3.46,1$ study).

\section{Quality of life of carers}

One study assessed the NPI-D carer distress scale at 24 weeks (IDEAL). No significant difference between rivastigmine and placebo was detected (ITT analysis, MD $0.00 ; 95 \% \mathrm{Cl}-1.07$ to 1.07 ).

\section{Comparison of rivastigmine $\left(10 \mathrm{~cm}^{2}(9.5 \mathrm{mg} /\right.$ day $)$ patch $)$ with} placebo

\section{Cognitive function}

The meta-analysis, using WMDs and MDs, showed a benefit of the $10 \mathrm{~cm}^{2}$ rivastigmine patch on cognitive function as measured by the ADAS-Cog, MMSE, TMT-A and MENFIS at 24 weeks:

- ADAS-cog (ITT analysis, WMD $-1.34 ; 95 \% \mathrm{Cl}-2.02$ to $-0.66, \mathrm{P}=$ 0.0001, 2 studies);

- MMSE (ITT analysis, WMD $0.64 ; 95 \% \mathrm{Cl} 0.26$ to $1.02, \mathrm{P}=0.0009$, 2 studies);

- TMT-A (ITT analysis, MD $-20.0 ; 95 \% \mathrm{Cl}-29.8$ to -10.2 , P $<0.0001$, 1 study);

- MENFIS (ITT analysis, MD $-1.30 ; 95 \% \mathrm{Cl}-2.32$ to $-0.28, \mathrm{P}=0.01,1$ study).

\section{Activities of daily living}

The ADCS-ADL showed benefit in favour of rivastigmine at 24 weeks (ITT analysis, MD 2.20; 95\% $\mathrm{Cl} 0.62$ to $3.78, \mathrm{P}=0.006,1$ study).

The DAD showed benefit in favour of rivastigmine at 24 weeks (ITT analysis, MD 2.3; $95 \% \mathrm{Cl} 0.34$ to $4.26, \mathrm{P}=0.02,1$ study).

\section{Global assessment}

The seven-point CIBIC-Plus scale measuring global clinical state was dichotomized by counting those showing no change or decline against those showing improvement and analysed using the Peto $\mathrm{OR}$. There was no difference between rivastigmine and placebo at 24 weeks (382/518 rivastigmine, $426 / 545$ placebo) (ITT analysis, OR $0.77 ; 95 \% \mathrm{Cl} 0.58$ to $1.02, \mathrm{P}=0.07,2$ studies).

\section{Withdrawals before the end of treatment}

There was a significant difference between rivastigmine and placebo in favour of placebo for total withdrawals before the end of treatment ( $123 / 580$ rivastigmine compared with $82 / 590$ placebo) (OR $1.67 ; 95 \% \mathrm{Cl} 1.23$ to $2.26, \mathrm{P}=0.001$, 2 studies).

\section{Adverse events}

There were significant differences between rivastigmine and placebo in favour of placebo for the total number of patients that had at least one adverse event by 24 weeks (395/578 rivastigmine compared with $361 / 588$ placebo) (OR $1.39 ; 95 \% \mathrm{Cl} 1.08$ to 1.80 , P $=0.01,2$ studies $)$ and withdrawals due to adverse events $(62 / 580$ rivastigmine compared with $36 / 590$ placebo) (OR $1.84 ; 95 \% \mathrm{Cl} 1.20$ to $2.82, \mathrm{P}=0.005,2$ studies).

There were significant differences between rivastigmine and placebo in favour of placebo for the total number of patients that had at least one adverse event at the application site: erythema (113/287 compared with 55/286) (OR 2.73 ; $95 \% \mathrm{Cl} 1.87$ to 3.98 , P $<0.00001,1$ study), application site pruritis (100/287 compared with $61 / 286$ ) (OR $1.97 ; 95 \% \mathrm{Cl} 1.36$ to $2.86, \mathrm{P}=0.0004,1$ study), application site oedema (31/287 compared with $7 / 286$ ) (OR 4.83; $95 \% \mathrm{Cl} 2.09$ to $11.15, \mathrm{P}=0.0002,1$ study), application site exfoliation 
(11/282 compared with $4 / 286$ ) (OR $3.68 ; 95 \% \mathrm{Cl} 1.20$ to $1.33, \mathrm{P}=$ 0.02 ), contact dermatitis (68/287 compared with 40/286) (OR 1.91; $95 \% \mathrm{Cl} 1.24$ to $2.94, \mathrm{P}=0.003,1$ study), nausea ( $41 / 578$ compared with $24 / 588$ ) (OR $1.80 ; 95 \% \mathrm{Cl} 1.07$ to $3.02, \mathrm{P}=0.03$, 2 studies) and vomiting (41/578 compared with $21 / 588$ ) (OR $2.06 ; 95 \% \mathrm{Cl} 1.20$ to $3.53, \mathrm{P}=0.009,2$ studies).

\section{Withdrawals before the end of treatment due to adverse events}

There was a significant difference between rivastigmine and placebo in favour of placebo for withdrawals due to adverse events (62/580 rivastigmine compared with $36 / 590$ placebo) (OR 1.84; $95 \%$ $\mathrm{Cl} 1.20$ to $2.82, \mathrm{P}=0.005$, 2 studies).

\section{Comparison of rivastigmine $\left(5 \mathrm{~cm}^{2}(4.6 \mathrm{mg} /\right.$ day $)$ patch) with placebo}

This comparison was made in one study (Nakamura 2011).

\section{Cognitive function}

There was no difference between rivastigmine and placebo at 24 weeks for cognitive function measured using the ADAS-Cog scale (ITT analysis, MD $0.80 ; 95 \% \mathrm{Cl}-1.62$ to 0.02 ), MMSE ITT analysis, MD $0.00 ; 95 \% \mathrm{Cl}-0.52$ to 0.52 ) and MENFIS (ITT analysis, MD $-0.70 ; 95 \%$ $\mathrm{Cl}-0.70,95 \% \mathrm{Cl}-1.72$ to 0.32 ).

\section{Activities of daily living}

There was no difference between rivastigmine and placebo at 24 weeks for activities of daily living measured using the DAD scale (ITT analysis, MD 1.20; $95 \% \mathrm{Cl}-0.73$ to 3.13 ).

\section{Global assessment}

There was no difference between rivastigmine and placebo at 24 weeks for global assessment measured using the CIBIC-plus J scale (212/269 rivastigmine, 226/267 placebo) (ITT analysis, OR 0.67; $95 \%$ $\mathrm{Cl} 0.43$ to 1.05$)$.

\section{Behavioural symptoms}

There was no difference between rivastigmine and placebo at 24 weeks for behavioural symptoms measured using the BEHAVE-AD scale (ITT analysis, MD 0.00; $95 \% \mathrm{Cl}-0.67$ to 0.67 ).

\section{Withdrawals before the end of treatment}

There was a significant difference between rivastigmine and placebo in favour of placebo for total withdrawals before the end of treatment (64/284 rivastigmine compared with $46 / 288$ placebo) (OR $1.53 ; 95 \% \mathrm{Cl} 1.01$ to $2.33, \mathrm{P}=0.05$ ).

\section{Adverse events}

There was a significant difference between rivastigmine and placebo in favour of placebo for the total number of patients that had at least one adverse event at 24 weeks (243/282 rivastigmine compared with $222 / 286$ placebo) $(\mathrm{OR} 1.80 ; 95 \% \mathrm{Cl} 1.16$ to $2.78, \mathrm{P}=$ 0.009), but no difference for deaths.

There were significant differences between rivastigmine and placebo in favour of placebo for the total number of patients that had at least one adverse event at the application site: erythema (106/282 compared with 55/286) (OR 2.53; 95\% Cl 1.73 to 3.70 , $\mathrm{P}<0.00001,1$ study), application site pruritis (92/282 compared with $61 / 286$ ) (OR $1.79 ; 95 \% \mathrm{Cl} 1.23$ to $2.60, \mathrm{P}=0.003,1$ study), application site oedema (35/282 compared with 7/286) (OR 5.65; $95 \% \mathrm{Cl} 2.46$ to $12.94, \mathrm{P}<0.0001,1$ study), application site exfoliation (14/282 compared with 4/286) (OR 3.68; $95 \% \mathrm{Cl} 1.20$ to $11.35, \mathrm{P}=$ 0.02 ), contact dermatitis (69/282 compared with 40/286) (OR 1.99; $95 \% \mathrm{Cl} 1.30$ to $3.06, \mathrm{P}=0.002,1$ study); but no difference between rivastigmine and placebo for adverse events of nasopharyngitis, nausea, vomiting and diarrhoea.

\section{Withdrawals before the end of treatment due to adverse events}

There was a significant difference between rivastigmine and placebo in favour of placebo for withdrawals due to adverse events (38/284 rivastigmine compared with $21 / 288$ placebo) (OR 1.96; $95 \%$ $\mathrm{Cl} 1.12$ to $3.44, \mathrm{P}=0.02$ ).

Comparison of rivastigmine $\left(10 \mathrm{~cm}^{2}(9.5 \mathrm{mg} /\right.$ day $)$ patch) with rivastigmine (6 to $12 \mathrm{mg} /$ day twice daily) capsules

\section{Cognitive function}

One study (IDEAL) showed no difference between the rivastigmine patch and rivastigmine capsules on cognitive function as measured by the ADAS-Cog, MMSE, TMT-A and MENFIS at 24 weeks:

- ADAS-cog (ITT analysis, MD 0.0; $95 \% \mathrm{Cl}-1.10$ to $1.10, \mathrm{P}=1.0,1$ study);

- MMSE (ITT analysis, MD $0.30 ; 95 \% \mathrm{Cl}-0.27$ to $0.87, \mathrm{P}=0.30,1$ study);

- TMT-A (ITT analysis, MD -2.6; $95 \% \mathrm{Cl}-13.5$ to $8.3, \mathrm{P}=0.64,1$ study);

- clock drawing (ITT analysis, MD $0.1 ; 95 \% \mathrm{Cl}-0.5$ to $0.7, \mathrm{P}=0.73$, 1 study).

\section{Activities of daily living}

The ADCS-ADL showed no difference between the rivastigmine patch and rivastigmine capsules at 24 weeks (ITT analysis, MD 0.40; $95 \% \mathrm{Cl}-1.23$ to $2.03, \mathrm{P}=0.63,1$ study).

\section{Global assessment}

The seven-point CIBIC-Plus scale measuring global clinical state was dichotomized by counting those showing no change or decline against those showing improvement and analysed using the Peto OR. There was no difference between the rivastigmine patch and rivastigmine capsules at 24 weeks (171/248 rivastigmine patch, $161 / 267253$ rivastigmine capsules) (ITT analysis, OR $1.27 ; 95 \% \mathrm{Cl}$ 0.88 to $1.84, P=0.21,1$ study).

\section{Behavioural symptoms}

One study assessed behavioural symptoms using the NPI (NPI-12). There was no difference between the rivastigmine patch and rivastigmine capsules (ITT analysis, MD $0.50 ; 95 \% \mathrm{Cl}-1.55$ to $2.55, \mathrm{P}$ $=0.63,1$ study).

\section{Withdrawals before the end of treatment}

There was no significant difference between rivastigmine and placebo for withdrawals before the end of treatment $(64 / 293$ compared with 63/297) (OR 1.09; $95 \% \mathrm{Cl} 0.70$ to $154, \mathrm{P}=0.85,1$ study).

\section{Adverse events}

There was a significant difference between the rivastigmine patch and rivastigmine capsules in favour of the patch for the total 
number of patients that had at least one adverse event by 24 weeks (147/291 rivastigmine compared with $186 / 294$ placebo) (OR 0.59; $95 \% \mathrm{Cl} 0.43$ to $0.82, \mathrm{P}=0.002,1$ study).

There were significant differences between the rivastigmine patch and rivastigmine capsules in favour of the patch for the total number of patients that had at least one adverse event of decreased appetite (2/291 compared with $12 / 294)$ (OR $0.16 ; 95 \% \mathrm{Cl} 0.04$ to $0.73, P=0.02,1$ study), dizziness (7/291 compared with $22 / 294)$ (OR $0.30 ; 95 \% \mathrm{Cl} 0.13$ to $0.72, \mathrm{P}=0.007,1$ study), asthenia $(5 / 291$ compared with $17 / 294$ ) (OR $0.28 ; 95 \% \mathrm{Cl} 0.10$ to $0.78, \mathrm{P}=0.01,1$ study), nausea (21/291 compared with 68/294) (OR 0.26; 95\% Cl 0.15 to $0.43, P<0.001,1$ study) and vomiting (18/291 compared with $50 / 294$ ) (OR 0.32; $95 \% \mathrm{Cl} 0.18$ to $0.57, \mathrm{P}<0.001,1$ study).

\section{Withdrawals before the end of treatment due to adverse events}

There was no significant difference between rivastigmine and placebo for withdrawals due to adverse events (28/293 rivastigmine compared with $24 / 297$ placebo) (OR $1.20 ; 95 \% \mathrm{Cl} 0.68$ to $2.13, \mathrm{P}=$ $0.53,1$ study).

\section{DISCUSSION}

\section{Summary of main results}

The results of the review showed the following main findings.

- The currently recommended doses of rivastigmine (6 to 12 $\mathrm{mg} /$ day in two divided doses for capsules and $9.5 \mathrm{mg} /$ day for transdermal patches) have some benefits compared to placebo at 26 weeks for cognitive function, activities of daily living and the physician rated global impression scales. No difference was found for behavioural symptoms or the impact on carers. Patients on rivastigmine are about twice as likely (OR of about 2) to experience adverse events or to withdraw from the trial before the end of the study.

- Limited evidence from one trial suggests that the transdermal formulation ( $9.5 \mathrm{mg} /$ day) is as effective as the oral formulation ( 6 to $12 \mathrm{mg} / \mathrm{day}$ ) and is associated with a lower incidence of adverse events but does not affect the rate of withdrawals due to adverse events.

\section{Outcomes}

The two cognitive tests used, the MMSE and ADAS-Cog, assess similar domains and a high correlation between the results would be expected. The results from 5 studies show that 6 to $12 \mathrm{mg}$ daily of oral rivastigmine improved the cognitive function of patients with mild to moderate probable Alzheimer's disease treated over a period of 26 weeks, by 0.8 points on the MMSE (range 0 to 30) and by 2.0 points on the ADAS-Cog (range 0 to 70 ), when compared with placebo. The results from 2 studies show that the $9.5 \mathrm{mg} /$ day of rivastigmine in a transdermal patch improved cognitive function by 0.6 points on the MMSE and 1.4 points on the ADAS-cog when compared with placebo. Pooling the data showed a treatment effect of 0.7 points on the MMSE and 1.8 points on the ADAS-Cog. There was a smaller effect on cognitive function in the 1 to $4 \mathrm{mg}$ daily oral treatment group.

Four studies assessed the effect of 6 to $12 \mathrm{mg}$ daily oral rivastigmine on activities of daily living as reported by a carer using the PDS rating scale (range 0 to 100). Rivastigmine showed a benefit of 2.2 points compared with placebo, but the difference between placebo and 1 to $4 \mathrm{mg}$ daily rivastigmine was not significant. The $10 \mathrm{~cm}^{2}$ $(9.5 \mathrm{mg} /$ day) patch showed a benefit of 2.2 points on the ADCS-ADL scale (range 0 to 54) when compared with placebo.

The US Food and Drug Administration (FDA) requires an independent clinician to assess global clinical state after interviewing the patient and the carer at baseline and the endpoint. When the results of global impression measures were dichotomized to compare the number of patients who improved with the numbers who showed no change or whose condition had deteriorated, the 6 to $12 \mathrm{mg}$ daily group was significantly better than the placebo group at 12 and 26 weeks, and there was a similar significant difference favouring the 1 to $4 \mathrm{mg}$ daily group over placebo at 26 weeks. The $10 \mathrm{~cm}^{2}(9.5 \mathrm{mg} /$ day) patch was also significantly better than placebo at 24 weeks.The clinician and carer, whilst following the guidelines for the application of the CIBIC-Plus, are essentially making an assessment of whether the patient has improved or not based on criteria relevant to them. This is perhaps closest to what is commonly meant by the term 'meaningful improvement'.

Minimal clinically important differences (MCID), patient derived scores that represent changes in a score that have meaning for patients, have been suggested for the ADAS- $\operatorname{cog}$ ( 3 points in severe AD (Howard 2011)) and MMSE (1.4 points in mild AD (Schrag 2012)). Comparing our findings with these we might conclude that the treatment effects for cognitive function are unlikely to be clinically relevant.

\section{Adverse effects}

When taking capsules, a fairly lengthy titration period of up to 12 weeks is needed to develop tolerance and to minimize adverse effects such as nausea, vomiting, diarrhoea, abdominal pain, dizziness, headache and anorexia. The target was to treat patients with a maximum tolerated dose administered in two divided doses, the upper limit being $12 \mathrm{mg}$ per day. There were significantly more total dropouts and dropouts due to adverse events from the 6 to $12 \mathrm{mg}$ daily dose groups than from placebo groups and therefore adverse effects remain a clinical issue. There was no hepatotoxicity associated with rivastigmine and no statistically or clinically significant changes in vital signs.

The continuous dose patch was introduced to improve tolerability. One study (IDEAL) tested two sizes of rivastigmine patch, one delivering a higher dose than previously tested in a $20 \mathrm{~cm}^{2}$ patch (17.4 mg/day) and one $10 \mathrm{~cm}^{2}$ patch $(9.5 \mathrm{mg} /$ day), a dose similar to the usual oral dose. Another study (Nakamura 2011) tested 5 $\mathrm{cm}^{2}$ (4.6 mg/day) and $10 \mathrm{~cm}^{2}$ (9.5 mg/day) patches. The smallest patch showed no treatment effect when compared with placebo for cognition, global function and activities of daily living. The efficacy of the $9.5 \mathrm{mg} /$ day patch was comparable to that of the capsules with a similar daily dose, but was associated with significantly fewer adverse events of nausea, vomiting, dizziness and asthenia. There was no difference in the number of withdrawals due to adverse events. Therefore, the $9.5 \mathrm{mg} /$ day patch appears to have advantages compared with both the higher dose patches and the 6 to $12 \mathrm{mg}$ /day capsules in terms of the overall incidence of adverse events, but it may not reduce the incidence of the more serious events that lead to cessation of treatment. 


\section{Overall completeness and applicability of evidence}

We were able to include evidence from both published and unpublished trials in this systematic review. There were 3319 participants. Most participants were in industry sponsored trials. Data from two independent trials $(n=162)$ were not available and we excluded data from two other independent trials $(n=75)$ from our analyses because of concerns about risk of bias. The participants in the included trials had mainly mild to moderate dementia due to Alzheimer's disease. They were not highly selected with respect to their general health so that all but the seriously ill were included. Only two trials included patients with severe dementia, and we excluded the data from one of these leaving data on only 218 patients with severe dementia included in the analyses.

The main limitations in the completeness and applicability of the evidence were the lack of long term data beyond 26 weeks and the limited range of outcomes measured. Beyond 26 weeks, some trials continued as an open label, extension phase. There were very few data on outcomes important to patients and carers, such as quality of life.

\section{Quality of the evidence}

The quality of the evidence at 26 weeks is moderate for most outcomes. Our main concern for the evidence is that only seven studies have contributed data to the meta-analysis, and all of these studies were either industry sponsored or industry funded. In addition, withdrawals from these studies were of concern.

The results from B352 nearly always showed greater benefits for rivastigmine on each outcome than demonstrated in B303/ B305, B304 and B351. B352 was responsible for the heterogeneity between trials that was reported for some of the measures of cognitive function. There are no obvious differences between B352 and the other phase III trials. It was conducted only in the US, but so was B351. The doses reached by patients in B352 were higher than those of B351, by $1.2 \mathrm{mg}$ per day on average. Results from B352 have been more extensively reported than the other three phase III trials but there is no reason to suppose that this trial is of any more importance in the overall assessment of rivastigmine. We have not downgraded the evidence based on this heterogeneity concern since the impact on the overall pooled results is small and does not change the interpretation of any of the results.

Outcomes such as behavioural symptoms and quality of life are important to patients but these were only reported by three studies and one study, respectively. Hence, the quality of evidence for these was lower.

\section{Potential biases in the review process}

The initial protocol of the review, which was published in 1998, had aimed to include all double-blinded randomised controlled trials (RCTs) of rivastigmine with a minimum study period of two weeks, regardless of the doses or formulations used. However, this resulted in a large number of possible comparisons. In addition, studies often used multiple instruments to report the same outcome, for example cognitive function was measured using the MMSE, ADAS-Cog and other tests. For some of these outcomes we decided to use only the most commonly used tests in the main analysis.
In this update we decided to concentrate on the currently recommended doses ( 6 and $12 \mathrm{mg} /$ day for oral doses, and $9.5 \mathrm{mg} /$ day for transdermal patches), and a minimum treatment duration of six months for the main analysis. We considered the decision to focus on longer term data was clinically sensible since a titration period was required to reach the target doses.

Mowla 2007, Karaman 2005, Ballard 2005 and Tai 2000, all nonindustry funded studies, did not provide data that could be included in the review.

\section{Agreements and disagreements with other studies or reviews}

Most patients from the four phase III trials continued in an open label phase for a further 26 weeks during which the maximum tolerated dose was administered. Results from these extension phases have been described as showing a possible beneficial effect of rivastigmine on disease progression (Product monograph, Novartis 1998). Reported results showed that patients who had received placebo or rivastigmine 1 to $4 \mathrm{mg}$ daily in the randomised phase showed initial improvement on the ADAS-Cog before declining at the same rate as the 6 to $12 \mathrm{mg}$ daily group, although remaining more impaired by approximately 1.5 points. These results must be interpreted with caution. The randomised, doubleblind conditions no longer prevailed. There had been differential dropout from the groups and there was no placebo group for the comparison. An imputed rate of decline for placebo patients was obtained by extrapolating from the randomised phase and not from actual observations.

There is much interest in the identification of patient characteristics that might predict a response to a cholinesterase inhibitor. Burns 2004 reported that cholinesterase inhibitors may be effective in patients with more severe disease. Data were pooled from three studies (B303/B305; B351; B352) for those with a baseline MMSE of $10,11$ or 12 ( $n=117)$, in the group treated with rivastigmine (6 to $12 \mathrm{mg} /$ day) or placebo, and the analysis showed that rivastigmine benefited those with more severe disease. This result has not added anything substantial to what was known already. The analysis of the total dataset from these trials demonstrated that rivastigmine was of benefit to the population randomised.

Erkinjuntti 2002, funded by Novartis Pharmaceuticals, investigated the response to rivastigmine of those without hypertension compared to those with using the data from B303/B305. They reported that particular benefits may be observed in those with vascular risk factors. These results are based on retrospective analysis of the study data and there has been no study confirming this finding using prospective data.

Farlow 2003a retrieved dropouts from the studies B303/B305, B351 and B352. These patients stopped treatment before the end of the trials but were invited back for assessment at the endpoint. Farlow concluded that those who had been in the rivastigmine groups had deteriorated less than those from the placebo groups, and therefore rivastigmine had provided a beneficial delay in disease progression. The two groups cannot be compared. The participants belong to a highly selected group, those who stopped treatment and agreed to return. The placebo group was much smaller than the rivastigmine group (38 compared with 88). Those who left the trial from the placebo group may have done so because their illness was more severe. This may have applied to some of those in the 
rivastigmine group who left but, in addition, there were those who left because they suffered from adverse effects. It is not possible to compare these two groups in a meaningful way.

Grossberg 2000 was a Novartis funded extension study examining the data from the four phase III studies and the related open label extension studies. Those who had been taking rivastigmine continuously for two years were compared with historical controls and the study concluded that rivastigmine has a beneficial effect on cognitive performance for up to two years in patients with Alzheimer's disease. These results must be treated with caution as the two groups are not comparable.

Several reviews of rivastigmine have been published. Schneider 1998 and Spencer 1998 both limited analysis and interpretation to the three trials B352, B303/B305 and B351. Spencer reported that "individual and pooled results indicate that rivastigmine usually produces cognitive, global and functional changes that indicate significantly less deterioration than was observed with placebo". Schneider reported that "the pooled analyses confirm the efficacy of rivastigmine in the treatment of both the cognitive and functional deficits of mild to moderately severe AD". Clegg 2002 was the report from NICE (National Institute of Clinical Excellence, UK) of the systematic review on which the decision was made that the cholinesterase inhibitors would be available on the National Health Service to treat those with Alzheimer's disease. Williams 2003 was a review of all aspects of rivastigmine, and summarised the clinical trials but without meta-analyses.

Hauber 2000 calculated the potential savings costs using rivastigmine compared with no treatment for Alzheimer's disease. Hauber used a disease stage model. Results from two phase III trials of rivastigmine, together with extrapolation beyond the six month duration of the trial, identified the stage of disease using the MMSE assessments. Costs of healthcare resource use was estimated as a function of MMSE, using data from Canadian sources. Rivastigmine was judged to be cost effective due to the delay in disease progression. The analysis was repeated in a UK and US setting. These results are not based on randomised evidence and rest on many assumptions. It would be unwise to base decisions on whether rivastigmine should be prescribed to patients on the basis of cost-effectiveness studies such as these. Fillit 2004 presents an excellent summary of the cost-effectiveness studies and of the assumptions on which they are based. Fillit concludes that the results from these studies are not reliable and that outcomes related to costs and healthcare resource use must be assessed in randomised clinical trials.

\section{AUTHORS' CONCLUSIONS}

\section{Implications for practice}

Use of rivastigmine in doses of 6 to $12 \mathrm{mg}$ daily is associated with statistically significant benefits in terms of cognitive function. Benefits are also seen in the activities of daily living and clinician rated global impression scale ratings, which suggests that they may be of clinical as well as statistical significance. At lower doses (4 mg or less total daily dose) differences were in the same direction and were significant for cognitive function. Significant differences in the CIBIC-Plus were seen at 26 weeks but not earlier. The $10 \mathrm{~cm}^{2}(9.5$ $\mathrm{mg} /$ day) patch has been tested in two placebo controlled trials and shows similar benefits to the 6 to $12 \mathrm{mg}$ oral dose. One double-blind placebo controlled study of longer than 26 weeks is included in this review, but the data were not included in the meta-analyses due to concerns about the study. This present review has not examined economic data.

Side effects observed were predictably related to the cholinergic actions of the drug. They may be related to the pharmacokinetics of the drug and merit further study. Three sizes of transdermal patch have been tested in two trials, and there is evidence that the $9.5 \mathrm{mg} /$ day patch is associated with fewer side effects than the capsules or the higher dose larger patches and has comparable efficacy to all three.

\section{Implications for research}

Longer term studies with a focus on clinically significant endpoints need to be linked to economic analyses to generate information on cost-utility.

\section{ACKNOWLEDGEMENTS}

Novartis (Pharma UK) has provided access to all the company results from the four phase III studies. Novartis (Pharma UK) and Novartis (Hellas) have provided abstracts of conference presentations, and lists and descriptions of trials.

The authors also wish to acknowledge the assistance of Lon Schneider in the development of the protocol for this review.

The authors acknowledge the significant contribution made by Jenny McCleery to the 2015 update. 


\section{REFERE N CES}

\section{References to studies included in this review}

B103 \{published data only\}

Agid $Y$, Dubois $B$ on behalf of the International Rivastigmine Investigators, Anand R, Gharabawi G. Efficacy and tolerability of rivastigmine in patients with dementia of the Alzheimer type. Current Therapeutic Research 1998;59(12):837-45.

Anand R, Gharabawi G, Enz A. Efficacy and safety results of the early phase studies with Exelon (ENA-713) in Alzheimer's Disease: an overview. Journal of Drug Development and Clinical Practice 1996;8(2):109-16.

\section{B104 \{published data only\}}

Anand R, Gharabawi G, Enz A. Efficacy and safety results of the early phase studies with Exelon (ENA-713) in Alzheimer's Disease: an overview. Journal of Drug Development and Clinical Practice 1996;8(2):109-16.

Forette F, Anand R, Gharabawi G. A phase II study in patients with Alzheimer's disease to assess the preliminary efficacy and maximum tolerated dose of rivastigmine $\left(\right.$ Exelon $\left.^{\circledR}\right)$. European Journal of Neurology 1999;6:423-9.

\section{B303/B305 \{published and unpublished data\}}

Anand R, Hartman R, Graham S. Effects of Alzheimer's disease severity on activities of daily living with long-term rivastigmine treatment. Journal of the American Geriatrics Society 2001;49(4):S151.

Anand R, Messina J, Veach J, Hartman R. Effects of rivastigmine in patients with moderately severe Alzheimer's disease. Sixth International Stockholm/Springfield Symposium on Advances in Alzheimer Therapy; April 5-8, 2000; Stockholm, Sweden. 2000:199.

Burns A, Spiegel R, Quarg P. Efficacy of rivastigmine in subjects with moderately severe Alzheimer's disease. International Journal of Geriatric Psychiatry 2004;19(3):243-9.

Erkinjuntti T, Skoog I, Lane R, Andrews C. Potential longterm effects of rivastigmine on disease progression may be linked to drug effects on vascular changes in Alzheimer brains. International Journal of Clinical Practice 2003;57(9):756-60.

Erkinjuntti T, Skoog I, Lane R, Andrews C. Rivastigmine in patients with Alzheimer's disease and concurrent hypertension. International Journal of Clinical Practice 2002;56(10):791-6.

Farlow M, Anand R, Messina J, Hartman R. Increased cognitive efficacy of rivastigmine in patients with moderate to severe Alzheimer's disease with co-existing vascular risk. Sixth International Stockholm/Springfield Symposium on Advances in Alzheimer Therapy; April 5-8, 2000; Stockholm, Sweden. 2000:206.

Farlow M, Messina J, Anand R, Hartman R, Veach J. Dose dependent effect of rivastigmine on progression of cognitive deterioration in Alzheimer's disease. Sixth International Stockholm/Springfield Symposium on Advances in Alzheimer Therapy; April 5-8, 2000; Stockholm, Sweden. 2000. 2000:172.
Farlow M, Potkin S, Koumaras B, Veach J, Mirski D. Analysis of outcome in retrieved dropout patients in a rivastigmine vs placebo, 26-week, Alzheimer disease trial. Archives of Neurology 2003;60:843-8.

Hebert M. [Alzheimer disease: efficacy and tolerance of rivastigmine] [Maladie d'Alzheimer: efficacite et tolerance de la rivastigmine]. Presse Medicale 1999;28(32):1757-8.

Kumar V, Messina J, Hartman R, Anand R. Long-term cognitive benefits of rivastigmine in Alzheimer's disease patients with vascular risk. Sixth International Stockholm/Springfield Symposium on Advances in Alzheimer Therapy; April 5-8, 2000; Stockholm, Sweden. 2000:215.

Lindesay J. An open label one-year extension of SDZ-ENA-713 studies B303, B304 and B305 to prospectively evaluate longterm safety, tolerability and efficacy of SDZ-ENA-713 in outpatients with probable Alzheimer's disease. National Research Register 2000.

Roesler M, Retz W, Retz Junginger P, Dennler HJ. Effect of twoyear treatment with the cholinesterase inhibitor rivastigmine on behavioural symptoms in Alzheimer's disease. BehaviouralNeurology 1998;11(4):211-6.

Rösler M. Efficacy and safety of rivastigmine in patients with Alzheimer's disease: International randomised controlled trial [Erratum]. BMJ 2001; Vol. 322, issue 7300:1456.

Rösler M, Anand R, Cicin-Sain A, Gauthier S, Agid Y, DalBianco P, et al on behalf of the B303 Exelon Study Group. Efficacy and safety of rivastigmine in patients with Alzheimer's disease: international randomised controlled trial. BMJ 1999;318(7184):633-8.

Rösler M, Dennler H, Retz W, Gastpar W. A double-blind placebo controlled study of ENA 713 in Alzheimer's disease (DAT). Pharmacopsychiatry 1997;30:212. [MEDLINE: SR-HANDSRCH]

Rösler M, Retz W, Retz Junginger P, Dennler HJ. Effects of twoyear treatment with the cholinesterase inhibitor rivastigmine on behavioural symptoms in Alzheimer's disease. BehaviouralNeurology 1998;11(4):211-6.

Vincent S, Andrews C, Lane R. Rivastigmine shows particular efficacy in Alzheimer patients with concomitant hypertension. Proceedings of the 7th International Geneva/Springfield Symposium on Advances in Alzheimer therapy, 2002 Apr 3-6, Geneva. 2002:253.

Wilkinson DG. Rivastigmine was effective and safe in Alzheimer disease. ACP Journal Club 1999;131(2):34. [MEDLINE: Cinahl]

\section{B304 \{published and unpublished data\}}

Feldman HH, Lane R. Rivastigmine: a placebo controlled trial of twice daily and three times daily regimens in patients with Alzheimer's disease. Journal of Neurology, Neurosurgery, and Psychiatry 2007;78(10):1056-63.

Lindesay J. An open label one-year extension of SDZ-ENA-713 studies B303, B304 and B305 to prospectively evaluate long- 
term safety, tolerability and efficacy of SDZ-ENA-713 in outpatients with probable Alzheimer's disease. National Research Register 2000.

Novartis. No title. Unpublished. Data provided by Novartis. No year.

Novartis Pharmaceuticals. ADENA Programme. Unpublished Data 1998.

\section{B351 \{unpublished data only\}}

Burns A, Spiegel R, Quarg P. Efficacy of rivastigmine in subjects with moderately severe Alzheimer's disease. International Journal of Geriatric Psychiatry 2004;19(3):243-9.

Farlow M, Potkin S, Koumaras B, Veach J, Mirski D. Analysis of outcome in retrieved dropout patients in a rivastigmine vs placebo, 26-week, Alzheimer disease trial. Archives of Neurology 2003;60:843-8.

Novartis. No title. Unpublished. Data provided by Novartis. No year.

Novartis Pharmaceuticals. ADENA Programme. Unpublished Data 1998.

\section{B352 \{published data only\}}

Burns A, Spiegel R, Quarg P. Efficacy of rivastigmine in subjects with moderately severe Alzheimer's disease. International Journal of Geriatric Psychiatry 2004;19(3):243-9.

Corey-Bloom J, Anand R, Veach J for ENA 713 B352 Study Group. A randomized trial evaluating the efficacy and safety of ENA 713 (rivastigmine tartrate), a new acetylcholinesterase inhibitor, in patients with mild to moderately severe Alzheimer's disease. International Journal of Geriatric Psychopharmacology 1998;1:55-65.

Doraiswamy M. The effects of rivastigmine on the Alzheimer's disease assessment scale-cognitive subscale items scores of patients with Alzheimer's disease. Health in aging the challenge and promise of new decade. Proceedings of the annual scientific meeting of the American Geriatrics Society and the American Federation for Aging Research; 2000 May 17-21, Nashville. 2000:173.

Doraiswamy PM, Anand R, Hartman R. Cognitive effects of rivastigmine in patients with mild to moderate alzheimer's disease compared to those with moderately-severe to severe AD. Clinical Neuropschological Assessment 2000;1(6):12.

Doraiswamy PM, Anand R, Hartman R. Long term cognitive effects in Alzheimer's disease patients stratified by vascular risk score and treated for 1 year with rivastigmine. Clinical Neuropschological Assessment 2000;1(6):14.

Farlow M, Hake A, Messina J, Veach J, Anand R. The response of patients with Alzheimer's disease to rivastigmine treatment is predicted by the rate of disease progression. Neurology 2000; Vol. 54 Suppl 3:A469.

Farlow M, Messina J, Anand R. Long term cognitive benefits associated with the use of rivastigmine in the treatment of Alzheimer's disease results following two years of treatment.
Proceedings of the Annual Scientific Meeting of the American Geriatric Society and the American Federation for Aging Research; 2000 May 17-21, Nashville. 2000:172.

Farlow M, Potkin S, Koumaras B, Veach J, Mirski D. Analysis of outcome in retrieved dropout patients in a rivastigmine vs placebo, 26-week, Alzheimer disease trial. Archives of Neurology 2003;60:843-8.

Farlow MR, Hake A, Messina J, Hartman R, Veach J, Anand R. Response of patients with Alzheimer disease to rivastigmine treatment is predicted by the rate of disease progression. Archives of Neurology 2001;58(3):417-22.

Ferris S. Improving day to day functioning in patients with $A D$. Proceedings of the Ninth Congress of the International Psychogeriatric Association; 1999 Aug 15-20, Vancouver. 1999:77.

Krishnan KR, Dorasiswamy PM, Messina J, Veach J, ENA 713 B352 Study Group. Rivastigmine slows stage specific global deterioration in Alzheimer's disease. Journal of the American Geriatrics Society 1999;47:S3.

Kumar V, Anand R, Messina J, Hartman R, Veach J. An efficacy and safety analysis of Exelon in Alzheimer's disease patients with concurrent vascular risk factors. European Journal of Neurology 2000;7(2):159-69.

Veach KR, Doraiswamy PM. Rivastigmine slows stage-specific global deterioration in Alzheimer's disease. Proceedings of the 152nd Annual Meeting of the American Psychiatric Association; 1999 May 15-20, Washington DC. 1999. [MEDLINE: SR-HANDSRCH]

\section{Ballard 2005 \{published data only\}}

Ballard C, Margallo-Lana M, Juszczak E, Douglas S, Swann A, Thomas A, et al. Quetiapine and rivastigmine and cognitive decline in Alzheimer's disease: randomised double blind placebo controlled trial. BMJ 2005;330:874.

IDEAL \{published data only\}

Alva G, Grossberg G, Schmitt F, Olin J. Influence of rivastigmine on activities of daily living: item responder analyses targeting improvement and atability. Annals of Neurology 2009; Vol. 66:S49.

Alva G, Grossberg GT, Schmitt FA, Meng X, Olin JT. Efficacy of rivastigmine transdermal patch on activities of daily living: item responder analyses. International Journal of Geriatric Psychiatry 2011; Vol. 26, issue 4:356-63.

Blesa R, Ballard C, Orgogozo JM, Lane R, Thomas SK. Caregiver preference for rivastigmine patches versus capsules for the treatment of Alzheimer's disease. Neurology 2007;69(4 Suppl 1):S23-8.

Cummings $\mathrm{J}$, Winblad $\mathrm{B}$. A rivastigmine patch for the treatment of Alzheimer's disease and Parkinson's disease dementia. Expert Review on Neurotherapeutics 2007;7(11):1457-63.

Cummings JL, Farlow MR, Meng X, Tekin S, Olin JT. Rivastigmine transdermal patch skin tolerability: results of a 1-year clinical 
trial in patients with mild-to-moderate Alzheimer's disease. Clinical Drug Investigation 2010; Vol. 30, issue 1:41-9.

Cummings JL, Ferris SH, Farlow MR, Olin JT, Meng XY. Effects of rivastigmine transdermal patch and capsule on aspects of Clinical Global Impression of Change in Alzheimer's disease: a retrospective analysis. Dementia and Geriatric Cognitive Disorders 2010; Vol. 29, issue 5:406-12.

Farlow M, Cummings J, Olin J. Conference publication. American Journal of Geriatric Psychiatry. Conference: AAGP Annual Meeting 2009 Honolulu, HI United States. Conference Start: 20090305 Conference End: 20090308. Conference Publication 2009; Vol. 17:A58-9.

Farlow MR, Grossberg GT, Meng X, Olin J, Somogyi M. Rivastigmine transdermal patch and capsule in Alzheimer's disease: influence of disease stage on response to therapy. International Journal of Geriatric Psychiatry 2011; Vol. 26, issue 12:1236-43.

Grossberg GT, Olin JT, Somogyi M, Meng X. Dose effects associated with rivastigmine transdermal patch in patients with mild-to-moderate Alzheimer's disease. International Journal of Clinical Practice 2011; Vol. 65, issue 4:465-71.

Grossberg GT, Schmitt FA, Meng X, Tekin S, Olin J. Reviews: effects of transdermal rivastigmine on ADAS-Cog items in mild-to-moderate Alzheimers disease. American Journal of Alzheimer's Disease and Other Dementias 2010; Vol. 25, issue 8:627-33.

Lee JH, Sevigny J. Effects of body weight on tolerability of rivastigmine transdermal patch: a post-hoc analysis of a doubleblind trial in patients with Alzheimer disease. Alzheimer Disease and Associated Disorders 2011; Vol. 25, issue 1:58-62.

Orgogozo J-M. Clinical studies investigating dose-related outcomes of cholinesterase inhibition with rivastigmine patch. European Journal of Neurology 2012; Vol. Conference: 16th Congress of the European Federation of Neurological Societies, EFNS Stockholm Sweden. Conference Start: 20120908 Conference End: 20120911. Conference Publication:, issue var.pagings.

Winblad B, Cummings J, Andreasen N, Grossberg G, Onofrj M, Sadowsky $C$, et al. A six-month double-blind, randomized, placebo-controlled study of a transdermal patch in Alzheimer's disease - rivastigmine patch versus capsule. International Journal of Geriatric Psychiatry 2007;22(5):456-67.

Winblad B, Grossberg G, Frolich L, Farlow M, Zechner S, Nagel J, Lane R. IDEAL: a 6-month, double-blind, placebo-controlled study of the first skin patch for Alzheimer's disease. Neurology 2007;69(4 Suppl 1):S14-S22.

Winblad B, Kawata AK, Beusterien KM, THomas SK, Wimo A, Lane R, et al. Caregiver preference for rivastigmine patch relative to capsules for treatment of probable Alzheimer's disease. International Journal of Geriatric Psychiatry 2007;22(5):485-91.

\section{Karaman 2005 \{published data only\}}

Karaman Y, Erdogan F, Koseoglu E, Turan T, Ersoy AO. A 12month study of the efficacy of rivastigmine in patients with advanced moderate Alzheimer's disease. Dementia and Geriatric Cognitive Disorders 2005;19(1):51-6.

\section{Lopez-Pousa 2005 \{published data only\}}

Lopez-Pousa S. Pilot, multicenter, randomized, double-blind, controlled, parallel efficacy and safety study of rivastigmine vs placebo in the treatment of cognitive and non-cognitive symptoms in patients with moderate-to-severe Alzheimer's disease. IFPMA Register 2005.

\section{Mowla 2007 \{published data only\}}

Mowla A, Mosavinasab M, Haghshenas H, Haghighi AB. Does serotonin augmentation have any effect on cognition and activities of daily living in Alzheimer's dementia? A doubleblind, placebo-controlled clinical trial. Journal of Clinical Psychopharmacology 2007;27(5):484-7.

\section{Nakamura 2011 \{published data only\}}

Nakamura Y, Imai Y, Shigeta M, Graf A, Shirahase T, Kim H, et al. A 24-week, randomized, double-blind, placebo-controlled study to evaluate the efficacy, safety and tolerability of the rivastigmine patch in Japanese patients with Alzheimer's disease. Dementia and Geriatric Cognitive Disorders Extra 2011; Vol. 1, issue 1:163-79.

\section{Tai 2000 \{published data only\}}

Tai CT, Liu CK, Sung SM, Pai MC, Hsu CY. The safety and efficacy of Exelon in Alzheimer's patients: A multicentre, randomized, 26-week study in Taiwan. International Journal of Neuropsychopharmacology 2000;3 Suppl 1:S356. [MEDLINE: SRHANDSRCH]

\section{References to studies excluded from this review \\ ACTION \{published data only\}}

Alva G, Cummings J, Galvin J, Meng X, Somogyi M. Infrequent skin reactions at the application site of the rivastigmine patch (4.6, 9.5 or $13.3 \mathrm{mg} / 24 \mathrm{~h}$ ): Analysis of two clinical studies revealed most were tolerable and manageable across all doses. Alzheimer's \& Dementia 2013;Conference: Alzheimer's Association International Conference 2013 Boston, MA United States. Conference Start: 20130713 Conference End: 20130718. Conference Publication:(var.pagings):P666.

Farlow M, Grossberg G, Sadowsky C, Meng X, Somgyi M. Longterm safety and efficacy of $13.3 \mathrm{mg} / 24 \mathrm{~h}$ rivastigmine patch in severe Alzheimer's disease: ACTivities of daily living and cognitION (ACTION) study. Journal of the Neurological Sciences 2013;Conference: 21st World Congress of Neurology Vienna Austria. Conference Start: 20130921 Conference End: 20130926. Conference Publication:(var.pagings):e339.

Farlow M, Grossberg G, Sadowsky C, Meng X, Somogyi M. A 24-week, open-label extension to the activities of daily living and cognition (ACTION) study: Long-term safety, tolerability and efficacy of a $13.3 \mathrm{mg} / 24 \mathrm{~h}$ rivastigmine patch in people with severe Alzheimer's disease. Alzheimer's \& Dementia 2013; Conference: Alzheimer's Association International 
Conference 2013 Boston, MA United States. Conference Start: 20130713 Conference End: 20130718. Conference Publication:(var.pagings):P655.

Farlow M, Grossberg G, Sadowsky C, Meng X, Somogyi M. Long-term safety, tolerability and efficacy of $13.3 \mathrm{mg} / 24 \mathrm{~h}$ rivastigmine patch in patients with severe Alzheimer's disease. Clinical Pharmacology in Drug Development 2013;Conference: 2013 American College of Clinical Pharmacology Annual Meeting Bethesda, MD United States. Conference Start: 20130922 Conference End: 20130924. Conference Publication:(var.pagings):43.

Farlow M, Meng X, Somogyi M. Efficacy, safety and tolerability of rivastigmine patch $13.3 \mathrm{mg} / 24 \mathrm{~h}(15 \mathrm{~cm} 2)$ versus $4.6 \mathrm{mg} / 24$ $\mathrm{h}(5 \mathrm{~cm} 2)$ in patients with severe Alzheimer's disease: Results of the activities of daily living and cognition (ACTION) study. American journal of geriatric psychiatry 2013;Conference: 2013 AAGP Annual Meeting Los Angeles, CA United States. Conference Start: 20130314 Conference End: 20130317(var.pagings):S139-40.

Farlow M, Sadowsky C, Velting D, Meng X, Islam Z. Predictors of response to $13.3 \mathrm{mg} / 24 \mathrm{~h}$ rivastigmine patch in patients with severe Alzheimer's disease. Neurology 2014.

Farlow MR, Doraiswamy PM, Meng X, Cooke K, Somogyi M. The effect of vascular risk factors on the efficacy of rivastigmine patch and capsule treatment in Alzheimer's disease. Dementia and Geriatric Cognitive Disorders Extra 2011; Vol. 1, issue 1:150-62.

Farlow MR, Ferris S, Somogyi M, Meng X. Efficacy of 13.3 $\mathrm{mg} / 24 \mathrm{~h}$ rivastigmine patch on global functioning and behavior in severe Alzheimer's disease. Annals of neurology 2013; Conference: 138th Annual Meeting of the American Neurological Association, ANA 2013 New Orleans, LA United States. Conference Start: 20131013 Conference End: 20131015. Conference Publication:(var.pagings):S91.

Farlow MR, Grossberg G, Gauthier S, Meng X, Olin JT. The ACTION study: methodology of a trial to evaluate safety and efficacy of a higher dose rivastigmine transdermal patch in severe Alzheimer's disease. Current Medical Research and Opinion 2010; Vol. 26, issue 10:2441-7.

Farlow MR, Grossberg GT, Sadowsky CH, Meng X, Somogyi M. A 24-week, randomized, controlled trial of rivastigmine patch 13.3 $\mathrm{mg} / 24 \mathrm{~h}$ versus $4.6 \mathrm{mg} / 24 \mathrm{~h}$ in severe Alzheimer's dementia. CNS Neuroscience \& Therapeutics 2013;19:745-52.

Farlow MR, Sadowsky CH, Velting DM, Meng X, Islam MZ. Evaluating response to high-dose $13.3 \mathrm{mg} / 24 \mathrm{~h}$ rivastigmine patch in patients with severe Alzheimer's disease. CNS Neuroscience \& Therapeutics 2015:No pagination specified.

Ferris S, Isaacson R, Velting D, Meng X. Cognitive efficacy of $13.3 \mathrm{mg} / 24 \mathrm{~h}$ versus $4.6 \mathrm{mg} / 24 \mathrm{~h}$ rivastigmine patch in severe Alzheimer's disease: Severe impairment battery factor analysis. Neurology 2014.

Grossberg G, Cummings J, Frolich L, Bellelli G, Molinuevo JL, Krahnke T. Efficacy of higher dose $13.3 \mathrm{mg} / 24 \mathrm{~h}$ rivastigmine patch on instrumental activities of daily living in patients with mild-to-moderate alzheimer's disease. American Journal of Alzheimer's Disease and Other Dementias 2013;28(6):583-91.

Grossberg G, Farlow M, Meng X, Somogyi M. Efficacy and safety of high-dose $13.3 \mathrm{mg} / 24 \mathrm{~h}$ rivastigmine patch in severe Alzheimer's disease with and without concomitant memantine use. Journal of the Neurological Sciences 2013;Conference: 21st World Congress of Neurology Vienna Austria. Conference Start: 20130921 Conference End: 20130926. Conference Publication:(var.pagings):e336.

Grossberg G, Farlow M, Meng X, Somogyi M. Efficacy, safety and tolerability of $13.3 \mathrm{mg} / 24 \mathrm{~h}$ rivastigmine patch in patients with severe alzheimer's disease with and without concomitant memantine. Clinical Pharmacology in Drug Development 2013; Conference: 2013 American College of Clinical Pharmacology Annual Meeting Bethesda, MD United States. Conference Start: 20130922 Conference End: 20130924. Conference Publication:(var.pagings): 42.

Grossberg G, Farlow M, Meng X, Somogyi M. Efficacy, safety and tolerability of a higher-dose $13.3 \mathrm{mg} / 24 \mathrm{~h}$ rivastigmine patch in people with severe Alzheimer's disease with and without concomitant memantine use. Alzheimer's \& Dementia 2013; Conference: Alzheimer's Association International Conference 2013 Boston, MA United States. Conference Start: 20130713 Conference End: 20130718. Conference Publication:(var.pagings):P656.

Micca J, Velting D, Meng X. Efficacy of $13.3 \mathrm{mg} / 24 \mathrm{~h}$ versus 4.6 $\mathrm{mg} / 24 \mathrm{~h}$ rivastigmine patch on activities of daily living in severe Alzheimer's disease: A factor analysis. Neurology 2014.

Sadowsky C, Somogyi M, Frolich L, Meng X. Effect of body mass index on the efficacy, safety and tolerability of a higher-dose $13.3 \mathrm{mg} / 24 \mathrm{~h}$ rivastigmine patch in people with severe Alzheimer's disease. Alzheimer's \& Dementia 2013;Conference: Alzheimer's Association International Conference 2013 Boston, MA United States. Conference Start: 20130713 Conference End: 20130718. Conference Publication:(var.pagings):P654.

Sadowsky CH, Grossberg GT, Somogyi M, Meng X. Predictors of sustained response to rivastigmine in patients with Alzheimer's disease: a retrospective analysis. Primary Care Companion to CNS Disorders 2011:13(3).

\section{Almkvist 2004 \{published data only\}}

Almkvist O, Darreh Shori T, Stefanova E, Spiegel R, Nordberg A. Preserved cognitive function after 12 months of treatment with rivastigmine in mild Alzheimer's disease in comparison with untreated $\mathrm{AD}$ and $\mathrm{MCl}$ patients. European Journal of Neurology 2004;11(4):253-61.

\section{Auriacombe 2002 \{published data only\}}

Auriacombe S, Pere JJ. No donepezil discontinuation effect in patients with Alzheimer's disease who were switched to rivastigmine after failing to benefit from donepezil treatment. Current Medical Research and Opinion 2003;19(8):715-7.

Auriacombe S, Pere JJ, Loria Kanza, Vellas B. Efficacy and safety of rivastigmine in patients with Alzheimer's disease who failed 
to benefit from treatment with donepezil. Current Medical Research and Opinion 2002;18(3):129-38.

\section{B105 \{published data only\}}

Anand R, Gharabawi G, Enz A. Efficacy and safety results of the early phase studies with Exelon (ENA-713) in Alzheimer's disease: an overview. Journal of Drug Development and Clinical Practice 1996;8(2):109-16.

Cutler N, Sramek J, Anand R. Safety and tolerance of ENA 713 in Alzheimer's disease (AD). Proceedings of the 8th European College of Neuropsychopharmacology Congress (ECNP); 1995 Sep 30-Oct 4, Venice. 1995. [MEDLINE: SR-HANDSRCH]

Cutler NR, Sramek JJ, Anand R. Safety and tolerance of ENA 713 in patients with Alzheimer's disease. Biological Psychiatry 1995;37(9):643.

Sramek J, Anand R, Wardle T, Irwin P, Hartman R, Cutler N. Safety/tolerability trial of SDZ ENA 713 in patients with probable Alzheimer's disease. Life Sciences 1996;58(15):1201-7.

\section{Bilikiewicz 2002 \{published data only\}}

Bilikiewicz A, Opala G, Podemski R, Puzynski S, Lapin J, Soltys K, et al. An open-label study to evaluate the safety, tolerability and efficacy of rivastigmine in patients with mild to moderate probable Alzheimer's disease in the community setting. Medical Science Monitor: International Medical Journal of Experimental and Clinical Research 2002;8(2):PI9-15.

\section{Blesa Gonzalez 2011 \{published data only\}}

Blesa Gonzalez R, Boada Rovira M, Martinez Parra C, GilSaladie D, Almagro CA, Gobartt Vazquez AL, et al. Evaluation of the convenience of changing the rivastigmine administration route in patients with Alzheimer disease. Neurologia 2011; Vol. 26 , issue $5: 262-71$.

\section{Brassen 2003 \{published data only\}}

Brassen S, Adler G. Short-term effects of acetylcholinesterase inhibitor treatment on EEG and memory performance in Alzheimer patients: an open, controlled trial. Pharmacopsychiatry 2003;36(6):304-8.

\section{Caffarra 2007 \{published data only\}}

Caffarra P, Vezzadini G, Copelli S, Dieci F, Messa G, Nonis E, Venneri A. Comparing treatment effects in a clinical sample of patients with probable Alzheimer's disease treated with two different cholinesterase inhibitors. Acta Biomedica 2007;78(1):16-21.

\section{Cummings 2000 \{published data only\}}

Aupperle PM, Koumaras B, Chen M, Rabinowicz A, Mirski D. Long-term effects of rivastigmine treatment on neuropsychiatric and behavioral disturbances in nursing home residents with moderate to severe Alzheimer's disease: results of a 52-week open-label study. Current Medical Research and Opinion 2004;20(10):1605-12.

Cummings J, Anand R, Koumaras, et al. Abstract S79.002. Neurology 2000;54:A468.

\section{Cutler 1998 \{published data only\}}

Cutler NR, Polinsky R, Sramek JJ, Enz A, Jhee S, Mancione L, et al. Dose-dependent CSF acetylcholinesterase inhibition by SDZ ENA 713 in Alzheimer's disease. Acta Neurologica Scandinavica 1998;97:244-50.

\section{Cutler 2000 \{published data only\}}

Cutler NR, Hossain M, McDonald C, Pommier F, Sedek G, Jhee SS, Sramek JJ. Pharmacokinetics of rivastigmine and its metabolite in patients with Alzheimer's disease. Biological Psychiatry 2000;47 Suppl 1:S161.

Hossain M, Jhee SS, Shiovitz T, McDonald C, Sedek G, Pommier F, Cutler NR. Non-blinded bioavailability study of oral and intravenous rivastigmine. Clinical Pharmacokinetics 2002;41(3):225-34

\section{Dantoine 2006 \{published data only\}}

Dantoine T, Auriacombe S, Sarazin M, Becker H, PereJJ, Bourdeix I. Rivastigmine monotherapy and combination therapy with memantine in patients with moderately severe Alzheimer's disease who failed to benefit from previous cholinesterase inhibitor treatment. International Journal of Clinical Practice 2006;60(1):110-8.

\section{Doraiswamy 2000a \{published data only\}}

Doraiswamy M. Early intervention with a cholinesterase inhibitor produces long-term beneficial effects in moderately severe ad patients. Proceedings of the World Alzheimer Congress; 2000 Jul 9-13, Washington. 2000a.

\section{Edwards 2002 \{published data only\}}

Edwards K, Goddman W, Anand R, Koumars B, Hartman R. Effect of Alzheimer's disease severity on psychotropic drug use and behavior in nursing home patients treated with rivastigmine. The 8th conference on Alzheimer's disease and related disorders, July 20-25, 2002, Stockholm, Sweden. 2002:296

\section{EXCEED \{published data only\}}

Anon. Double-blind trial will compare two anti-Alzheimer's drugs. Journal of Dementia Care 2001c; Vol. 9, issue 5:6.

Blesa R, Bullock R, He Y, Bergman H, Gambina G, Meyer J, et al. Effect of butyrylcholinesterase genotype on the response to rivastigmine or donepezil in younger patients with Alzheimer's disease. Pharmacogenetic Genomics 2006;16(11):771-4.

Bullock R, Bergman H, Touchon J, Gasmbina G, He Y, Nagel J, Lane R. Effect of age on response to rivastigmine or donepezil in patients with Alzheimer's disease. Current Medical Research and Opinion 2006;22(3):483-94.

Bullock R, Touchon J, Bergman H, Gambina G, He Y, Rapatz G, et al. Rivastigmine and donepezil treatment in moderate to moderately severe Alzheimer's disease over a 2-year period. Current Medical Research and Opinion 2005;21(8):1317-27.

Bullock R, Touchon J, Bergman H, Gambina G, He Y, Rapatz G, et al. Rivastigmine and donepezil treatment in moderate to moderately-severe Alzheimer's disease over a 2-year period. Current Medical Research and Opinion 2005;21(8):1317-28. 
Bullock RA, Gambina G, Lane R, Nagel J. Rationale and design of EXCEED, a 24-month, double-blind study comparing rivastigmine and donepezil. Annals of Neurology 2002;52(3 Suppl 1):30.

Touchon J, Bergman H, Bullock R, Rapatz G, Nagel J, Lane R. Response to rivastigmine or donepezil in Alzheimer's patients with symptoms suggestive of concomitant Lewy body pathology. Current Medical Research and Opinion 2006;22(1):49-59.

\section{Frankfort 2007 \{published data only\}}

Frankfort SV, Appels BA, de Boer A, Tulner LR, van Campen JPCM, Koks CHW, et al. Identification of responders and reactive domains to rivastigmine in Alzheimer's disease. Pharmacoepidemiology and Drug Safety 2007;16(5):545-51.

\section{Fuschillo 2001 \{published data only\}}

Fuschillo C, La Pia S, Campana F, Pinto A, De Simone L. Cognitive deficits in Alzheimer's disease: treatment with acetylcholinesterase inhibitor agents. Archives of Gerontology and Geriatrics 2001;33 Suppl 1:151-8.

\section{Holmes 2007 \{published data only\}}

Holmes C, Wilkinson D, Dean C, Clare C, El-Okl M, Hensford C, Moghul S. Risperidone and rivastigmine and agitated behaviour in severe Alzheimer's disease: a randomised double blind placebo controlled study. International Journal of Geriatric Psychiatry 2007;22(4):380-1.

\section{InDDEx \{published data only\}}

Feldman H, Scheltens E, Hermann N, Ferris S, Mesenbrink P, Satlin A, Mancione L. Behavioral symptoms in mild cognitive impairment findings from the InDDEx study. The 8th conference on Alzheimer's Disease and Related Disorders, July 20-25, 2002, Stockholm, Sweden. 2002:522.

Feldman H, Scheltens P, Scarpini E, Hermann N, Mesenbrink P, Mancione $L$, et al. Behavioural symptoms in mild cognitive impairment. Neurology 2004;62:1199-201.

Ferris S. Investigation into Delay to Diagnosis of Alzheimer's Disease with Exelon (InDDEx). Alzheimer's Disease Education and Referral Center (ADEAR) 1999a. [MEDLINE: www.alzheimers.org]

Ferris S, Feldman P, Mesenbrink P, Mancione L, Satlin A. Mild Cognitive impairment and Alzheimer's disease are these distinct study populations clinical trials. The 8th conference on Alzheimer's Disease and Related Disorders, July 20-25, 2002, Stockholm, Sweden. 2002:570.

Rossor MN. A prospective randomised $\mathrm{mc}$ double blind placebo controlled parallel group study of the effect of Exelon on the time to clinical diagnosis of Alzheimer's disease in subjects with mild cognitive impairment. Current Controlled Trials 2001.

Rossor MN. Investigation into delay to diagnosis of Alzheimer's Disease with Exelon (InDDEx). Current Controlled Trials 2000.

Sharma T. A prospective, randomized, multi-centre, doubleblind, placebo-controlled, parallel-group study of the effect of
Exelon on the time to clinical diagnosis of Alzheimer's disease in subjects with mild cognitive impairment. National Research Register 2000.

Sharma T. Investigating the neural correlates of cognitive enhancement with rivastigmine (Exelon (C)) using functional magnetic resonance imaging in people with mild Alzheimer's disease. National Research Register 2001.

Sharma T. Structural and functional MRI correlates of memory disorder in people with mild cognitive impairments or Alzheimer's disease. National Research Register 2003.

\section{Kim 2002 \{published data only\}}

Kim SY. A 24 week trial investigating the safety tolerability and efficacy of rivastigmine in mild to moderately severe Alzheimer's disease patients in Korea. The 8th conference on Alzheimer's Disease and Related Disorders, July 20-25, 2002, Stockholm, Sweden. 2002:360.

\section{Malsch 2001 \{published data only\}}

Malsch U, Dennler HJ. [Treatment of Alzheimer's disease: Tolerability of rivastigmine during the initial period]. Psychopharmacology 2001;27(6):337-42.

\section{McMillan 1999 \{published data only\}}

McMillan H. Drug treatment of Alzheimer's disease and responders to rivastigmine beyond 12 weeks [letter]. International Journal of Geriatric Psychiatry 1999; Vol. 14, issue 12:1078-9.

\section{Novartis 2005 \{published data only\}}

Novartis Pharmaceuticals Corporation. An open-label extension to evaluate the efficacy and safety of the rivastigmine transdermal patch in patients with probable Alzheimer's sisease. ClinicalTrials.gov 2005.

\section{OPTIMA \{published data only\}}

Alva G, Isaacson R, Sadowsky C, Grossberg G, Meng X, Somogyi M. Efficacy of higher-dose $13.3 \mathrm{mg} / 24 \mathrm{~h}(15 \mathrm{~cm} 2)$ rivastigmine patch on the Alzheimer's Disease Assessment Scale-cognitive subscale: domain and individual item analysis. International Journal of Geriatric Psychiatry 2014;29(9):920-7.

Black S, Bakchine S, Bellelli G, Molinuevo JL, Downs P, Caputo A, et al. Efficacy of the $13.3 \mathrm{MG} / 24 \mathrm{~h}$ rivastigmine patchoninstrumentalactivitiesofdaily living in the optimising transdermal exelon in mild-to-moderate Alzheimer's disease (optima) study: Prospective subgroup analysis by disease severity and time-to-meet decline. Alzheimer's and Dementia 2012; Vol. Conference: Alzheimer's Association International Conference 2012 Vancouver, BC Canada. Conference Start: 20120714 Conference End: 20120719. Conference Publication:, issue var.pagings.

Blesa R, Martinez-Lage P, Monsch AU, Downs P, Strohmaier C. Caregiver preference for rivastigmine patch in the OPtimising Transdermal exelon In Mild-to-moderate Alzheimer's disease (OPTIMA) Study. European Journal of Neurology 2012; Vol. Conference: 16th Congress of the European Federation of Neurological Societies, EFNS Stockholm Sweden. Conference 
Start: 20120908 Conference End: 20120911. Conference Publication:, issue var.pagings.

Cummings J, Bellelli G, Black S, Bakchine S, Krahnke T, Strohmaier C. The rivastigmine high-dose, $13 \mathrm{mg} / 24 \mathrm{~h}(15 \mathrm{~cm} 2)$, transdermal patch provides daily living benefits to people with severe Alzheimer's disease: Retrospective analyses of the optimising transdermal exelon in mild-to-moderate Alzheimer's disease (OPTIMA) study. Alzheimer's \& Dementia 2013; Conference: Alzheimer's Association International Conference 2013 Boston, MA United States. Conference Start: 20130713 Conference End: 20130718. Conference Publication:(var.pagings):P658.

Cummings J, Froelich L, Black SE, Bakchine S, Bellelli G, Molinuevo J, et al. Randomized, double-blind, parallelgroup, 48-week study for efficacy and safety of a higher-dose rivastigmine patch ( $15 \mathrm{vs} .10 \mathrm{~cm}$ ) in Alzheimer's disease. Dementia and Geriatric Cognitive Disorders 2012; Vol. 33, issue 5:341-53.

Cummings J, Froelich L, Black SE, Bakchine S, Bellelli G, Molinuevo JL, et al. Randomized, double-blind, parallelgroup, 48-week study for efficacy and safety of a higher-dose rivastigmine patch ( $15 \mathrm{vs} .10 \mathrm{~cm} 2$ ) in Alzheimer's disease. Dementia \& Geriatric Cognitive Disorders 2012; Vol. 33, issue 5:341-53.

Cummings J, Froelich L, Black SE, Bakchine S, Bellelli G, Molinuevo JL, et al. Randomized, double-blind, parallelgroup, 48-week study for efficacy and safety of a higher-dose rivastigmine patch (15 vs. $10 \mathrm{~cm} 2$ ) in Alzheimer's disease. Dementia and Geriatric Cognitive Disorders 2012;33(5):341-53.

Cummings J, Frolich L, Black S, Bakchine S, Bellelli G, Molinuevo J, et al. Managing functional and cognitive decline in patients with mild-to-moderate Alzheimer's disease: a 48-week, randomized, double-blind evaluation of $13.3 \mathrm{mg} / 24 \mathrm{~h}(15 \mathrm{~cm} 2)$ versus $9.5 \mathrm{mg} / 24 \mathrm{H}(10 \mathrm{~cm} 2)$ rivastigmine patch. Neurology 2012; Vol. Conference: 64th American Academy of Neurology Annual Meeting New Orleans, LA United States. Conference Start: 20120421 Conference End: 20120428. Conference Publication:, issue var.pagings.

Cummings J, Grossberg G, Alva G, Caputo A, Downs P, Strohmaier C. High-dose $13.3 \mathrm{MG} / 24$ h rivastigmine transdermal patch demonstrates efficacy on instrumental activities of daily living: Individual item analysis. Alzheimer's and Dementia 2012; Vol. Conference: Alzheimer's Association International Conference 2012 Vancouver, BC Canada. Conference Start: 20120714 Conference End: 20120719. Conference Publication: issue var.pagings.

Frampton JE. Rivastigmine transdermal patch $13.3 \mathrm{mg} / 24 \mathrm{~h}$ : a review of Its use in the management of mild to moderate Alzheimer's dementia. Drugs \& Aging 2014;31(8):639-49.

Frolich L. High-dose rivastigmine patch: Results from the optima study. Neurobiology of Aging 2012; Vol. Conference: 12th International Stockholm/Springfield Symposium on Advances in Alzheimer Therapy Stockholm Sweden. Conference Start: 20120509 Conference End: 20120512. Conference Publication:, issue var.pagings.
Frolich L, Monsch A, Kressig R, Downs P, Caputo A, Strohmaier C. Comparisons of patient characteristics in subpopulations of the optimising transdermal Exelon in mild-to-moderate Alzheimer's disease (OPTIMA) study. Alzheimer's and Dementia 2012; Vol. Conference: Alzheimer's Association International Conference 2012 Vancouver, BC Canada. Conference Start: 20120714 Conference End: 20120719. Conference Publication:, issue var.pagings.

Frolich L, Touchon J, Massaia M, Callegari F, Strohmaier C. Safety and tolerability of $9.5 \mathrm{mg} / 24 \mathrm{~h}(10 \mathrm{~cm} 2)$ and $13.3 \mathrm{mg} / 24 \mathrm{~h}$ $(15 \mathrm{~cm} 2)$ rivastigmine patches: results from the optimising transdermal Exelon in mild-to-moderate Alzheimer's disease (OPTIMA) study. European Journal of Neurology 2012; Vol. Conference: 16th Congress of the European Federation of Neurological Societies, EFNS Stockholm Sweden. Conference Start: 20120908 Conference End: 20120911. Conference Publication:, issue var.pagings.

Molinuevo JL, Cummings J, Frolich L, Galvin J, Krahnke T, Strohmaier C. High-dose $13.3 \mathrm{mg} / 24 \mathrm{~h}$ rivastigmine patch efficacy and safety in mild-to-moderate Alzheimer's disease with and without concomitant memantine use. Journal of the Neurological Sciences 2013;Conference: 21st World Congress of Neurology Vienna Austria. Conference Start: 20130921 Conference End: 20130926. Conference Publication:(var.pagings):e348.

Molinuevo JL, Grossberg G, Frolich L, Galvin J, Krahnke T, Strohmaier $\mathrm{C}$. Incidence and predictors of response to the $13.3(15 \mathrm{~cm} 2)$ and $9.5 \mathrm{mg} / 24 \mathrm{~h}(10 \mathrm{~cm} 2)$ rivastigmine patch in the optimising transdermal Exelon in mild-to-moderate Alzheimer's disease (OPTIMA) study. Alzheimer's \& Dementia 2013;Conference: Alzheimer's Association International Conference 2013 Boston, MA United States. Conference Start: 20130713 Conference End: 20130718. Conference Publication:(var.pagings):P656-7.

Molinuevo JL, Grossberg G, Frolich L, Galvin J, Krahnke T, Strohmaier C. Predictors of response to the 13.3 and $9.5 \mathrm{mg} / 24$ $\mathrm{h}$ rivastigmine patch: The optimizing transdermal Exelon in mild-to-moderate Alzheimer's disease (optima) study. Journal of the neurological sciences 2013;Conference: 21st World Congress of Neurology Vienna Austria. Conference Start: 20130921 Conference End: 20130926. Conference Publication:(var.pagings):e336.

Sadowsky C, Frolich L, Meng X, Somogyi M. Effect of body mass index on the efficacy, safety and tolerability of higher-dose $13.3 \mathrm{mg} / 24 \mathrm{~h}$ rivastigmine patch in severe Alzheimer's disease. Clinical Pharmacology in Drug Development 2013;Conference: 2013 American College of Clinical Pharmacology Annual Meeting Bethesda, MD United States. Conference Start: 20130922 Conference End: 20130924. Conference Publication:(var.pagings):42-3.

Potkin 1999a \{published data only\}

Potkin SG, Anand R, Fleming K, Alva G, Keator D, Carreon D, et al. Brain metabolic and clinical effects of rivastigmine in Alzheimer's disease. International Journal of Neuropsychopharmacology 2001;4(3):223-30. 
Potkin SG, Wu JC, Messina J, Fleming K, Keator D, Bunney WE, An R. Neuroimaging techniques and applications. Proceedings of the 152nd Annual Meeting of the American Psychiatric Association; 1999 May 15-20, Washington DC. 1999. [MEDLINE: SR-HANDSRCH]

\section{Riepe 2005 \{published data only\}}

Riepe MW, Adler G, Ibach B, Weinkauf B, Tracik F. Adding memantine to therapy with rivastigmine in patients with mild to moderate Alzheimer's disease: results of a 12-week pilot study. 57th Annual Meeting of the American Academy of Neurology, Miami Beach, April 2005. 2005, issue P06.081.

\section{Rozzini 2002 \{published data only\}}

Rozzini L, Bargnani C, Bosio A, Chia F, Franzani S, Leonardi R, et al. Acetylcholinesterase inhibitors are effective in real world patients with mild to moderate Alzheimer disease evidence from a large population treated with rivastigmine or donepezil. The 8th conference on Alzheimer's Disease and Related Disorders, July 20-25, 2002, Stockholm, Sweden. 2002:329.

Rozzini L, Bargnani C, Bosio A, Chia F, Franzoni S, Leonardi R, et al. Comparison of efficacy and safety of rivastigmine and donepezil in patients with mild to moderate Alzheimer disease: results from a multicentre randomised trial. Proceedings of the 7th International Geneva/Springfield Symposium on Advances in Alzheimer Therapy, 2002 Apr 3-6, Geneva. 2002:240.

\section{Schmidt 2002 \{published data only\}}

Schmidt R, Lechner A, Petrovic K. Rivastigmine in outpatient services: experience of 114 neurologists in Austria. International Clinical Psychopharmacology 2002;17(2):81-5.

Shanks 2001 \{published data only\}

Shanks MF, Venneri A, Staff RT, Pestell SJ, Forbes KE, Gemmell HG, Murray AD. Cerebral blood flow and cognition enhanced by rivastigmine in a controlled study of Alzheimer's disease. Alzheimer's Disease International, 17th International Conference, Christchurch, New Zealand, 25-27 October 2001. 2001:37.

\section{Shua-Haim 2002a \{published data only\}}

Shua-Haim J, Smith J, Potel S. A head to study of donepezil (Aricept), rivastigmine (Exelon) and galantamine (Reminyl) for the treatment of Alzheimer's disease safety tolerability clinical and caregiver impression after 4-5 months of treatment: a prospective study. The 8th conference on Alzheimer's Disease and Related Disorders, July 20-25, 2002, Stockholm, Sweden. 2002:286

\section{Shua-Haim 2002b \{published data only\}}

Shua-Haim J, Smith J, Amin S, Shua-Haim V. Comparison of combination therapy with rivastigmine exelon and donepezil aricept versus rivastigmine alone for treatment of Alzheimer's disease safety tolerability and clinical experience after one year of treatment a cross section study. The 8th conference on Alzheimer's Disease and Related Disorders, July 20-25, 2002, Stockholm, Sweden. 2002:292.

\section{Shua-Haim 2002c \{published data only\}}

Shua-Haim JR, Smith JM, Amin S. Slow dose escalation of rivastigmine (Exelon ${ }^{\circledR}$ ) treatment of agitation in patients with alzheimer disease: an eight month prospective study. The International Symposium on Advances in Alzheimer Therapy, 2002, Geneva. 2002:242.

\section{Small 2005 \{published data only\}}

Small GW, Kaufer D, Mendiondo MS, Quarg P, Spiegel R. Cognitive performance in Alzheimer's disease patients receiving rivastigmine for up to 5 years. International Journal of Clinical Practice 2005;59(4):473-7.

\section{Sobow 2002 \{published data only\}}

Sobow T. Cholinesterase inhibitors in the real world: donepezil vs rivastigmine tolerability study. Proceedings of the 7th International Geneva/Springfield Symposium on Advances in Alzheimer Therapy, 2002 Apr 3-6, Geneva. 2002:244.

\section{Stefanova 2002 \{published data only\}}

Stefanova E, Blennow K, Darreh-Shori T, Hellstrom-Lindhal E, Wall A, Almkvist O, et al. Evaluation of cerebral glucose metabolism, CSF-TAU and CSF-A342 after long-term rivastigmine and tacrine treatments in Alzheimer disease patients. Proceedings of the 7th International Geneva/ Springfield Symposium on Advances in Alzheimer Therapy, 2002 Apr 3-6, Geneva. 2002:246.

\section{Thomas 2001 \{published data only\}}

Thomas A, lacono D, Bonanni L, D' Andreamatteo G, Onofrj M. Donepezil, rivastigmine, and vitamin $\mathrm{E}$ in Alzheimer disease: A combined P300 event-related potentials/neuropsychologic evaluation over 6 months. Clinical Neuropharmacology 2001;24(1):31-42.

\section{Tsolaki 2002 \{published data only\}}

Tsolaki M, Gerothanassis D, Aristotle CP. Efficacy and safety of cholinesterase inhibitors a longitudinal comparative study between donepezil and rivastigmine. The 8th conference on Alzheimer's Disease and Related Disorders, July 20-25, 2002, Stockholm, Sweden. 2002:2038.

\section{Venneri 2002 \{published data only\}}

Venneri A, Shanks MF. Charting patterns of progression in treated and untreated patients with Alzheimer's disease using SPECT. The 8th conference on Alzheimer's Disease and Related Disorders, July 20-25, 2002, Stockholm, Sweden. 2002:474.

\section{Wang 2001 \{published data only\}}

Wang Y, Chen Q, Zhang Z, et al. The treatment by using rivastigmine for patients with alzheimer disease: results of a multicenter, randomized, open-labeled, controlled clinical trial. Chinese Journal of Neurology 2001;34(4):210-3.

\section{Wang 2003 \{published data only\}}

Wang QH, Zhang ZX, Xu XH. [Efficacy of rivastigmine in treating mild to severe alzheimer's disease with different hachinski ischemia index]. Chinese Journal of Neurology 2003;36(1):44-7. 


\section{Weiser 2002 \{published data only\}}

Weiser M, Davidson M, Rotmensch H, Korczyn A, Hartman R, Cicin-Sain A, Anand R. A pilot randomised open label trial assessing safety and pharmacokinetic parameters of co administration of rivastigmine with risperidone in dementia patients with behavioral disturbances. The 8th conference on Alzheimer's Disease and Related Disorders, July 20-25, 2002, Stockholm, Sweden. 2002:633.

Weiser M, Rotmensch HH, Korczyn AD, Hartman R, Cicin Sain A, Anand R, Rivastigmine Risperidone Study Group. A pilot, randomized, open-label trial assessing safety and pharmacokinetic parameters of co-administration of rivastigmine with risperidone in dementia patients with behavioral disturbances. International Journal of Geriatric Psychiatry 2002;17(4):343-6.

\section{Werber 2002 \{published data only\}}

Werber EA, Klein C, Rabey MJ. Evaluation of cholinergic treatment in demented by $\mathrm{p} 300$ evoked related potentials. The 8th conference on Alzheimer's Disease and Related Disorders, July 20-25, 2002, Stockholm, Sweden. 2002:442.

\section{Wilkinson 2002 \{published data only\}}

Bullock R, Passmore F, Potocnik F, Hock C. The tolerability, ease of use and efficacy of donepezil and rivastigmine in Alzheimer's disease patients: a 12-week, multinational, comparative study. Journal of the American Geriatrics Society 2001;49(4):S19.

Potocnik FC, Smith R, Passmore P, Hock C, Wilkinson D, Maud CM, Hopker S. Tolerability, ease of use, and efficacy of donepezil and rivastigmine in Alzheimer's disease patients. Proceedings of the Annual Meeting of the American Psychiatric Association; 2001 May 5-10; New Orleans. 2001.

Wilkinson D, Passmore P, Potocnik F, Maud C, Hock C. Donepezil compared to rivastigmine in Alzheimer's disease: similar efficacy but better tolerability and physician and caregiver satisfaction in a multinational randomized trial. Proceedings of the 14th Annual Meeting of the American Association for Geriatric Psychiatry; 2001 Feb 23-26, San Francisco. 2001.

Wilkinson DG, Passmore AP, Bullock R, Hopker SW, Smith R, Potocnik FCV, et al. A multinational, randomised, 12-week, comparative study of donepezil and rivastigmine in patients with mild to moderate Alzheimer's disease. International Journal of Clinical Practice 2002;56(6):441-6.

\section{Additional references}

\section{Benton 1974}

Benton AL. Revised visual retention test. 4th Edition. San Antonio, Texas: The Psychological Association, 1974.

\section{Birks 2006}

Birks JS, Harvey R. Donepezil for dementia due to Alzheimer's disease. Cochrane Database of Systematic Reviews 2006, Issue 1. [Art. No.: CD001190. DOI: 10.1002/14651858.CD001190]

\section{Birks 2008}

Birks J. The evidence for the efficacy of cholinesterase inhibitors in the treatment of Alzheimer's disease is convincing. International Psychogeriatrics 2008;20(2):279-86.

\section{Blessed 1968}

Blessed G, Tomlinson BE, Roth M. The association between quantitative measures of dementia and senile change in the cerebral grey matter of elderly subjects. British Journal of Psychiatry 1968;114:797-811.

\section{Brunner 1990}

Brunner C, Spiegel R. Eine Validierungsstudie mit der NOSGER (Nurses' Observation Scale for Geriatric Patients), einem neuen Beurteilungsinstrument für die Psychogeriatrie [Eine Validierungsstudie mit der NOSGER (Nurses' Observation Scale for Geriatric Patients), einem neuen Beurteilungsinstrument für die Psychogeriatrie]. Zeitschr für Psychologie 1990;XIX(3):211-9.

\section{Burns 2004}

Burns A, Spiegel R, Quarg P. Efficacy of rivastigmine in subjects with moderately severe Alzheimer's disease. International Journal of Geriatric Psychiatry 2004;19(3):243-9.

\section{Clegg 2002}

Clegg A, Bryant J, Nicholson T, Mclntyre L, De Broe S, Gerard K, Waugh N. Clinical and cost-effectiveness of donepezil, rivastigmine, and galantamine for Alzheimer's disease: a systematic review. International Journal of Technology Assessment in Health Care 2002;18(3):497-507.

\section{Cohen-Mansfield 1995}

Cohen-Mansfield J. Assessment of disruptive behaviour/ agitation in the elderly: function, methods and difficulties. Journal of Geriatric Psychiatry Neurology 1995;8:52-60.

\section{Cummings 1994}

Cummings JL, Mega M, Gray K, Rosenburg-Thompson S, Carusi DA, Gornbein J. The Neuropsychiatric Inventory: Comprehensive assessment of psychopathology in dementia. Neurology 1994;44:2308-13.

\section{DeJong 1989}

DeJong R, Osterlund OW, Roy GW. Measurement of Qualityof-Life changes in patients with Alzheimer's Disease. Clinical Therapeutics 1989;11(4):545-54.

\section{DSM IV}

American Psychiatric Association. Diagnostic and Statistical Manual of Mental Disorders. 4th Edition. Washington DC: American Psychiatric Press, 1994.

\section{Erkinjuntti 2002}

Erkinjuntti T, Skoog I, Lane R, Andrews C. Rivastigmine in patients with Alzheimer's disease and concurrent hypertension. International Journal of Clinical Practice 2002;56:791-6.

\section{Farlow 2003a}

Farlow M, Potkin S, Koumaras B, Veach J, Mirski D. Analysis of outcome in retrieved dropout patients in a rivastigmine vs 
placebo, 26-week, Alzheimer disease trial. Archives of Neurology 2003a;60(6):843-8.

\section{Fillit 2004}

Fillit $\mathrm{H}$, Hill J. The economic benefits of acetylcholinesterase inhibitors for patients with alzheimer disease and associated dementias. Alzheimer Disease and Associated Disorders 2004;18 Suppl 1:S24-9.

\section{Folstein 1975}

Folstein MF, Folstein SE, McHugh PR. 'Mini-Mental State': A practical method for grading the cognitive state of patients for the clinician. Journal of Psychiatric Research 1975;12:189-98.

\section{Fuld 1981}

Fuld PA. The Fuld object memory evaluation. Chicago: Steeling Instrument Co., 1981.

\section{Galasko 1997}

Galasko D, Schmitt FA, Sano M, et al. An inventory to assess activities of daily living for clinical trials in Alzheimer's disease. The Alzheimer's Disease Cooperative Study. Alzheimer Disease and Associated Disorders 1997;11:33-9.

\section{Gelinas 1999}

Gelinas I, Gauthier L, McIntyre M, Gauthier S. Development of a functional measure for persons with Alzheimer's disease: the disability assessment for dementia. American Journal of Occupational Therapy 1999;53:471-81.

\section{Grossberg 2000}

Grossberg GT, Stahelin HB, Messina JC, Anand R, Veach J. Lack of adverse pharmacodynamic drug interactions with rivastigmine and twenty-two classes of medications. International Journal of Geriatric Psychiatry 2000;15:242-7.

\section{Guy 1976}

Guy W (editor). ECDEU Assessment manual for psychopharmacology. Rockville: National Institute of Mental Health, 1976.

\section{Guyatt 2008}

Guyatt GH, Oxman AD, Vist GE, Kunz R, Falck-Ytter Y, AlonsoCoello P, Schunemann HJ. GRADE: an emerging consensus on rating quality of evidence and strength of recommendations. BMJ 2008;336:924.

\section{Hauber 2000}

Hauber AB, Gnanasakthy A, Mauskopf JA. Savings in the cost of caring for patients with Alzheimer's disease in Canada: an analysis of treatment with rivastigmine. Clinical Therapeutics 2000;22(4):439-51.

\section{Helsinki declaration}

Declaration of Helsinki. http://www.faseb.org/arvo/ helsinki.htm.

\section{Higgins 2011}

Cochrane Handbook for Systematic Reviews of Interventions Version 5.1.0. In: Higgins JPT, Green S editor(s). [updated March
2011]. Available from www.cochrane-handbook.org.: The Cochrane Collaboration, 2011.

\section{Homma 1991}

Homma A, Niina R, Ishii T, Hasegawa K. Development of a new rating scale for dementia in the elderly: Mental Function Impairment Scale (MENFIS). Japanese Journal of Geriatric Psychiatry 1991;2:1217-22.

\section{Howard 2011}

Howard R, Phillips P, Johnson T, O'Brien J, Sheehan B, Lindesay $\mathrm{J}$, et al. Determining the minimum clinically important differences for outcomes in the DOMINO trial. International Journal of Geriatric Psychiatry 2011;26(8):812-7.

\section{Jann 2000}

Jann MW. Rivastigmine, a new-generation cholinesterase inhibitor for the treatment of Alzheimer's disease. Pharmacotherapy 2000;20:1-12.

\section{Kennedy 1999}

Kennedy JS, Polinsky RJ, Johnson B, Loosen P, Enz A, Laplanche R, et al. Preferential cerebrospinal fluid acetylcholinesterase inhibition by rivastigmine in humans. Journal of Clinical Psychopharmacology 1999;19:513-21.

\section{McKhann 1984}

McKhann G, Drachman D, Folstein M, Katzman R, Price D, Stadlan EM. Clinical Diagnosis of Alzheimer's Disease: Report of the NINCDS-ADRDA Work Group under the auspices of Department of Health and Human Services Task Force on Alzheimer's Disease. Neurology 1984;34:939-44.

\section{Novartis 1998}

Novartis Pharmaceutical (UK) Limited. EXELON (rivastigmine) Beyond cognition: prolonging functional ability. Product monograph. EXELON (rivastigmine) Beyond cognition: prolonging functional ability. Product monograph. Frimley, 1998.

\section{Panisset 1994}

Panisset M, Roudier M, Saxton J, Boller F. Severe impairment battery: a neurological test for severely demented patients. Archives of Neurology 1994;51:41-5.

\section{Polinsky 1998}

Polinsky RJ. Clinical pharmacology of rivastigmine: A newgeneration acetylcholinesterase inhibitor for the treatment of Alzheimer's disease. Clinical Therapeutics 1998;20(4):634-46.

\section{Reisberg 1982}

Reisberg B, Ferris SH, De Leon MJ, Crook T. The global deterioration scale for assessment of primary degenerative dementia. American Journal of Psychiatry 1982;139:1136-9.

\section{Reisberg 1989}

Reisberg B, Franssen E. Stage specific incidence of potentially remediable behavioral symptoms in aging and $A D$ : a study of 120 patients using the BEHAVE-AD. Bulletin of Clinical Neuroscience 1989;54:95-112. 


\section{Reisberg 1994}

Reisberg B, Ferris SH. CIBIC-plus interview guide. Unknown, 1994.

\section{Reitan 1958}

Reitan RM. The validity of the Trail Making Test as an indicator of organic brain damage. Perceptual and Motor Skills 1958;8:271-6.

\section{Rosen 1984}

Rosen WG, Mohs RC, Davis KL. A new rating scale for Alzheimer's disease. American Journal of Psychiatry 1984;41:356-64.

\section{Saxton 1990}

Saxton J, McGonigle-Gibson K, Swihart A, Miller M, Boller F. Assessment of severely impaired patients: description and validation of a new neuropsychological test battery. Psychological Assessment 1990;2:298-303.

\section{Schneider 1997}

Schneider LS, Olin JT, Doody RS, et al. Validity and reliability of the Alzheimer's Disease Cooperative Study-Clinical Global Impression of Change. The Alzheimer's Disease Cooperative Study. Alzheimer Disease and Associated Disorders 1997;11 Suppl 2:S22-S32.

\section{Schneider 1998}

Schneider LS, Anand R, Farlow MR. Systematic review of the efficacy of rivastigmine for patients with Alzheimer's disease. International Journal of Geriatric Psychopharmacology 1998;1:S26-S34.

\section{Schrag 2012}

Schrag A, Schott JM, Alzheimer's Disease Neuroimaging Initiative. Research paper: What is the clinically relevant change on the ADAS-Cog?. Journal of Neurology, Neurosurgery, and Psychiatry 2012;83(2):171-3.

\section{Schulz 1995}

Schulz KF, Chalmers I, Hayes RJ, Altman DG. Empirical evidence of bias: dimensions of methodological quality associated with estimates of treatment effects in controlled trials. JAMA 1995;273:408-12.

\section{Spencer 1998}

Spencer CM, Noble S. Rivastigmine. A review of its use in Alzheimer's disease. Drugs \& Aging 1998;13(5):391-411.

\section{Watson 1993}

Watson YI, Arfken CL, Birge SJ. Clock completion: an objective screening test for dementia. Journal of the American Geriatric Society 1993;41:1235-40.

\section{Wechsler 1987}

Wechsler D. Wechsler Memory Scale-Revised (WMS-R). San Antonio: Psychological Corporation Harcourt Brace Jovanovich Inc, 1987.

\section{Williams 2003}

Williams BR, Nazarians A, Gill MA. A review of rivastigmine: a reversible cholinesterase inhibitor. Clinical Therapeutics 2003;25(6):1634-53.

\section{References to other published versions of this review Birks 2000}

Birks J, Grimley Evans J, lakovidou V, Tsolaki M. Rivastigmine for Alzheimer's disease. Cochrane Database of Systematic Reviews 2000, Issue 4. [DOI: 10.1002/14651858.CD001191]

\section{CHARACTERISTICS OF STUDIES}

Characteristics of included studies [ordered by study ID]

\section{B103}

Methods Double-blinded, 3 arm, parallel-group randomised controlled trial 13 week treatment followed by 2 weeks of washout with placebo with an optional double-masked extension

Participants

Setting: Europe and UK; 54 centres, between March 1991 and March 1992 Sample size: 402 participants (226 female, 176 male), 133 in the $6 \mathrm{mg} /$ day group, 136 in the $4 \mathrm{mg} /$ day group and 133 in the placebo group Age: range 50 to 90 years, mean age 69.4 years Inclusion criteria:

- Age 50 to 90 years

- Had a diagnosis of DSM-III for mild to moderate dementia, NINCDS-ADRDA criteria for probable AD, MMSE score of at least 16 points and able to perform 3 out of 4 other tests of the psychometric battery

- Medication for non-cognitive aspects of AD or concomitant conditions was allowed

\section{Exclusion criteria:}

- cognitive enhancing medications were discontinued for 3 weeks before entry

Interventions 1. Rivastigmine: $4 \mathrm{mg} /$ day divided into 2 doses (titrated to target dose in 1 week)


B103 (Continued)

2. Rivastigmine: $6 \mathrm{mg} /$ day divided into 2 doses (titrated to target dose in 3 weeks)

3. Placebo (identical) taken twice daily

Doses maintained for 10 weeks after titration period to week 13 . All patients then had a 2 week washout period with placebo (single-blinded)

\begin{tabular}{|c|c|}
\hline Outcomes & $\begin{array}{l}\text { Outcomes measured at baseline and at } 13 \text { weeks } \\
\text { 1. Cognitive function } \\
\text { - Mini Mental State Examination (MMSE) } \\
\text { - Fuld Object-Memory Test (OME) } \\
\text { - Benton Visual Retention Test (VRT) } \\
\text { - Trail Making Test (TMT) } \\
\text { - Digitial symbol substitution test (DSST) } \\
\text { - Nurses' Observation Scale for Geriatric Patients (NOSGER) } \\
\text { 2. Activities of daily living } \\
\text { - Nurses' Observation Scale for Geriatric Patients (NOSGER) } \\
\text { - Performace of three individual activities of daily living } \\
\text { 3. Behavioural symptoms } \\
\text { - Nurses' Observation Scale for Geriatric Patients (NOSGER) } \\
\text { 4. Physician rated global impression tests } \\
\text { - Clinical Global Impression of Change (CGIC) } \\
\text { 5. Incidence of adverse events } \\
\text { - reported as incidence of most frequent events: nausea, vomiting, diarrhoea, abdominal pain, } \\
\text { 6. Discontinuation } \\
\text { headache and dizziness }\end{array}$ \\
\hline Source of funding & Novartis Pharma Ltd \\
\hline Declaration of interest & Study sponsored by Novartis Pharma \\
\hline Notes & $\begin{array}{l}\text { Primary hypothesis:to assess short term ( } 3 \text { month) symptomatic efficacy of rivastigmine } 4 \text { and } 6 \mathrm{mg} / \mathrm{d} \\
\text { compared with placebo in patients with } \mathrm{AD}\end{array}$ \\
\hline
\end{tabular}

\section{Risk of bias}

Bias Authors' judgement Support for judgement

Random sequence genera- Low risk Patients were assigned a randomisation number by the investigator in chronotion (selection bias) logical order according to a list generated by study sponsor (Novartis)

\begin{tabular}{lll}
\hline $\begin{array}{l}\text { Allocation concealment } \\
\text { (selection bias) }\end{array}$ & Low risk & Method not described \\
\hline $\begin{array}{l}\text { Blinding of participants } \\
\begin{array}{l}\text { and personnel (perfor- } \\
\text { mance bias) }\end{array}\end{array}$ & Low risk & $\begin{array}{l}\text { Active medication and placebo capsules had the same physical appearance, } \\
\text { and the number of capsules for each dose intake was the same in all three } \\
\text { groups }\end{array}$ \\
\hline
\end{tabular}


B103 (Continued)

Blinding of outcome as- Low risk sessment (detection bias)

All outcomes

\begin{tabular}{lll}
\hline $\begin{array}{l}\text { Incomplete outcome data } \\
\text { (attrition bias) } \\
\text { All outcomes }\end{array}$ & Unclear risk & $\begin{array}{l}\text { A total of 346/402 (86\%) patients completed study. Analyses done with ITT } \\
\text { population with imputations for missing values and an observed case popula- } \\
\text { tion }\end{array}$ \\
\hline $\begin{array}{l}\text { Selective reporting (re- } \\
\text { porting bias) }\end{array}$ & Low risk & Outcomes listed in protocol were reported \\
\hline
\end{tabular}

B104

$\begin{array}{ll}\text { Methods } & \text { Double-blinded, } 3 \text { arm parallel-group randomised controlled trial } \\ & 18 \text { week treatment }\end{array}$

Participants

Setting: Europe and Canada; 11 centres, between January 1993 and September 1993

Sample size: 114 participants

Age: range years, mean age years

\section{Inclusion criteria:}

- Age up to 90 years

- Diagnosis of mild to moderate dementia according to DSM III-R, and probable AD according to NINCDS-ADRDA criteria

- MMSE score between 12 and 26 points

Exclusion criteria: concomitant conditions or medications that may confound assessment of dementia; current diagnosis or history of significant medical, neurological or psychiatric disorder

\section{Interventions}
1. Rivastigmine: 6 to $12 \mathrm{mg} /$ day divided into 2 doses
2. Rivastigmine: 6 to $12 \mathrm{mg} /$ day divided into 3 doses
3. Placebo (identical looking) twice daily
Titration to a maximum dose of $12 \mathrm{mg}$ /day or maximum tolerated dose during weeks 1 to 10 , followed by 8 weeks maintenance of dose

\section{Outcomes}

\section{Measured at 18 weeks}

1. Cognitive function

- Alzheimer's Disease Assessment Scale (ADAS-Cog)

- Wechsler Memory Scale (WMS) (digit span, delayed recall, word fluency)

2. Activities of daily living

- Nurses' Observation Scale for Geriatric Patients (NOSGER)

3.Global evaluation (physician rated)

- CIBIC plus
4. Behavioural symptoms
- Nurses' Observation Scale for Geriatric Patients (NOSGER)
5. Incidence of adverse events
6. Discontinuation 
B104 (Continued)

- withdrawal due to adverse events

\begin{tabular}{ll}
\hline Source of funding & Novartis Pharma Ltd \\
\hline Declaration of interest & Sponsored by Novartis Pharma Ltd \\
\hline Notes & Main hypothesis: to investigate tolerability of rivastigmine \\
& $\begin{array}{l}10 \text { week titration phase to a maximum of } 12 \text { mg daily or maximum tolerated dose, then } 8 \text { weeks main- } \\
\text { tenance phase }\end{array}$
\end{tabular}

\section{Risk of bias}

\begin{tabular}{|c|c|c|}
\hline Bias & Authors' judgement & Support for judgement \\
\hline $\begin{array}{l}\text { Random sequence genera- } \\
\text { tion (selection bias) }\end{array}$ & Low risk & $\begin{array}{l}\text { Not described } \\
\text { "patients were randomly assigned to one of three treatment groups" }\end{array}$ \\
\hline $\begin{array}{l}\text { Allocation concealment } \\
\text { (selection bias) }\end{array}$ & Low risk & $\begin{array}{l}\text { Not described } \\
\text { Comment: likely to be low risk since this is a large multicentre trial }\end{array}$ \\
\hline $\begin{array}{l}\text { Blinding of participants } \\
\text { and personnel (perfor- } \\
\text { mance bias) } \\
\text { All outcomes }\end{array}$ & High risk & $\begin{array}{l}\text { Identifical placebo used, taken twice daily } \\
\text { Comment: this effectively unblinded the group assigned to three times daily } \\
\text { regimen }\end{array}$ \\
\hline $\begin{array}{l}\text { Blinding of outcome as- } \\
\text { sessment (detection bias) } \\
\text { All outcomes }\end{array}$ & Unclear risk & $\begin{array}{l}\text { Clinician who rated the CIBIC did not have access to baseline results and psy- } \\
\text { chometric tests and also did not ask questions; however, it was unclear how } \\
\text { effective this was }\end{array}$ \\
\hline $\begin{array}{l}\text { Incomplete outcome data } \\
\text { (attrition bias) } \\
\text { All outcomes }\end{array}$ & High risk & $\begin{array}{l}\text { A total of } 85 / 114 \text { ( } 75 \%) \text { completed the study. Numbers of participants who } \\
\text { completed the study were different between groups: } 92 \% \text { for placebo, } 89 \% \text { for } \\
\text { three times daily group and } 78 \% \text { for twice daily group. The efficacy analysis } \\
\text { was conducted only in "valid" patients, defined as all those patients who had } \\
\text { completed the study according to protocol }\end{array}$ \\
\hline $\begin{array}{l}\text { Selective reporting (re- } \\
\text { porting bias) }\end{array}$ & Low risk & Outcomes listed in protocol reported \\
\hline
\end{tabular}

\section{B303/B305}

Methods Double-blinded, placebo controlled 3 arm parallel-group randomised controlled trial

26 weeks of treatment

\section{Participants}

Setting: 45 centres, Europe and North America

Sample size: 725 participants ( 428 female, 297 male)

Age: 45 to 95 years, mean age 72 years

Inclusion criteria:

- DSM-IV, NINCDS-ADRDA criteria for probable AD

- MMSE 10 to 26 inclusive

- 50 to 85 years old (outside this range with approval of medical expert)

- most concomitant diseases, most medications

\section{Exclusion criteria:}


B303/B305 (Continued)

- severe and unstable cardiac disease, severe obstructive pulmonary disease, other life threatening conditions (e.g. rapidly progressing malignancies)

- anticholinergic drugs, acetylcholine precursor health food supplements, memory enhancers, insulin, psychotropic drugs (apart from occasional use of chloral hydrate for agitation or insomnia)

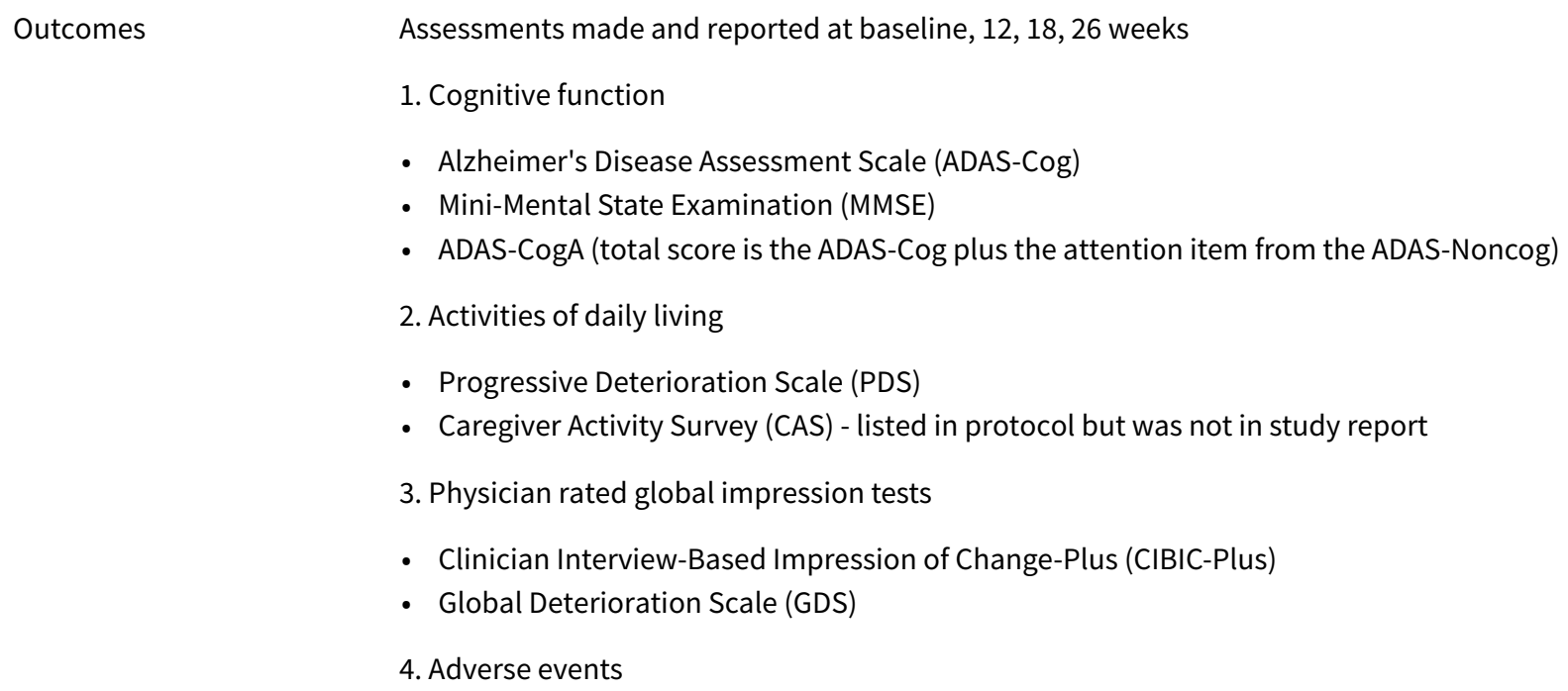

Outcomes

Assessments made and reported at baseline, 12, 18, 26 weeks

1. Cognitive function

- Alzheimer's Disease Assessment Scale (ADAS-Cog)

- Mini-Mental State Examination (MMSE)

- ADAS-CogA (total score is the ADAS-Cog plus the attention item from the ADAS-Noncog)

2. Activities of daily living

- Progressive Deterioration Scale (PDS)

- Caregiver Activity Survey (CAS) - listed in protocol but was not in study report

3. Physician rated global impression tests

- Clinician Interview-Based Impression of Change-Plus (CIBIC-Plus)

- Global Deterioration Scale (GDS)

4. Adverse events

\begin{tabular}{ll}
\hline Source of funding & Novartis Pharma \\
\hline Declaration of interest & Sponsored by Novartis Pharma \\
\hline Notes & Main hypothesis: to assess the effects of rivastigmine on the core domains of AD
\end{tabular}

\section{Risk of bias}

\begin{tabular}{lll}
\hline Bias & Authors' judgement & Support for judgement \\
\hline $\begin{array}{l}\text { Random sequence genera- } \\
\text { tion (selection bias) }\end{array}$ & Low risk & $\begin{array}{l}\text { "randomly allocated ... according to a computer generated randomisation } \\
\text { code at Novartis Pharma" }\end{array}$ \\
\hline $\begin{array}{l}\text { Allocation concealment } \\
\text { (selection bias) }\end{array}$ & Low risk & Not described \\
\hline $\begin{array}{l}\text { Blinding of participants } \\
\begin{array}{l}\text { and personnel (perfor- } \\
\text { mance bias) }\end{array}\end{array}$ & Low risk & Identical placebo, and "the number taken were the same at each dose for all \\
All outcomes & groups" \\
\hline $\begin{array}{l}\text { Blinding of outcome as- } \\
\text { sessment (detection bias) } \\
\begin{array}{l}\text { All outcomes } \\
\hline\end{array}\end{array}$ & Low risk & Not described \\
\hline
\end{tabular}


B303/B305 (Continued)

Incomplete outcome data Unclear risk An 80\% completion (581/725). Proportion of participant completions was un(attrition bias) balanced across groups: $203 / 239$ (87\%) in placebo, $209 / 243(86 \%)$ in low dose rivastigmine (1 to $4 \mathrm{mg} /$ day) and 164/243 (67.5\%) in higher dose (6 to $2 \mathrm{mg}$ / day) group

Selective reporting (re- Unclear risk One of the outcomes listed in protocol, CAS, was not reported
porting bias)

\section{B304}

Methods Double-blinded, placebo controlled, parallel-group randomised controlled trial

26 week treatment and follow up

Participants

Setting: 37 centres, Australia, Canada, Italy, South Africa, UK and Ireland

Sample size: 678 participants out of 788 screened

Age: mean age 71.4 years

Inclusion criteria:

- DSM-IV, NINCDS-ADRDA criteria for probable AD

- MMSE range 10 to 26 inclusive

\section{Exclusion criteria:}

- significant illness, severe chronic pulmonary disease, psychiatric or neurological disorder, severe cardiovascular problems, clinically significant laboratory tests, including those indicative of impaired renal or liver function

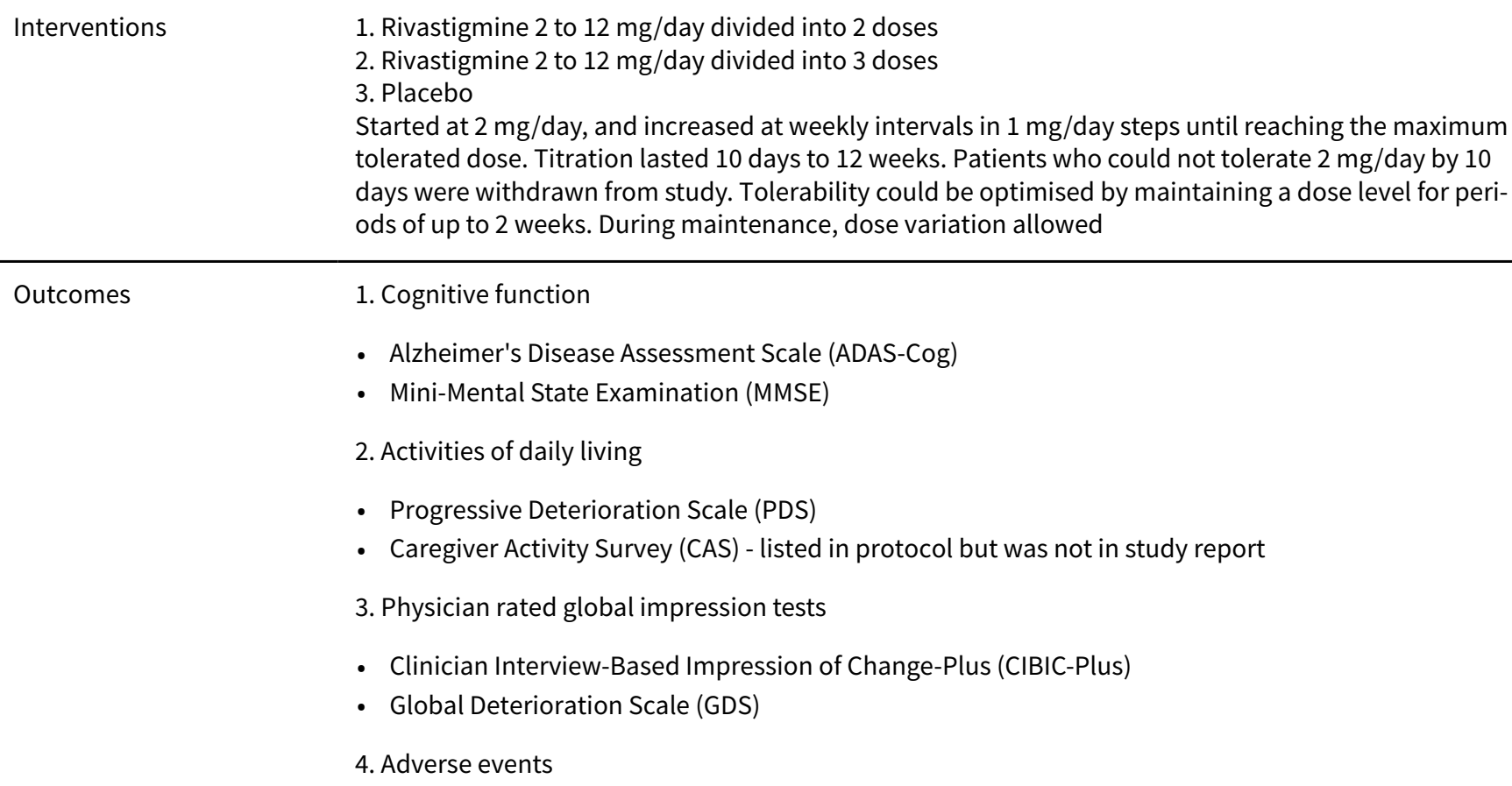

\section{Outcomes}

1. Cognitive function

- Alzheimer's Disease Assessment Scale (ADAS-Cog)

- Mini-Mental State Examination (MMSE)

2. Activities of daily living

- Progressive Deterioration Scale (PDS)

- Caregiver Activity Survey (CAS) - listed in protocol but was not in study report

3. Physician rated global impression tests

- Clinician Interview-Based Impression of Change-Plus (CIBIC-Plus)

- Global Deterioration Scale (GDS)

4. Adverse events

\begin{tabular}{ll}
\hline Source of funding & Funded by Novartis \\
\hline Declaration of interest & Sponsored by Novartis Pharma \\
\hline
\end{tabular}


B304 (Continued)

Notes

Main hypothesis: to evaluate the efficacy and safety of individual highest well tolerated doses (range 2

to $12 \mathrm{mg} / \mathrm{d}$ ) of rivastigmine twice or three times daily for 26 weeks compared to placebo, in the therapy

of patients with probable $A D$

\section{Risk of bias}

\begin{tabular}{|c|c|c|}
\hline Bias & Authors' judgement & Support for judgement \\
\hline $\begin{array}{l}\text { Random sequence genera- } \\
\text { tion (selection bias) }\end{array}$ & Low risk & Comment: not described, likely to be low risk; large multicentre trial \\
\hline $\begin{array}{l}\text { Allocation concealment } \\
\text { (selection bias) }\end{array}$ & Low risk & Comment: not described, likely to be low risk, large multicentre trial \\
\hline $\begin{array}{l}\text { Blinding of participants } \\
\text { and personnel (perfor- } \\
\text { mance bias) } \\
\text { All outcomes }\end{array}$ & Low risk & $\begin{array}{l}\text { "Administration of each dose level was achieved by using a combination of ac- } \\
\text { tive medication and placebo so that the appropriate daily dose was presented } \\
\text { as } 2 \text { capsules t.i.d" } \\
\text { Comment: used matching placebo, number of capsules taken were the same } \\
\text { at each dose }\end{array}$ \\
\hline
\end{tabular}

\begin{tabular}{lll}
\hline $\begin{array}{l}\text { Blinding of outcome as- } \\
\text { sessment (detection bias) } \\
\text { All outcomes }\end{array}$ & Unclear risk & Not described \\
\hline $\begin{array}{l}\text { Incomplete outcome data } \\
\text { (attrition bias) }\end{array}$ & Unclear risk & $\begin{array}{l}\text { Overall } 82 \% \text { completion, 83\% in three times daily group, 76\% in two times } \\
\text { daily group, 85\% in placebo group. Comment: data were imputed using 're- } \\
\text { trieved dropout' assessment, or last observed carried forward (LOCF) if re- } \\
\text { trieved dropout was not available }\end{array}$ \\
\hline
\end{tabular}

$\begin{array}{ll}\begin{array}{l}\text { Selective reporting (re- } \\ \text { porting bias) }\end{array} & \text { Low risk }\end{array}$

B351

\begin{tabular}{ll}
\hline Methods & Double-blinded, placebo controlled, parallel-group randomised controlled trial \\
& 26 week treatment and follow up \\
\hline Participants & Setting: USA, 14 centres between December 1994 to 22 March 1996 \\
Sample size: 702 participants (393 female, 309 male) \\
Age: range 45 to 89 years, mean 74.5 years \\
Inclusion criteria: \\
- 50 years or older \\
- DSM-IV, NINCDS-ADRDA criteria for probable AD, MMSE range 10 to 26 inclusive \\
- head computed tomography or magnetic resonance imaging scan consistent with AD within 12 \\
months
\end{tabular}

\section{Exclusion criteria:}

- severe and unstable medical illnesses

- anticholinergic drugs, acetylcholine precursor health food supplements, memory enhancers, insulin, psychotropic drugs (apart from occasional use of chloral hydrate for agitation or insomnia)

Interventions 1. Rivastigmine: $3 \mathrm{mg} /$ day divided into 2 doses


B351 (Continued)

2. Rivastigmine: $6 \mathrm{mg} /$ day divided into 2 doses

3. Rivastigmine: $9 \mathrm{mg} /$ day divided into 2 doses

4. Placebo

Titration during weeks 1 to 12 to the fixed dose, fixed dose between week 13 and 26 , no dose reductions allowed

Patients who discontinued prematurely were asked to return at weeks 12,18 , and 26 for efficacy evaluation

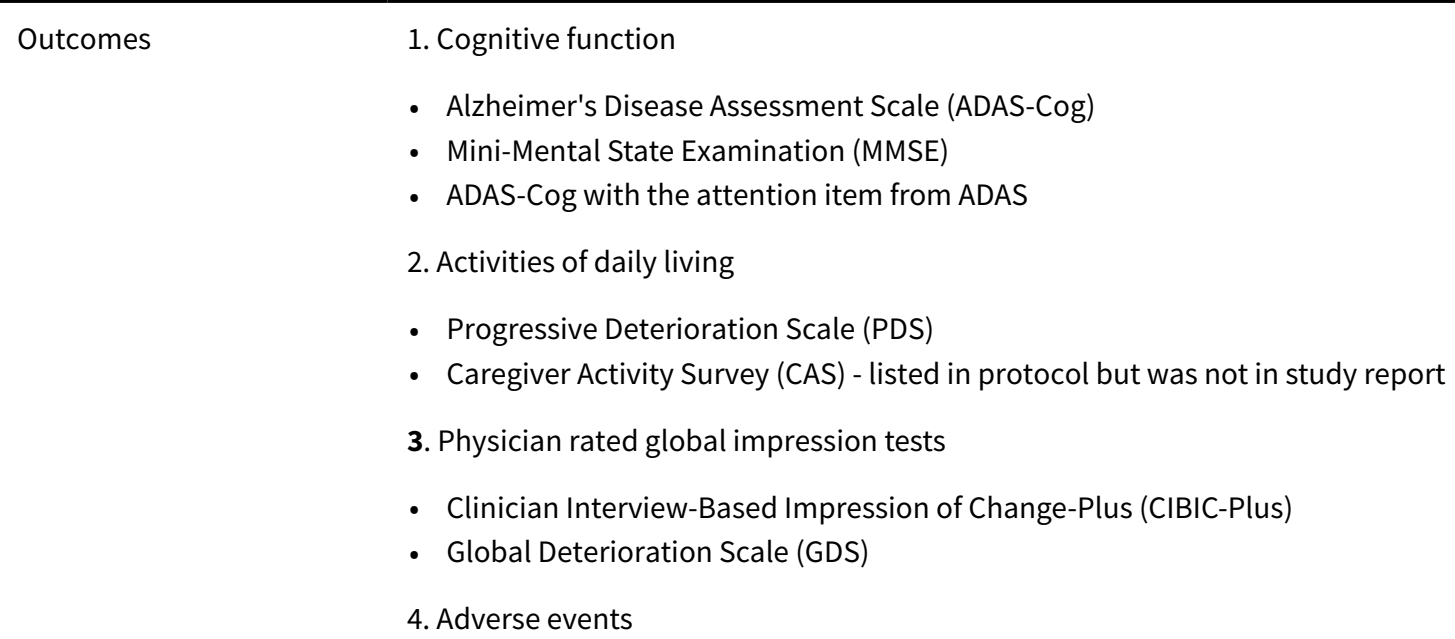

\begin{tabular}{ll}
\hline Source of funding & Novartis Pharma \\
\hline Declaration of interest & Novartis Pharma \\
\hline Notes & $\begin{array}{l}\text { Main hypothesis: to evaluate the efficacy and safety of } 3 \text { fixed doses of rivastigmine }(3,6,9 \text { mg/day) and } \\
\text { placebo for } 26 \text { weeks of treatment, and dose-efficacy and dose-safety relationships in patients with } \\
\text { probable mild to moderate } A D \\
\text { Assessments: baseline, } 12,18,26 \text { weeks }\end{array}$
\end{tabular}

\section{Risk of bias}

\begin{tabular}{|c|c|c|}
\hline Bias & Authors' judgement & Support for judgement \\
\hline $\begin{array}{l}\text { Random sequence genera- } \\
\text { tion (selection bias) }\end{array}$ & Low risk & Not described, likely low risk \\
\hline $\begin{array}{l}\text { Allocation concealment } \\
\text { (selection bias) }\end{array}$ & Low risk & Not described, likely low risk \\
\hline $\begin{array}{l}\text { Blinding of participants } \\
\text { and personnel (perfor- } \\
\text { mance bias) } \\
\text { All outcomes }\end{array}$ & Unclear risk & No information available \\
\hline $\begin{array}{l}\text { Blinding of outcome as- } \\
\text { sessment (detection bias) } \\
\text { All outcomes }\end{array}$ & Unclear risk & No information available \\
\hline $\begin{array}{l}\text { Incomplete outcome data } \\
\text { (attrition bias) } \\
\text { All outcomes }\end{array}$ & High risk & $\begin{array}{l}\text { A } 66 \% \text { completion rate overall. Higher percentage in the } 9 \text { mg group (49\%) and } \\
6 \mathrm{mg}(37 \%) \text { group discontinued compared to the placebo group }(25 \%)\end{array}$ \\
\hline
\end{tabular}


B351 (Continued)

Selective reporting (re- Unclear risk Study data were not published, obtained from the company. Only data pooled porting bias) with other studies were published by the pharmaceutical company (pooled with B303 and B352)

Other bias High risk

B352

Methods

Double-blinded, placebo controlled, parallel-group randomised controlled trial

26 week treatment and follow up

Setting: USA, 22 centres
Sample size: 699 participants ( 426 female, 273 male)
Age: range 45 to 89 years, mean 74.5 years
Inclusion criteria:
- DSM-IV, NINCDS-ADRDA criteria for probable AD, MMSE range 10 to 26 inclusive
- head computed tomography or magnetic resonance imaging scan consistent with AD within 12
months
- most concomitant disease, most medications

\section{Exclusion:}

- severe and unstable medical illnesses

- anticholinergic drugs, acetylcholine precursor health food supplements, memory enhancers, insulin

- psychotropic drugs (apart from occasional use of chloral hydrate for agitation or insomnia)

\begin{tabular}{ll}
\hline Interventions & $\begin{array}{l}\text { 1. Rivastigmine } 1 \text { to } 4 \mathrm{mg} / \text { day divided into } 2 \text { doses } \\
\text { 2. Rivastigmine } 6 \text { to } 12 \mathrm{mg} / \text { day divided into } 2 \text { doses } \\
\text { 3. Placebo } \\
\text { Titration phase (fixed dose) weeks } 0 \text { to } 7 \text {, flexible phase weeks } 8 \text { to } 26 \text {, dose twice daily with food }\end{array}$ \\
\hline Outcomes & 1. Cognitive function \\
- Alzheimer's Disease Assessment Scale (ADAS-Cog) & Mini-Mental State Examination (MMSE) \\
2. Activities of daily living \\
- Progressive Deterioration Scale (PDS) \\
- Caregiver Activity Survey (CAS) - listed in protocol but was not in study report \\
3. Physician rated global impression tests \\
- Clinician Interview-Based Impression of Change-Plus (CIBIC-Plus) \\
Assessments: baseline, 12, 18, 26 weeks \\
\hline Source of funding
\end{tabular}

\section{Risk of bias}

Rivastigmine for Alzheimer's disease (Review) 
B352 (Continued)

\begin{tabular}{|c|c|c|}
\hline Bias & Authors' judgement & Support for judgement \\
\hline $\begin{array}{l}\text { Random sequence genera- } \\
\text { tion (selection bias) }\end{array}$ & Low risk & $\begin{array}{l}\text { Randomisation procedures managed by Statistical Programming Group at } \\
\text { Corning-Besselaar, independent of sponsor and investigating centres }\end{array}$ \\
\hline $\begin{array}{l}\text { Allocation concealment } \\
\text { (selection bias) }\end{array}$ & Low risk & $\begin{array}{l}\text { "At each study site, the research coordinator accessed an interactive voice re- } \\
\text { sponse system that assigned the next available patient randomisation num- } \\
\text { ber, thus maintaining the blind in assigning medication to patients throughout } \\
\text { the study and serving as a tracking system for all randomised patients." }\end{array}$ \\
\hline $\begin{array}{l}\text { Blinding of participants } \\
\text { and personnel (perfor- } \\
\text { mance bias) } \\
\text { All outcomes }\end{array}$ & Low risk & $\begin{array}{l}\text { Throughout the study all patients received two capsules twice daily } \\
\text { Comment: identifical placebo appearance, dosing schedule and good alloca- } \\
\text { tion concealment }\end{array}$ \\
\hline
\end{tabular}

Incomplete outcome data High risk
(attrition bias)

Rate of completion differed between arms, 197/235 (84\%) in placebo, 199/233

All outcomes $(85 \%)$ in low dose arm, and 149/231 (65\%) in the high dose arm

\begin{tabular}{l}
$\begin{array}{l}\text { Selective reporting (re- } \\
\text { porting bias) }\end{array}$ \\
\hline
\end{tabular}

Ballard 2005

\begin{tabular}{|c|c|}
\hline Methods & $\begin{array}{l}\text { Double-blinded, placebo controlled } 3 \text { arm, randomised controlled trial } \\
26 \text { weeks }\end{array}$ \\
\hline Participants & $\begin{array}{l}\text { Setting: UK, participants lived in care facilities } \\
\text { Sample size: } 93 \text { ( } 74 \text { female, } 19 \text { male), } 31 \text { in each group } \\
\text { Age: mean } 83.8 \text { (SD } 7.7 \text { ) years } \\
\text { Inclusion criteria: } \\
\text { - lived in care facilities } \\
\text { - } \quad \text { probable or possible AD } \\
\text { - clinically significant agitation and CMAI > } 39 \text { for at least } 6 \text { weeks } \\
\text { - } \text { age > } 60 \text { years } \\
\text { - NPI irritability or aberrant motor behaviour score } \geq 4 \\
\text { - no use of antipsychotic or cholinesterase inhibitors within } 4 \text { weeks of randomisation } \\
\text { Exclusion: } \\
\text { - } \text { severe, advanced, progressive or unstable disease } \\
\text { - poorly controlled medical conditions, bradycardia, sick sinus syndrome, active uncontrolled peptic } \\
\text { ulceration within past three months, clinically significant urinary condition }\end{array}$ \\
\hline Interventions & $\begin{array}{l}\text { 1. Quetiapine (50 to } 100 \mathrm{mg} / \text { day in two doses) } \\
\text { 2. Rivastigmine ( } 6 \text { to } 12 \mathrm{mg} / \text { day in two doses) } \\
\text { 3. Placebo }\end{array}$ \\
\hline
\end{tabular}


Ballard 2005 (Continued)
Outcomes
1. Cogntive function
- Severe impairment battery (SIB) measured at 6 weeks
2. Behavioral symptoms
- Cohen-Mansfield Agitation Inventory (CMAI)
Patients were evaluated at 6,12 and 26 weeks

\begin{tabular}{ll}
\hline Source of funding & $\begin{array}{l}\text { Alzheimer's Research Trust, general donation to the main investigator's (Clive Ballard) research pro- } \\
\text { gramme and profits from previously completed commercial trials }\end{array}$ \\
\hline Declaration of interest & $\begin{array}{l}\text { Main investigator has received honoraria and research donations to support this research programme } \\
\text { from Novartis and Astra Zeneca (manufacturers) }\end{array}$ \\
\hline Notes & \\
\hline
\end{tabular}

\section{Risk of bias}

\begin{tabular}{lll}
\hline Bias & Authors' judgement & Support for judgement \\
\hline $\begin{array}{l}\text { Random sequence genera- } \\
\text { tion (selection bias) }\end{array}$ & Low risk & $\begin{array}{l}\text { "Computer generated with block randomisation (block sizes of three and six)" } \\
\text { done by study statistician using Stata }\end{array}$ \\
\hline $\begin{array}{l}\text { Allocation concealment } \\
\text { (selection bias) }\end{array}$ & Low risk & $\begin{array}{l}\text { "The randomisation clinician faxed a form to the statistician, who communi- } \\
\text { cated allocation to the pharmacy, ensuring concealment" }\end{array}$ \\
\hline $\begin{array}{l}\text { Blinding of participants } \\
\text { and personnel (perfor- } \\
\text { mance bias) } \\
\text { All outcomes }\end{array}$ & Low risk & Double-dummy design used, placebo for both types of drugs used \\
\hline
\end{tabular}

\begin{tabular}{lll}
\hline $\begin{array}{l}\text { Blinding of outcome as- } \\
\text { sessment (detection bias) } \\
\text { All outcomes }\end{array}$ & Unclear risk & Method not described \\
\hline $\begin{array}{l}\text { Incomplete outcome data } \\
\begin{array}{l}\text { (attrition bias) } \\
\text { All outcomes }\end{array}\end{array}$ & High risk & $\begin{array}{l}\text { High number of participants not completing treatment. Outcomes were only } \\
\text { available for about half of all patient randomised for the SIB (cognitive func- } \\
\text { tion) and CMAl (behavioural disturbance) at 26 weeks }\end{array}$
\end{tabular}

\begin{tabular}{lll}
\hline $\begin{array}{l}\text { Selective reporting (re- } \\
\text { porting bias) }\end{array}$ & Unclear risk & $\begin{array}{l}\text { Unclear why report emphasised } 6 \text { week results (still within titration period), } \\
\text { rather than 26 week data }\end{array}$ \\
& Comment - insufficient information to determine \\
\hline Other bias & Unclear risk & Unclear. Some patients were excluded from trial \\
\hline
\end{tabular}

IDEAL

\begin{tabular}{ll}
\hline Methods & Double-blinded, placebo controlled, parallel-group randomised controlled trial \\
& 24 weeks \\
\hline
\end{tabular}

Setting: North, South and Central America, Asia and Europe, 21 countries, 100 centres
Sample size: 1195 participants ( 796 female, 399 male) out of 1464 screened
Age: range 50 to 85 years, mean 73.3 (SD 7.8) years


IDEAL (Continued)

\section{MMSE mean 16.5 (SD 3.0)}

\section{Inclusion criteria:}

- DSM-IV for dementia of Alzheimer's type, NINCDS-ADRDA criteria for probable AD

- MMSE range 10 to 20

- head computed tomography or magnetic resonance imaging scan consistent with AD within 12 months, most concomitant disease, most medications

\section{Exclusion criteria:}

- severe and unstable medical illnesses

- the use of any investigational drugs, new psychotropic or dopaminergic drugs, cholinesterase inhibitors or anticholinergic agents during the 4 weeks prior to randomisation was prohibited

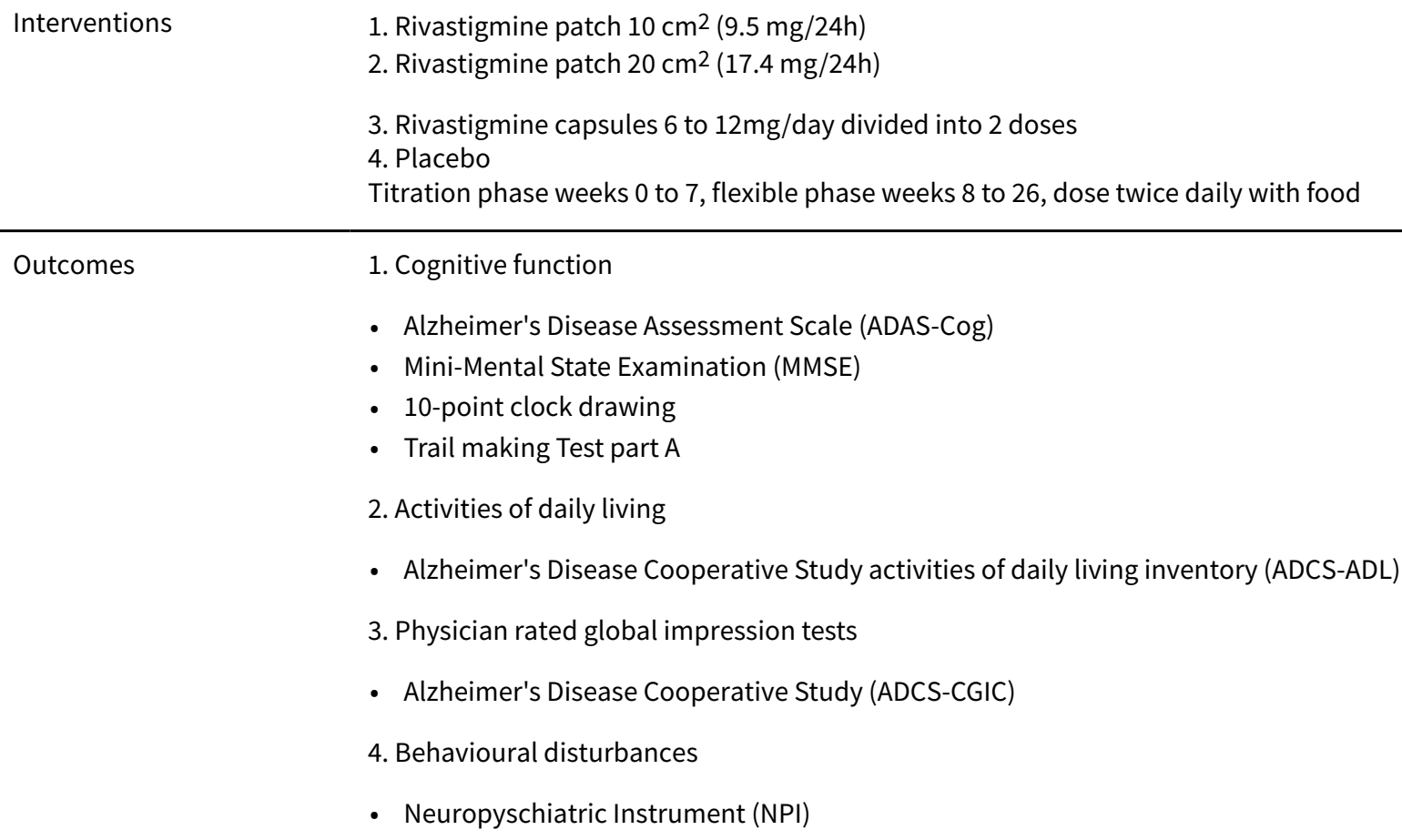
co-investigators, entered into a central database using electronic data capture software, and analysed by Novartis Pharma AG, which vouches for the data and the analysis"

\begin{tabular}{ll}
\hline Declaration of interest & Some of the investigators were employees of Novartis Pharma \\
\hline Notes & There was a 4-week screening period prior to randomisation
\end{tabular}

\section{Risk of bias}

\begin{tabular}{lll}
\hline Bias & Authors' judgement & Support for judgement \\
\hline $\begin{array}{l}\text { Random sequence genera- } \\
\text { tion (selection bias) }\end{array}$ & Low risk & $\begin{array}{l}\text { "Patients were sequentially assigned the lowest available identification num- } \\
\text { ber at each centre, Automated random assignment of treatment using interac- } \\
\text { tive voice-response system." }\end{array}$ \\
\hline $\begin{array}{l}\text { Allocation concealment } \\
\text { (selection bias) }\end{array}$ & Low risk & $\begin{array}{l}\text { automated random assignment of treatment using interactive voice-response } \\
\text { system. Independent rater at } 16 \text { and } 24 \text { weeks who had no access to other da- } \\
\text { ta. }\end{array}$ \\
\hline
\end{tabular}


IDEAL (Continued)

Blinding of participants Low risk_double dummy used, patients received placebo capsule and/or patch and personnel (performance bias)

All outcomes

$\begin{array}{ll}\text { Blinding of outcome as- } & \text { Unclear risk }\end{array}$

All outcomes

Incomplete outcome data Unclear risk

About $79 \%$ completion in active treatment arms, and $88 \%$ in placebo arm at 26 (attrition bias) weeks. Main ITT analysis used LOCF imputation.

All outcomes

\begin{tabular}{lll}
\hline $\begin{array}{l}\text { Selective reporting (re- } \\
\text { porting bias) }\end{array}$ & Unclear risk & Insufficient information to determine risk \\
\hline Other bias & Unclear risk & None identified. \\
\hline
\end{tabular}

Karaman 2005

\begin{tabular}{ll}
\hline Methods & Double-blinded, placebo controlled, parallel-group randomised controlled trial \\
52 weeks
\end{tabular}

Participants

Setting: Turkey

Sample size: 44 participants ( 24 female, 20 male), mean MMSE 12.2

Age: mean age 73.8 years

\section{Inclusion criteria:}

- dementia of the AD type, DSM-IV, NINCDS-ADRDA criteria for probable AD, supported by CT scan or MRI performed within 6 months before entry

- age between 60 and 90 years

- advanced, moderate AD: MMSE score < 14, ADAS-Cog score > 30

\section{Exclusion criteria:}

- significant gastrointestinal illness; renal, hepatic, endocrine or cardiovascular disease; psychiatric or neurological disorder

- cholinomimetic agent in preceding 60 days, other antidementia drugs

\begin{tabular}{ll} 
Interventions & 1. Rivastigmine $12 \mathrm{mg} /$ day divided into 2 doses \\
2. Placebo \\
Titration phase weeks 0 to $2,1.5 \mathrm{mg}$ twice daily \\
Week 3 to $4,3.0$ twice daily; week 5 to $6,4.5 \mathrm{mg}$ twice daily; week 7 to $8,6 \mathrm{mg}$ twice daily \\
\hline Outcomes & 1. Cognitive function \\
- Alzheimer's Disease Assessment Scale (ADAS-Cog) & Mini-Mental State Examination (MMSE) \\
2. Activities of daily living \\
- Alzheimer's Disease Cooperative Study activities of daily living inventory (ADCS-ADL) \\
- Disability Assessment for Dementia (DAD) \\
3. Physician rated global impression tests \\
- Global Deterioration Scale (GDS)
\end{tabular}


Karaman 2005 (Continued)

- Clinician Interview-Based Impression of Change (CIBIC)

\begin{tabular}{ll}
\hline Source of funding & Not stated \\
\hline Declaration of interest & Not stated \\
\hline Notes & $\begin{array}{l}\text { Baseline study characteristics reported were those of randomised patients who had received trial med- } \\
\text { ication }\end{array}$ \\
\hline
\end{tabular}

\section{Risk of bias}

\begin{tabular}{lll}
\hline Bias & Authors' judgement & Support for judgement \\
\hline $\begin{array}{l}\text { Random sequence genera- } \\
\text { tion (selection bias) }\end{array}$ & Unclear risk & $\begin{array}{l}\text { "Patients were randomly assigned to receive treatment with rivastigmine or } \\
\text { placebo" }\end{array}$ \\
\hline $\begin{array}{l}\text { Allocation concealment } \\
\text { (selection bias) }\end{array}$ & Unclear risk & Unclear - not stated \\
\hline $\begin{array}{l}\text { Blinding of participants } \\
\text { and personnel (perfor- } \\
\text { mance bias) }\end{array}$ & Low risk & "identical tablets were given" \\
$\begin{array}{l}\text { All outcomes } \\
\end{array}$
\end{tabular}

\begin{tabular}{|c|c|c|}
\hline $\begin{array}{l}\text { Blinding of outcome as- } \\
\text { sessment (detection bias) } \\
\text { All outcomes }\end{array}$ & Unclear risk & $\begin{array}{l}\text { "Rivastigmine and placebo were administered as identical tablets taken twice } \\
\text { daily. In the rivastigmine group, patients received rivastigmine twice daily with } \\
\text { food" }\end{array}$ \\
\hline
\end{tabular}

All outcomes

There was no indication in paper how the investigators or outcomes assessors were blinded

$\begin{array}{ll}\begin{array}{l}\text { Incomplete outcome data } \\ \text { (attrition bias) }\end{array} & \begin{array}{l}\text { Data from } 21 / 24 \text { patients in the rivastigmine group (and all the placebo pa- } \\ \text { tients) were available at } 52 \text { weeks. There was no information about loss to fol- } \\ \text { All outcomes }\end{array} \\ \begin{array}{l}\text { low up, but the following was stated in the methods section: "At the conclu- } \\ \text { sion of the } 8 \text {-week study visit, participants who tolerated the drug well and } \\ \text { perceived benefit were invited to continue rivastigmine treatment." It is un- } \\ \text { clear how many patients were excluded because they did not 'benefit' or 'tol- } \\ \text { erate' the drug well }\end{array}\end{array}$

\begin{tabular}{|c|c|c|}
\hline $\begin{array}{l}\text { Selective reporting (re- } \\
\text { porting bias) }\end{array}$ & Unclear risk & Insufficient information to determine \\
\hline Other bias & High risk & $\begin{array}{l}\text { As this study only extended the continuation to those who had perceived to } \\
\text { benefit at the } 8 \text { week visit, this potentially introduced bias and broke the ran- } \\
\text { domisation. It was not reported how many patients who were randomised ini- } \\
\text { tially continued to the } 52 \text { week study }\end{array}$ \\
\hline
\end{tabular}

\section{Lopez-Pousa 2005}

\begin{tabular}{ll}
\hline Methods & Double-blinded, placebo controlled, parallel-group randomised controlled trial \\
& 26 weeks \\
\hline Participants & Setting: Spain, 21 centres \\
& Sample size: 218 participants, $77 \%$ female, mean MMSE 8.8 \\
& Age: mean age 77.6 years
\end{tabular}


Lopez-Pousa 2005 (Continued)

\section{Inclusion criteria:}

- age 55 years and above

- dementia of AD type DSM-IV, NINCDS-ADRDA criteria for probable AD

- severe AD, MMSE range 5 to 12 inclusive, GDS 5 to 6 , Hachinski scale score of 4

\section{Exclusion criteria:}

- sensitivity to cholinergic-like drugs

- history of drug abuse, severe advanced disease, severe unstable cardiovascular disease, sinoatrial block, second or third degree atrioventricular block, institutionalisation, other cholinesterase inhibitors

- other investigational drugs within 4 week entry to study

\begin{tabular}{ll}
\hline Interventions & 1. Rivastigmine $12 \mathrm{mg} /$ day divided into 2 doses \\
2. Placebo \\
Titration phase weeks 0 to $4,1.5 \mathrm{mg}$ twice daily \\
Weeks 5 to $8,3.0 \mathrm{mg}$ twice daily; weeks 9 to $12,4.5 \mathrm{mg}$ twice daily; weeks 13 to $16,6 \mathrm{mg}$ twice daily \\
\hline Outcomes & 1. Cognitive function \\
- Mini-Mental State Examination (MMSE) \\
- Severe Impairment Battery (SIB) \\
2. Activities of daily living \\
- Alzheimer's Disease Cooperative Study activities of daily living (ADCS-ADL) \\
3. Behavioural symptoms \\
- Neuropsychiatric Instrument (NPI): NPI-4 and NPI-10 \\
4. Physician rated global impression tests \\
- Alzheimer's Disease Cooperative Study (ADCS-CGIC) \\
- Global Deterioration Scale (GDS) \\
Other scales: \\
Blessed Dementia Scale (Blessed 1968), a multidimensional performance scale
\end{tabular}

Source of funding Not stated in study publication

Declaration of interest

Likely to be linked to pharmaceutical company, 2 of the 4 authors were employees of Novartis, randomisation scheme generated by a contract research organisation but was "reviewed" by Novartis

\section{Notes}

\section{Risk of bias}

\begin{tabular}{lll}
\hline Bias & Authors' judgement & Support for judgement \\
\hline $\begin{array}{l}\text { Random sequence genera- } \\
\text { tion (selection bias) }\end{array}$ & Low risk & "Computer generated randomisation schedule", in blocks of 4 \\
\hline $\begin{array}{l}\text { Allocation concealment } \\
\text { (selection bias) }\end{array}$ & Unclear risk & $\begin{array}{l}\text { "Eligible patients, identified at an initial screening visit were allocated ran- } \\
\text { domisation number at second visit" }\end{array}$ \\
& Unclear whether this allocation was concealed \\
\hline
\end{tabular}




\section{Lopez-Pousa 2005 (Continued)}

Blinding of participants Low risk_ "Rivastigmine and placebo hard capsules were identical in appearance" and personnel (performance bias)

All outcomes

\begin{tabular}{|c|c|c|}
\hline $\begin{array}{l}\text { Blinding of outcome as- } \\
\text { sessment (detection bias) } \\
\text { All outcomes }\end{array}$ & Low risk & $\begin{array}{l}\text { "Medical monitors, centre personnel, patients and caregivers were blinded to } \\
\text { treatment". Randomisation data were not available until after the study had } \\
\text { been completed and the database locked }\end{array}$ \\
\hline $\begin{array}{l}\text { Incomplete outcome data } \\
\text { (attrition bias) } \\
\text { All outcomes }\end{array}$ & Low risk & $\begin{array}{l}\text { An } 83.5 \% \text { completion in treatment arm, } 88.1 \% \text { completion in placebo } \\
\text { ITT population was } 104 / 109 \text { in the treatment arm, 106/109 in the placebo arm } \\
\text { Comment: early withdrawals were followed up. Documented, small percent- } \\
\text { age of missing data }\end{array}$ \\
\hline $\begin{array}{l}\text { Selective reporting (re- } \\
\text { porting bias) }\end{array}$ & Unclear risk & Insufficient information \\
\hline
\end{tabular}

Mowla 2007

Methods Double-blinded, 3 arm, placebo controlled, parallel-group randomised controlled trial

12 week study; 6 week single-blind placebo run-in period was included to exclude responders

Participants

Setting: Iran

Sample size: 122 patients, 41 in rivastigmine group, 41 in placebo group

Age: mean age 69.2 years, $53.5 \%$ female

Inclusion criteria:

- mild to moderate AD, diagnosed according to DSM-IV

- MMSE 10 to 24, mean 16.1 (4.0)

- Brief Cognitive Rating Scale 3 to 5

- Hachinski Ischemic Score $<4$

- premorbid IQ > 80

\section{Exclusion criteria:}

- dementia of other etiology, severe organic disease

- other psychiatric disorder; Hamilton depression score $<10$

I. Rivastigmine 6 to $12 \mathrm{mg} / \mathrm{day}$, twice daily
2. Rivastigmine 6 to $12 \mathrm{mg} / \mathrm{day}$ twice daily + fluoxetine $20 \mathrm{mg} / \mathrm{day}$
2. Placebo
No information was given as to whether there was any titration

Outcomes

1. Cognitive function

- Mini-Mental State Examination (MMSE)

- Wechsler Memory Scale (WMS-III)

2. Activities of daily living (ADL) 
Mowla 2007 (Continued)

- used a scale by Lawton and Brody 1969. This scale contains 8 items in Instrumental ADL and 6 items in Basic ADL, scored between 1 to 5 ( 1 = completely able, 5 = thoroughly unable)

3. Physician rated global impression tests

- Clinical global impression (CGI)

\begin{tabular}{ll}
\hline Source of funding & Shiraz University of Medical Science Grant 83-421 \\
\hline Declaration of interest & None stated \\
\hline
\end{tabular}

Notes

\section{Risk of bias}

\begin{tabular}{|c|c|c|}
\hline Bias & Authors' judgement & Support for judgement \\
\hline $\begin{array}{l}\text { Random sequence genera- } \\
\text { tion (selection bias) }\end{array}$ & Unclear risk & Method not stated \\
\hline $\begin{array}{l}\text { Allocation concealment } \\
\text { (selection bias) }\end{array}$ & Unclear risk & Method not stated \\
\hline \multirow{2}{*}{$\begin{array}{l}\text { Blinding of participants } \\
\text { and personnel (perfor- } \\
\text { mance bias) } \\
\text { All outcomes }\end{array}$} & Unclear risk & $\begin{array}{l}\text { "Same number of drugs were given to the patients of the } 3 \text { groups", "there } \\
\text { were no significant difference between the groups with respect to taking other } \\
\text { medications" }\end{array}$ \\
\hline & & $\begin{array}{l}\text { Comment: mentioned use of placebo, but unclear if these were identical to ac- } \\
\text { tive treatments - all participants had received placebo during a } 6 \text { week run-in } \\
\text { period }\end{array}$ \\
\hline
\end{tabular}

\begin{tabular}{lll}
$\begin{array}{l}\text { Blinding of outcome as- } \\
\text { sessment (detection bias) } \\
\text { All outcomes }\end{array}$ & Low risk & "Same number of drugs were given to the patients of the 3 groups" \\
\hline $\begin{array}{l}\text { Incomplete outcome data } \\
\text { (attrition bias) } \\
\text { All outcomes }\end{array}$ & Unclear risk & $\begin{array}{l}\text { Dropout rate was } 7 / 41(17 \%) \text { in the rivastigmine group, and } 8 / 40(20 \%) \text { in the } \\
\text { placebo group. Stated that "major cause of withdrawal was adverse events } \\
\text { compared with loss of efficacy as the most common cause for group C". Actual } \\
\text { causes of loss to follow up not reported, relatively high numbers of loss to fol- } \\
\text { low up for a short study of } 12 \text { weeks }\end{array}$ \\
\hline Other bias & High risk & $\begin{array}{l}\text { "a single blind placebo } 6 \text { week run in period was included to exclude placebo } \\
\text { responders" }\end{array}$ \\
\hline
\end{tabular}

Nakamura 2011

\begin{tabular}{ll}
\hline Methods & Multicentre, randomised, double-blind, placebo controlled, 3 arm, parallel-group trial of 24 weeks \\
& A dose finding study (NCT00423085) \\
\hline Participants & Inclusion criteria: \\
- & patients with dementia of Alzheimer's type according to DSM-IV and probable AD according to criteria \\
& of NINCDS-ADRDA, MMSE 10 to 20 \\
- & age 50 to 85 years
\end{tabular}

\section{Exclusion criteria:}


Nakamura 2011 (Continued)

- any other condition that can explain the patient's dementia

- advanced, progressive disease that can prevent evaluation or put participants at risk

- use of rivastigmine in the past

- use of donepezil, other cholinesterase inhibitors, approved treatments for AD or other centrally acting anticholinergic drugs during the 4 weeks prior to efficacy assessments at baseline

$\begin{array}{ll}\text { Interventions } & \text { 1. A } 5 \mathrm{~cm}^{2} \text { patch ( } 4.6 \mathrm{mg} / \text { day rivastigmine) } \\ \text { 2. A } 10 \mathrm{~cm}^{2} \text { patch }(9.5 \mathrm{mg} / \text { day rivastigmine) } \\ \text { 3. Placebo }\end{array}$

Participants were titrated to their target dose at 4 week intervals over 16 weeks, followed by an 8 week maintenance dose at weeks 17 to 24

1. Cognitive function
- Japanese version ADAS-cog
- Mental Function Impairment (MENFIS)
2. Activities of daily living
- Disability Assessment for Dementia (DAD)
3. Physician rated global impression tests
- Japanese version CIBIC-Plus
4. Behavioural symptoms
- Behavioural Pathology in AD (BEHAVE-AD)

Results were reported as intention-to-treat last observation carried forward at 24 weeks. Assessments were done during weeks 8,16 and 24

\begin{abstract}
Source of funding
A total of $4 / 9$ authors had no interest to declare; the rest were employees of either Novartis or ONO

Alpha-Plus Medical Communications Ltd (UK) provided medical writing and editorial support in the production of this manuscript; this service was sponsored by Novartis and ONO
\end{abstract}

Declaration of interest Sponsored by Novartis and ONO Pharmaceutical Ltd (they jointly developed and marketed the transdermal patch in Japan)

Notes

\title{
Risk of bias
}

\begin{tabular}{|c|c|c|}
\hline Bias & Authors' judgement & Support for judgement \\
\hline $\begin{array}{l}\text { Random sequence genera- } \\
\text { tion (selection bias) }\end{array}$ & Low risk & $\begin{array}{l}\text { "The patient registration centre provided a randomisation number to the eligi- } \\
\text { ble participants and randomisation lists were generated by a Drug ALlocation } \\
\text { Controller". A dynamic allocation was utilised, using body weight }(<45,45 \text { to }< \\
55 \text { and } \geq 55 \mathrm{~kg}) \text { and MMSE score ( } \leq 15,>15 \text { points) as factors }\end{array}$ \\
\hline $\begin{array}{l}\text { Allocation concealment } \\
\text { (selection bias) }\end{array}$ & Low risk & $\begin{array}{l}\text { Likely to be low risk. Investigators had to offer enrolment to all eligible pa- } \\
\text { tients. Allocation number provided after eligibility criteria confirmed }\end{array}$ \\
\hline \multirow{2}{*}{$\begin{array}{l}\text { Blinding of participants } \\
\text { and personnel (perfor- } \\
\text { mance bias) } \\
\text { All outcomes }\end{array}$} & Unclear risk & $\begin{array}{l}\text { "Randomisation data kept strictly confidential by the Study Drug Allocation } \\
\text { Controller until the time of unblinding" (only permitted during emergencies } \\
\text { and at conclusion of study) }\end{array}$ \\
\hline & & However, 3 different patch sizes were used, $2.5 \mathrm{~cm}^{2}, 5 \mathrm{~cm}^{2}, 7.5 \mathrm{~cm}^{2}$ and $10 \mathrm{~cm}^{2}$ \\
\hline
\end{tabular}


Nakamura 2011 (Continued)

Since the higher dose group $\left(10 \mathrm{~cm}^{2}\right)$ used bigger patches than the maximum for the $5 \mathrm{~cm}^{2}$ group, unclear how blinding was maintained

\begin{tabular}{|c|c|c|}
\hline $\begin{array}{l}\text { Blinding of outcome as- } \\
\text { sessment (detection bias) }\end{array}$ & Low risk & $\begin{array}{l}\text { "patients, investigator staff, persons performing the assessments and data an- } \\
\text { alysts were all blinded" }\end{array}$ \\
\hline
\end{tabular}

"patients, investigator staff, persons performing the assessments and data an-

\begin{tabular}{lll}
\hline $\begin{array}{l}\text { Incomplete outcome data } \\
\text { (attrition bias) } \\
\text { All outcomes }\end{array}$ & Unclear risk & $\begin{array}{l}\text { An 80.3\% completion rate of study; 88\% in placebo, about 80\% in active treat- } \\
\text { ment available as ITT-observed cases at week 24 }\end{array}$ \\
\hline $\begin{array}{l}\text { Selective reporting (re- } \\
\text { porting bias) }\end{array}$ & Low risk & Outcomes listed in protocol were reported \\
\hline Other bias & Low risk & None identified \\
\hline
\end{tabular}

\section{Tai 2000}

\begin{tabular}{ll}
\hline Methods & Double-blinded randomised controlled trial \\
& 26 weeks follow up \\
\hline
\end{tabular}

\begin{tabular}{ll}
\hline Participants & $\begin{array}{l}\text { Setting: Taiwan } \\
\text { Sample size: } 80\end{array}$ \\
Inclusion criteria: & mild to moderate AD \\
\hline Interventions & $\begin{array}{l}\text { 1. Rivastigmine: } 3 \mathrm{mg} / \text { day divided into } 2 \text { doses, escalating by } 3 \mathrm{mg} / \text { day not faster than every two weeks } \\
\text { until a dose that was not tolerated was reached } \\
\text { 2. Placebo }\end{array}$
\end{tabular}

\begin{tabular}{ll}
\hline Outcomes & Cognitive Function \\
- MMSE & Neuropsychological Tests (NPT) \\
2.Activities of daily living \\
- none stated \\
3. Physician rated global impression tests \\
- CIBIC-Plus \\
- Global Deterioration Scale \\
5. Frequency of adverse events \\
6. Withdrawal due to adverse events \\
- study only reported overall withdrawals \\
\hline Source of funding & Not stated \\
\hline Declaration of interest & Not stated \\
\hline
\end{tabular}

Notes 
Tai 2000 (Continued)

\section{Risk of bias}

\begin{tabular}{|c|c|c|}
\hline Bias & Authors' judgement & Support for judgement \\
\hline $\begin{array}{l}\text { Random sequence genera- } \\
\text { tion (selection bias) }\end{array}$ & Unclear risk & No information. Only abstract available \\
\hline $\begin{array}{l}\text { Allocation concealment } \\
\text { (selection bias) }\end{array}$ & Unclear risk & No information. Only abstract available \\
\hline $\begin{array}{l}\text { Blinding of participants } \\
\text { and personnel (perfor- } \\
\text { mance bias) } \\
\text { All outcomes }\end{array}$ & Unclear risk & No information. Only abstract available \\
\hline $\begin{array}{l}\text { Blinding of outcome as- } \\
\text { sessment (detection bias) } \\
\text { All outcomes }\end{array}$ & Unclear risk & No information. Only abstract available \\
\hline $\begin{array}{l}\text { Incomplete outcome data } \\
\text { (attrition bias) } \\
\text { All outcomes }\end{array}$ & Unclear risk & Insufficient information to judge. Only abstract available \\
\hline $\begin{array}{l}\text { Selective reporting (re- } \\
\text { porting bias) }\end{array}$ & Unclear risk & Insufficient information to judge. Only abstract available \\
\hline Other bias & Unclear risk & Insufficient information to judge. Only abstract available \\
\hline
\end{tabular}

Characteristics of excluded studies [ordered by study ID]

\begin{tabular}{ll}
\hline Study & Reason for exclusion \\
\hline ACTION & This trial compared two sizes of rivastigmine patches, but there was no placebo group \\
\hline Almkvist 2004 & This trial studied particular aspects of memory, but used historical controls as the untreated group \\
\hline Auriacombe 2002 & $\begin{array}{l}\text { Open label, } 6 \text { month study of rivastigmine for patients who had failed to benefit from donepezil. } \\
\text { Later extended to } 12 \text { months }\end{array}$ \\
\hline B105 & THis was a randomised, placebo controlled trial, but the duration was only 9 weeks \\
\hline Bilikiewicz 2002 & Open label study of rivastigmine in community setting \\
\hline Blesa Gonzalez 2011 & $\begin{array}{l}\text { Trial investigating adverse events on changing to patches from tablets. There were 2 groups using } \\
\text { patches, and one group continuing on tablets, but no placebo group. The trial was open label, and } \\
\text { data were not reported for all groups, limiting usable comparisons }\end{array}$ \\
\hline Brassen 2003 & $\begin{array}{l}\text { An unblinded study. Open controlled design of rivastigmine compared with donepezil, 35 AD pa- } \\
\text { tients }\end{array}$ \\
\hline Caffarra 2007 & \begin{tabular}{l} 
There was no placebo group. Comparison of rivastigmine with donepezil, retrospective study \\
\hline Cummings 2000
\end{tabular} \\
\hline
\end{tabular}




\begin{tabular}{|c|c|}
\hline Study & Reason for exclusion \\
\hline Cutler 1998 & Open label non-randomised study \\
\hline Cutler 2000 & Open label study investigating the pharmacokinetics of oral and intravenous rivastigmine \\
\hline Dantoine 2006 & $\begin{array}{l}\text { Comparison of rivastigmine with rivastigmine plus memantine in AD patients previously failing to } \\
\text { respond on donepezil or galantamine, open label study }\end{array}$ \\
\hline Doraiswamy $2000 a$ & Open label extension to either B303 or B352 \\
\hline Edwards 2002 & $\begin{array}{l}\text { Open label study of nursing home patients, all on rivastigmine. Outcome was assessment of use of } \\
\text { psychotropics }\end{array}$ \\
\hline EXCEED & $\begin{array}{l}\text { Donepezil compared with rivastigmine. A } 24 \text { month randomised controlled trial with no placebo } \\
\text { group }\end{array}$ \\
\hline Frankfort 2007 & $\begin{array}{l}\text { Study of effect of rivastigmine on specific cognitive domains. This is not an randomised controlled } \\
\text { trial, treatment group compared with historical controls }\end{array}$ \\
\hline Fuschillo 2001 & Randomised study of donepezil compared with rivastigmine for AD. No placebo group \\
\hline Holmes 2007 & Randomised study of rivastigmine compared with risperidone, no placebo group \\
\hline InDDEx & $\begin{array}{l}\text { Randomised placebo controlled study of rivastigmine for patients with mild cognitive impairment } \\
\text { but not dementia }\end{array}$ \\
\hline
\end{tabular}

\begin{tabular}{|c|c|}
\hline Kim 2002 & A 24 week open label study, all on rivastigmine \\
\hline Malsch 2001 & Open label 8 week study, patients randomised to two different titration schemes \\
\hline McMillan 1999 & Open label study of early non-responders \\
\hline Novartis 2005 & Open label extension study \\
\hline OPTIMA & This trial compared two sizes of rivastigmine patches, but there was no placebo group \\
\hline Potkin 1999a & $\begin{array}{l}\text { Investigation of brain metabolism using positron emission tomography (PET) scans from } 27 \text { pa- } \\
\text { tients chosen non-randomly from study B351 }\end{array}$ \\
\hline Riepe 2005 & This is not a randomised controlled trial; 12 week open label study of rivastigmine + memantine \\
\hline Rozzini 2002 & Randomised trial comparing rivastigmine with donepezil. No placebo group \\
\hline Schmidt 2002 & Open label study on the use of rivastigmine in routine clinical practice \\
\hline Shanks 2001 & Open label study, all on rivastigmine, assessing cerebral flow only \\
\hline Shua-Haim 2002a & A 5 month study, comparing donepezil with rivastigmine with galantamine. No placebo group \\
\hline Shua-Haim 2002b & Open label treatment of agitation in patients with $A D$ \\
\hline Shua-Haim 2002c & Donepezil, compared with rivastigmine, compared with galantamine \\
\hline Small 2005 & A pooled study of two open label extension studies of rivastigmine \\
\hline Sobow 2002 & Retrospective review of patients who had been prescribed rivastigmine or donepezil \\
\hline
\end{tabular}




\begin{tabular}{ll}
\hline Study & Reason for exclusion \\
\hline Stefanova 2002 & Rivastigmine compared with tacrine in matched groups \\
\hline Thomas 2001 & Open label trial \\
\hline Tsolaki 2002 & Retrospective study, comparing donepezil with rivastigmine \\
\hline Venneri 2002 & $\begin{array}{l}\text { Non-randomised study of } 4 \text { patients. Rates of progression of disease in those treated with rivastig- } \\
\text { mine compared with untreated patients }\end{array}$ \\
\hline Wang 2001 & Open label, randomised study, comparing rivastigmine with donepezil \\
\hline Wang 2003 & Open label study of rivastigmine \\
\hline Weiser 2002 & $\begin{array}{l}\text { Open label pilot study. Patients randomised to rivastigmine and risperidone, alone or in combina- } \\
\text { tion }\end{array}$ \\
\hline Werber 2002 & $\begin{array}{l}\text { Non-randomised study of donepezil compared with tacrine, with rivastigmine. Outcome is cogni- } \\
\text { tion related brain evoked potential }\end{array}$ \\
\hline Wilkinson 2002 & \begin{tabular}{l} 
Randomised, 12 week, open label study comparing donepezil with rivastigmine. No placebo group \\
\hline
\end{tabular}
\end{tabular}

\section{DATA AND ANALYSES}

Comparison 1. Rivastigmine (capsules 6 to $12 \mathrm{mg} /$ day in two divided doses or $10 \mathrm{~cm}^{2}$ ( $9.5 \mathrm{mg} / \mathrm{day}$ ) patch) versus placebo

\begin{tabular}{|c|c|c|c|c|}
\hline Outcome or subgroup title & $\begin{array}{l}\text { No. of } \\
\text { studies }\end{array}$ & $\begin{array}{l}\text { No. of } \\
\text { partici- } \\
\text { pants }\end{array}$ & Statistical method & Effect size \\
\hline $\begin{array}{l}1 \text { ADAS-Cog (change from baseline at 24-26 } \\
\text { weeks) ITT }\end{array}$ & 6 & 3232 & $\begin{array}{l}\text { Mean Difference (IV, Fixed, 95\% } \\
\mathrm{Cl})\end{array}$ & $\begin{array}{l}-1.79[-2.21 \\
-1.37]\end{array}$ \\
\hline $\begin{array}{l}2 \text { MMSE (change from baseline at } 24-26 \text { weeks) } \\
\text { ITT }\end{array}$ & 6 & 3205 & $\begin{array}{l}\text { Mean Difference (IV, Fixed, 95\% } \\
\mathrm{Cl})\end{array}$ & $0.74[0.52,0.97]$ \\
\hline $\begin{array}{l}3 \text { Activities of daily living (change from baseline at } \\
24-26 \text { weeks) ITT }\end{array}$ & 6 & 3230 & $\begin{array}{l}\text { Std. Mean Difference (IV, Fixed, } \\
95 \% \mathrm{CI})\end{array}$ & $0.20[0.13,0.27]$ \\
\hline $\begin{array}{l}4 \text { Clinical Global Impression (no change or worse } \\
\text { at 24-26 weeks) ITT }\end{array}$ & 7 & 3338 & Odds Ratio (M-H, Fixed, 95\% Cl) & $0.68[0.58,0.80]$ \\
\hline $\begin{array}{l}5 \text { Behavioural symptoms (change from baseline at } \\
24-26 \text { weeks) ITT }\end{array}$ & 3 & 1529 & $\begin{array}{l}\text { Std. Mean Difference (IV, Fixed, } \\
95 \% \mathrm{Cl} \text { ) }\end{array}$ & $\begin{array}{l}-0.04[-0.14 \\
0.06]\end{array}$ \\
\hline $\begin{array}{l}6 \text { Withdrawals before end of treatment at 24-26 } \\
\text { weeks }\end{array}$ & 7 & 3569 & Odds Ratio (M-H, Fixed, 95\% Cl) & $2.06[1.74,2.45]$ \\
\hline 7 at least one adverse event by $24-26$ weeks & 7 & 3587 & Odds Ratio (M-H, Fixed, 95\% Cl) & $2.16[1.82,2.57]$ \\
\hline
\end{tabular}




\begin{tabular}{llllll}
\hline Outcome or subgroup title & $\begin{array}{l}\text { No. of } \\
\text { studies }\end{array}$ & $\begin{array}{l}\text { No. of } \\
\text { partici- } \\
\text { pants }\end{array}$ & Statistical method & Effect size \\
\hline $\begin{array}{l}8 \text { NPI-D carer distress scale (change from baseline } \\
\text { at 24-26 weeks) ITT }\end{array}$ & 1 & 529 & $\begin{array}{l}\text { Mean Difference (IV, Fixed, 95\% } \\
\text { Cl) }\end{array}$ & $\begin{array}{l}0.10[-0.91, \\
1.11]\end{array}$ \\
\hline
\end{tabular}

Analysis 1.1. Comparison 1 Rivastigmine (capsules 6 to $12 \mathrm{mg} /$ day in two divided doses or $10 \mathrm{~cm}^{2}$ $(9.5 \mathrm{mg} / \mathrm{day}$ ) patch) versus placebo, Outcome 1 ADAS-Cog (change from baseline at 24-26 weeks) ITT.

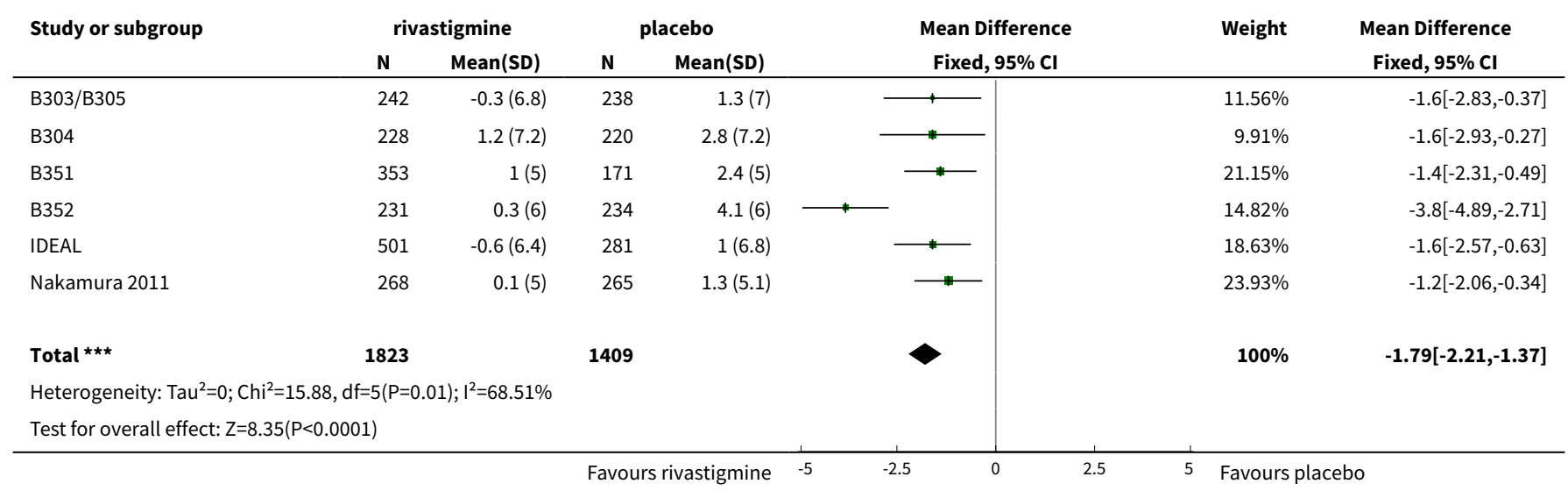

Analysis 1.2. Comparison 1 Rivastigmine (capsules 6 to $12 \mathrm{mg}$ /day in two divided doses or $10 \mathrm{~cm}^{2}$ (9.5 mg/day) patch) versus placebo, Outcome 2 MMSE (change from baseline at 24-26 weeks) ITT.

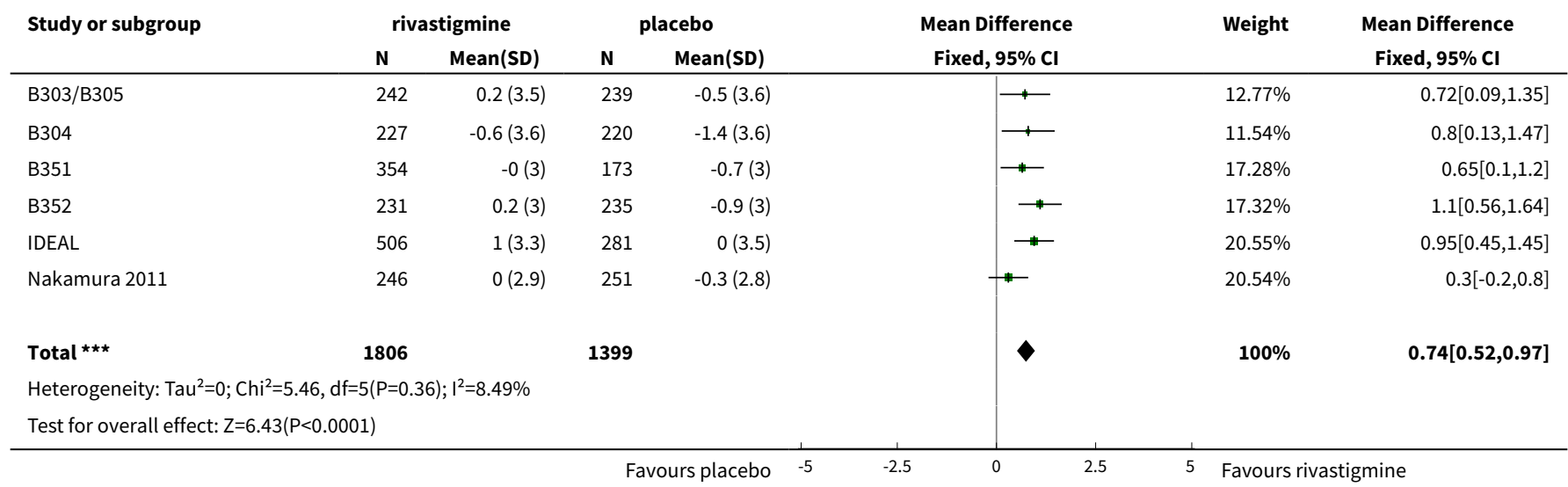


Analysis 1.3. Comparison 1 Rivastigmine (capsules 6 to $12 \mathrm{mg} /$ day in two divided doses or $10 \mathrm{~cm}^{2}(9.5 \mathrm{mg} /$ day) patch) versus placebo, Outcome 3 Activities of daily living (change from baseline at 24-26 weeks) ITT.

\begin{tabular}{|c|c|c|c|c|c|c|c|c|}
\hline \multirow[t]{2}{*}{ Study or subgroup } & \multicolumn{2}{|c|}{ rivastigmine } & \multicolumn{2}{|c|}{ placebo } & \multirow{2}{*}{\multicolumn{2}{|c|}{$\begin{array}{c}\text { Std. Mean Difference } \\
\text { Fixed, } 95 \% \mathrm{Cl} \\
\end{array}$}} & \multirow[t]{2}{*}{ Weight } & \multirow{2}{*}{$\begin{array}{c}\text { Std. Mean Difference } \\
\text { Fixed, } 95 \% \mathrm{Cl} \\
\end{array}$} \\
\hline & $\mathbf{N}$ & Mean(SD) & $\mathbf{N}$ & $\operatorname{Mean}(S D)$ & & & & \\
\hline B303/B305 & 241 & $0(13.2)$ & 237 & $-2.2(13.4)$ & & $\longrightarrow$ & $15.41 \%$ & $0.17[-0.01,0.34]$ \\
\hline B304 & 227 & $-2.7(11.1)$ & 221 & $-4.9(11.2)$ & & - & $14.42 \%$ & $0.2[0.01,0.38]$ \\
\hline B351 & 349 & $-2.3(10.4)$ & 173 & $-3.1(10.3)$ & & + & $14.95 \%$ & $0.08[-0.11,0.26]$ \\
\hline B352 & 231 & $-1.5(10.3)$ & 233 & $-4.9(10.3)$ & & $\longrightarrow$ & $14.8 \%$ & $0.33[0.15,0.51]$ \\
\hline IDEAL & 501 & $-0.3(9.5)$ & 281 & $-2.3(9.4)$ & & —- & $23.17 \%$ & $0.21[0.06,0.36]$ \\
\hline Total ${ }^{\star \star \star}$ & 1818 & & 1412 & & & & $100 \%$ & $0.2[0.13,0.27]$ \\
\hline \multicolumn{9}{|c|}{ Heterogeneity: $\mathrm{Tau}^{2}=0 ; \mathrm{Chi}^{2}=3.83, \mathrm{df}=5(\mathrm{P}=0.57) ; \mathrm{I}^{2}=0 \%$} \\
\hline \multicolumn{9}{|c|}{ Test for overall effect: $Z=5.49(P<0.0001)$} \\
\hline & & & & irs placebo & -0.5 & 0.5 & Favour & ine \\
\hline
\end{tabular}

Analysis 1.4. Comparison 1 Rivastigmine (capsules 6 to $12 \mathrm{mg} /$ day in two divided doses or $10 \mathrm{~cm}^{2}(9.5 \mathrm{mg} /$ day) patch) versus placebo, Outcome 4 Clinical Global Impression (no change or worse at 24-26 weeks) ITT.

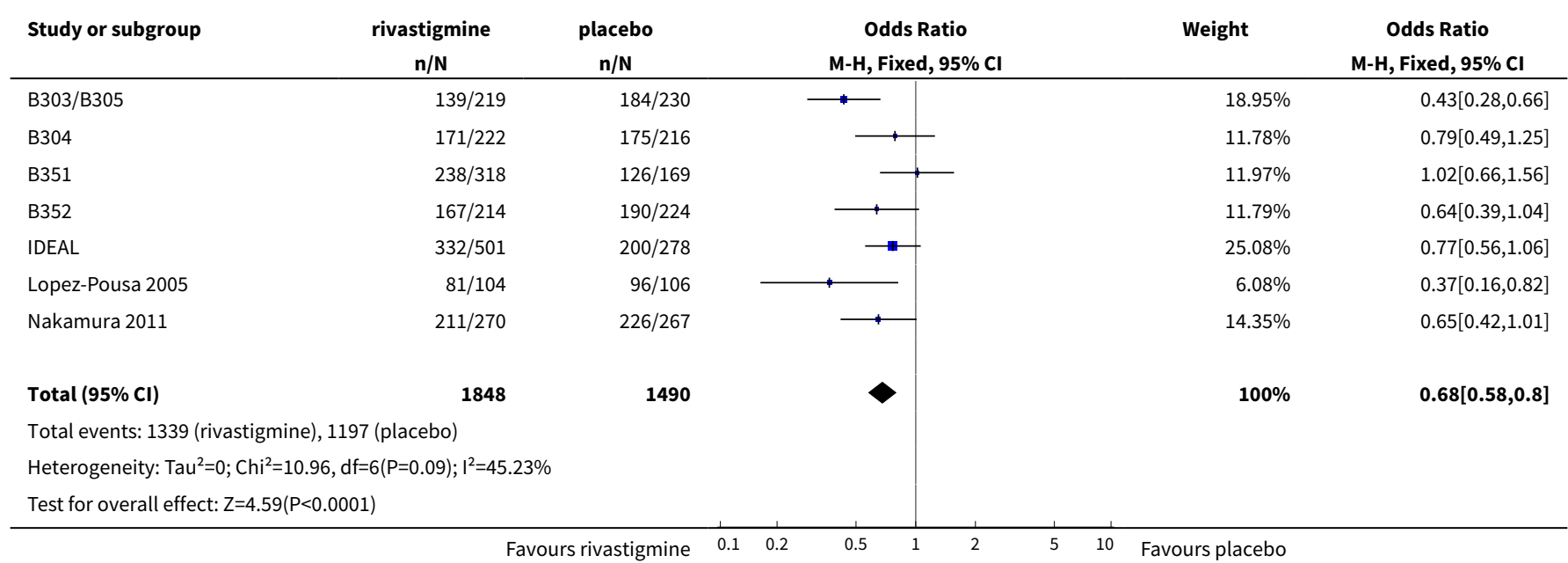

Analysis 1.5. Comparison 1 Rivastigmine (capsules 6 to $12 \mathrm{mg} /$ day in two divided doses or $10 \mathrm{~cm}^{2}(9.5 \mathrm{mg}$ / day) patch) versus placebo, Outcome 5 Behavioural symptoms (change from baseline at 24-26 weeks) ITT.

\begin{tabular}{|c|c|c|c|c|c|c|c|}
\hline \multirow[t]{2}{*}{ Study or subgroup } & \multicolumn{2}{|c|}{ rivastigmine } & \multicolumn{2}{|c|}{ placebo } & \multirow{2}{*}{$\begin{array}{c}\text { Std. Mean Difference } \\
\text { Fixed, } 95 \% \mathrm{Cl}\end{array}$} & \multirow[t]{2}{*}{ Weight } & \multirow{2}{*}{$\begin{array}{c}\text { Std. Mean Difference } \\
\text { Fixed, } 95 \% \mathrm{Cl}\end{array}$} \\
\hline & $\mathbf{N}$ & Mean(SD) & $\mathbf{N}$ & Mean(SD) & & & \\
\hline IDEAL & 501 & $-1.9(11.9)$ & 281 & $-1.7(13.8)$ & -1 & $49.1 \%$ & $-0.02[-0.17,0.13]$ \\
\hline Lopez-Pousa 2005 & 104 & $-0.1(15.2)$ & 106 & $1.7(17.5)$ & $\rightarrow+$ & $14.3 \%$ & $-0.11[-0.38,0.16]$ \\
\hline Nakamura 2011 & 270 & $-0.3(4.7)$ & 267 & $-0.1(3.8)$ & \begin{tabular}{l|l}
$\boldsymbol{\Psi}$ \\
$\boldsymbol{1}$
\end{tabular} & $36.6 \%$ & $-0.05[-0.22,0.12]$ \\
\hline 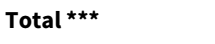 & 875 & & 654 & & & $100 \%$ & $-0.04[-0.14,0.06]$ \\
\hline Test for overall effect & & & & & & & \\
\hline
\end{tabular}


Analysis 1.6. Comparison 1 Rivastigmine (capsules 6 to $12 \mathrm{mg} /$ day in two divided doses or $10 \mathrm{~cm}^{2}$ (9.5 $\mathrm{mg} / \mathrm{day})$ patch) versus placebo, Outcome 6 Withdrawals before end of treatment at 24-26 weeks.

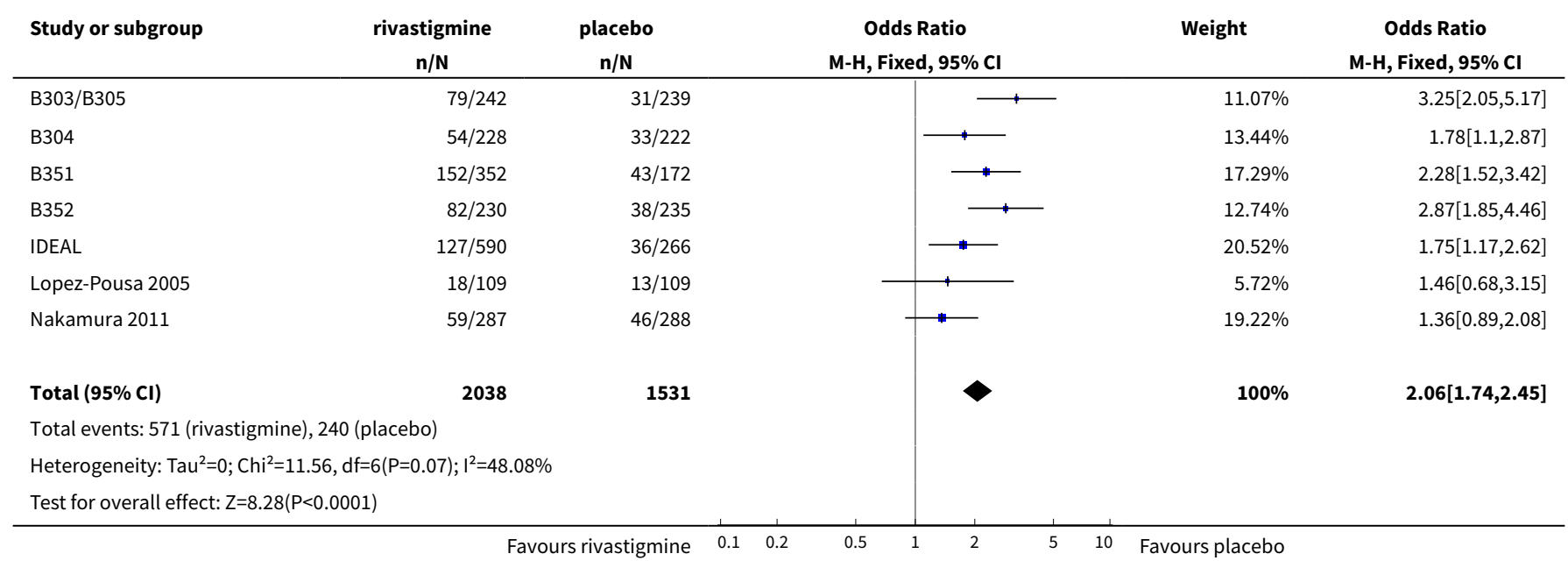

Analysis 1.7. Comparison 1 Rivastigmine (capsules 6 to $12 \mathrm{mg} /$ day in two divided doses or 10 $\mathrm{cm}^{2}$ (9.5 $\mathrm{mg} / \mathrm{day}$ ) patch) versus placebo, Outcome 7 at least one adverse event by 24-26 weeks.

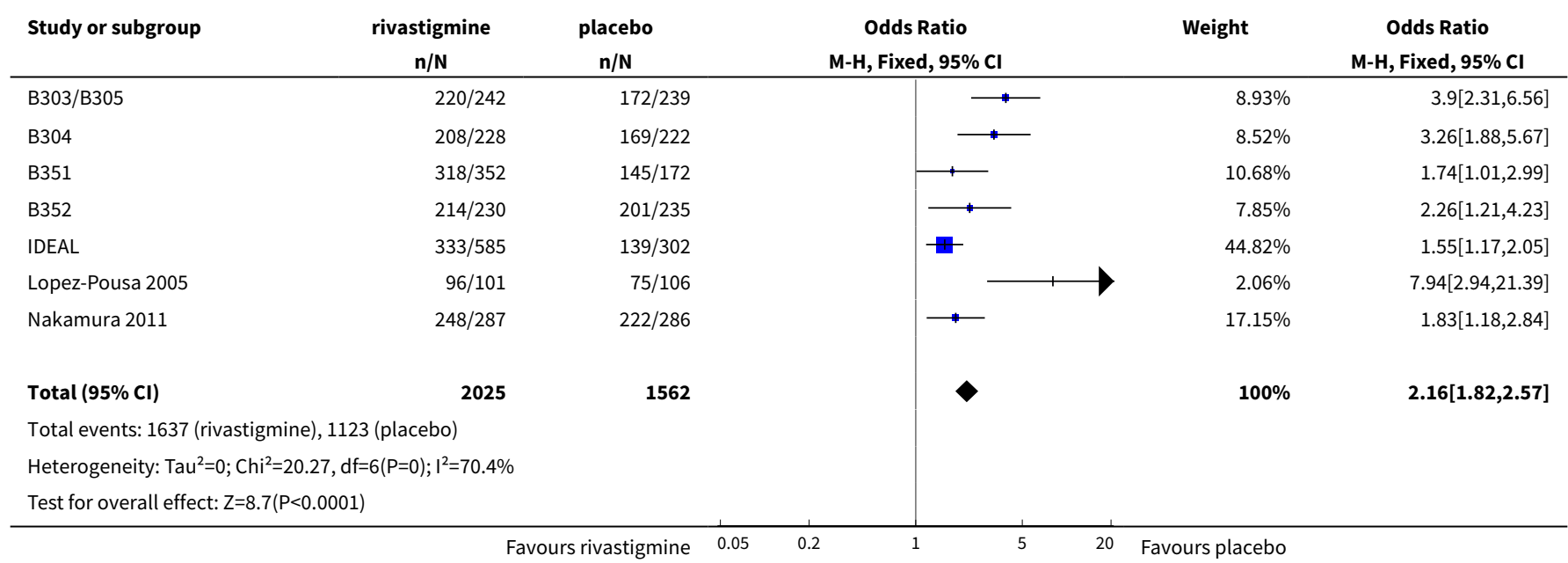

Analysis 1.8. Comparison 1 Rivastigmine (capsules 6 to $12 \mathrm{mg} /$ day in two divided doses or $10 \mathrm{~cm}^{2}(9.5 \mathrm{mg}$ / day) patch) versus placebo, Outcome 8 NPI-D carer distress scale (change from baseline at 24-26 weeks) ITT.

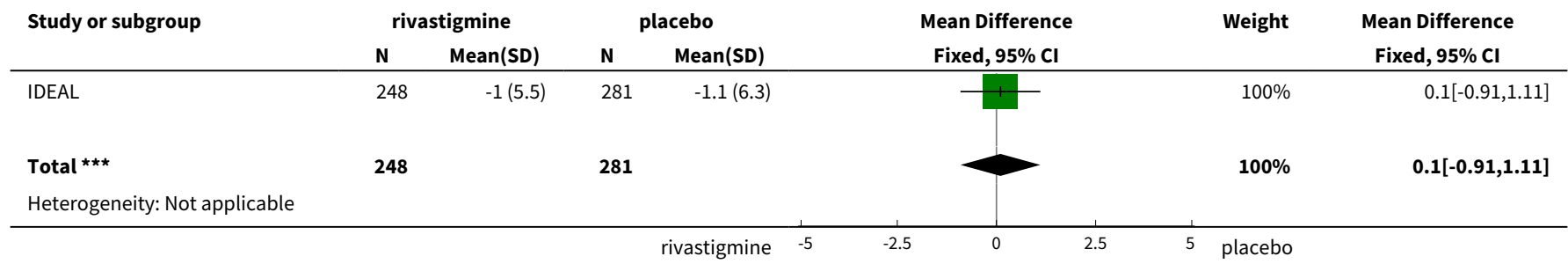




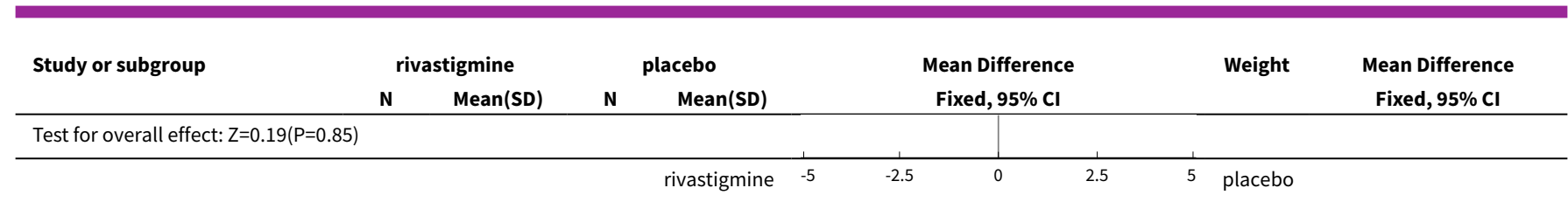

\section{Comparison 2. Rivastigmine oral capsules ( 1 to $4 \mathrm{mg} /$ day or 6 to $12 \mathrm{mg}$ /day in two divided doses) versus placebo}

\begin{tabular}{|c|c|c|c|c|}
\hline Outcome or subgroup title & $\begin{array}{l}\text { No. of } \\
\text { studies }\end{array}$ & $\begin{array}{l}\text { No. of } \\
\text { partici- } \\
\text { pants }\end{array}$ & Statistical method & Effect size \\
\hline $\begin{array}{l}1 \text { ADAS-Cog (change from baseline at } \\
12 \text { weeks) ITT }\end{array}$ & 4 & & Mean Difference (IV, Fixed, 95\% CI) & Subtotals only \\
\hline 1.1 rivastigmine $(1-4 \mathrm{mg} / \mathrm{d})$ vs placebo & 3 & 1293 & Mean Difference (IV, Fixed, 95\% CI) & $-0.31[-0.87,0.25]$ \\
\hline $\begin{array}{l}1.2 \text { rivastigmine }(6-12 \mathrm{mg} / \mathrm{d}) \text { vs place- } \\
\text { bo }\end{array}$ & 4 & 1917 & Mean Difference (IV, Fixed, 95\% CI) & $\begin{array}{l}-1.49[-1.96 \\
-1.01]\end{array}$ \\
\hline $\begin{array}{l}2 \text { ADAS-Cog (change from baseline at } \\
26 \text { weeks) ITT }\end{array}$ & 5 & & Mean Difference (IV, Fixed, 95\% CI) & Subtotals only \\
\hline 2.1 rivastigmine $(1-4 \mathrm{mg} / \mathrm{d})$ vs placebo & 3 & 1293 & Mean Difference (IV, Fixed, 95\% CI) & $\begin{array}{l}-0.84[-1.48 \\
-0.19]\end{array}$ \\
\hline $\begin{array}{l}2.2 \text { rivastigmine }(6-12 \mathrm{mg} / \mathrm{d}) \text { vs place- } \\
\text { bo }\end{array}$ & 5 & 2451 & Mean Difference (IV, Fixed, 95\% CI) & $\begin{array}{l}-1.99[-2.49 \\
-1.50]\end{array}$ \\
\hline $\begin{array}{l}3 \text { MMSE (change from baseline at } 26 \\
\text { weeks) ITT }\end{array}$ & 5 & & Mean Difference (IV, Fixed, 95\% CI) & Subtotals only \\
\hline 3.1 rivastigmine $(1-4 \mathrm{mg} / \mathrm{d})$ vs placebo & 3 & 1297 & Mean Difference (IV, Fixed, 95\% CI) & $0.43[0.08,0.78]$ \\
\hline $\begin{array}{l}3.2 \text { rivastigmine }(6-12 \mathrm{mg} / \mathrm{d}) \text { vs place- } \\
\text { bo }\end{array}$ & 5 & 2458 & Mean Difference (IV, Fixed, 95\% CI) & $0.82[0.56,1.08]$ \\
\hline $\begin{array}{l}4 \text { SIB (change from baseline at } 26 \\
\text { weeks) }\end{array}$ & 1 & & Mean Difference (IV, Fixed, 95\% CI) & Subtotals only \\
\hline 4.1 Rivastigmine $6-12 \mathrm{mg} /$ day & 1 & 210 & Mean Difference (IV, Fixed, 95\% CI) & $4.53[0.47,8.59]$ \\
\hline $\begin{array}{l}5 \text { ADCS-ADL (change from baseline at } \\
26 \text { weeks) ITT }\end{array}$ & 1 & & Mean Difference (IV, Fixed, 95\% CI) & Subtotals only \\
\hline $\begin{array}{l}5.1 \text { rivastigmine }(6-12 \mathrm{mg} / \mathrm{d}) \text { vs place- } \\
\text { bo }\end{array}$ & 1 & 535 & Mean Difference (IV, Fixed, 95\% CI) & $1.80[0.20,3.40]$ \\
\hline $\begin{array}{l}6 \text { PDS (change from baseline at } 12 \\
\text { weeks) ITT }\end{array}$ & 4 & & Mean Difference (IV, Fixed, 95\% CI) & Subtotals only \\
\hline 6.1 rivastigmine $(1-4 \mathrm{mg} / \mathrm{d})$ vs placebo & 3 & 1288 & Mean Difference (IV, Fixed, 95\% CI) & $-0.77[-1.84,0.30]$ \\
\hline $\begin{array}{l}6.2 \text { rivastigmine }(6-12 \mathrm{mg} / \mathrm{d}) \text { vs place- } \\
\text { bo }\end{array}$ & 4 & 1912 & Mean Difference (IV, Fixed, 95\% CI) & $1.08[0.19,1.98]$ \\
\hline
\end{tabular}




\begin{tabular}{|c|c|c|c|c|}
\hline Outcome or subgroup title & $\begin{array}{l}\text { No. of } \\
\text { studies }\end{array}$ & $\begin{array}{l}\text { No. of } \\
\text { partici- } \\
\text { pants }\end{array}$ & Statistical method & Effect size \\
\hline $\begin{array}{l}7 \text { PDS (change from baseline at } 26 \\
\text { weeks ) ITT }\end{array}$ & 4 & & Mean Difference (IV, Fixed, 95\% CI) & Subtotals only \\
\hline 7.1 rivastigmine $(1-4 \mathrm{mg} / \mathrm{d}$ ) vs placebo & 3 & 1288 & Mean Difference (IV, Fixed, 95\% CI) & $-0.38[-1.61,0.84]$ \\
\hline $\begin{array}{l}7.2 \text { rivastigmine }(6-12 \mathrm{mg} / \mathrm{d}) \text { vs place- } \\
\text { bo }\end{array}$ & 4 & 1912 & Mean Difference (IV, Fixed, 95\% CI) & $2.15[1.13,3.16]$ \\
\hline $\begin{array}{l}8 \text { Clinical Global Impression (no } \\
\text { change or worse at } 12 \text { weeks) ITT }\end{array}$ & 4 & & Peto Odds Ratio (Peto, Fixed, 95\% Cl) & Subtotals only \\
\hline 8.1 rivastigmine $(1-4 \mathrm{mg} / \mathrm{d})$ vs placebo & 3 & 1220 & Peto Odds Ratio (Peto, Fixed, 95\% Cl) & $0.93[0.72,1.21]$ \\
\hline $\begin{array}{l}8.2 \text { rivastigmine }(6-12 \mathrm{mg} / \mathrm{d}) \text { vs place- } \\
\text { bo }\end{array}$ & 4 & 1775 & Peto Odds Ratio (Peto, Fixed, 95\% Cl) & $0.74[0.60,0.92]$ \\
\hline $\begin{array}{l}9 \text { Clinical Global Impression (no } \\
\text { change or worse at } 26 \text { weeks ) ITT }\end{array}$ & 6 & & Peto Odds Ratio (Peto, Fixed, 95\% Cl) & Subtotals only \\
\hline 9.1 rivastigmine $(1-4 \mathrm{mg} / \mathrm{d})$ vs placebo & 3 & 1237 & Peto Odds Ratio (Peto, Fixed, 95\% Cl) & $0.71[0.55,0.93]$ \\
\hline $\begin{array}{l}9.2 \text { rivastigmine }(6-12 \mathrm{mg} / \mathrm{d}) \text { vs place- } \\
\text { bo }\end{array}$ & 6 & 2553 & Peto Odds Ratio (Peto, Fixed, 95\% Cl) & $0.66[0.55,0.79]$ \\
\hline $\begin{array}{l}10 \mathrm{GDS} \text { ( moderately severe, severe, or } \\
\text { very severe dementia at } 26 \text { weeks) ITT }\end{array}$ & 4 & & Peto Odds Ratio (Peto, Fixed, 95\% Cl) & Subtotals only \\
\hline $\begin{array}{l}10.1 \text { rivastigmine }(1-4 \mathrm{mg} / \mathrm{d}) \text { vs place- } \\
\text { bo }\end{array}$ & 3 & 1296 & Peto Odds Ratio (Peto, Fixed, 95\% Cl) & $0.90[0.71,1.14]$ \\
\hline $\begin{array}{l}10.2 \text { rivastigmine }(6-12 \mathrm{mg} / \mathrm{d}) \text { vs place- } \\
\text { bo }\end{array}$ & 4 & 1923 & Peto Odds Ratio (Peto, Fixed, 95\% Cl) & $0.78[0.64,0.94]$ \\
\hline $\begin{array}{l}11 \text { CGIC (little or no improvement, or } \\
\text { worse at } 12 \text { weeks) ITT }\end{array}$ & 1 & & Peto Odds Ratio (Peto, Fixed, 95\% Cl) & Subtotals only \\
\hline $\begin{array}{l}11.1 \text { rivastigmine }(1-4 \mathrm{mg} / \mathrm{d}) \text { vs place- } \\
\text { bo }\end{array}$ & 1 & 269 & Peto Odds Ratio (Peto, Fixed, 95\% Cl) & $1.03[0.60,1.77]$ \\
\hline $\begin{array}{l}11.2 \text { rivastigmine }(6-12 \mathrm{mg} / \mathrm{d}) \text { vs place- } \\
\text { bo }\end{array}$ & 1 & 266 & Peto Odds Ratio (Peto, Fixed, $95 \% \mathrm{Cl}$ ) & $0.72[0.43,1.22]$ \\
\hline $\begin{array}{l}12 \text { Behavioural disturbance NPI-10 or } \\
\text { NPI- } 12 \text { (change from baseline at } 26 \\
\text { weeks) ITT }\end{array}$ & 2 & & Std. Mean Difference (IV, Fixed, 95\% Cl) & Subtotals only \\
\hline $\begin{array}{l}12.1 \text { Rivastigmine ( } 6-12 \mathrm{mg} / \text { day) vs } \\
\text { placebo }\end{array}$ & 2 & 744 & Std. Mean Difference (IV, Fixed, 95\% Cl) & $-0.06[-0.20,0.09]$ \\
\hline $\begin{array}{l}13 \text { withdrawals before end of treat- } \\
\text { ment at } 12 \text { weeks }\end{array}$ & 1 & & Peto Odds Ratio (Peto, Fixed, 95\% Cl) & Subtotals only \\
\hline $\begin{array}{l}13.1 \text { rivastigmine }(1-4 \mathrm{mg} / \mathrm{d}) \text { vs place- } \\
\text { bo }\end{array}$ & 1 & 269 & Peto Odds Ratio (Peto, Fixed, 95\% Cl) & $2.15[0.95,4.89]$ \\
\hline
\end{tabular}




\begin{tabular}{|c|c|c|c|c|}
\hline Outcome or subgroup title & $\begin{array}{l}\text { No. of } \\
\text { studies }\end{array}$ & $\begin{array}{l}\text { No. of } \\
\text { partici- } \\
\text { pants }\end{array}$ & Statistical method & Effect size \\
\hline $\begin{array}{l}13.2 \text { rivastigmine }(6-12 \mathrm{mg} / \mathrm{d}) \text { vs place- } \\
\text { bo }\end{array}$ & 1 & 266 & Peto Odds Ratio (Peto, Fixed, 95\% Cl) & $2.60[1.19,5.67]$ \\
\hline $\begin{array}{l}14 \text { withdrawals before end of treat- } \\
\text { ment at } 26 \text { weeks }\end{array}$ & 6 & & Peto Odds Ratio (Peto, Fixed, 95\% Cl) & Subtotals only \\
\hline $\begin{array}{l}14.1 \text { rivastigmine }(1-4 \mathrm{mg} / \mathrm{d}) \text { vs place- } \\
\text { bo }\end{array}$ & 3 & 1290 & Peto Odds Ratio (Peto, Fixed, 95\% Cl) & $1.01[0.75,1.34]$ \\
\hline $\begin{array}{l}14.2 \text { rivastigmine }(6-12 \mathrm{mg} / \mathrm{d}) \text { vs place- } \\
\text { bo }\end{array}$ & 6 & 2701 & Peto Odds Ratio (Peto, Fixed, 95\% Cl) & $2.19[1.83,2.63]$ \\
\hline $\begin{array}{l}15 \text { at least one adverse event by the } \\
\text { end of titration period }\end{array}$ & 4 & & Peto Odds Ratio (Peto, Fixed, 95\% Cl) & Subtotals only \\
\hline $\begin{array}{l}15.1 \text { rivastigmine }(1-4 \mathrm{mg} / \mathrm{d}) \text { vs place- } \\
\text { bo }\end{array}$ & 3 & 1290 & Peto Odds Ratio (Peto, Fixed, 95\% Cl) & $1.04[0.82,1.31]$ \\
\hline $\begin{array}{l}15.2 \text { rivastigmine }(6-12 \mathrm{mg} / \mathrm{d}) \text { vs place- } \\
\text { bo }\end{array}$ & 4 & 1920 & Peto Odds Ratio (Peto, Fixed, 95\% Cl) & $2.96[2.39,3.68]$ \\
\hline $\begin{array}{l}16 \text { at least one adverse event by } 26 \\
\text { weeks }\end{array}$ & 6 & & Peto Odds Ratio (Peto, Fixed, 95\% Cl) & Subtotals only \\
\hline 16.1 rivastigmine $(1-4 \mathrm{mg} / \mathrm{d})$ vs placebo & 3 & 1290 & Peto Odds Ratio (Peto, Fixed, 95\% Cl) & $0.93[0.71,1.23]$ \\
\hline $\begin{array}{l}16.2 \text { rivastigmine }(6-12 \mathrm{mg} / \mathrm{d}) \text { vs place- } \\
\text { bo }\end{array}$ & 6 & 2726 & Peto Odds Ratio (Peto, Fixed, 95\% Cl) & $2.49[2.05,3.02]$ \\
\hline $\begin{array}{l}17 \text { dropouts due to adverse events by } \\
12 \text { weeks }\end{array}$ & 1 & & Peto Odds Ratio (Peto, Fixed, $95 \% \mathrm{Cl}$ ) & Subtotals only \\
\hline 17.1 rivastigmine $(4 \mathrm{mg} / \mathrm{d})$ vs placebo & 1 & 269 & Peto Odds Ratio (Peto, Fixed, 95\% Cl) & $2.70[1.06,6.84]$ \\
\hline 17.2 rivastigmine $(6 \mathrm{mg} / \mathrm{d})$ vs placebo & 1 & 266 & Peto Odds Ratio (Peto, Fixed, 95\% Cl) & $3.11[1.28,7.56]$ \\
\hline $\begin{array}{l}18 \text { dropouts due to adverse events by } \\
26 \text { weeks }\end{array}$ & 6 & & Peto Odds Ratio (Peto, Fixed, 95\% Cl) & Subtotals only \\
\hline $\begin{array}{l}18.1 \text { rivastigmine }(1-4 \mathrm{mg} / \mathrm{d}) \text { vs place- } \\
\text { bo }\end{array}$ & 3 & 1290 & Peto Odds Ratio (Peto, Fixed, 95\% Cl) & $1.03[0.69,1.52]$ \\
\hline $\begin{array}{l}18.2 \text { rivastigmine }(6-12 \mathrm{mg} / \mathrm{d}) \text { vs place- } \\
\text { bo }\end{array}$ & 6 & 2729 & Peto Odds Ratio (Peto, Fixed, 95\% Cl) & $2.73[2.19,3.41]$ \\
\hline $\begin{array}{l}19 \text { at least one adverse event of de- } \\
\text { creased appetite by } 26 \text { weeks }\end{array}$ & 1 & & Peto Odds Ratio (Peto, Fixed, 95\% Cl) & Subtotals only \\
\hline $\begin{array}{l}19.1 \text { rivastigmine }(6-12 \mathrm{mg} / \mathrm{d}) \text { vs place- } \\
\text { bo }\end{array}$ & 1 & 596 & Peto Odds Ratio (Peto, Fixed, 95\% Cl) & $3.51[1.26,9.79]$ \\
\hline $\begin{array}{l}20 \text { at least one adverse event of weight } \\
\text { decrease by } 26 \text { weeks }\end{array}$ & 1 & & Peto Odds Ratio (Peto, Fixed, 95\% Cl) & Subtotals only \\
\hline
\end{tabular}




\begin{tabular}{|c|c|c|c|c|}
\hline Outcome or subgroup title & $\begin{array}{l}\text { No. of } \\
\text { studies }\end{array}$ & $\begin{array}{l}\text { No. of } \\
\text { partici- } \\
\text { pants }\end{array}$ & Statistical method & Effect size \\
\hline $\begin{array}{l}20.1 \text { rivastigmine }(6-12 \mathrm{mg} / \mathrm{d}) \text { vs place- } \\
\text { bo }\end{array}$ & 1 & 596 & Peto Odds Ratio (Peto, Fixed, 95\% Cl) & $3.55[1.46,8.66]$ \\
\hline $\begin{array}{l}21 \text { at least one adverse event of nausea } \\
\text { by the end of titration period }\end{array}$ & 5 & & Peto Odds Ratio (Peto, Fixed, 95\% Cl) & Subtotals only \\
\hline 21.1 rivastigmine $(1-4 \mathrm{mg} / \mathrm{d})$ vs placebo & 4 & 1559 & Peto Odds Ratio (Peto, Fixed, 95\% Cl) & $1.85[1.36,2.52]$ \\
\hline $\begin{array}{l}21.2 \text { rivastigmine }(6-12 \mathrm{mg} / \mathrm{d}) \text { vs place- } \\
\text { bo }\end{array}$ & 5 & 2186 & Peto Odds Ratio (Peto, Fixed, 95\% Cl) & $5.57[4.59,6.75]$ \\
\hline $\begin{array}{l}22 \text { at least one adverse event of nausea } \\
\text { by } 26 \text { weeks }\end{array}$ & 6 & & Peto Odds Ratio (Peto, Fixed, 95\% Cl) & Subtotals only \\
\hline 22.1 rivastigmine $(1-4 \mathrm{mg} / \mathrm{d})$ vs placebo & 3 & 1290 & Peto Odds Ratio (Peto, Fixed, 95\% Cl) & $1.74[1.28,2.36]$ \\
\hline $\begin{array}{l}22.2 \text { rivastigmine }(6-12 \mathrm{mg} / \mathrm{d} \text { bid }) \text { vs } \\
\text { placebo }\end{array}$ & 6 & 2726 & Peto Odds Ratio (Peto, Fixed, 95\% Cl) & $5.36[4.50,6.40]$ \\
\hline $\begin{array}{l}23 \text { at least one adverse event of vomit- } \\
\text { ing by the end of titration period }\end{array}$ & 5 & & Peto Odds Ratio (Peto, Fixed, 95\% Cl) & Subtotals only \\
\hline 23.1 rivastigmine $(1-4 \mathrm{mg} / \mathrm{d})$ vs placebo & 4 & 1559 & Peto Odds Ratio (Peto, Fixed, 95\% Cl) & $1.97[1.22,3.16]$ \\
\hline $\begin{array}{l}23.2 \text { rivastigmine }(6-12 \mathrm{mg} / \mathrm{d}) \text { vs place- } \\
\text { bo }\end{array}$ & 5 & 2187 & Peto Odds Ratio (Peto, Fixed, 95\% Cl) & $5.72[4.48,7.29]$ \\
\hline $\begin{array}{l}24 \text { at least one adverse event of vomit- } \\
\text { ing by } 26 \text { weeks }\end{array}$ & 6 & & Peto Odds Ratio (Peto, Fixed, 95\% Cl) & Subtotals only \\
\hline 24.1 rivastigmine $(1-4 \mathrm{mg} / \mathrm{d})$ vs placebo & 3 & 1290 & Peto Odds Ratio (Peto, Fixed, 95\% Cl) & $1.65[1.08,2.52]$ \\
\hline $\begin{array}{l}24.2 \text { rivastigmine }(6-12 \mathrm{mg} / \mathrm{d}) \text { vs place- } \\
\text { bo }\end{array}$ & 6 & 2726 & Peto Odds Ratio (Peto, Fixed, 95\% Cl) & $5.15[4.20,6.32]$ \\
\hline $\begin{array}{l}25 \text { at least one adverse event of diar- } \\
\text { rhoea by the end of titration period }\end{array}$ & 5 & & Peto Odds Ratio (Peto, Fixed, 95\% Cl) & Subtotals only \\
\hline 25.1 rivastigmine $(1-4 \mathrm{mg} / \mathrm{d})$ vs placebo & 4 & 1559 & Peto Odds Ratio (Peto, Fixed, 95\% Cl) & $0.99[0.68,1.42]$ \\
\hline $\begin{array}{l}25.2 \text { rivastigmine }(6-12 \mathrm{mg} / \mathrm{d}) \text { vs place- } \\
\text { bo }\end{array}$ & 5 & 2186 & Peto Odds Ratio (Peto, Fixed, 95\% Cl) & $1.97[1.51,2.57]$ \\
\hline $\begin{array}{l}26 \text { at least one adverse event of diar- } \\
\text { rhoea by } 26 \text { weeks }\end{array}$ & 5 & & Peto Odds Ratio (Peto, Fixed, 95\% Cl) & Subtotals only \\
\hline 26.1 rivastigmine $(1-4 \mathrm{mg} / \mathrm{d})$ vs placebo & 3 & 1290 & Peto Odds Ratio (Peto, Fixed, 95\% Cl) & $0.93[0.67,1.31]$ \\
\hline $\begin{array}{l}26.2 \text { rivastigmine }(6-12 \mathrm{mg} / \mathrm{d}) \text { vs place- } \\
\text { bo }\end{array}$ & 5 & 2516 & Peto Odds Ratio (Peto, Fixed, 95\% Cl) & $1.76[1.39,2.24]$ \\
\hline $\begin{array}{l}27 \text { at least one adverse event of } \\
\text { anorexia by the end of titration period }\end{array}$ & 4 & & Peto Odds Ratio (Peto, Fixed, 95\% Cl) & Subtotals only \\
\hline
\end{tabular}




\begin{tabular}{|c|c|c|c|c|}
\hline Outcome or subgroup title & $\begin{array}{l}\text { No. of } \\
\text { studies }\end{array}$ & $\begin{array}{l}\text { No. of } \\
\text { partici- } \\
\text { pants }\end{array}$ & Statistical method & Effect size \\
\hline 27.1 rivastigmine $(1-4 \mathrm{mg} / \mathrm{d})$ vs placebo & 3 & 1290 & Peto Odds Ratio (Peto, Fixed, 95\% Cl) & $2.21[1.24,3.95]$ \\
\hline $\begin{array}{l}27.2 \text { rivastigmine }(6-12 \mathrm{mg} / \mathrm{d}) \text { vs place- } \\
\text { bo }\end{array}$ & 4 & 1920 & Peto Odds Ratio (Peto, Fixed, 95\% Cl) & $4.94[3.56,6.85]$ \\
\hline $\begin{array}{l}28 \text { at least one adverse event of } \\
\text { anorexia by } 26 \text { weeks }\end{array}$ & 5 & & Peto Odds Ratio (Peto, Fixed, 95\% Cl) & Subtotals only \\
\hline 28.1 rivastigmine $(1-4 \mathrm{mg} / \mathrm{d})$ vs placebo & 3 & 1290 & Peto Odds Ratio (Peto, Fixed, 95\% Cl) & $2.13[1.29,3.52]$ \\
\hline $\begin{array}{l}28.2 \text { rivastigmine }(6-12 \mathrm{mg} / \mathrm{d}) \text { vs place- } \\
\text { bo }\end{array}$ & 5 & 2130 & Peto Odds Ratio (Peto, Fixed, 95\% Cl) & $4.46[3.34,5.95]$ \\
\hline $\begin{array}{l}29 \text { at least one adverse event of } \\
\text { headache by the end of titration period }\end{array}$ & 5 & & Peto Odds Ratio (Peto, Fixed, 95\% Cl) & Subtotals only \\
\hline 29.1 rivastigmine $(1-4 \mathrm{mg} / \mathrm{d})$ vs placebo & 4 & 1559 & Peto Odds Ratio (Peto, Fixed, 95\% Cl) & $0.97[0.69,1.37]$ \\
\hline $\begin{array}{l}29.2 \text { rivastigmine }(6-12 \mathrm{mg} / \mathrm{d}) \text { vs place- } \\
\text { bo }\end{array}$ & 5 & 2186 & Peto Odds Ratio (Peto, Fixed, 95\% Cl) & $1.64[1.26,2.14]$ \\
\hline $\begin{array}{l}30 \text { at least one adverse event of } \\
\text { headache by } 26 \text { weeks }\end{array}$ & 5 & & Peto Odds Ratio (Peto, Fixed, 95\% Cl) & Subtotals only \\
\hline 30.1 rivastigmine $(1-4 \mathrm{mg} / \mathrm{d})$ vs placebo & 3 & 1290 & Peto Odds Ratio (Peto, Fixed, 95\% Cl) & $1.17[0.84,1.64]$ \\
\hline $\begin{array}{l}30.2 \text { rivastigmine }(6-12 \mathrm{mg} / \mathrm{d}) \text { vs place- } \\
\text { bo }\end{array}$ & 5 & 2516 & Peto Odds Ratio (Peto, Fixed, 95\% Cl) & $1.72[1.34,2.21]$ \\
\hline $\begin{array}{l}31 \text { at least one adverse event of insom- } \\
\text { nia by the end of titration period }\end{array}$ & 4 & & Peto Odds Ratio (Peto, Fixed, 95\% Cl) & Subtotals only \\
\hline 31.1 rivastigmine $(1-4 \mathrm{mg} / \mathrm{d})$ vs placebo & 3 & 1290 & Peto Odds Ratio (Peto, Fixed, 95\% Cl) & $1.04[0.64,1.67]$ \\
\hline $\begin{array}{l}31.2 \text { rivastigmine }(6-12 \mathrm{mg} / \mathrm{d}) \text { vs place- } \\
\text { bo }\end{array}$ & 4 & 1920 & Peto Odds Ratio (Peto, Fixed, 95\% Cl) & $1.40[0.94,2.09]$ \\
\hline $\begin{array}{l}32 \text { at least one adverse event of insom- } \\
\text { nia by } 26 \text { weeks }\end{array}$ & 4 & & Peto Odds Ratio (Peto, Fixed, 95\% Cl) & Subtotals only \\
\hline 32.1 rivastigmine $(1-4 \mathrm{mg} / \mathrm{d})$ vs placebo & 3 & 1290 & Peto Odds Ratio (Peto, Fixed, 95\% Cl) & $1.05[0.70,1.58]$ \\
\hline $\begin{array}{l}32.2 \text { rivastigmine }(6-12 \mathrm{mg} / \mathrm{d}) \text { vs place- } \\
\text { bo }\end{array}$ & 4 & 1920 & Peto Odds Ratio (Peto, Fixed, 95\% Cl) & $1.33[0.95,1.87]$ \\
\hline $\begin{array}{l}33 \text { at least one adverse event of syn- } \\
\text { cope by the end of titration period }\end{array}$ & 4 & & Peto Odds Ratio (Peto, Fixed, 95\% Cl) & Subtotals only \\
\hline 33.1 rivastigmine $(1-4 \mathrm{mg} / \mathrm{d})$ vs placebo & 3 & 1290 & Peto Odds Ratio (Peto, Fixed, 95\% Cl) & $1.50[0.43,5.20]$ \\
\hline $\begin{array}{l}33.2 \text { rivastigmine }(6-12 \mathrm{mg} / \mathrm{d}) \text { vs place- } \\
\text { bo }\end{array}$ & 4 & 1920 & Peto Odds Ratio (Peto, Fixed, 95\% Cl) & $2.16[0.99,4.68]$ \\
\hline
\end{tabular}




\begin{tabular}{|c|c|c|c|c|}
\hline Outcome or subgroup title & $\begin{array}{l}\text { No. of } \\
\text { studies }\end{array}$ & $\begin{array}{l}\text { No. of } \\
\text { partici- } \\
\text { pants }\end{array}$ & Statistical method & Effect size \\
\hline $\begin{array}{l}34 \text { at least one adverse event of syn- } \\
\text { cope by } 26 \text { weeks }\end{array}$ & 4 & & Peto Odds Ratio (Peto, Fixed, 95\% Cl) & Subtotals only \\
\hline 34.1 rivastigmine $(1-4 \mathrm{mg} / \mathrm{d})$ vs placebo & 3 & 1290 & Peto Odds Ratio (Peto, Fixed, 95\% Cl) & $1.00[0.37,2.69]$ \\
\hline $\begin{array}{l}34.2 \text { rivastigmine }(6-12 \mathrm{mg} / \mathrm{d} \text { bid) vs } \\
\text { placebo }\end{array}$ & 4 & 1920 & Peto Odds Ratio (Peto, Fixed, 95\% Cl) & $1.72[0.96,3.11]$ \\
\hline $\begin{array}{l}35 \text { at least one adverse event of ab- } \\
\text { dominal pain by the end of titration } \\
\text { period }\end{array}$ & 5 & & Peto Odds Ratio (Peto, Fixed, 95\% Cl) & Subtotals only \\
\hline 35.1 rivastigmine $(1-4 \mathrm{mg} / \mathrm{d})$ vs placebo & 4 & 1559 & Peto Odds Ratio (Peto, Fixed, 95\% Cl) & $1.16[0.72,1.88]$ \\
\hline $\begin{array}{l}35.2 \text { rivastigmine }(6-12 \mathrm{mg} / \mathrm{d}) \text { vs place- } \\
\text { bo }\end{array}$ & 5 & 2186 & Peto Odds Ratio (Peto, Fixed, 95\% Cl) & $2.50[1.80,3.48]$ \\
\hline $\begin{array}{l}36 \text { at least one adverse event of ab- } \\
\text { dominal pain by } 26 \text { weeks }\end{array}$ & 4 & & Peto Odds Ratio (Peto, Fixed, 95\% Cl) & Subtotals only \\
\hline 36.1 rivastigmine $(1-4 \mathrm{mg} / \mathrm{d})$ vs placebo & 3 & 1290 & Peto Odds Ratio (Peto, Fixed, 95\% Cl) & $1.20[0.77,1.87]$ \\
\hline $\begin{array}{l}36.2 \text { rivastigmine }(6-12 \mathrm{mg} / \mathrm{d}) \text { vs place- } \\
\text { bo }\end{array}$ & 4 & 1920 & Peto Odds Ratio (Peto, Fixed, 95\% Cl) & $2.24[1.65,3.05]$ \\
\hline $\begin{array}{l}37 \text { at least one adverse event of dizzi- } \\
\text { ness by the end of titration period }\end{array}$ & 5 & & Peto Odds Ratio (Peto, Fixed, 95\% Cl) & Subtotals only \\
\hline 37.1 rivastigmine $(1-4 \mathrm{mg} / \mathrm{d})$ vs placebo & 4 & 1559 & Peto Odds Ratio (Peto, Fixed, 95\% Cl) & $0.99[0.70,1.39]$ \\
\hline $\begin{array}{l}37.2 \text { rivastigmine }(6-12 \mathrm{mg} / \mathrm{d}) \text { vs place- } \\
\text { bo }\end{array}$ & 5 & 2186 & Peto Odds Ratio (Peto, Fixed, 95\% Cl) & $2.38[1.86,3.04]$ \\
\hline $\begin{array}{l}38 \text { at least one adverse event of dizzi- } \\
\text { ness by } 26 \text { weeks }\end{array}$ & 5 & & Peto Odds Ratio (Peto, Fixed, 95\% Cl) & Subtotals only \\
\hline 38.1 rivastigmine $(1-4 \mathrm{mg} / \mathrm{d})$ vs placebo & 3 & 1290 & Peto Odds Ratio (Peto, Fixed, 95\% Cl) & $1.25[0.91,1.72]$ \\
\hline $\begin{array}{l}38.2 \text { rivastigmine }(6-12 \mathrm{mg} / \mathrm{d}) \text { vs place- } \\
\text { bo }\end{array}$ & 5 & 2516 & Peto Odds Ratio (Peto, Fixed, 95\% Cl) & $2.24[1.78,2.82]$ \\
\hline $\begin{array}{l}39 \text { at least one adverse event of bone } \\
\text { fracture by the end of titration period }\end{array}$ & 4 & & Peto Odds Ratio (Peto, Fixed, 95\% Cl) & Subtotals only \\
\hline 39.1 rivastigmine $(1-4 \mathrm{mg} / \mathrm{d})$ vs placebo & 3 & 1290 & Peto Odds Ratio (Peto, Fixed, 95\% Cl) & $0.83[0.25,2.72]$ \\
\hline $\begin{array}{l}39.2 \text { rivastigmine }(6-12 \mathrm{mg} / \mathrm{d}) \text { vs place- } \\
\text { bo }\end{array}$ & 4 & 1920 & Peto Odds Ratio (Peto, Fixed, 95\% Cl) & $0.95[0.37,2.46]$ \\
\hline $\begin{array}{l}40 \text { at least one adverse event of bone } \\
\text { fracture by } 26 \text { weeks }\end{array}$ & 4 & & Peto Odds Ratio (Peto, Fixed, 95\% Cl) & Subtotals only \\
\hline 40.1 rivastigmine $(1-4 \mathrm{mg} / \mathrm{d})$ vs placebo & 3 & 1290 & Peto Odds Ratio (Peto, Fixed, 95\% Cl) & $0.60[0.27,1.34]$ \\
\hline
\end{tabular}




\begin{tabular}{|c|c|c|c|c|}
\hline Outcome or subgroup title & $\begin{array}{l}\text { No. of } \\
\text { studies }\end{array}$ & $\begin{array}{l}\text { No. of } \\
\text { partici- } \\
\text { pants }\end{array}$ & Statistical method & Effect size \\
\hline $\begin{array}{l}40.2 \text { rivastigmine }(6-12 \mathrm{mg} / \mathrm{d}) \text { vs place- } \\
\text { bo }\end{array}$ & 4 & 1920 & Peto Odds Ratio (Peto, Fixed, 95\% Cl) & $0.70[0.34,1.42]$ \\
\hline $\begin{array}{l}41 \text { at least one adverse event of asthe- } \\
\text { nia by } 26 \text { weeks }\end{array}$ & 1 & & Peto Odds Ratio (Peto, Fixed, 95\% Cl) & Subtotals only \\
\hline $\begin{array}{l}41.1 \text { rivastigmine }(6-12 \mathrm{mg} / \mathrm{d}) \text { vs place- } \\
\text { bo }\end{array}$ & 1 & 596 & Peto Odds Ratio (Peto, Fixed, 95\% Cl) & $4.37[1.79,10.65]$ \\
\hline $\begin{array}{l}42 \text { at least one severe adverse event by } \\
\text { the end of titration period }\end{array}$ & 4 & & Peto Odds Ratio (Peto, Fixed, 95\% Cl) & Subtotals only \\
\hline 42.1 rivastigmine $(1-4 \mathrm{mg} / \mathrm{d})$ vs placebo & 3 & 1290 & Peto Odds Ratio (Peto, Fixed, 95\% Cl) & $0.94[0.62,1.42]$ \\
\hline $\begin{array}{l}42.2 \text { rivastigmine }(6-12 \mathrm{mg} / \mathrm{d}) \text { vs place- } \\
\text { bo }\end{array}$ & 4 & 1920 & Peto Odds Ratio (Peto, Fixed, 95\% Cl) & $1.88[1.39,2.55]$ \\
\hline $\begin{array}{l}43 \text { at least one serious adverse event } \\
\text { by } 26 \text { weeks }\end{array}$ & 6 & & Peto Odds Ratio (Peto, Fixed, 95\% Cl) & Subtotals only \\
\hline 43.1 rivastigmine $(1-4 \mathrm{mg} / \mathrm{d})$ vs placebo & 3 & 1290 & Peto Odds Ratio (Peto, Fixed, 95\% Cl) & $0.98[0.70,1.36]$ \\
\hline $\begin{array}{l}43.2 \text { rivastigmine }(6-12 \mathrm{mg} / \mathrm{d}) \text { vs place- } \\
\text { bo }\end{array}$ & 6 & 2726 & Peto Odds Ratio (Peto, Fixed, 95\% Cl) & $1.17[0.93,1.47]$ \\
\hline $\begin{array}{l}44 \text { deaths before end of treatment at } \\
12 \text { weeks }\end{array}$ & 1 & & Peto Odds Ratio (Peto, Fixed, 95\% Cl) & Subtotals only \\
\hline 44.1 rivastigmine $(1-4 \mathrm{mg} / \mathrm{d})$ vs placebo & 1 & 269 & Peto Odds Ratio (Peto, Fixed, 95\% Cl) & $7.34[0.76,71.14]$ \\
\hline $\begin{array}{l}44.2 \text { rivastigmine }(6-12 \mathrm{mg} / \mathrm{d}) \text { vs place- } \\
\text { bo }\end{array}$ & 1 & 266 & Peto Odds Ratio (Peto, Fixed, 95\% Cl) & $\begin{array}{l}7.45[0.46 \\
119.66]\end{array}$ \\
\hline $\begin{array}{l}45 \text { deaths before end of treatment at } \\
26 \text { weeks }\end{array}$ & 6 & & Peto Odds Ratio (Peto, Fixed, 95\% Cl) & Subtotals only \\
\hline 45.1 rivastigmine $(1-4 \mathrm{mg} / \mathrm{d})$ vs placebo & 3 & 1290 & Peto Odds Ratio (Peto, Fixed, 95\% Cl) & $1.98[0.20,19.15]$ \\
\hline $\begin{array}{l}45.2 \text { rivastigmine }(6-12 \mathrm{mg} / \mathrm{d}) \text { vs place- } \\
\text { bo }\end{array}$ & 6 & 2737 & Peto Odds Ratio (Peto, Fixed, 95\% Cl) & $1.16[0.40,3.37]$ \\
\hline $\begin{array}{l}46 \text { CIBIC-Plus (no change or worse at } \\
12 \text { weeks) OC }\end{array}$ & 4 & & Peto Odds Ratio (Peto, Fixed, 95\% Cl) & Subtotals only \\
\hline 46.1 rivastigmine $(1-4 \mathrm{mg} / \mathrm{d})$ vs placebo & 3 & 1179 & Peto Odds Ratio (Peto, Fixed, 95\% Cl) & $0.95[0.72,1.23]$ \\
\hline $\begin{array}{l}46.2 \text { rivastigmine }(6-12 \mathrm{mg} / \mathrm{d}) \text { vs place- } \\
\text { bo }\end{array}$ & 4 & 1630 & Peto Odds Ratio (Peto, Fixed, 95\% Cl) & $0.72[0.58,0.91]$ \\
\hline $\begin{array}{l}47 \text { CIBIC-Plus (no change or worse at } \\
26 \text { weeks) OC }\end{array}$ & 4 & & Peto Odds Ratio (Peto, Fixed, 95\% Cl) & Subtotals only \\
\hline 47.1 rivastigmine $(1-4 \mathrm{mg} / \mathrm{d})$ vs placebo & 3 & 1036 & Peto Odds Ratio (Peto, Fixed, 95\% Cl) & $0.67[0.50,0.89]$ \\
\hline
\end{tabular}




\begin{tabular}{|c|c|c|c|c|}
\hline Outcome or subgroup title & $\begin{array}{l}\text { No. of } \\
\text { studies }\end{array}$ & $\begin{array}{l}\text { No. of } \\
\text { partici- } \\
\text { pants }\end{array}$ & Statistical method & Effect size \\
\hline $\begin{array}{l}47.2 \text { rivastigmine }(6-12 \mathrm{mg} / \mathrm{d}) \text { vs place- } \\
\text { bo }\end{array}$ & 4 & 1353 & Peto Odds Ratio (Peto, Fixed, 95\% Cl) & $0.63[0.49,0.81]$ \\
\hline $\begin{array}{l}48 \text { CIBIC-Plus (no change or worse at } \\
12 \text { weeks) OC+RDO }\end{array}$ & 4 & & Peto Odds Ratio (Peto, Fixed, 95\% Cl) & Subtotals only \\
\hline 48.1 rivastigmine $(1-4 \mathrm{mg} / \mathrm{d})$ vs placebo & 3 & 1221 & Peto Odds Ratio (Peto, Fixed, 95\% Cl) & $0.94[0.72,1.22]$ \\
\hline $\begin{array}{l}48.2 \text { rivastigmine }(6-12 \mathrm{mg} / \mathrm{d}) \text { vs place- } \\
\text { bo }\end{array}$ & 4 & 1777 & Peto Odds Ratio (Peto, Fixed, 95\% Cl) & $0.75[0.60,0.93]$ \\
\hline $\begin{array}{l}49 \text { CIBIC-Plus (no change or worse at } \\
26 \text { weeks)OC+RDO }\end{array}$ & 4 & & Peto Odds Ratio (Peto, Fixed, 95\% Cl) & Subtotals only \\
\hline 49.1 rivastigmine $(1-4 \mathrm{mg} / \mathrm{d})$ vs placebo & 3 & 1093 & Peto Odds Ratio (Peto, Fixed, 95\% Cl) & $0.68[0.52,0.91]$ \\
\hline $\begin{array}{l}49.2 \text { rivastigmine }(6-12 \mathrm{mg} / \mathrm{d}) \text { vs place- } \\
\text { bo }\end{array}$ & 4 & 1542 & Peto Odds Ratio (Peto, Fixed, 95\% Cl) & $0.65[0.51,0.82]$ \\
\hline $\begin{array}{l}50 \text { CIBIC-Plus (no change or worse at } \\
12 \text { weeks) ALL+OC }\end{array}$ & 4 & & Peto Odds Ratio (Peto, Fixed, 95\% Cl) & Subtotals only \\
\hline 50.1 rivastigmine $(1-4 \mathrm{mg} / \mathrm{d})$ vs placebo & 3 & 1293 & Peto Odds Ratio (Peto, Fixed, 95\% Cl) & $1.00[0.77,1.30]$ \\
\hline $\begin{array}{l}50.2 \text { rivastigmine }(6-12 \mathrm{mg} / \mathrm{d}) \text { vs place- } \\
\text { bo }\end{array}$ & 4 & 1917 & Peto Odds Ratio (Peto, Fixed, 95\% Cl) & $0.90[0.72,1.13]$ \\
\hline $\begin{array}{l}51 \text { CIBIC-Plus (no change or worse at } \\
26 \text { weeks) ALL+OC }\end{array}$ & 4 & & Peto Odds Ratio (Peto, Fixed, 95\% Cl) & Subtotals only \\
\hline 51.1 rivastigmine $(1-4 \mathrm{mg} / \mathrm{d})$ vs placebo & 3 & 1297 & Peto Odds Ratio (Peto, Fixed, 95\% CI) & $0.73[0.55,0.96]$ \\
\hline $\begin{array}{l}51.2 \text { rivastigmine }(6-12 \mathrm{mg} / \mathrm{d}) \text { vs place- } \\
\text { bo }\end{array}$ & 4 & 1921 & Peto Odds Ratio (Peto, Fixed, 95\% Cl) & $0.88[0.69,1.12]$ \\
\hline $\begin{array}{l}52 \text { ADAS-Cog (change from baseline at } \\
12 \text { weeks) OC }\end{array}$ & 4 & & Mean Difference (IV, Fixed, 95\% CI) & Subtotals only \\
\hline 52.1 rivastigmine $(1-4 \mathrm{mg} / \mathrm{d})$ vs placebo & 3 & 1187 & Mean Difference (IV, Fixed, 95\% CI) & $-0.46[-1.08,0.15]$ \\
\hline $\begin{array}{l}52.2 \text { rivastigmine }(6-12 \mathrm{mg} / \mathrm{d}) \text { vs place- } \\
\text { bo }\end{array}$ & 4 & 1646 & Mean Difference (IV, Fixed, 95\% Cl) & $\begin{array}{l}-1.80[-2.33 \\
-1.27]\end{array}$ \\
\hline $\begin{array}{l}53 \text { ADAS-Cog (change from baseline at } \\
26 \text { weeks) OC }\end{array}$ & 4 & & Mean Difference (IV, Fixed, 95\% CI) & Subtotals only \\
\hline 53.1 rivastigmine $(1-4 \mathrm{mg} / \mathrm{d})$ vs placebo & 3 & 1045 & Mean Difference (IV, Fixed, 95\% CI) & $\begin{array}{l}-0.97[-1.72 \\
-0.21]\end{array}$ \\
\hline $\begin{array}{l}53.2 \text { rivastigmine }(6-12 \mathrm{mg} / \mathrm{d}) \text { vs place- } \\
\text { bo }\end{array}$ & 4 & 1379 & Mean Difference (IV, Fixed, 95\% CI) & $\begin{array}{l}-2.62[-3.29 \\
-1.94]\end{array}$ \\
\hline $\begin{array}{l}54 \text { ADAS-Cog (change from baseline at } \\
12 \text { weeks) OC+RDO }\end{array}$ & 4 & & Mean Difference (IV, Fixed, 95\% CI) & Subtotals only \\
\hline
\end{tabular}




\begin{tabular}{|c|c|c|c|c|}
\hline Outcome or subgroup title & $\begin{array}{l}\text { No. of } \\
\text { studies }\end{array}$ & $\begin{array}{l}\text { No. of } \\
\text { partici- } \\
\text { pants }\end{array}$ & Statistical method & Effect size \\
\hline 54.1 rivastigmine $(1-4 \mathrm{mg} / \mathrm{d})$ vs placebo & 3 & 1231 & Mean Difference (IV, Fixed, 95\% Cl) & $-0.37[-0.96,0.23]$ \\
\hline $\begin{array}{l}54.2 \text { rivastigmine }(6-12 \mathrm{mg} / \mathrm{d}) \text { vs place- } \\
\text { bo }\end{array}$ & 4 & 1795 & Mean Difference (IV, Fixed, 95\% Cl) & $\begin{array}{l}-1.38[-1.89 \\
-0.88]\end{array}$ \\
\hline $\begin{array}{l}55 \text { ADAS-Cog (change from baseline at } \\
26 \text { weeks) OC+RDO }\end{array}$ & 4 & & Mean Difference (IV, Fixed, 95\% Cl) & Subtotals only \\
\hline 55.1 rivastigmine $(1-4 \mathrm{mg} / \mathrm{d})$ vs placebo & 3 & 1123 & Mean Difference (IV, Fixed, 95\% Cl) & $\begin{array}{l}-1.07[-1.80 \\
-0.34]\end{array}$ \\
\hline $\begin{array}{l}55.2 \text { rivastigmine }(6-12 \mathrm{mg} / \mathrm{d}) \text { vs place- } \\
\text { bo }\end{array}$ & 4 & 1547 & Mean Difference (IV, Fixed, 95\% Cl) & $\begin{array}{l}-2.39[-3.03 \\
-1.74]\end{array}$ \\
\hline
\end{tabular}

\section{Analysis 2.1. Comparison 2 Rivastigmine oral capsules ( 1 to $4 \mathrm{mg} /$ day or 6 to $12 \mathrm{mg} /$ day in two divided doses) versus placebo, Outcome 1 ADAS-Cog (change from baseline at 12 weeks) ITT.}

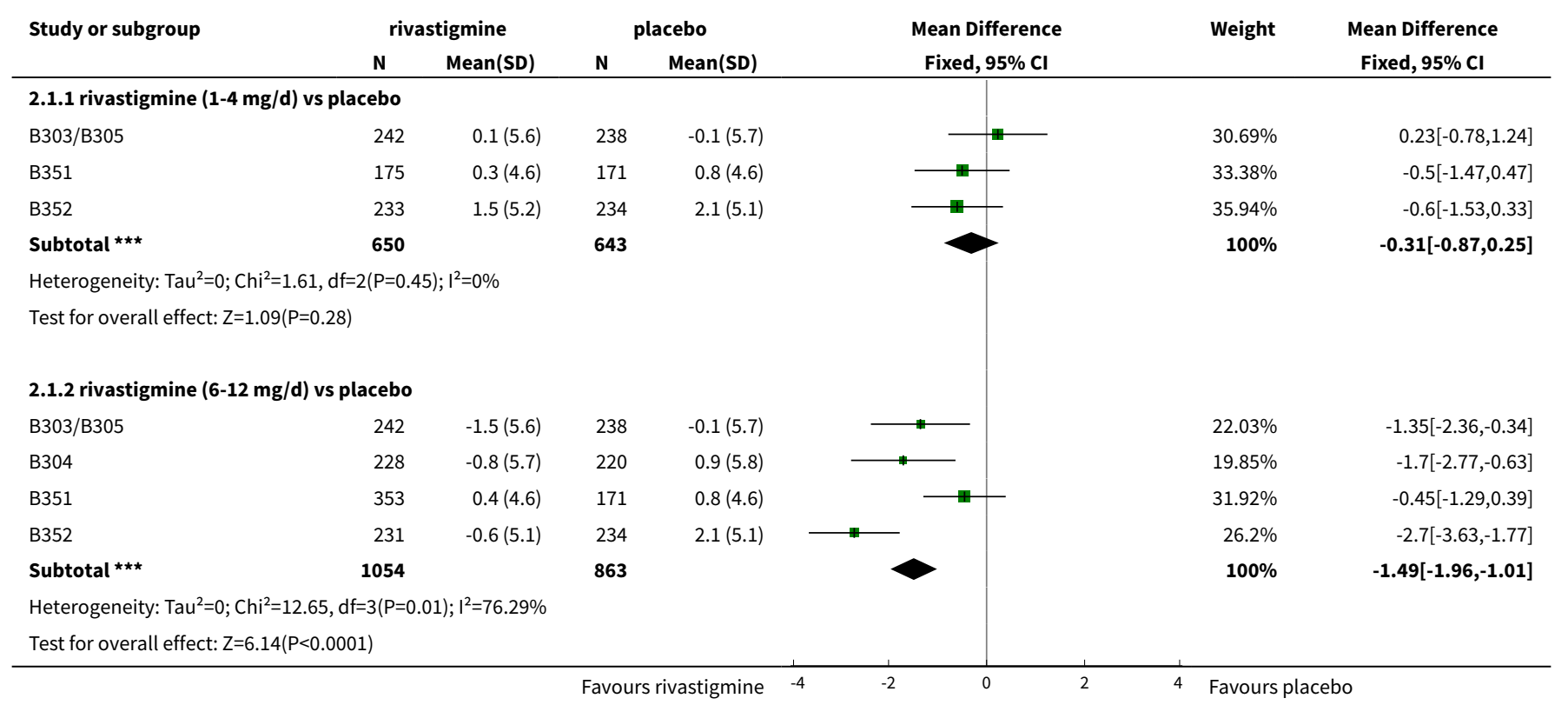

Analysis 2.2. Comparison 2 Rivastigmine oral capsules (1 to $4 \mathrm{mg} / \mathrm{day}$ or 6 to $12 \mathrm{mg} / \mathrm{day}$ in two divided doses) versus placebo, Outcome 2 ADAS-Cog (change from baseline at 26 weeks) ITT.

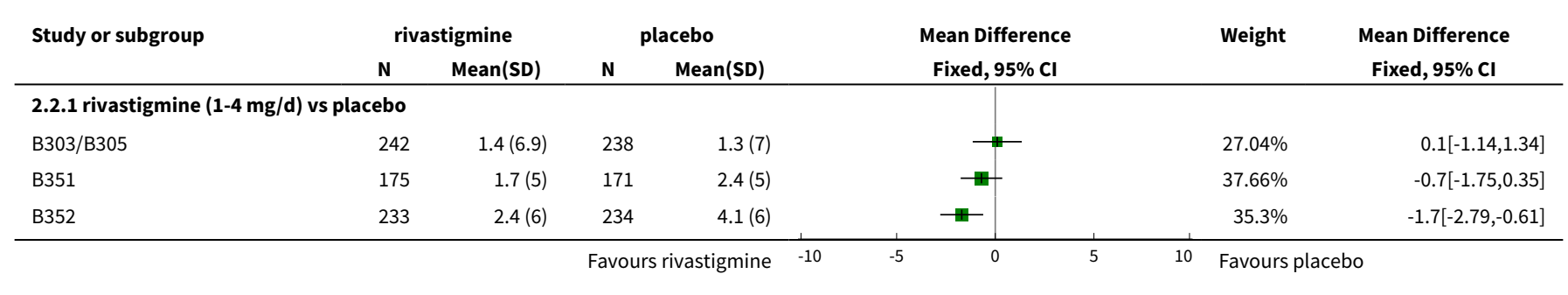




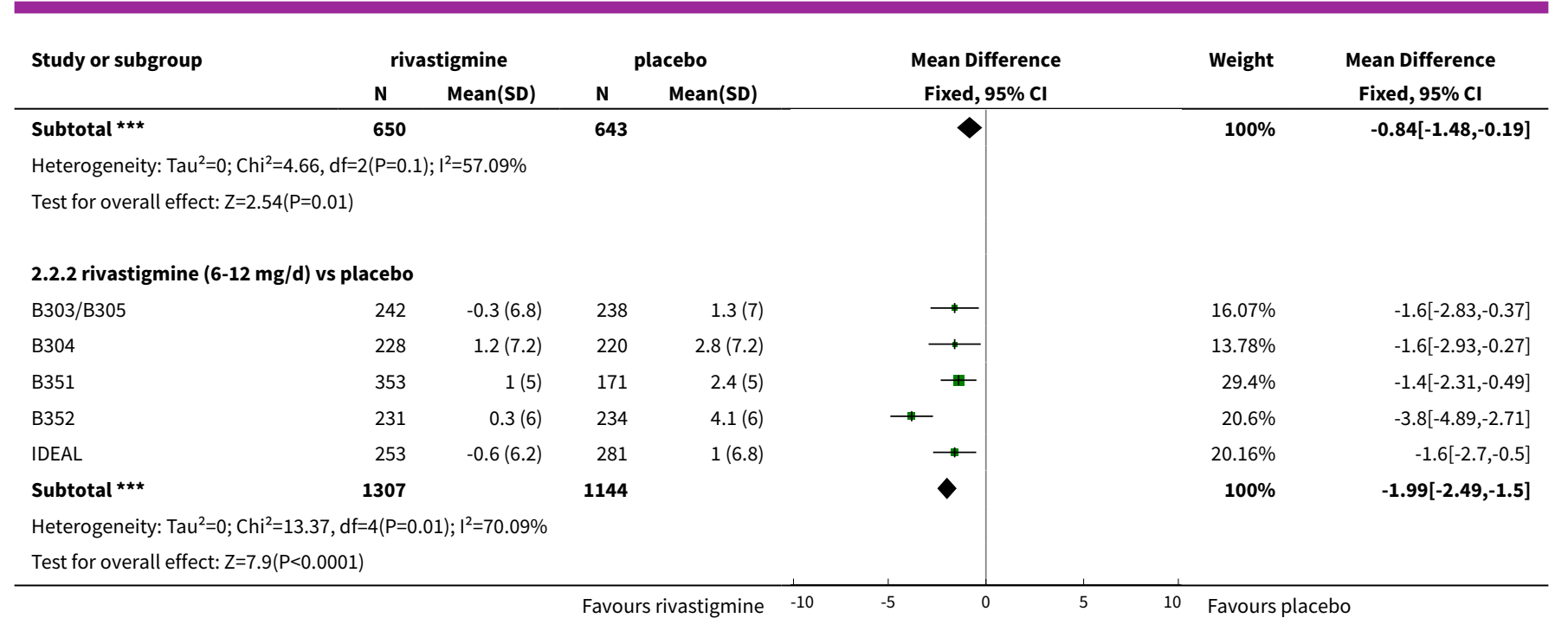

Analysis 2.3. Comparison 2 Rivastigmine oral capsules (1 to $4 \mathrm{mg} / \mathrm{day}$ or 6 to $12 \mathrm{mg} / \mathrm{day}$ in two divided doses) versus placebo, Outcome 3 MMSE (change from baseline at 26 weeks) ITT.

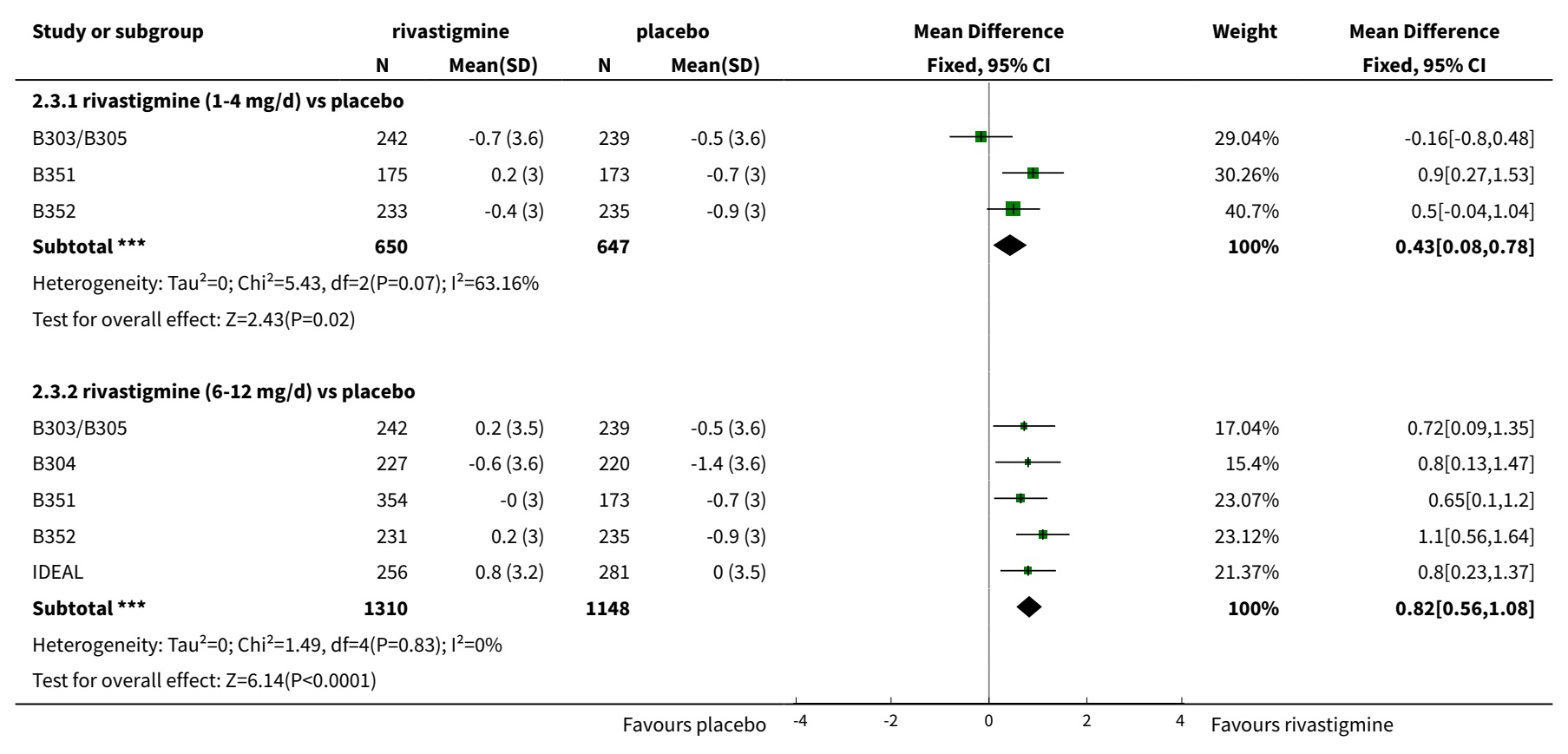

Analysis 2.4. Comparison 2 Rivastigmine oral capsules ( 1 to $4 \mathrm{mg} /$ day or 6 to $12 \mathrm{mg} /$ day in two divided doses) versus placebo, Outcome 4 SIB (change from baseline at 26 weeks).

\begin{tabular}{|c|c|c|c|c|c|c|c|c|}
\hline \multirow[t]{2}{*}{ Study or subgroup } & \multicolumn{2}{|c|}{ rivastigmine } & \multicolumn{2}{|c|}{ placebo } & & \multirow{2}{*}{$\begin{array}{c}\text { Mean Difference } \\
\text { Fixed, } 95 \% \mathrm{Cl}\end{array}$} & \multirow[t]{2}{*}{ Weight } & \multirow{2}{*}{$\begin{array}{c}\text { Mean Difference } \\
\text { Fixed, } 95 \% \mathrm{Cl}\end{array}$} \\
\hline & $\mathbf{N}$ & Mean(SD) & $\mathbf{N}$ & $\operatorname{Mean}(\mathrm{SD})$ & & & & \\
\hline \multicolumn{9}{|c|}{ 2.4.1 Rivastigmine $6-12 \mathrm{mg} / \mathrm{day}$} \\
\hline Lopez-Pousa 2005 & 104 & $-1.4(15)$ & 106 & $-5.9(15)$ & & & $100 \%$ & $4.53[0.47,8.59]$ \\
\hline 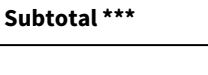 & 104 & & 106 & & & & $100 \%$ & $4.53[0.47,8.59]$ \\
\hline
\end{tabular}




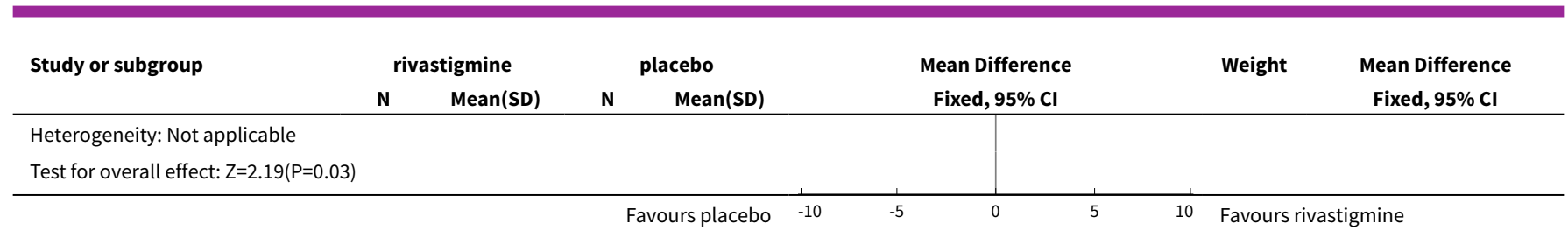

Analysis 2.5. Comparison 2 Rivastigmine oral capsules ( 1 to $4 \mathrm{mg} /$ day or 6 to $12 \mathrm{mg} /$ day in two divided doses) versus placebo, Outcome 5 ADCS-ADL (change from baseline at 26 weeks) ITT.

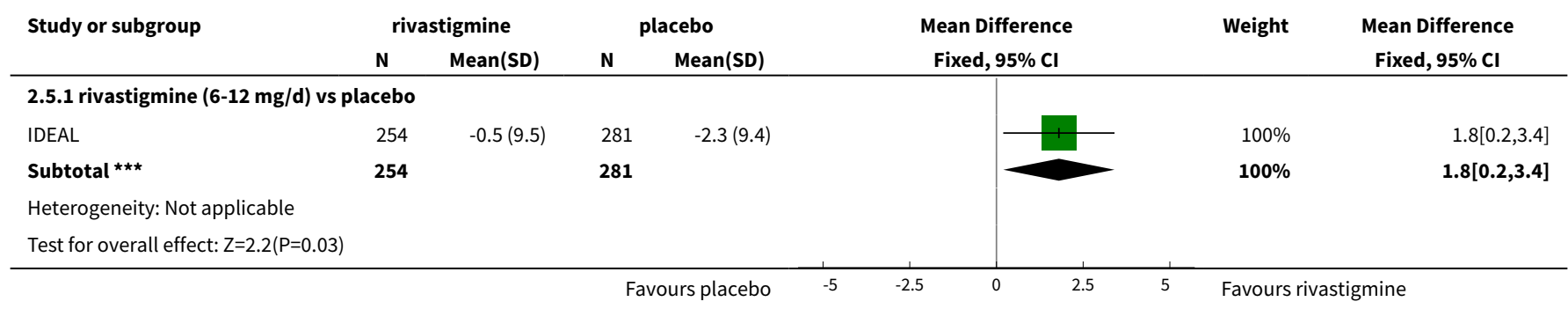

Analysis 2.6. Comparison 2 Rivastigmine oral capsules ( 1 to $4 \mathrm{mg} /$ day or 6 to $12 \mathrm{mg} / \mathrm{day}$ in two divided doses) versus placebo, Outcome 6 PDS (change from baseline at 12 weeks) ITT.

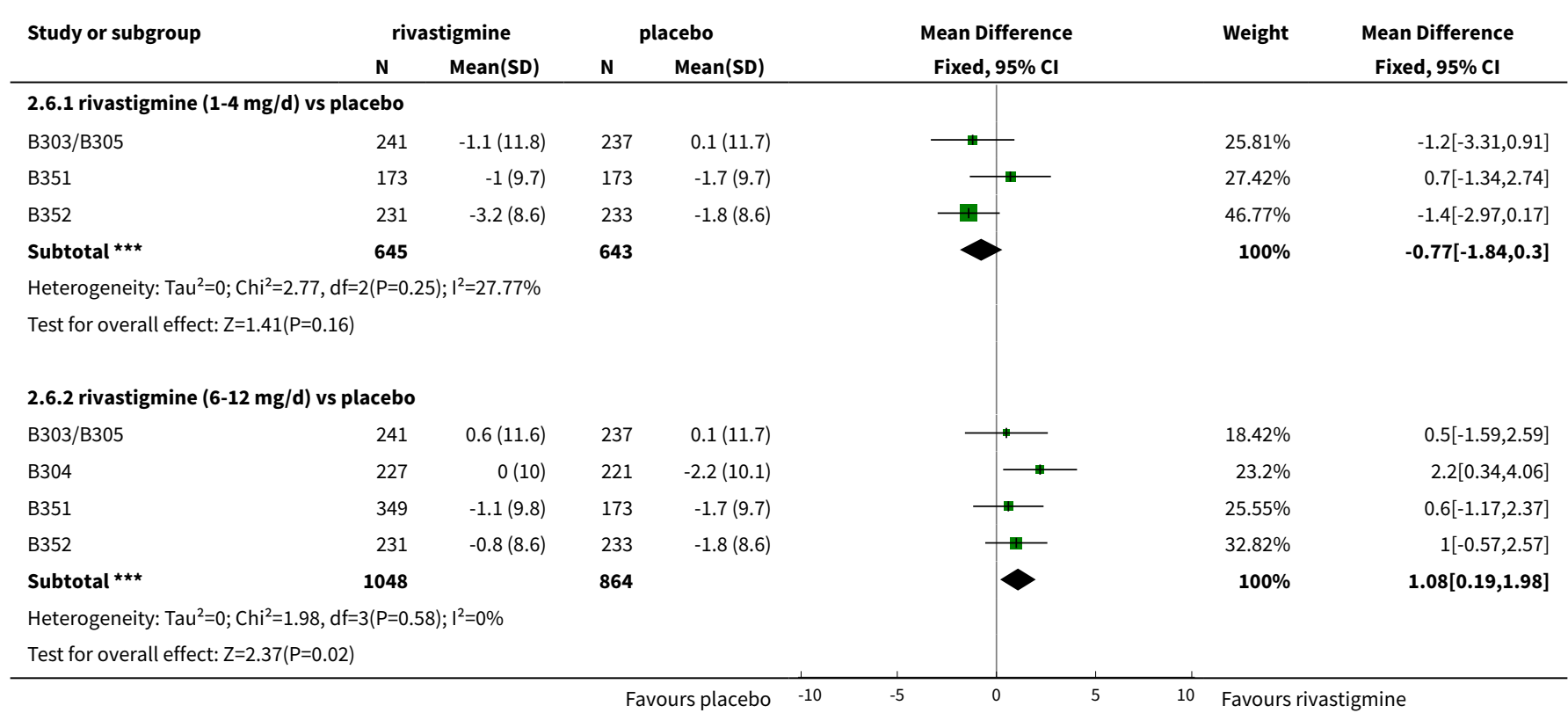


Analysis 2.7. Comparison 2 Rivastigmine oral capsules ( 1 to $4 \mathrm{mg} /$ day or 6 to $12 \mathrm{mg}$ /day in two divided doses) versus placebo, Outcome 7 PDS (change from baseline at 26 weeks) ITT.

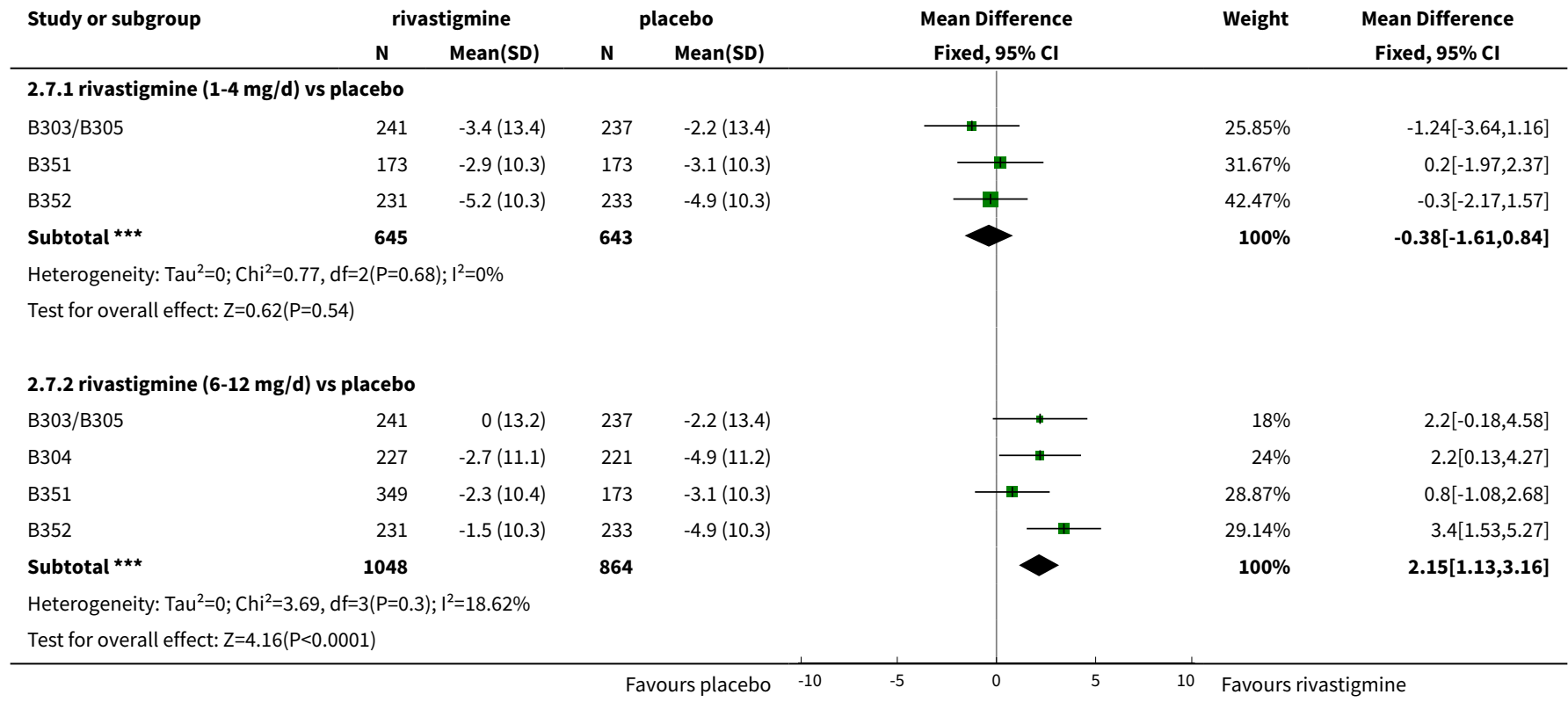

Analysis 2.8. Comparison 2 Rivastigmine oral capsules ( 1 to $4 \mathrm{mg} /$ day or 6 to $12 \mathrm{mg} /$ day in two divided
doses) versus placebo, Outcome 8 Clinical Global Impression (no change or worse at 12 weeks) ITT.

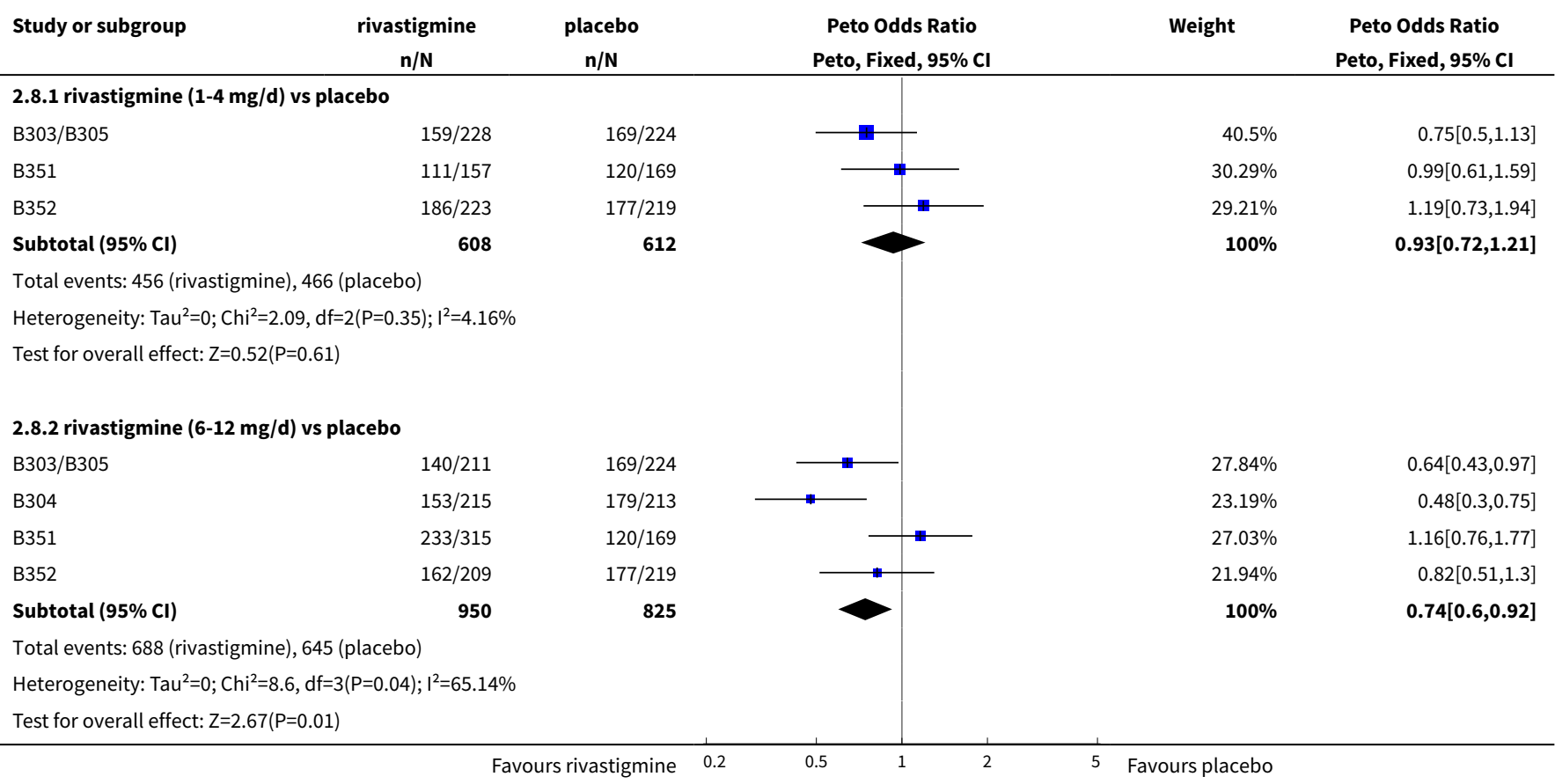


Analysis 2.9. Comparison 2 Rivastigmine oral capsules ( 1 to $4 \mathrm{mg} /$ day or 6 to $12 \mathrm{mg} /$ day in two divided doses) versus placebo, Outcome 9 Clinical Global Impression (no change or worse at 26 weeks) ITT.

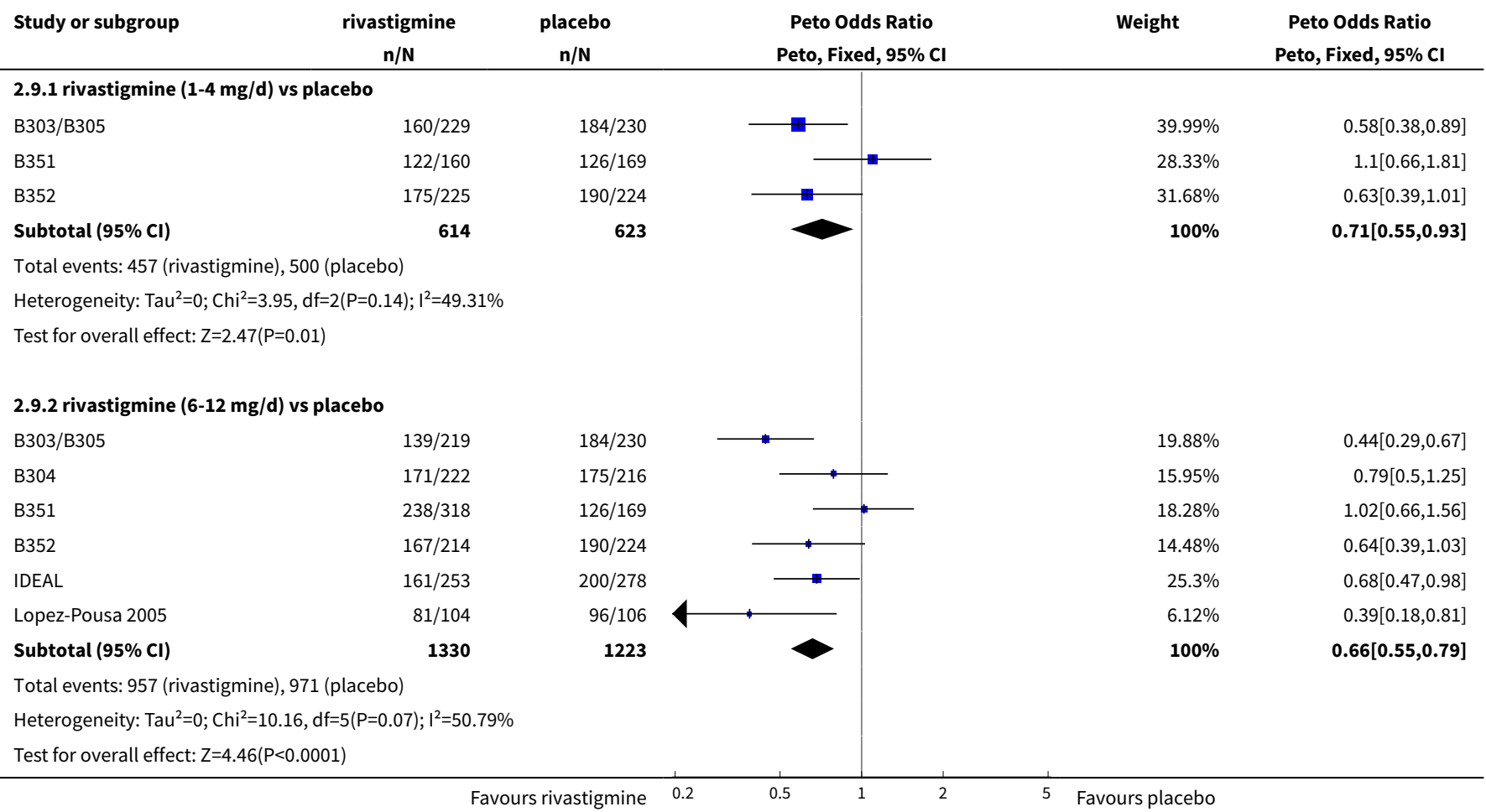

Analysis 2.10. Comparison 2 Rivastigmine oral capsules ( 1 to $4 \mathrm{mg} /$ day or 6 to $12 \mathrm{mg} /$ day in two divided doses) versus placebo, Outcome 10 GDS( moderately severe, severe, or very severe dementia at 26 weeks) ITT.

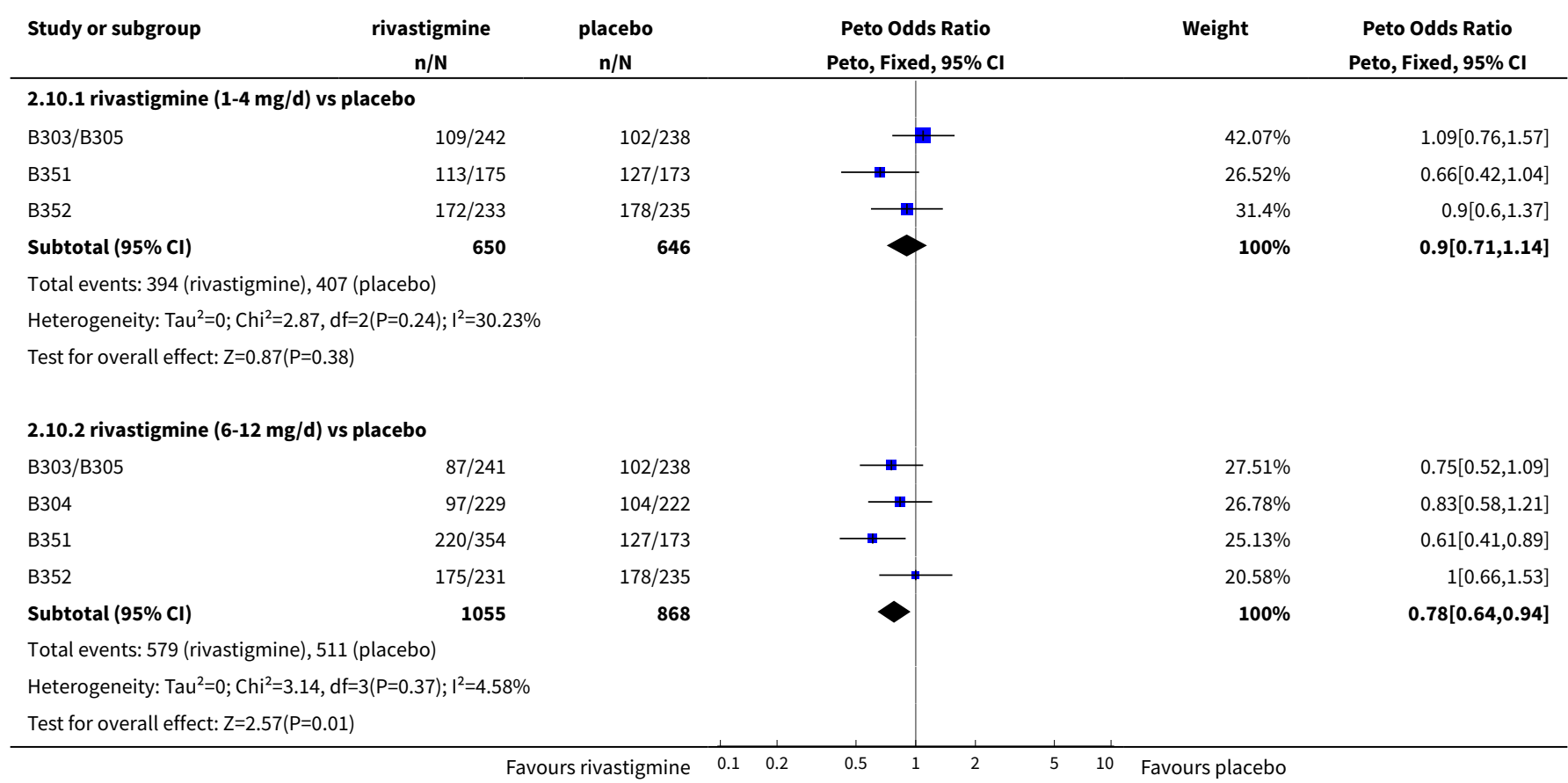


Analysis 2.11. Comparison 2 Rivastigmine oral capsules (1 to $4 \mathrm{mg} / \mathrm{day}$ or 6 to $12 \mathrm{mg} /$ day in two divided doses) versus placebo, Outcome 11 CGIC (little or no improvement, or worse at 12 weeks) ITT.

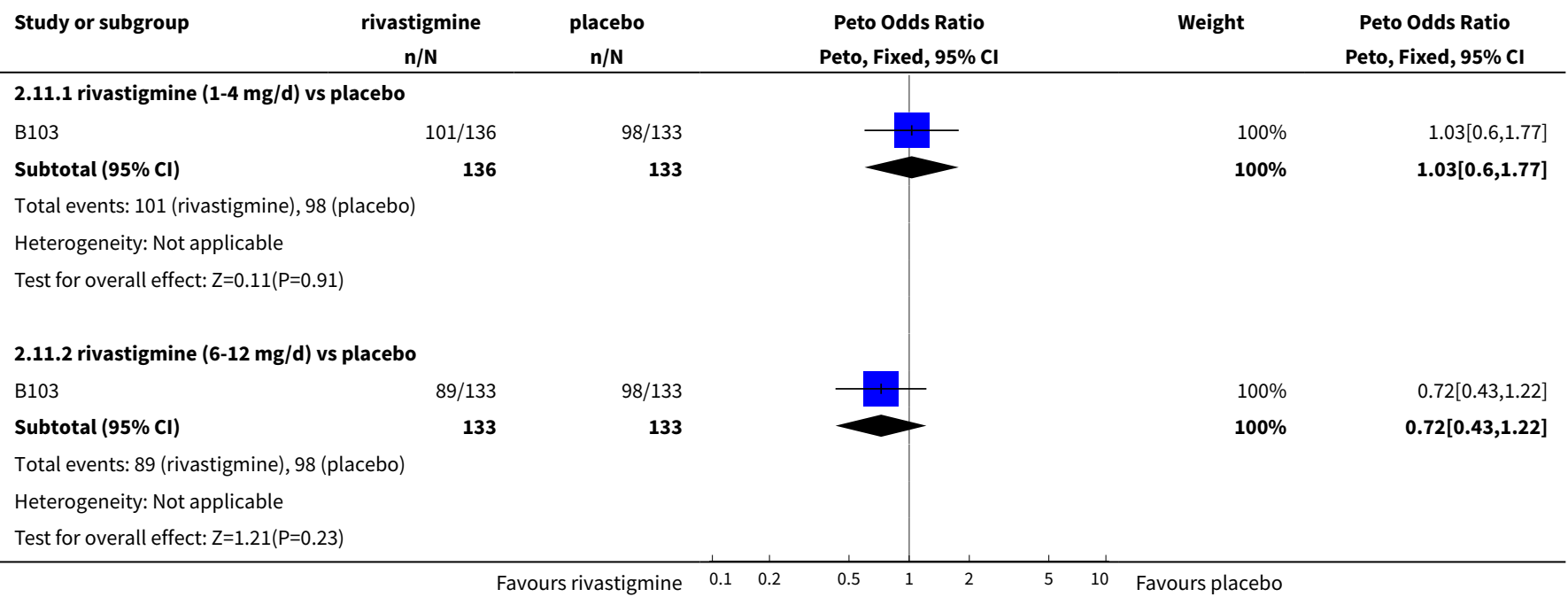

Analysis 2.12. Comparison 2 Rivastigmine oral capsules (1 to $4 \mathrm{mg} /$ day or 6 to $12 \mathrm{mg} /$ day in two divided doses) versus placebo, Outcome 12 Behavioural disturbance NPI-10 or NPI-12 (change from baseline at 26 weeks) ITT.

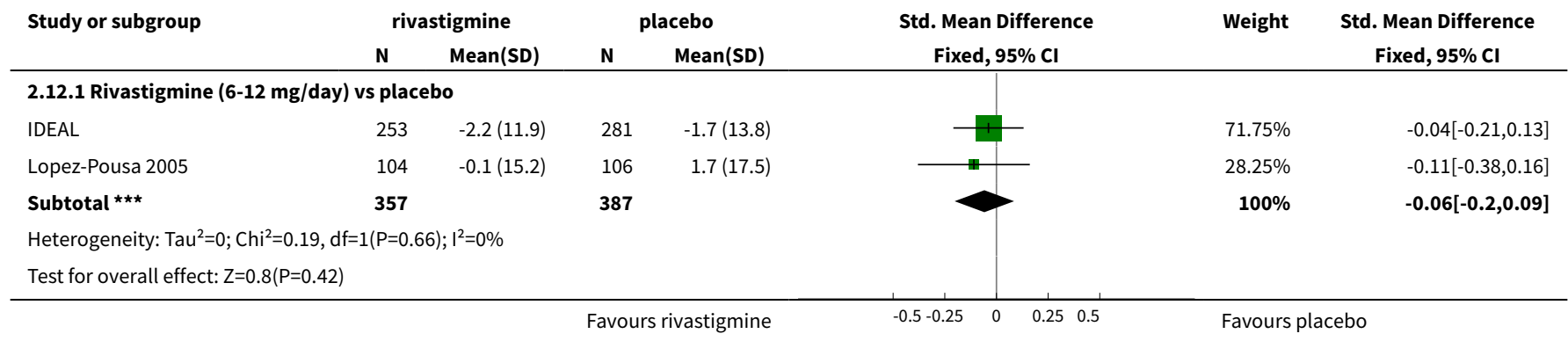

\section{Analysis 2.13. Comparison 2 Rivastigmine oral capsules (1 to $4 \mathrm{mg} / \mathrm{day}$ or 6 to $12 \mathrm{mg} / \mathrm{day}$ in two} divided doses) versus placebo, Outcome 13 withdrawals before end of treatment at 12 weeks.

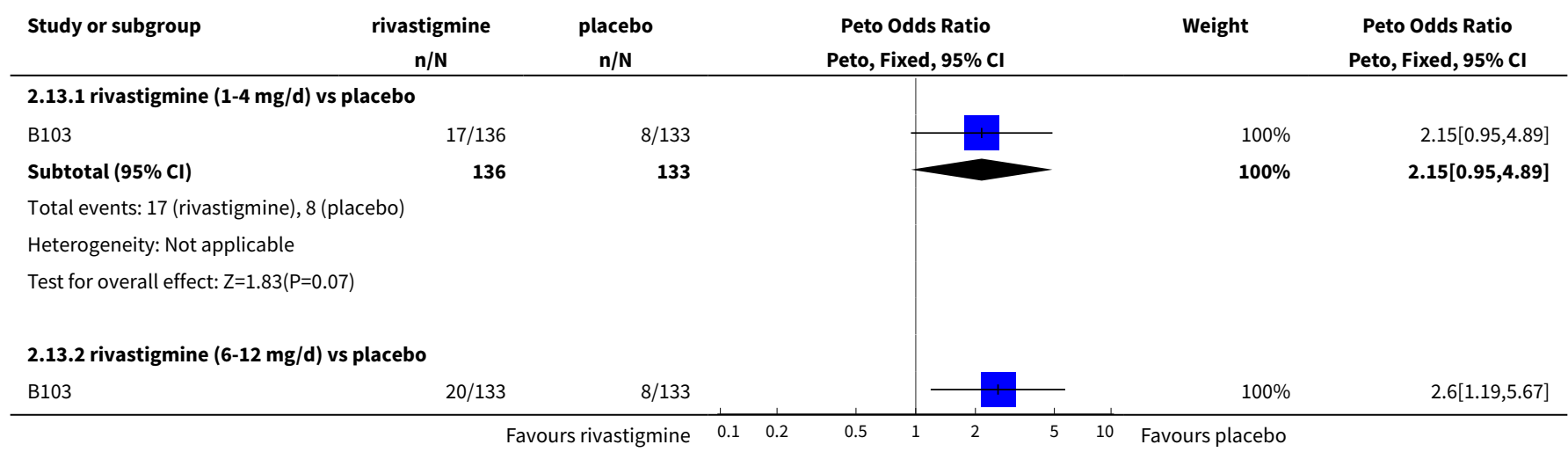




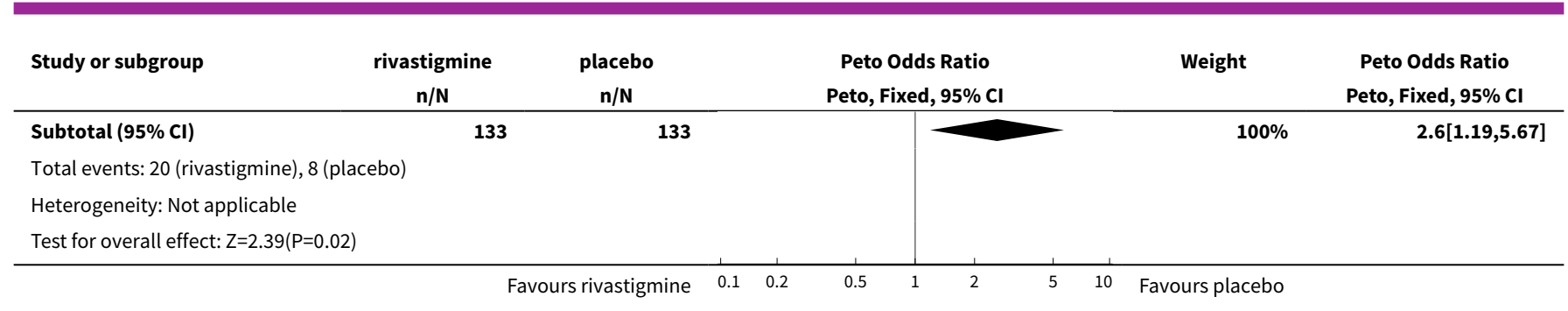

\section{Analysis 2.14. Comparison 2 Rivastigmine oral capsules ( $1 \mathrm{to} 4 \mathrm{mg} /$ day or 6 to $12 \mathrm{mg} /$ day in two} divided doses) versus placebo, Outcome 14 withdrawals before end of treatment at 26 weeks.

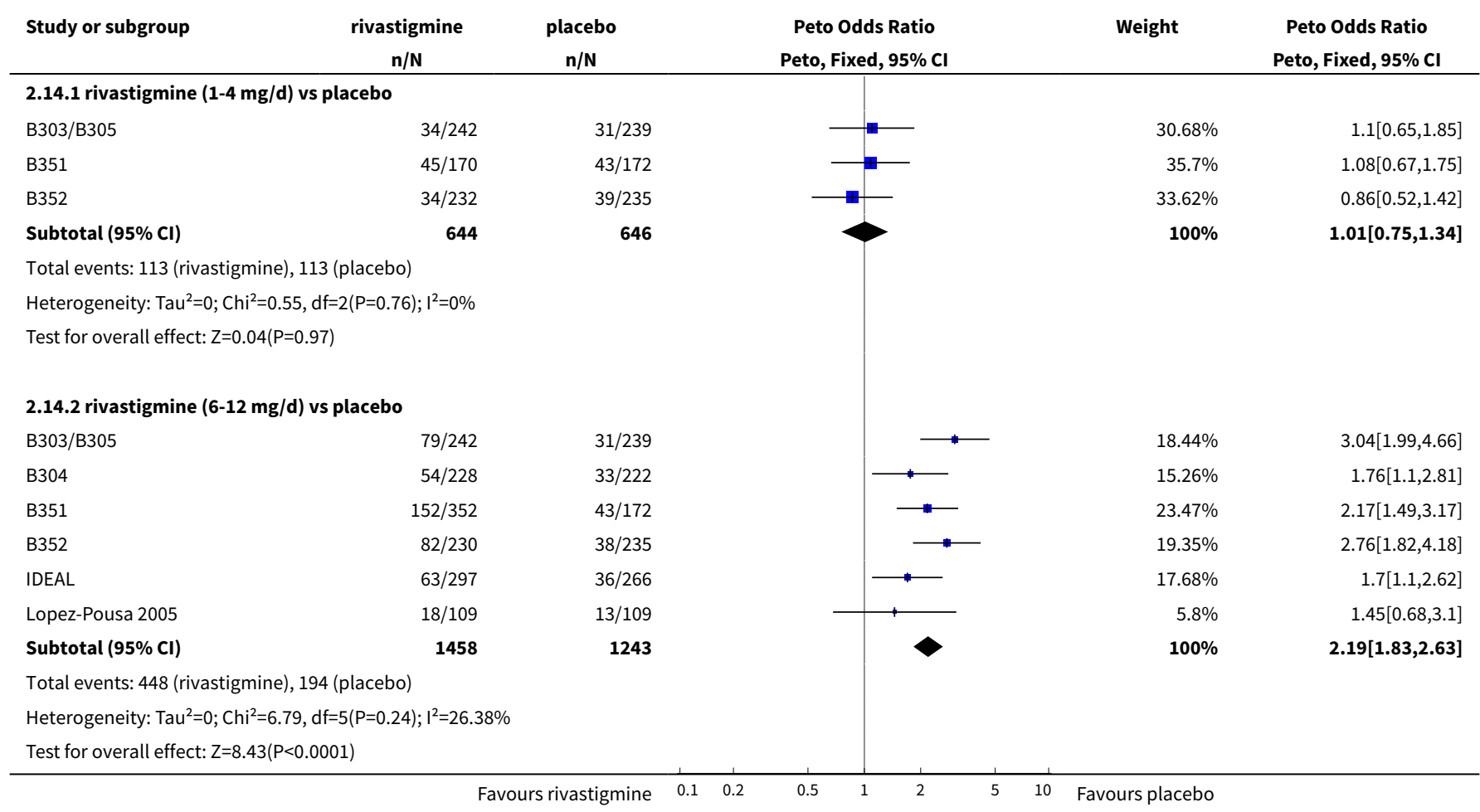

Analysis 2.15. Comparison 2 Rivastigmine oral capsules (1 to $4 \mathrm{mg} /$ day or 6 to $12 \mathrm{mg} /$ day in two divided doses) versus placebo, Outcome 15 at least one adverse event by the end of titration period.

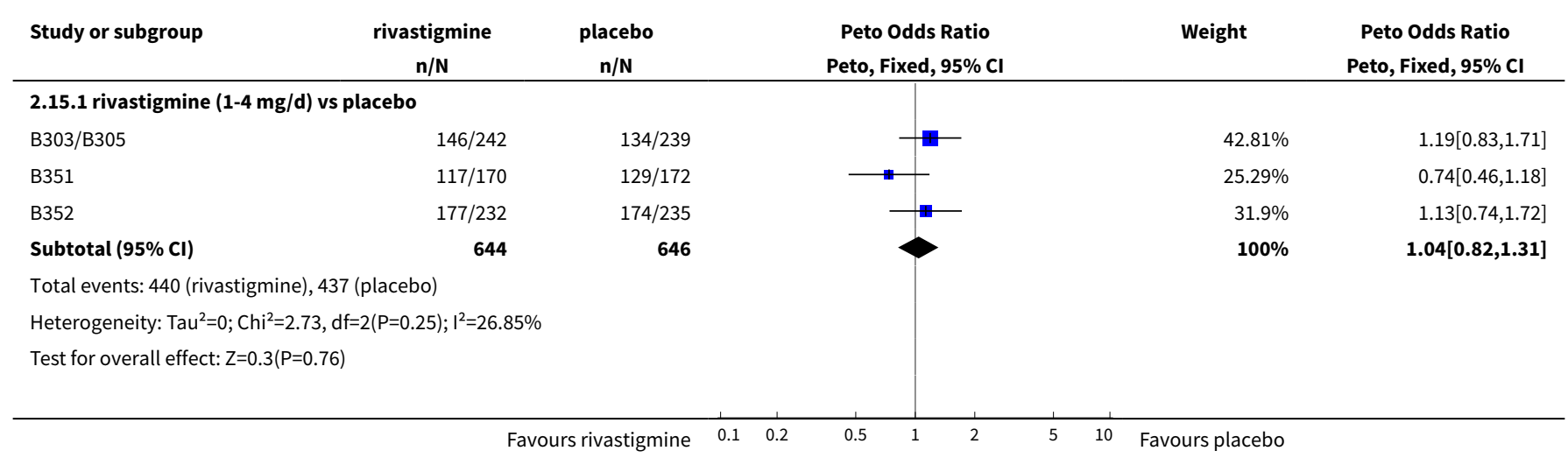




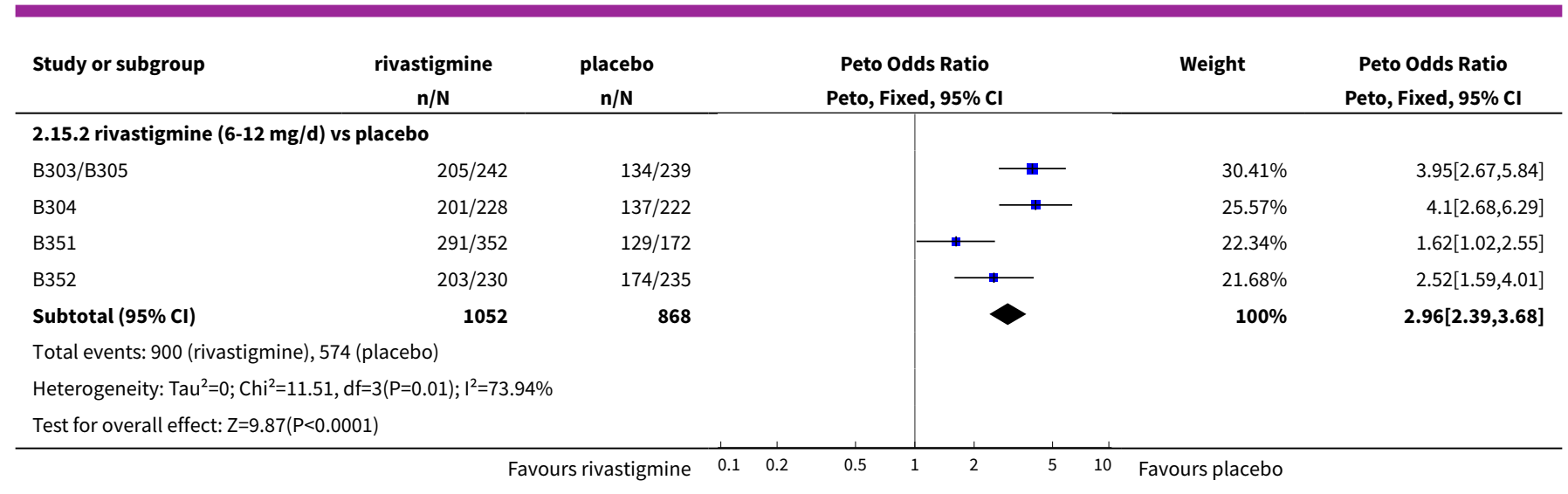

Analysis 2.16. Comparison 2 Rivastigmine oral capsules (1 to $4 \mathrm{mg} /$ day or 6 to $12 \mathrm{mg} / \mathrm{day}$ in two divided doses) versus placebo, Outcome 16 at least one adverse event by 26 weeks.

\begin{tabular}{|c|c|c|c|c|c|}
\hline Study or subgroup & $\begin{array}{c}\text { rivastigmine } \\
n / N\end{array}$ & $\begin{array}{c}\text { placebo } \\
n / N\end{array}$ & $\begin{array}{c}\text { Peto Odds Ratio } \\
\text { Peto, Fixed, } 95 \% \mathrm{Cl}\end{array}$ & Weight & $\begin{array}{c}\text { Peto Odds Ratio } \\
\text { Peto, Fixed, 95\% Cl }\end{array}$ \\
\hline \multicolumn{6}{|c|}{ 2.16.1 rivastigmine $(1-4 \mathrm{mg} / \mathrm{d})$ vs placebo } \\
\hline B303/B305 & $172 / 242$ & $172 / 239$ & & $48.13 \%$ & $0.96[0.64,1.42]$ \\
\hline B351 & $131 / 170$ & $145 / 172$ & $\rightarrow$ & $26.19 \%$ & $0.63[0.37,1.08]$ \\
\hline B352 & $206 / 232$ & $201 / 235$ & & $25.69 \%$ & $1.34[0.78,2.3]$ \\
\hline Subtotal $(95 \% \mathrm{Cl})$ & 644 & 646 & & $100 \%$ & $0.93[0.71,1.23]$ \\
\hline \multicolumn{6}{|c|}{ Total events: 509 (rivastigmine), 518 (placebo) } \\
\hline \multicolumn{6}{|c|}{ Heterogeneity: $\mathrm{Tau}^{2}=0 ; \mathrm{Chi}^{2}=3.79, \mathrm{df}=2(\mathrm{P}=0.15) ; \mathrm{I}^{2}=47.24 \%$} \\
\hline \multicolumn{6}{|c|}{ Test for overall effect: $Z=0.48(P=0.63)$} \\
\hline \multicolumn{6}{|c|}{ 2.16.2 rivastigmine $(6-12 \mathrm{mg} / \mathrm{d})$ vs placebo } \\
\hline B303/B305 & $220 / 242$ & $172 / 239$ & $\rightarrow-$ & $17.89 \%$ & $3.5[2.21,5.55]$ \\
\hline B304 & $208 / 228$ & $169 / 222$ & $\rightarrow$ & $15.09 \%$ & $3.03[1.84,5]$ \\
\hline B352 & $214 / 230$ & $201 / 235$ & $\longrightarrow$ & $11.01 \%$ & $2.18[1.22,3.92]$ \\
\hline IDEAL & $186 / 294$ & $139 / 302$ & \# & $36.43 \%$ & $2[1.45,2.76]$ \\
\hline Lopez-Pousa 2005 & $96 / 104$ & $75 / 106$ & $\longrightarrow$ & $7.85 \%$ & $4.13[2.06,8.27]$ \\
\hline Subtotal $(95 \% \mathrm{Cl})$ & 1450 & 1276 & $\boldsymbol{\nabla}$ & $100 \%$ & $2.49[2.05,3.02]$ \\
\hline \multicolumn{6}{|c|}{ Total events: 1242 (rivastigmine), 901 (placebo) } \\
\hline \multicolumn{6}{|c|}{ Heterogeneity: $\mathrm{Tau}^{2}=0 ; \mathrm{Chi}^{2}=7.97, \mathrm{df}=5(\mathrm{P}=0.16) ; \mathrm{I}^{2}=37.29 \%$} \\
\hline \multicolumn{6}{|c|}{ Test for overall effect: $Z=9.18(P<0.0001)$} \\
\hline
\end{tabular}

Analysis 2.17. Comparison 2 Rivastigmine oral capsules ( 1 to $4 \mathrm{mg} /$ day or 6 to $12 \mathrm{mg} /$ day in two divided doses) versus placebo, Outcome 17 dropouts due to adverse events by 12 weeks.

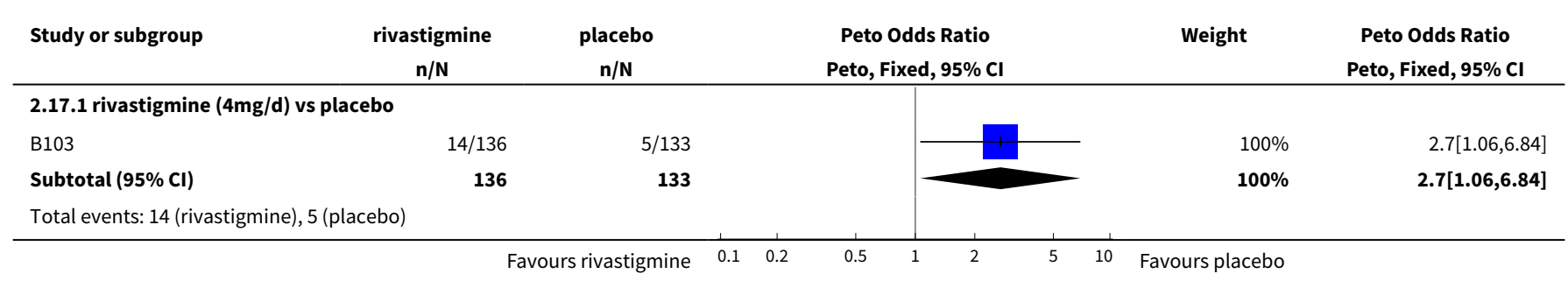




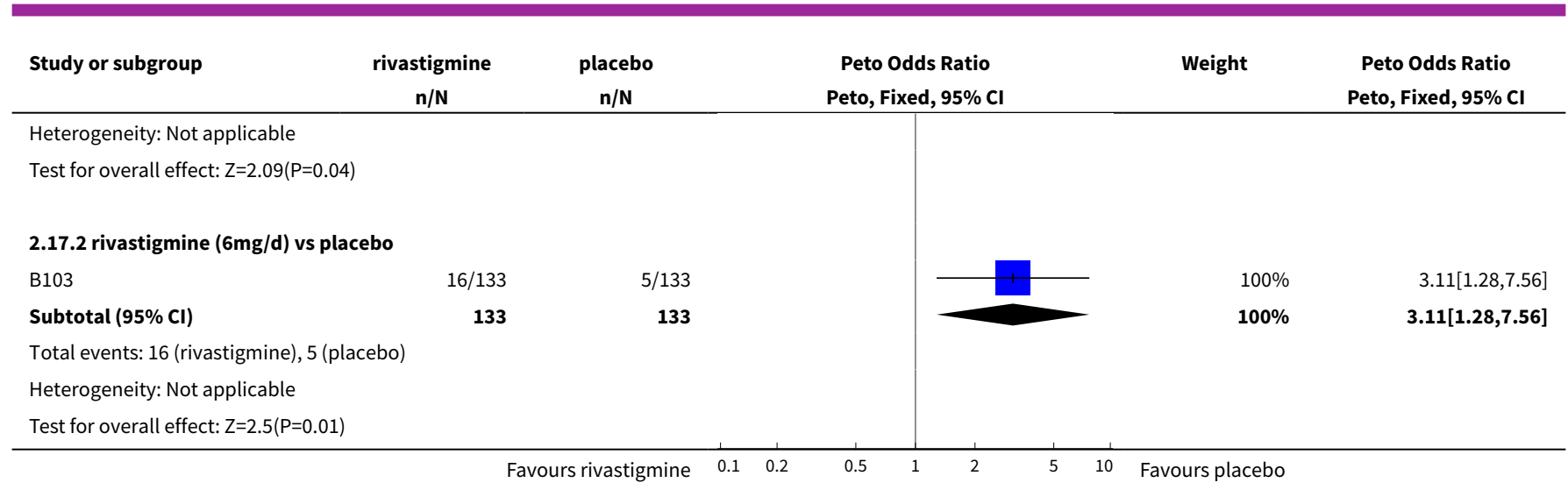

Analysis 2.18. Comparison 2 Rivastigmine oral capsules (1 to $4 \mathrm{mg} /$ day or 6 to $12 \mathrm{mg} /$ day in two divided doses) versus placebo, Outcome 18 dropouts due to adverse events by 26 weeks.

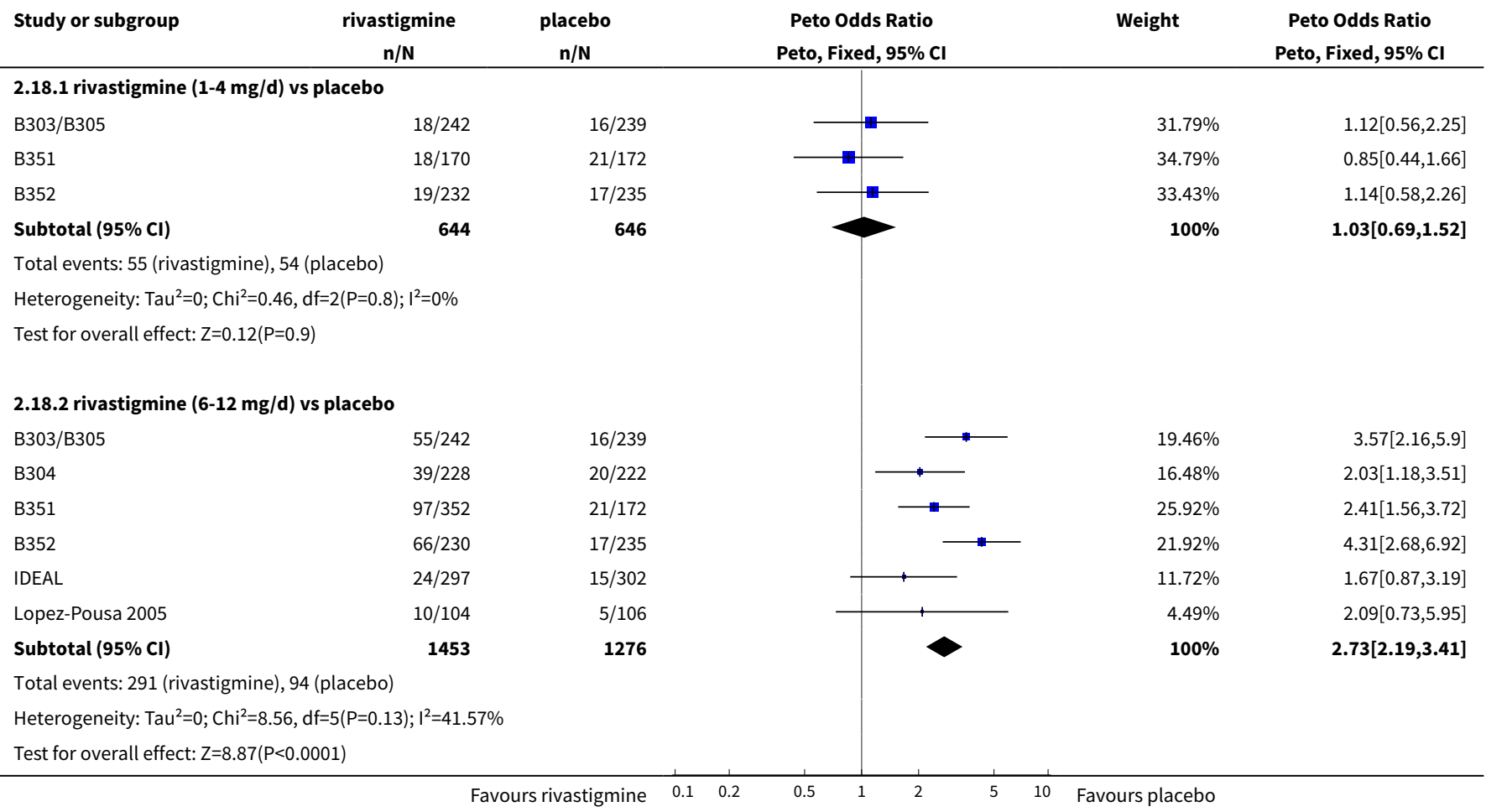

\section{Analysis 2.19. Comparison 2 Rivastigmine oral capsules (1 to $4 \mathrm{mg} /$ day or 6 to $12 \mathrm{mg} /$ day in two divided} doses) versus placebo, Outcome 19 at least one adverse event of decreased appetite by 26 weeks.

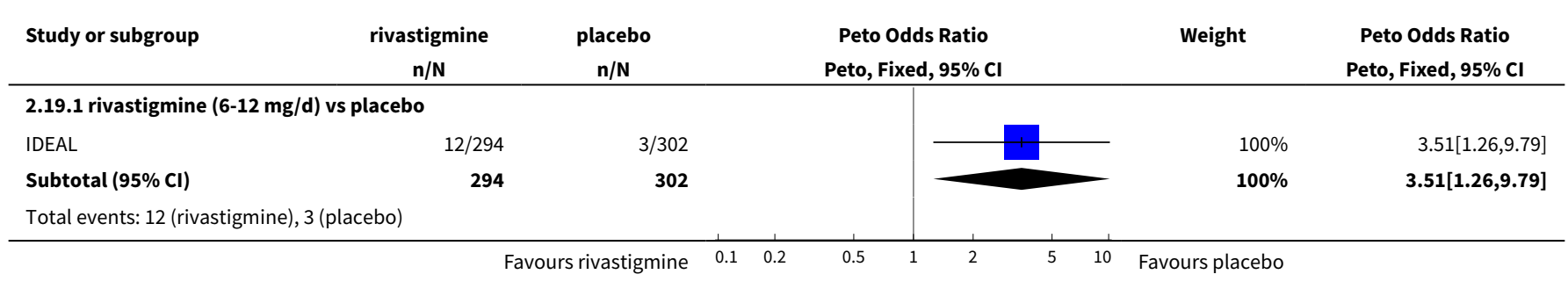




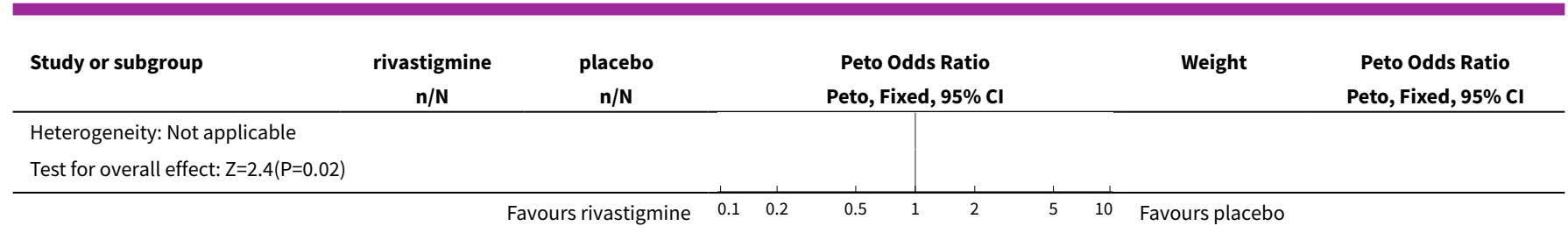

Analysis 2.20. Comparison 2 Rivastigmine oral capsules (1 to $4 \mathrm{mg} /$ day or 6 to $12 \mathrm{mg} /$ day in two divided doses) versus placebo, Outcome 20 at least one adverse event of weight decrease by 26 weeks.

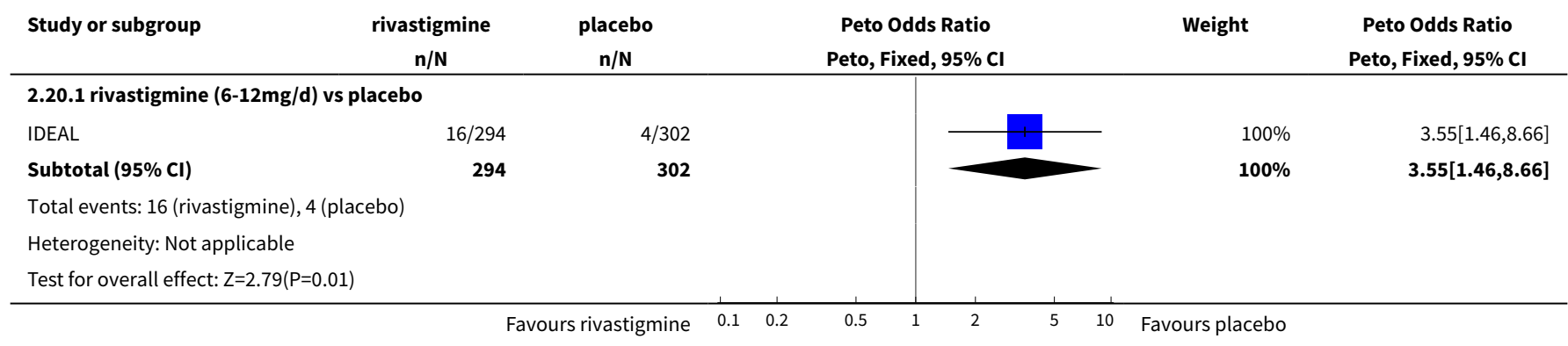

Analysis 2.21. Comparison 2 Rivastigmine oral capsules ( $1 \mathrm{to} 4 \mathrm{mg} /$ day or 6 to $12 \mathrm{mg} /$ day in two divided doses) versus placebo, Outcome 21 at least one adverse event of nausea by the end of titration period.

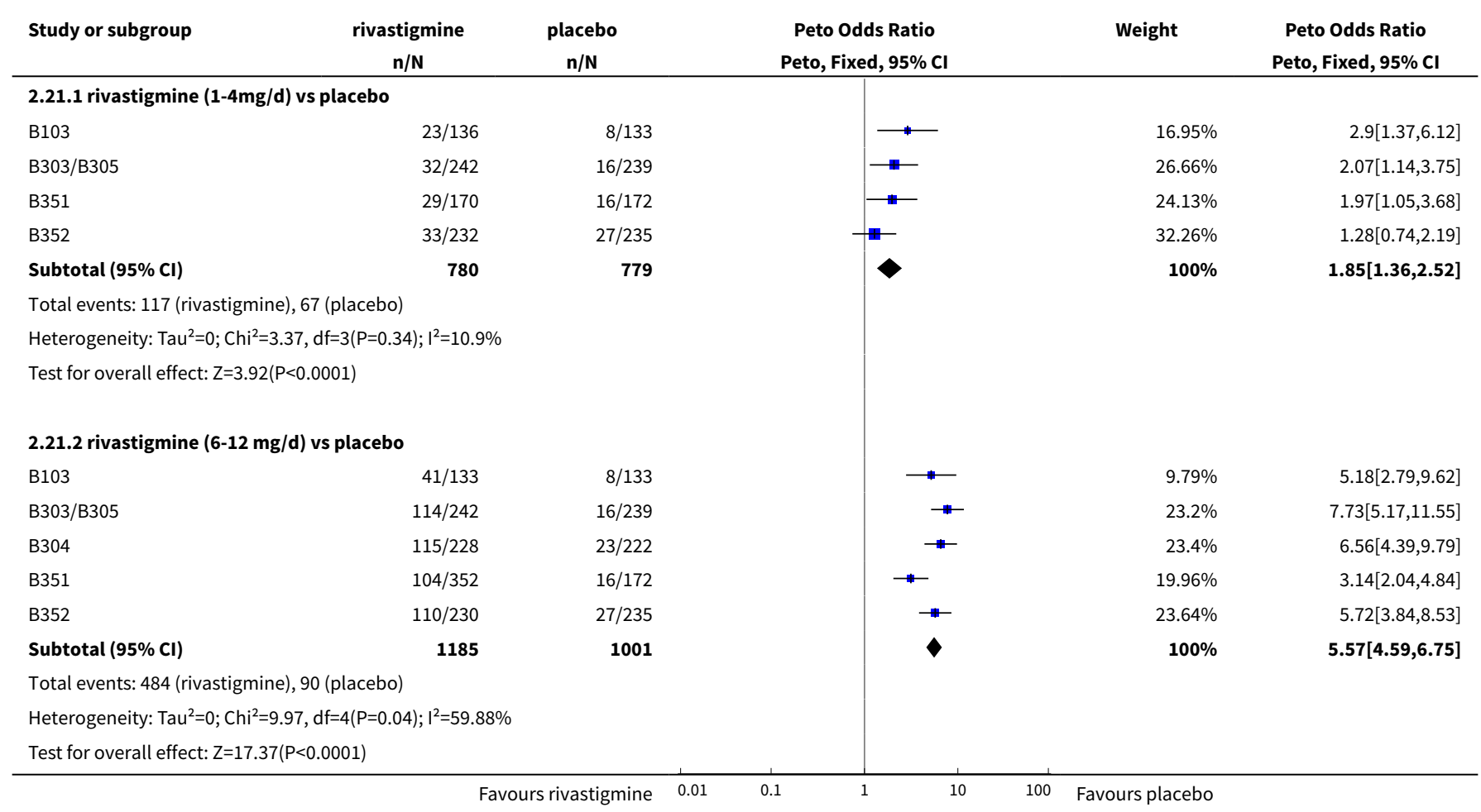


Analysis 2.22. Comparison 2 Rivastigmine oral capsules ( $1 \mathrm{to} 4 \mathrm{mg} /$ day or 6 to $12 \mathrm{mg} /$ day in two divided doses) versus placebo, Outcome 22 at least one adverse event of nausea by 26 weeks.

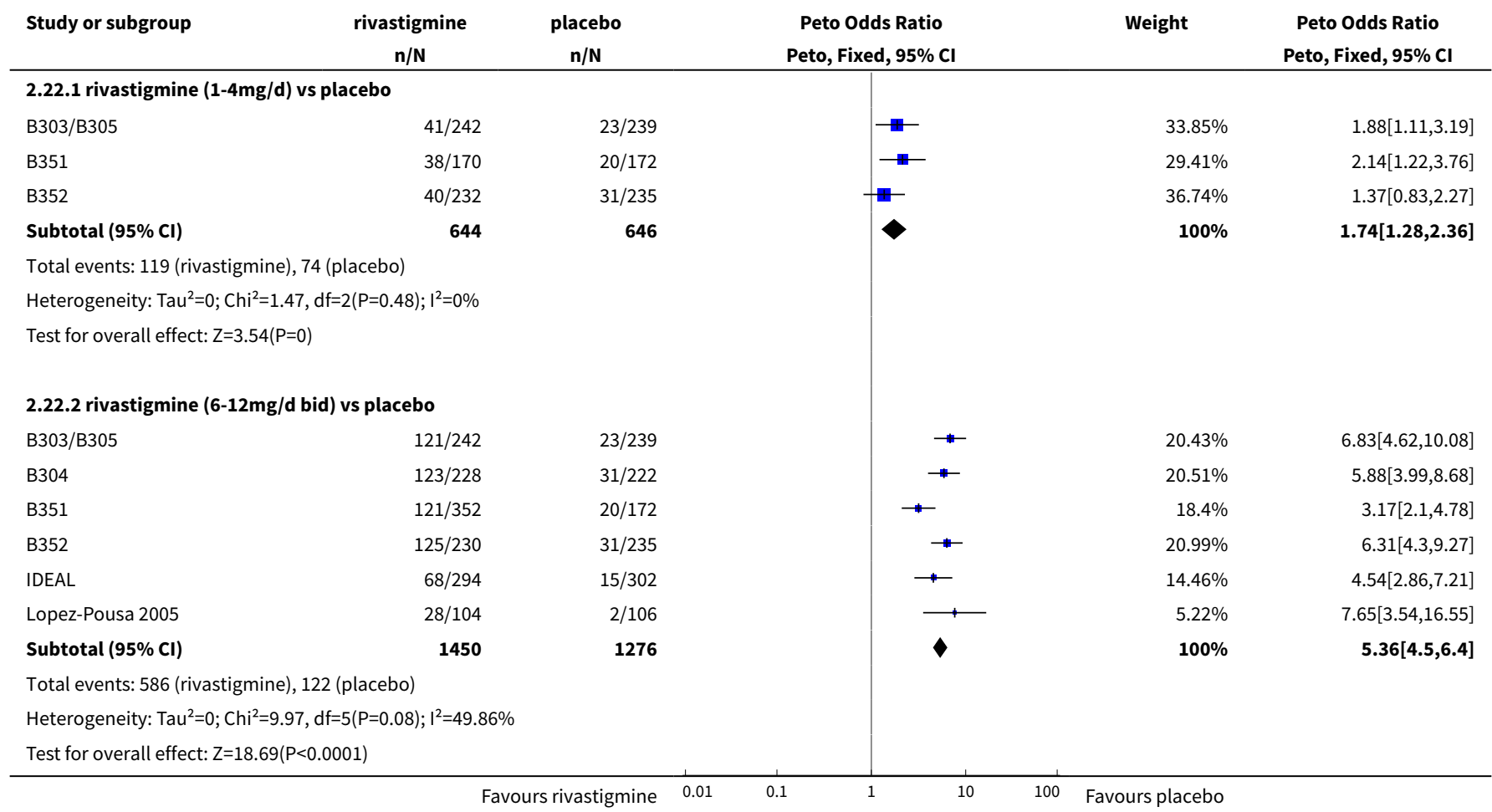

Analysis 2.23. Comparison 2 Rivastigmine oral capsules ( 1 to $4 \mathrm{mg} /$ day or 6 to $12 \mathrm{mg} /$ day in two divided doses) versus placebo, Outcome 23 at least one adverse event of vomiting by the end of titration period.

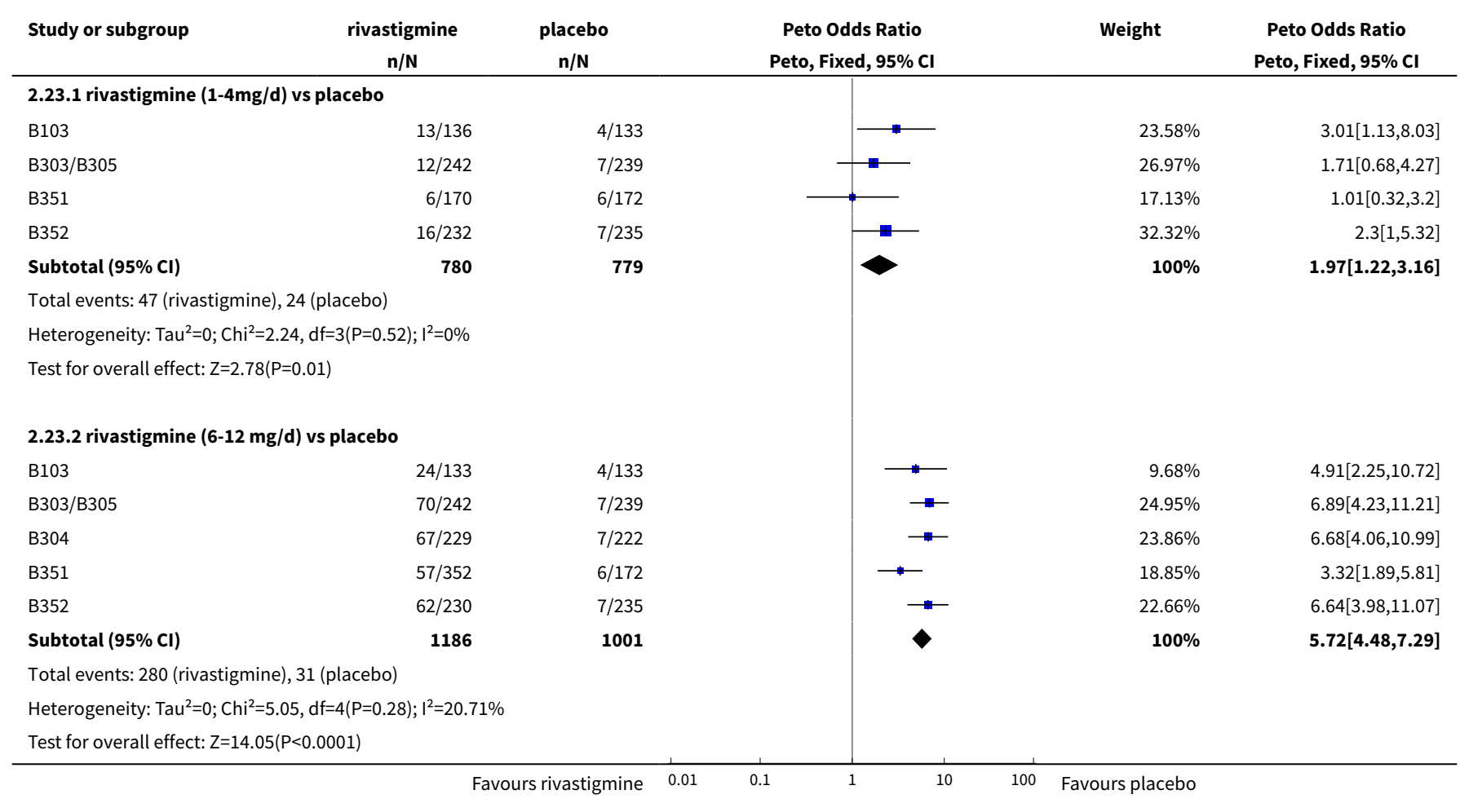


Analysis 2.24. Comparison 2 Rivastigmine oral capsules (1 to $4 \mathrm{mg} / \mathrm{day}$ or 6 to $12 \mathrm{mg} /$ day in two divided doses) versus placebo, Outcome 24 at least one adverse event of vomiting by 26 weeks.

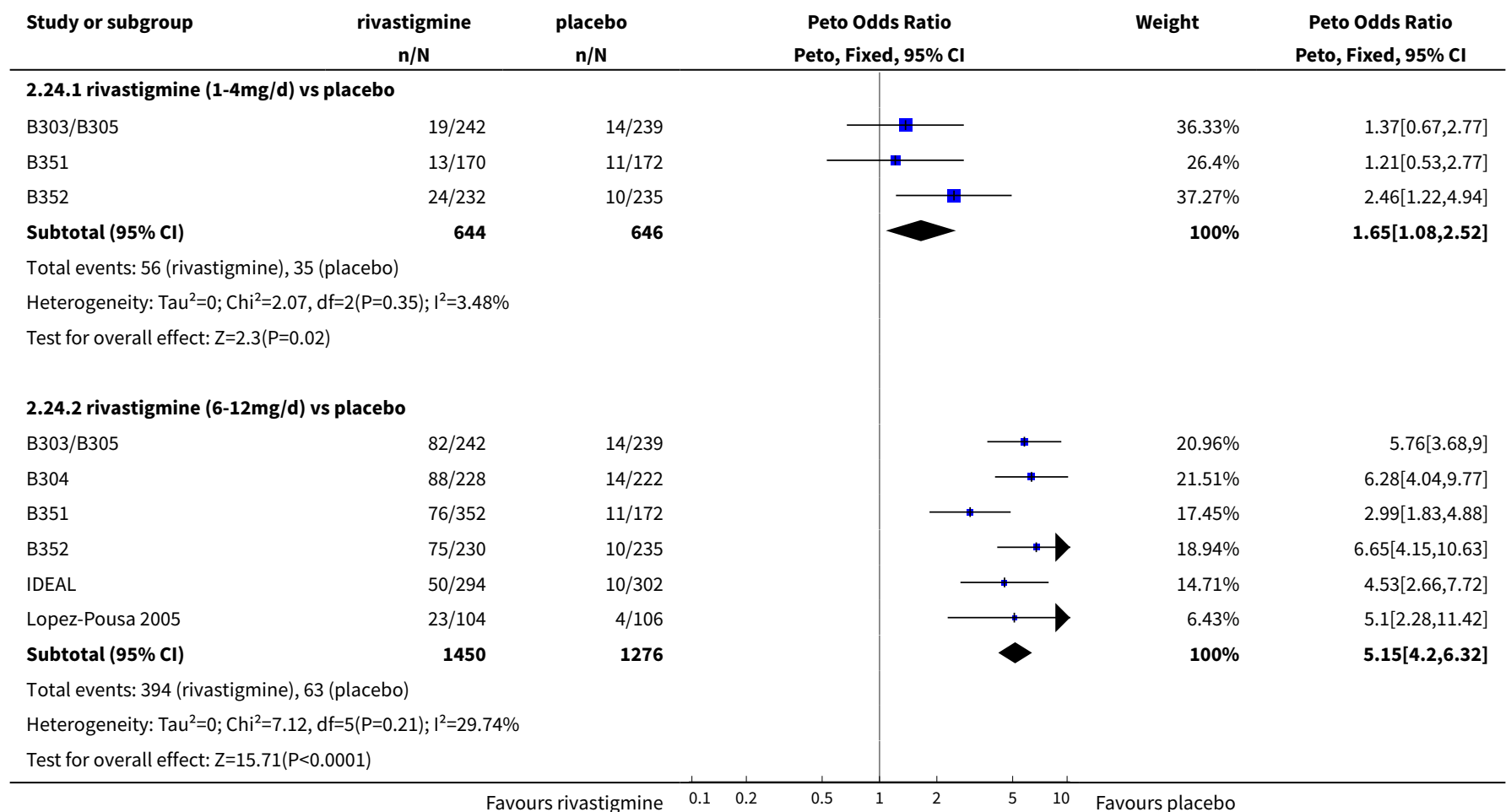

Analysis 2.25. Comparison 2 Rivastigmine oral capsules ( 1 to $4 \mathrm{mg} /$ day or 6 to $12 \mathrm{mg} /$ day in two divided doses) versus placebo, Outcome 25 at least one adverse event of diarrhoea by the end of titration period.

\begin{tabular}{|c|c|c|c|c|c|}
\hline Study or subgroup & $\begin{array}{c}\text { rivastigmine } \\
\mathrm{n} / \mathrm{N}\end{array}$ & $\begin{array}{c}\text { placebo } \\
n / N\end{array}$ & $\begin{array}{c}\text { Peto Odds Ratio } \\
\text { Peto, Fixed, } 95 \% \mathrm{Cl}\end{array}$ & Weight & $\begin{array}{c}\text { Peto Odds Ratio } \\
\text { Peto, Fixed, } 95 \% \mathrm{Cl}\end{array}$ \\
\hline \multicolumn{6}{|c|}{ 2.25.1 rivastigmine $(1-4 \mathrm{mg} / \mathrm{d})$ vs placebo } \\
\hline B103 & $9 / 136$ & $2 / 133$ & $\longrightarrow$ & $9.24 \%$ & $3.67[1.1,12.23]$ \\
\hline B303/B305 & $19 / 242$ & $16 / 239$ & $\rightarrow-$ & $28.39 \%$ & $1.19[0.6,2.36]$ \\
\hline B351 & $13 / 170$ & $19 / 172$ & $\longrightarrow$ & $25.39 \%$ & $0.67[0.32,1.39]$ \\
\hline B352 & $21 / 232$ & $26 / 235$ & - & $36.98 \%$ & $0.8[0.44,1.46]$ \\
\hline \multicolumn{6}{|c|}{ Total events: 62 (rivastigmine), 63 (placebo) } \\
\hline \multicolumn{6}{|c|}{ Heterogeneity: $\mathrm{Tau}^{2}=0 ; \mathrm{Chi}^{2}=6.38, \mathrm{df}=3(\mathrm{P}=0.09) ; \mathrm{I}^{2}=52.99 \%$} \\
\hline \multicolumn{6}{|c|}{ Test for overall effect: $Z=0.08(P=0.94)$} \\
\hline \multicolumn{6}{|c|}{ 2.25.2 rivastigmine $(6-12 \mathrm{mg} / \mathrm{d})$ vs placebo } \\
\hline B103 & $16 / 133$ & $2 / 133$ & $\longrightarrow$ & $7.76 \%$ & $5.27[2.03,13.7]$ \\
\hline B304 & $32 / 228$ & $16 / 222$ & $\longrightarrow$ & $19.81 \%$ & $2.04[1.12,3.72]$ \\
\hline B351 & $49 / 352$ & $19 / 172$ & - & $24.1 \%$ & $1.29[0.75,2.22]$ \\
\hline B352 & $48 / 230$ & $26 / 235$ & $\rightarrow-$ & $28.74 \%$ & $2.08[1.26,3.41]$ \\
\hline Subtotal $(95 \% \mathrm{CI})$ & 1185 & 1001 & 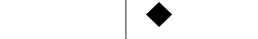 & $100 \%$ & $1.97[1.51,2.57]$ \\
\hline \multicolumn{6}{|c|}{ Total events: 176 (rivastigmine), 79 (placebo) } \\
\hline
\end{tabular}




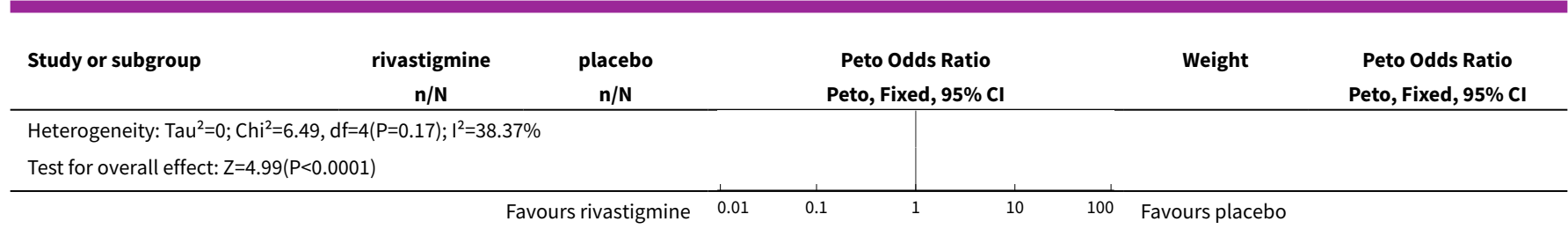

Analysis 2.26. Comparison 2 Rivastigmine oral capsules (1 to $4 \mathrm{mg} /$ day or 6 to $12 \mathrm{mg} /$ day in two divided doses) versus placebo, Outcome 26 at least one adverse event of diarrhoea by 26 weeks.

\begin{tabular}{|c|c|c|c|c|c|}
\hline Study or subgroup & $\begin{array}{c}\text { rivastigmine } \\
\mathrm{n} / \mathrm{N}\end{array}$ & $\begin{array}{c}\text { placebo } \\
n / N\end{array}$ & $\begin{array}{c}\text { Peto Odds Ratio } \\
\text { Peto, Fixed, } 95 \% \mathrm{Cl}\end{array}$ & Weight & $\begin{array}{l}\text { Peto Odds Ratio } \\
\text { Peto, Fixed, } 95 \% \mathrm{Cl}\end{array}$ \\
\hline \multicolumn{6}{|c|}{2.26 .1 rivastigmine $(1-4 \mathrm{mg} / \mathrm{d})$ vs placebo } \\
\hline B303/B305 & $23 / 242$ & $21 / 239$ & - & $29.79 \%$ & $1.09[0.59,2.02]$ \\
\hline B351 & $20 / 170$ & $21 / 172$ & 1 & $26.91 \%$ & $0.96[0.5,1.84]$ \\
\hline B352 & $31 / 232$ & $37 / 235$ & 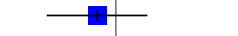 & $43.3 \%$ & $0.83[0.49,1.38]$ \\
\hline Subtotal $(95 \% \mathrm{Cl})$ & 644 & 646 & & $100 \%$ & $0.93[0.67,1.31]$ \\
\hline \multicolumn{6}{|c|}{ Total events: 74 (rivastigmine), 79 (placebo) } \\
\hline \multicolumn{6}{|c|}{ Heterogeneity: $\mathrm{Tau}^{2}=0 ; \mathrm{Ch}^{2}=0.46, \mathrm{df}=2(\mathrm{P}=0.79) ; \mathrm{I}^{2}=0 \%$} \\
\hline \multicolumn{6}{|c|}{ Test for overall effect: $Z=0.4(P=0.69)$} \\
\hline \multicolumn{6}{|c|}{2.26 .2 rivastigmine $(6-12 \mathrm{mg} / \mathrm{d})$ vs placebo } \\
\hline В303/В305 & $40 / 242$ & $21 / 239$ & $\longrightarrow$ & $20.15 \%$ & $2.01[1.17,3.44]$ \\
\hline B304 & $40 / 228$ & $20 / 222$ & $\longrightarrow$ & $19.68 \%$ & $2.09[1.21,3.6]$ \\
\hline B351 & $58 / 352$ & $21 / 172$ & $\rightarrow-$ & $22.39 \%$ & $1.39[0.84,2.32]$ \\
\hline B352 & $57 / 230$ & $37 / 235$ & $\longrightarrow$ & $28.38 \%$ & $1.75[1.11,2.75]$ \\
\hline IDEAL & $16 / 294$ & $10 / 302$ & 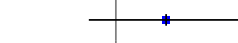 & $9.4 \%$ & $1.67[0.76,3.65]$ \\
\hline Subtotal $(95 \% \mathrm{Cl})$ & 1346 & 1170 & > & $100 \%$ & $1.76[1.39,2.24]$ \\
\hline \multicolumn{6}{|c|}{ Total events: 211 (rivastigmine), 109 (placebo) } \\
\hline \multicolumn{6}{|c|}{ Heterogeneity: Tau $^{2}=0 ; \mathrm{Chi}^{2}=1.44, \mathrm{df}=4(\mathrm{P}=0.84) ; \mathrm{l}^{2}=0 \%$} \\
\hline Test for overall effec & & & & & \\
\hline
\end{tabular}

Analysis 2.27. Comparison 2 Rivastigmine oral capsules (1 to $4 \mathrm{mg} /$ day or 6 to $12 \mathrm{mg} /$ day in two divided doses) versus placebo, Outcome 27 at least one adverse event of anorexia by the end of titration period.

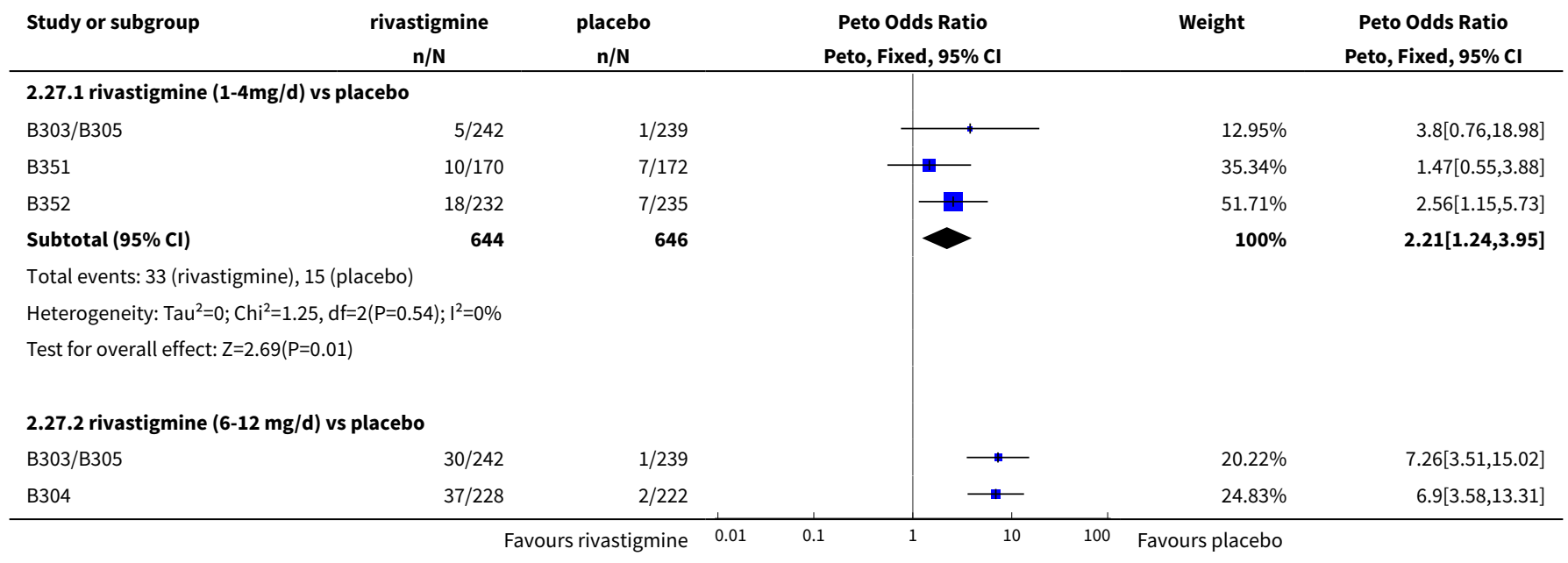




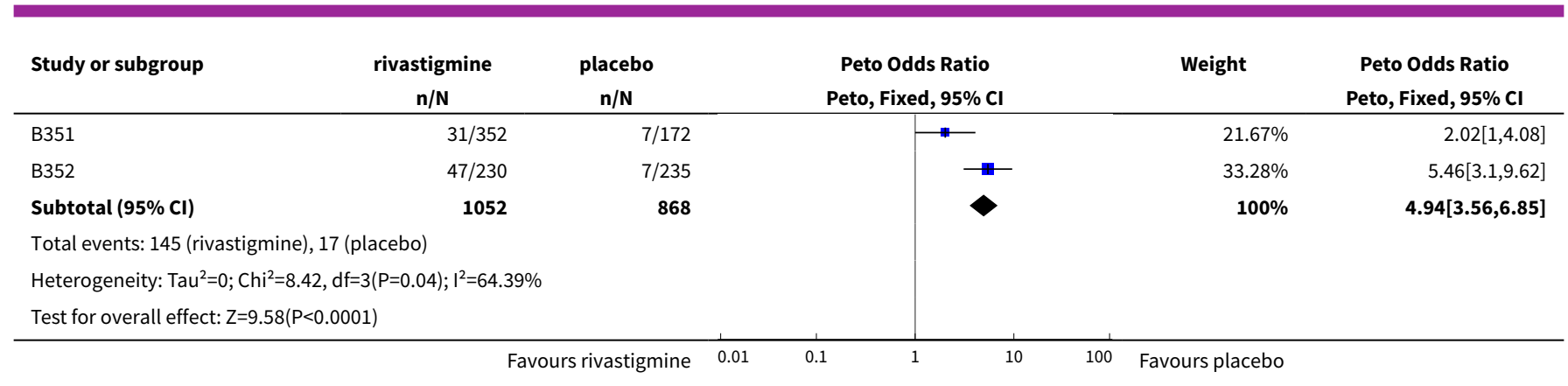
Analysis 2.28. Comparison 2 Rivastigmine oral capsules ( 1 to $4 \mathrm{mg} /$ day or 6 to $12 \mathrm{mg} /$ day in two
divided doses) versus placebo, Outcome 28 at least one adverse event of anorexia by 26 weeks.

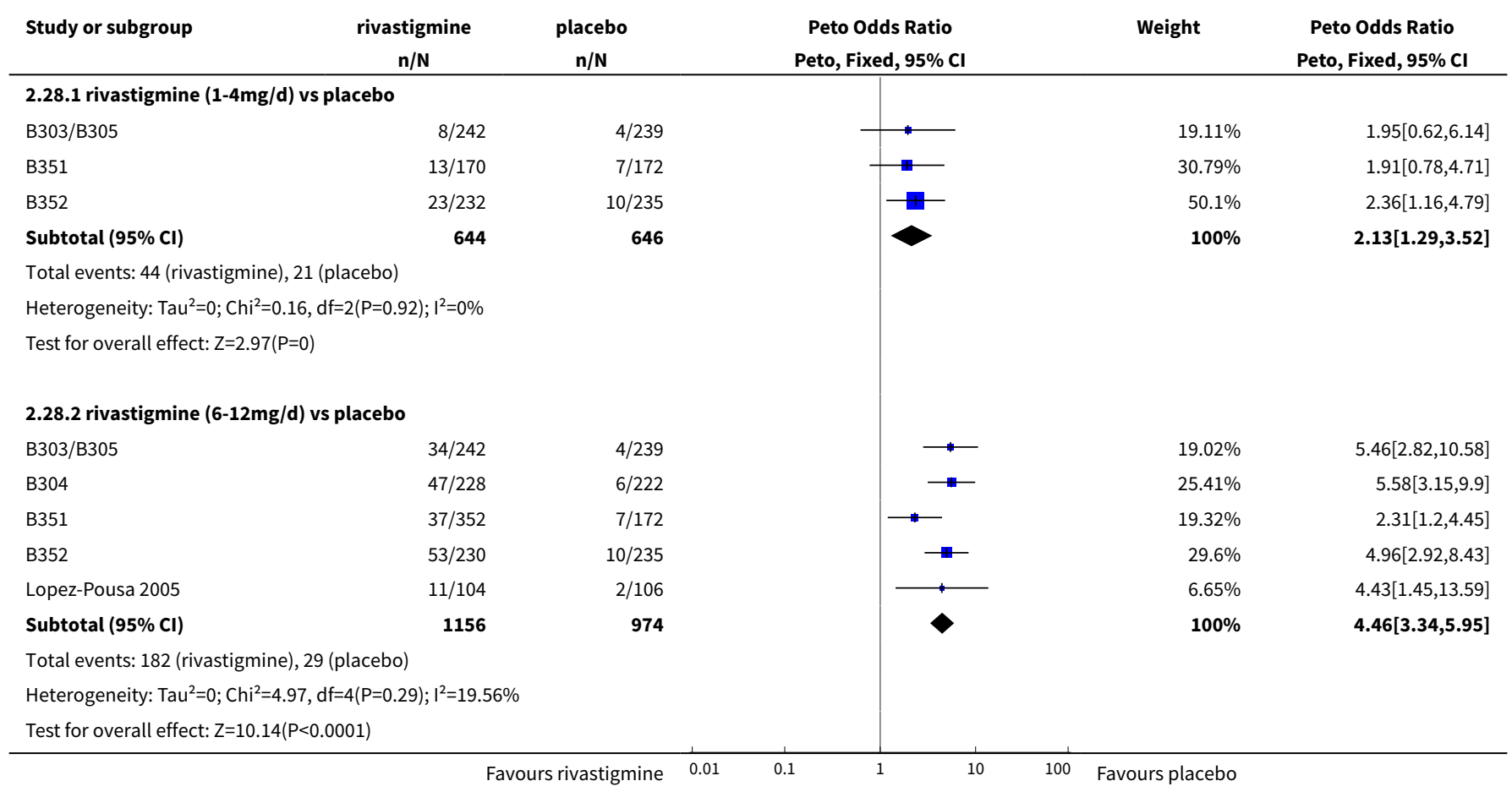

Analysis 2.29. Comparison 2 Rivastigmine oral capsules ( 1 to $4 \mathrm{mg} /$ day or 6 to $12 \mathrm{mg} /$ day in two divided doses) versus placebo, Outcome 29 at least one adverse event of headache by the end of titration period.

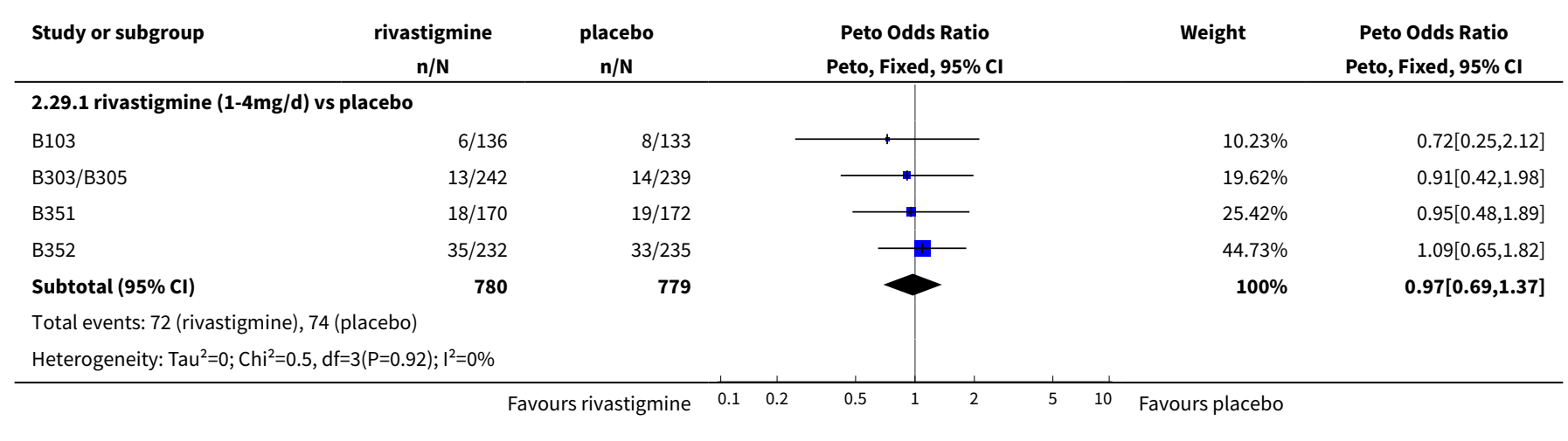




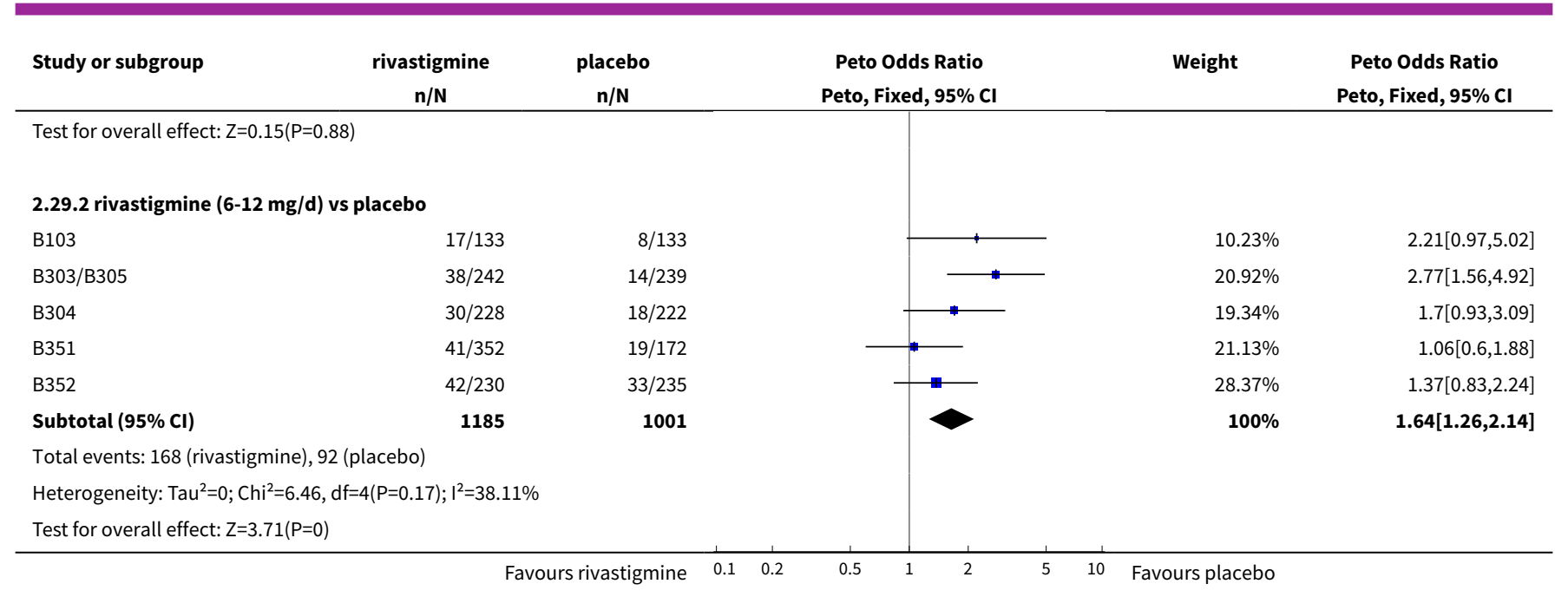

Analysis 2.30. Comparison 2 Rivastigmine oral capsules (1 to $4 \mathrm{mg} /$ day or 6 to $12 \mathrm{mg} /$ day in two divided doses) versus placebo, Outcome 30 at least one adverse event of headache by 26 weeks.

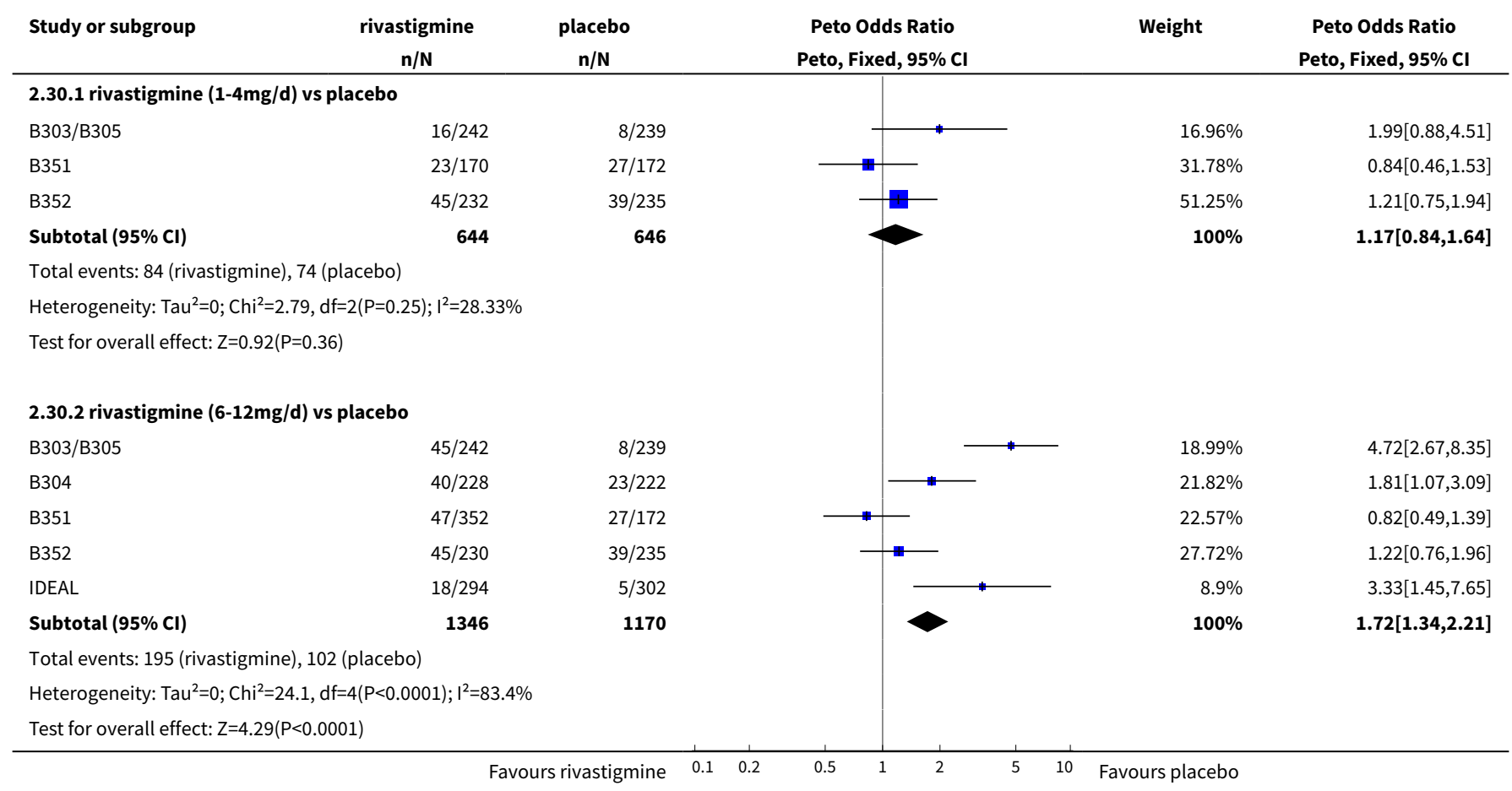

Analysis 2.31. Comparison 2 Rivastigmine oral capsules ( 1 to $4 \mathrm{mg} /$ day or 6 to $12 \mathrm{mg} /$ day in two divided doses) versus placebo, Outcome 31 at least one adverse event of insomnia by the end of titration period.

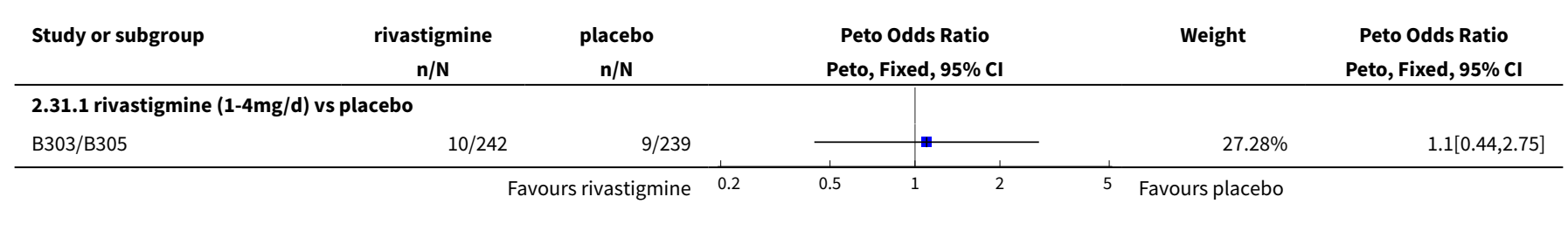




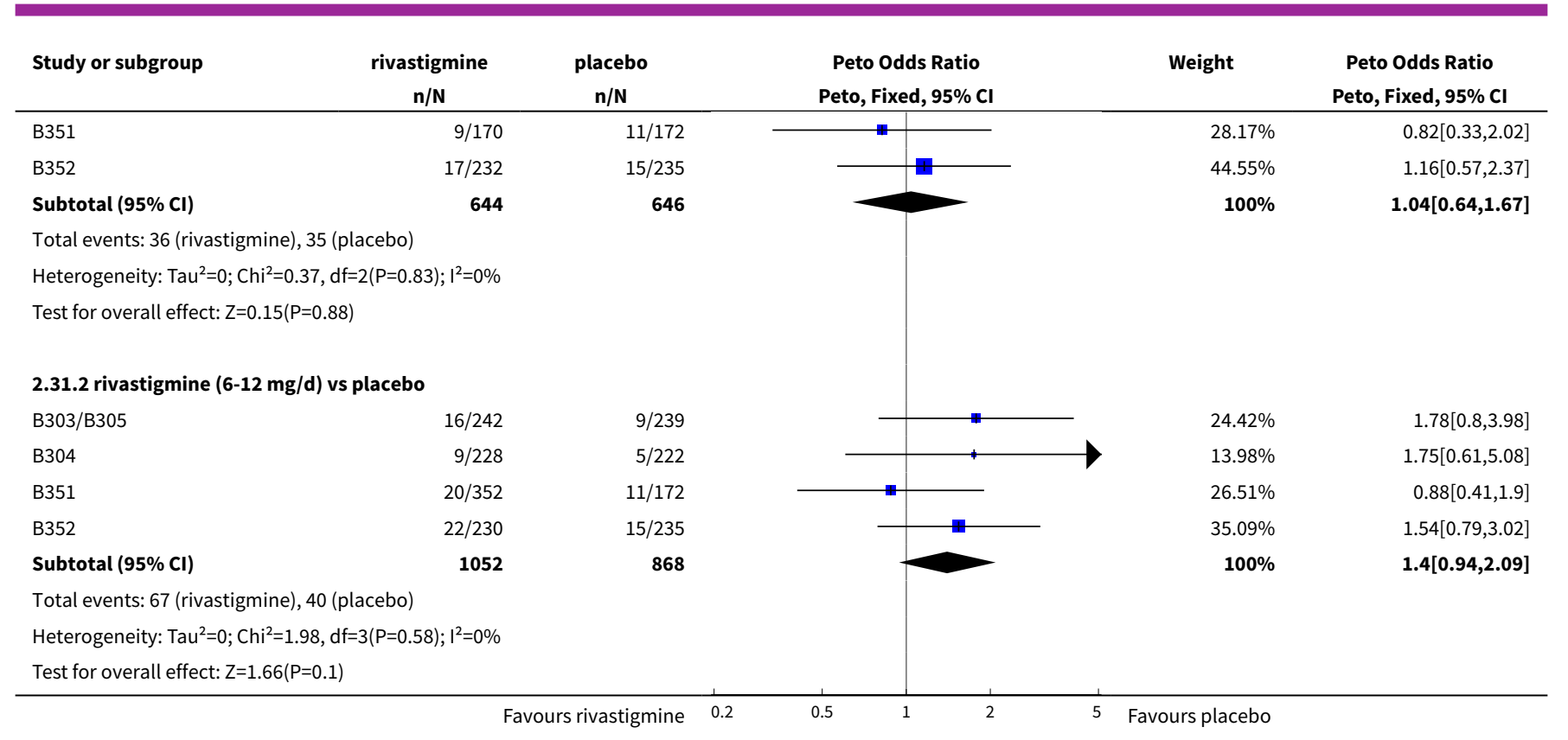

Analysis 2.32. Comparison 2 Rivastigmine oral capsules (1 to $4 \mathrm{mg} /$ day or 6 to $12 \mathrm{mg} /$ day in two divided doses) versus placebo, Outcome 32 at least one adverse event of insomnia by 26 weeks.

\begin{tabular}{|c|c|c|c|c|c|}
\hline Study or subgroup & $\begin{array}{c}\text { rivastigmine } \\
\mathrm{n} / \mathrm{N} \\
\end{array}$ & $\begin{array}{c}\text { placebo } \\
\mathrm{n} / \mathrm{N}\end{array}$ & $\begin{array}{c}\text { Peto Odds Ratio } \\
\text { Peto, Fixed, } 95 \% \mathrm{Cl}\end{array}$ & Weight & $\begin{array}{c}\text { Peto Odds Ratio } \\
\text { Peto, Fixed, } 95 \% \mathrm{Cl}\end{array}$ \\
\hline \multicolumn{6}{|c|}{ 2.32.1 rivastigmine $(1-4 \mathrm{mg} / \mathrm{d})$ vs placebo } \\
\hline B303/B305 & $13 / 242$ & $12 / 239$ & & $25.39 \%$ & $1.07[0.48,2.4]$ \\
\hline B351 & $15 / 170$ & $14 / 172$ & & $28.46 \%$ & $1.09[0.51,2.33]$ \\
\hline B352 & $24 / 232$ & $24 / 235$ & & $46.15 \%$ & $1.01[0.56,1.84]$ \\
\hline Subtotal $(95 \% \mathrm{Cl})$ & 644 & 646 & & $100 \%$ & $1.05[0.7,1.58]$ \\
\hline \multicolumn{6}{|c|}{ Total events: 52 (rivastigmine), 50 (placebo) } \\
\hline \multicolumn{6}{|c|}{ Heterogeneity: $\mathrm{Tau}^{2}=0 ; \mathrm{Chi}^{2}=0.03, \mathrm{df}=2(\mathrm{P}=0.99) ; \mathrm{I}^{2}=0 \%$} \\
\hline \multicolumn{6}{|c|}{ Test for overall effect: $Z=0.24(P=0.81)$} \\
\hline \multicolumn{6}{|c|}{ 2.32.2 rivastigmine $(6-12 \mathrm{mg} / \mathrm{d})$ vs placebo } \\
\hline B303/B305 & $17 / 242$ & $12 / 239$ & & $20.63 \%$ & $1.42[0.67,3.01]$ \\
\hline B304 & $13 / 228$ & $8 / 222$ & & $15.16 \%$ & $1.6[0.67,3.84]$ \\
\hline B351 & $30 / 352$ & $14 / 172$ & & $26.91 \%$ & $1.05[0.54,2.03]$ \\
\hline B352 & $32 / 230$ & $24 / 235$ & & $37.29 \%$ & $1.42[0.81,2.48]$ \\
\hline Subtotal $(95 \% \mathrm{Cl})$ & 1052 & 868 & & $100 \%$ & $1.33[0.95,1.87]$ \\
\hline \multicolumn{6}{|c|}{ Total events: 92 (rivastigmine), 58 (placebo) } \\
\hline \multicolumn{6}{|c|}{ Heterogeneity: $\mathrm{Tau}^{2}=0 ; \mathrm{Chi}^{2}=0.75, \mathrm{df}=3(\mathrm{P}=0.86) ; \mathrm{I}^{2}=0 \%$} \\
\hline \multicolumn{6}{|c|}{ Test for overall effect: $Z=1.65(P=0.1)$} \\
\hline
\end{tabular}


Analysis 2.33. Comparison 2 Rivastigmine oral capsules $(1$ to $4 \mathrm{mg} /$ day or 6 to $12 \mathrm{mg} /$ day in two divided doses) versus placebo, Outcome 33 at least one adverse event of syncope by the end of titration period.

\begin{tabular}{|c|c|c|c|c|c|}
\hline Study or subgroup & $\begin{array}{c}\text { rivastigmine } \\
\mathrm{n} / \mathrm{N}\end{array}$ & $\begin{array}{c}\text { placebo } \\
n / N\end{array}$ & $\begin{array}{c}\text { Peto Odds Ratio } \\
\text { Peto, Fixed, } 95 \% \mathrm{Cl}\end{array}$ & Weight & $\begin{array}{c}\text { Peto Odds Ratio } \\
\text { Peto, Fixed, } 95 \% \mathrm{Cl}\end{array}$ \\
\hline \multicolumn{6}{|c|}{ 2.33.1 rivastigmine $(1-4 \mathrm{mg} / \mathrm{d})$ vs placebo } \\
\hline B303/B305 & $4 / 242$ & $0 / 239$ & & $39.97 \%$ & $7.39[1.03,52.79]$ \\
\hline B351 & $1 / 170$ & $2 / 172$ & $\longrightarrow$ & $29.99 \%$ & $0.52[0.05,5.01]$ \\
\hline B352 & $1 / 232$ & $2 / 235$ & $\mathbf{q}$ & $30.04 \%$ & $0.52[0.05,5.01]$ \\
\hline Subtotal $(95 \% \mathrm{Cl})$ & 644 & 646 & & $100 \%$ & $1.5[0.43,5.2]$ \\
\hline \multicolumn{6}{|c|}{ Total events: 6 (rivastigmine), 4 (placebo) } \\
\hline \multicolumn{6}{|c|}{ Heterogeneity: $\mathrm{Tau}^{2}=0 ; \mathrm{Chi}^{2}=4.21, \mathrm{df}=2(\mathrm{P}=0.12) ; \mathrm{I}^{2}=52.54 \%$} \\
\hline \multicolumn{6}{|c|}{ Test for overall effect: $Z=0.64(P=0.52)$} \\
\hline \multicolumn{6}{|c|}{ 2.33.2 rivastigmine $(6-12 \mathrm{mg} / \mathrm{d})$ vs placebo } \\
\hline B303/B305 & $3 / 242$ & $0 / 239$ & & $11.68 \%$ & $7.36[0.76,71.08]$ \\
\hline B304 & $6 / 228$ & $3 / 222$ & 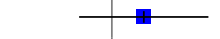 & $34.56 \%$ & $1.92[0.51,7.17]$ \\
\hline B352 & $4 / 230$ & $2 / 235$ & & $23.2 \%$ & $2.01[0.4,10.02]$ \\
\hline Subtotal $(95 \% \mathrm{Cl})$ & 1052 & 868 & & $100 \%$ & $2.16[0.99,4.68]$ \\
\hline \multicolumn{6}{|c|}{ Total events: 20 (rivastigmine), 7 (placebo) } \\
\hline \multicolumn{6}{|c|}{ Heterogeneity: $\operatorname{Tau}^{2}=0 ; \mathrm{Chi}^{2}=1.32, \mathrm{df}=3(\mathrm{P}=0.73) ; \mathrm{I}^{2}=0 \%$} \\
\hline Test for overall effect & & & & & \\
\hline
\end{tabular}

Analysis 2.34. Comparison 2 Rivastigmine oral capsules (1 to $4 \mathrm{mg} /$ day or 6 to $12 \mathrm{mg}$ /day in two divided doses) versus placebo, Outcome 34 at least one adverse event of syncope by 26 weeks.

\begin{tabular}{|c|c|c|c|c|c|}
\hline Study or subgroup & $\begin{array}{c}\text { rivastigmine } \\
\mathrm{n} / \mathrm{N} \\
\end{array}$ & $\begin{array}{c}\text { placebo } \\
n / N\end{array}$ & $\begin{array}{c}\text { Peto Odds Ratio } \\
\text { Peto, Fixed, } 95 \% \mathrm{Cl}\end{array}$ & Weight & $\begin{array}{c}\text { Peto Odds Ratio } \\
\text { Peto, Fixed, } 95 \% \mathrm{Cl}\end{array}$ \\
\hline \multicolumn{6}{|c|}{ 2.34.1 rivastigmine $(1-4 \mathrm{mg} / \mathrm{d})$ vs placebo } \\
\hline B303/B305 & $4 / 242$ & $2 / 239$ & $\mathbf{m}$ & $37.51 \%$ & $1.94[0.39,9.68]$ \\
\hline B351 & $1 / 170$ & $2 / 172$ & & $18.84 \%$ & $0.52[0.05,5.01]$ \\
\hline B352 & $3 / 232$ & $4 / 235$ & & $43.65 \%$ & $0.76[0.17,3.37]$ \\
\hline Subtotal $(95 \% \mathrm{CI})$ & 644 & 646 & & $100 \%$ & $1[0.37,2.69]$ \\
\hline \multicolumn{6}{|c|}{ Heterogeneity: $\mathrm{Tau}^{2}=0 ; \mathrm{Chi}^{2}=1.1, \mathrm{df}=2(\mathrm{P}=0.58) ; \mathrm{I}^{2}=0 \%$} \\
\hline \multicolumn{6}{|c|}{ Test for overall effect: $Z=0.01(P=0.99)$} \\
\hline \multicolumn{6}{|c|}{ 2.34.2 rivastigmine $(6-12 \mathrm{mg} / \mathrm{d}$ bid $)$ vs placebo } \\
\hline B303/B305 & $5 / 242$ & $2 / 239$ & + & $15.64 \%$ & $2.35[0.53,10.45]$ \\
\hline B304 & $10 / 228$ & $7 / 222$ & - & $37.09 \%$ & $1.4[0.53,3.69]$ \\
\hline B352 & $5 / 230$ & $4 / 235$ & 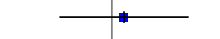 & $20.01 \%$ & $1.28[0.34,4.79]$ \\
\hline Subtotal $(95 \% \mathrm{Cl})$ & 1052 & 868 & & $100 \%$ & $1.72[0.96,3.11]$ \\
\hline \multicolumn{6}{|c|}{ Total events: 32 (rivastigmine), 15 (placebo) } \\
\hline \multicolumn{6}{|c|}{ Heterogeneity: $\mathrm{Tau}^{2}=0 ; \mathrm{Chi}^{2}=0.84, \mathrm{df}=3(\mathrm{P}=0.84) ; \mathrm{I}^{2}=0 \%$} \\
\hline Test for overall effec & & & & & \\
\hline
\end{tabular}


Analysis 2.35. Comparison 2 Rivastigmine oral capsules ( 1 to $4 \mathrm{mg} /$ day or 6 to $12 \mathrm{mg} /$ day in two divided doses) versus placebo, Outcome 35 at least one adverse event of abdominal pain by the end of titration period.

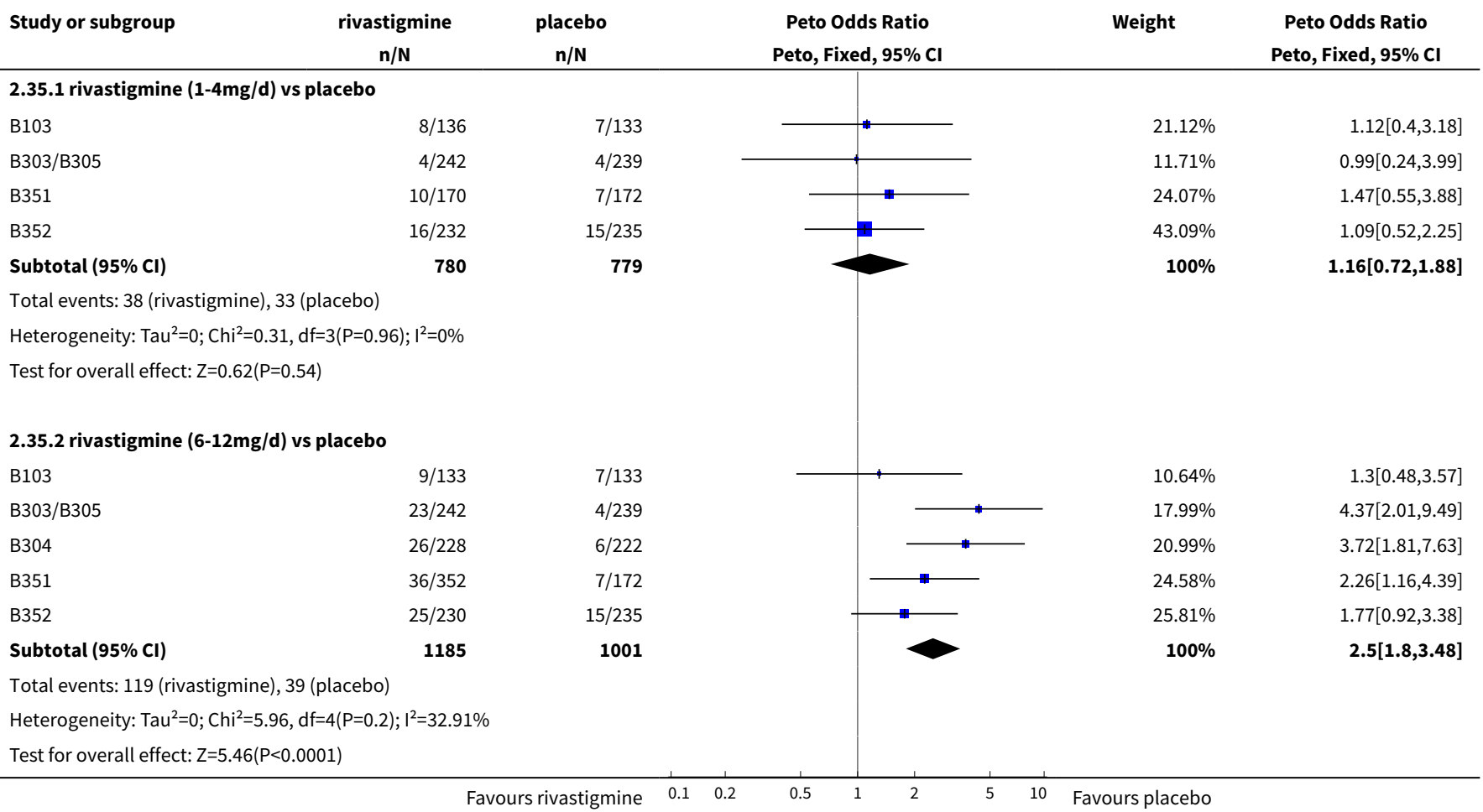

Analysis 2.36. Comparison 2 Rivastigmine oral capsules ( 1 to $4 \mathrm{mg} /$ day or 6 to $12 \mathrm{mg} /$ day in two divided doses) versus placebo, Outcome 36 at least one adverse event of abdominal pain by 26 weeks.

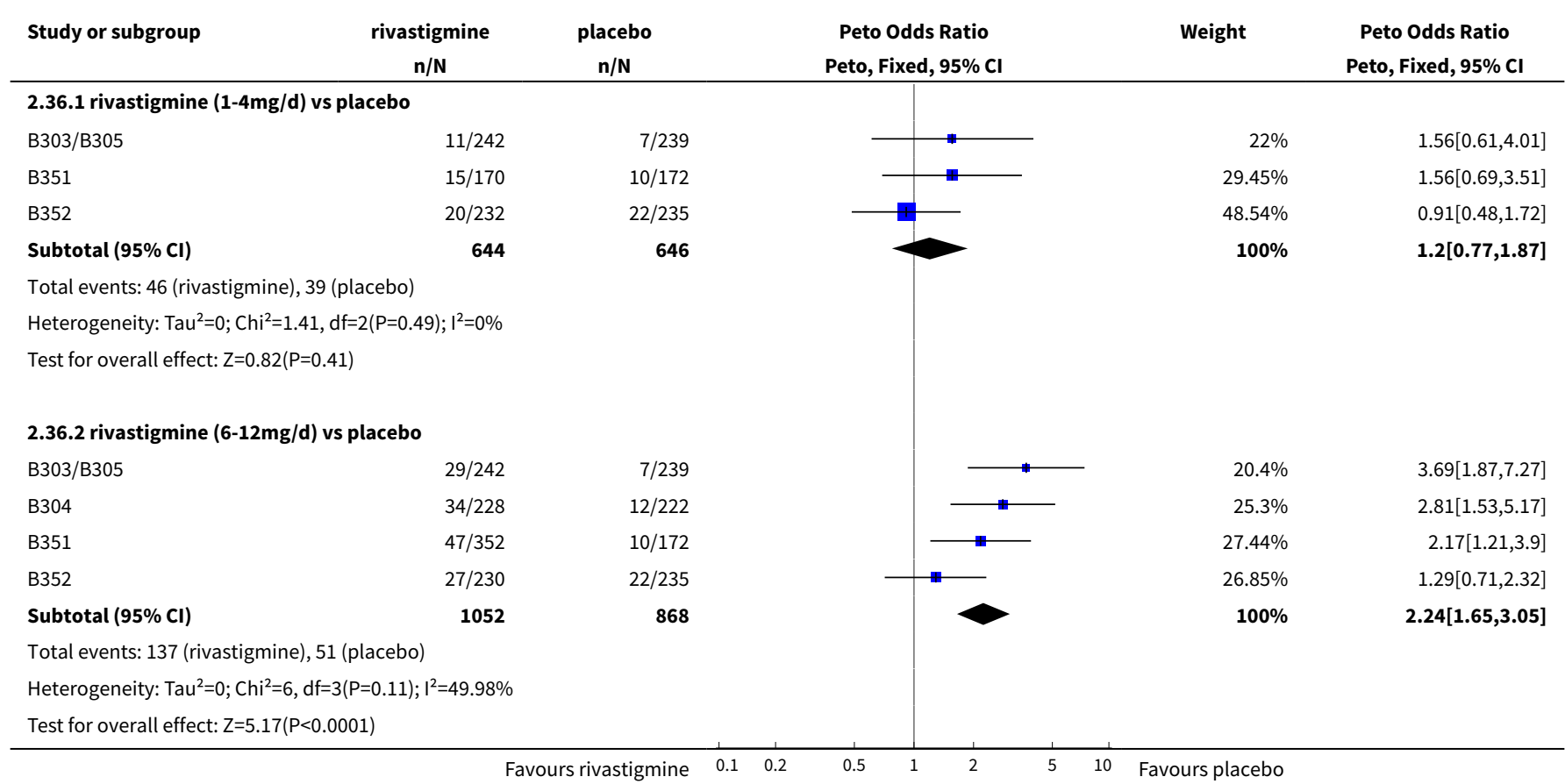


Analysis 2.37. Comparison 2 Rivastigmine oral capsules (1 to $4 \mathrm{mg} /$ day or 6 to $12 \mathrm{mg} /$ day in two divided doses) versus placebo, Outcome 37 at least one adverse event of dizziness by the end of titration period.

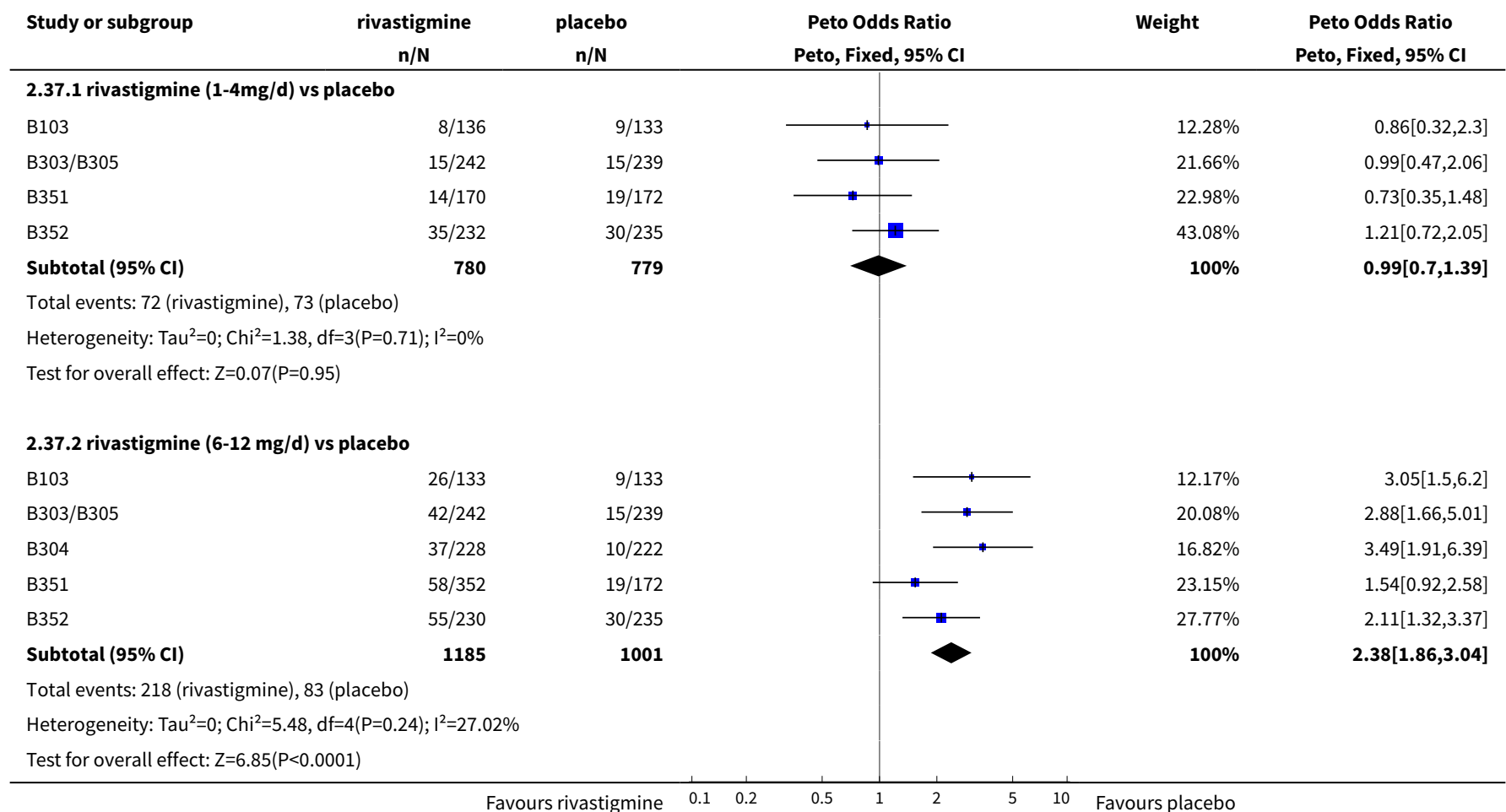

Analysis 2.38. Comparison 2 Rivastigmine oral capsules ( 1 to $4 \mathrm{mg} /$ day or 6 to $12 \mathrm{mg} /$ day in two divided doses) versus placebo, Outcome 38 at least one adverse event of dizziness by 26 weeks.

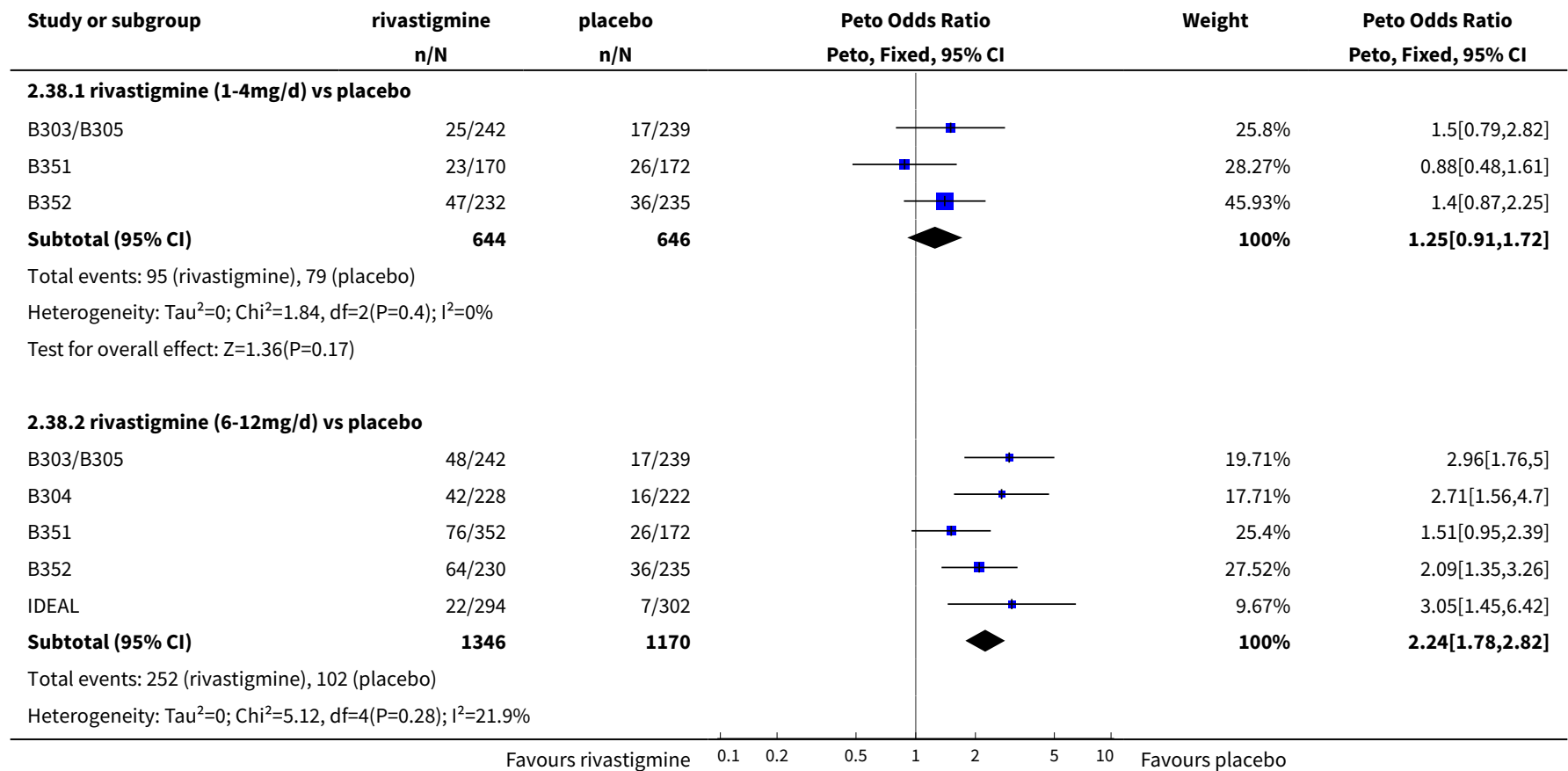




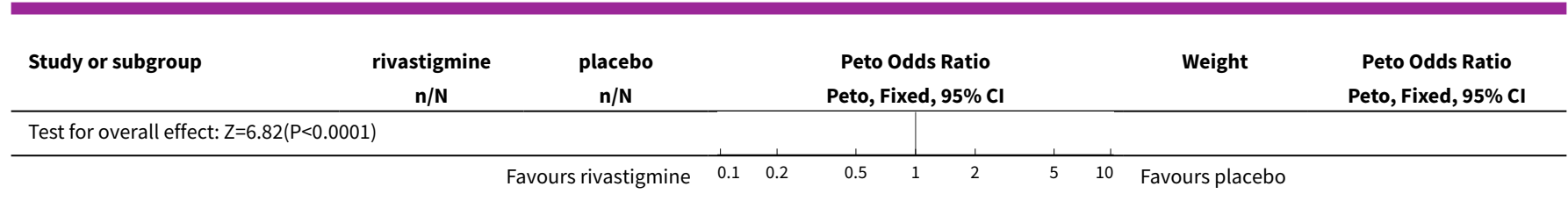

Analysis 2.39. Comparison 2 Rivastigmine oral capsules (1 to $4 \mathrm{mg} /$ day or 6 to $12 \mathrm{mg} / \mathrm{day}$ in two divided doses) versus placebo, Outcome 39 at least one adverse event of bone fracture by the end of titration period.

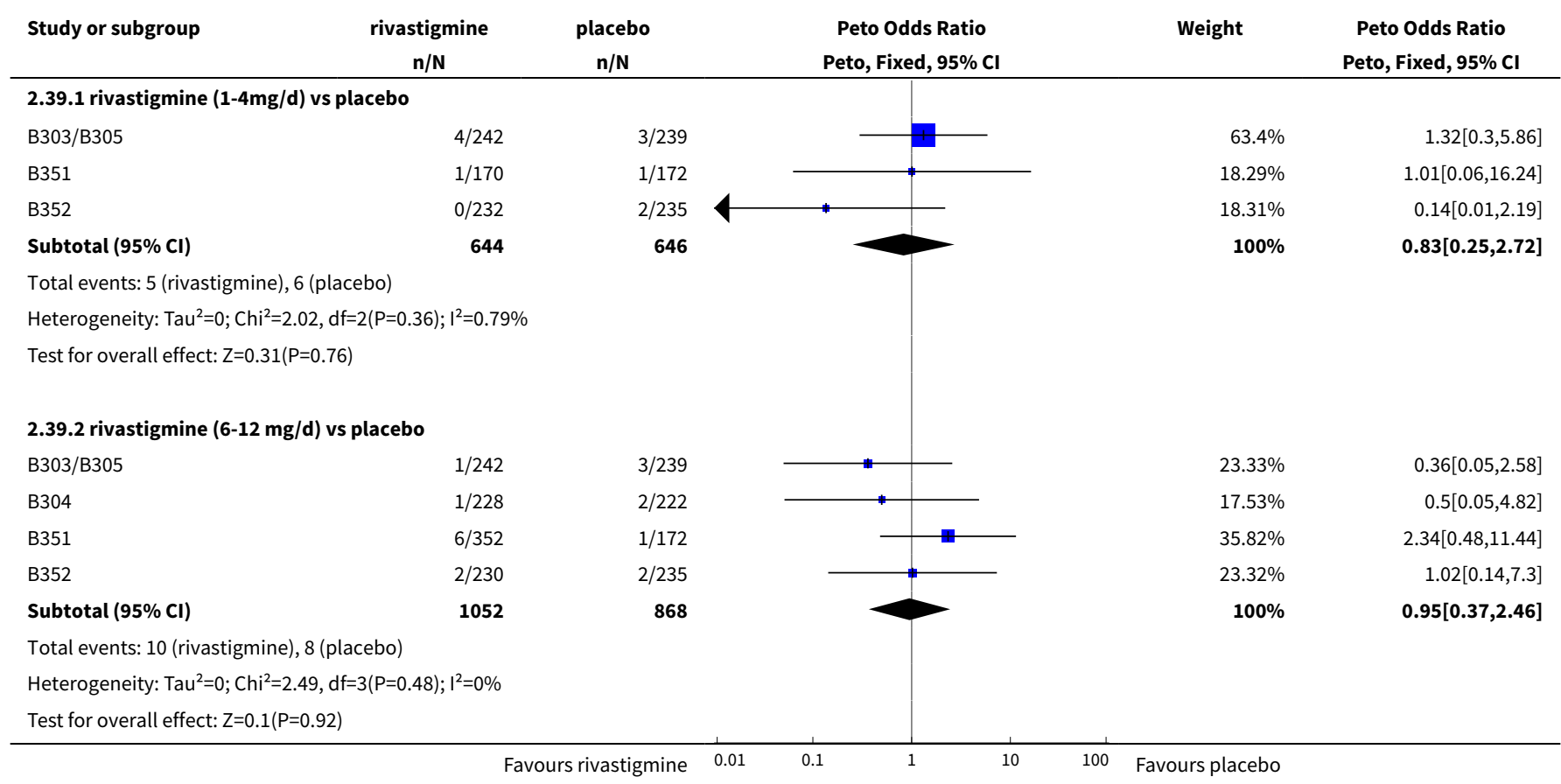

Analysis 2.40. Comparison 2 Rivastigmine oral capsules ( 1 to $4 \mathrm{mg} /$ day or 6 to $12 \mathrm{mg}$ /day in two divided doses) versus placebo, Outcome $\mathbf{4 0}$ at least one adverse event of bone fracture by 26 weeks.

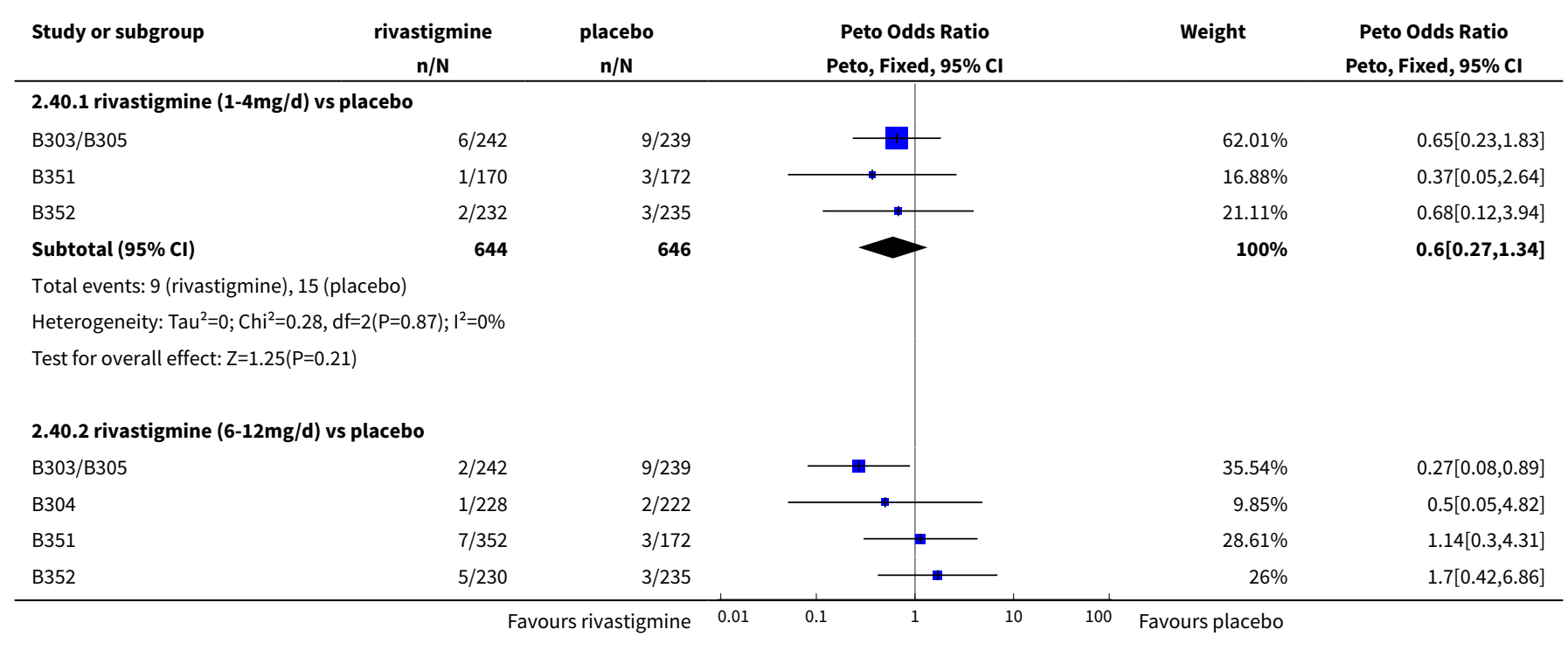




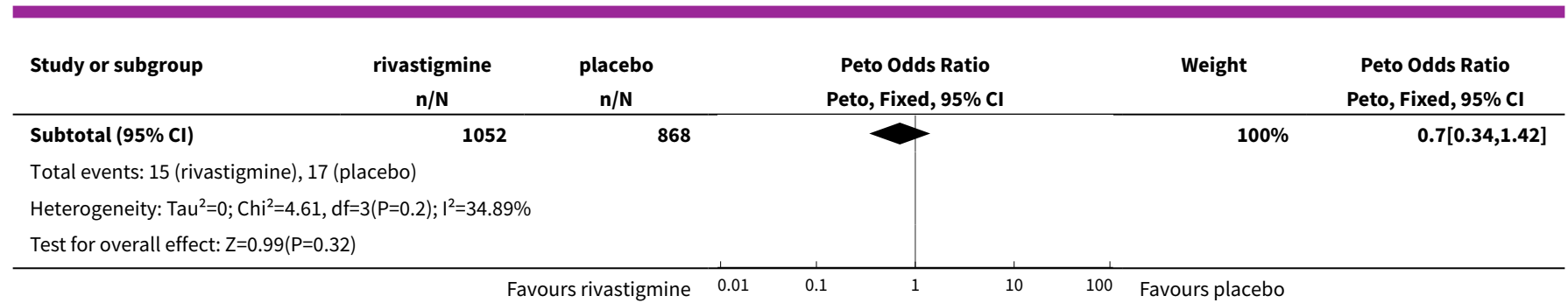

\section{Analysis 2.41. Comparison 2 Rivastigmine oral capsules $(1 \mathrm{to} 4 \mathrm{mg} /$ day or 6 to $12 \mathrm{mg} /$ day in two} divided doses) versus placebo, Outcome 41 at least one adverse event of asthenia by 26 weeks.

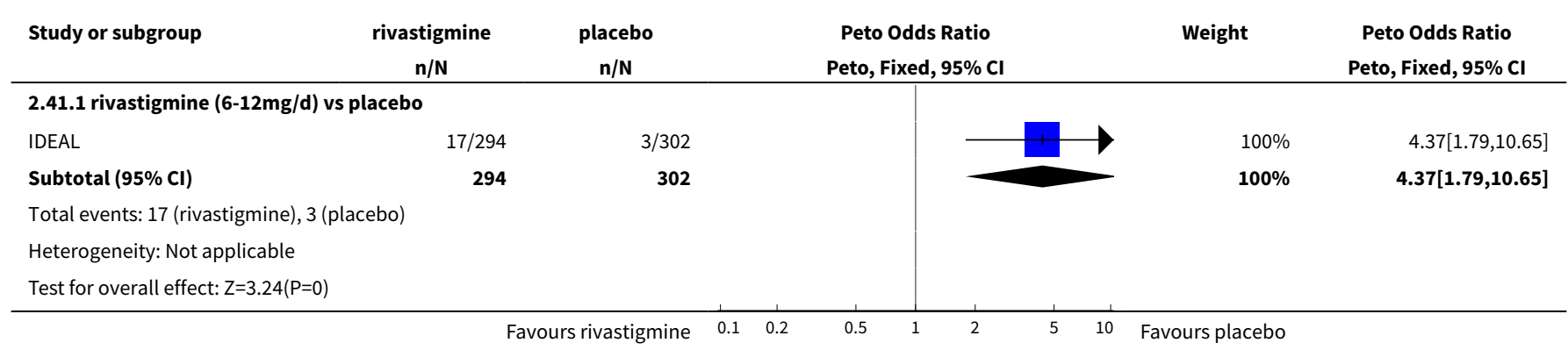

\section{Analysis 2.42. Comparison 2 Rivastigmine oral capsules (1 to $4 \mathrm{mg} /$ day or 6 to $12 \mathrm{mg} /$ day in two divided doses) versus placebo, Outcome 42 at least one severe adverse event by the end of titration period.}

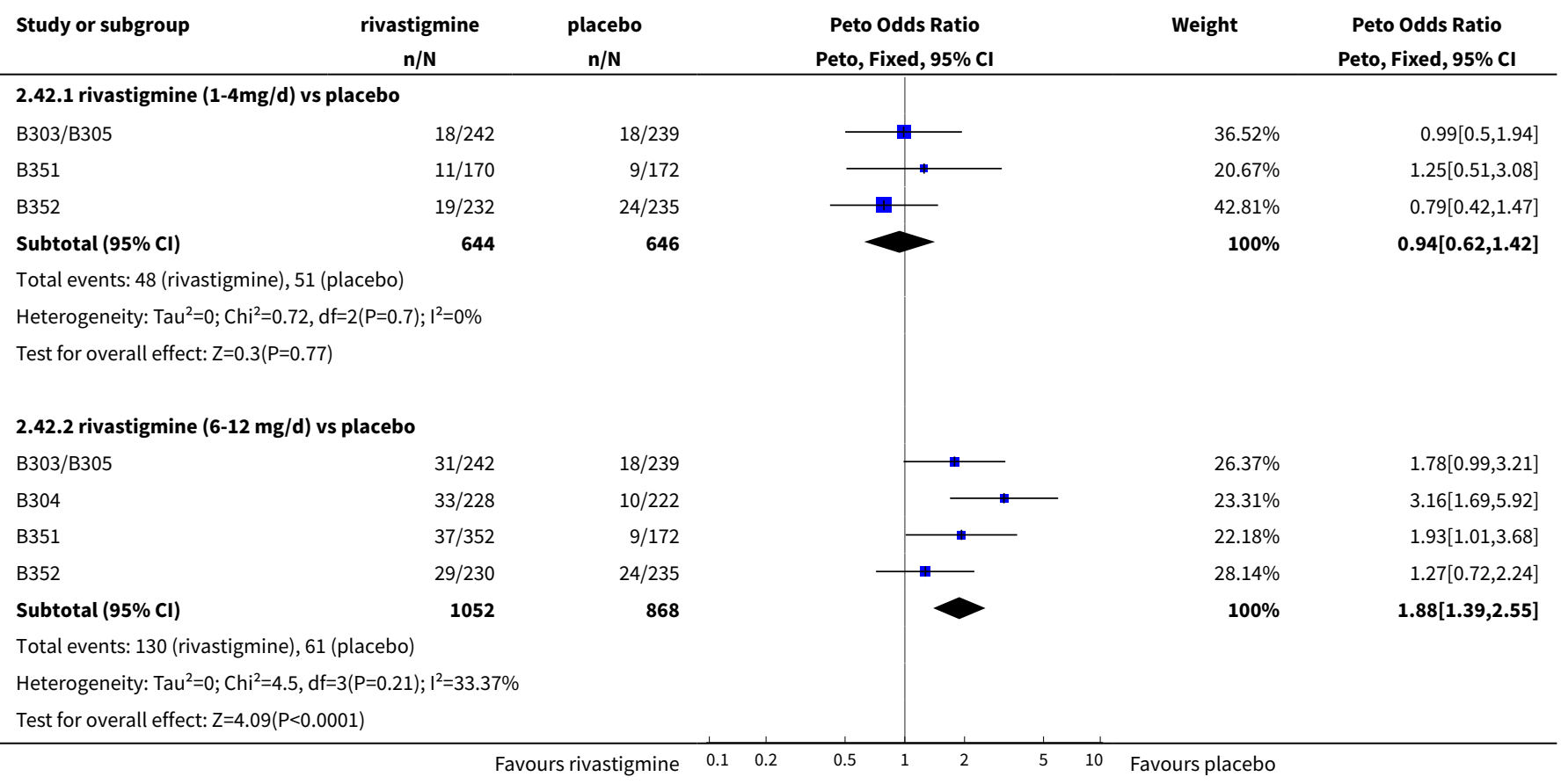


Analysis 2.43. Comparison 2 Rivastigmine oral capsules (1 to $4 \mathrm{mg} /$ day or 6 to $12 \mathrm{mg} /$ day in two divided doses) versus placebo, Outcome 43 at least one serious adverse event by 26 weeks.

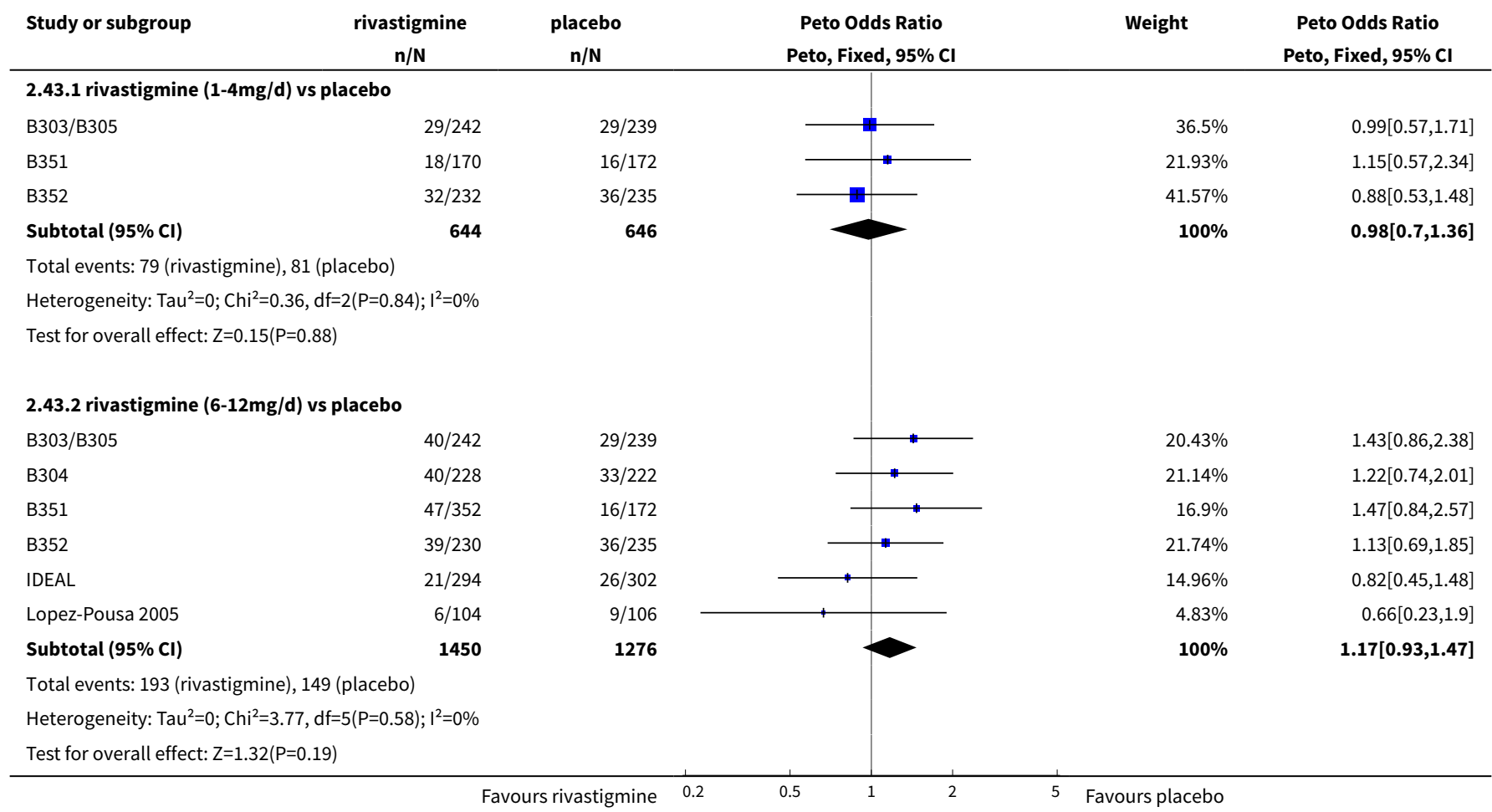

Analysis 2.44. Comparison 2 Rivastigmine oral capsules (1 to $4 \mathrm{mg} /$ day or 6 to $12 \mathrm{mg} /$ day in two divided doses) versus placebo, Outcome 44 deaths before end of treatment at 12 weeks.

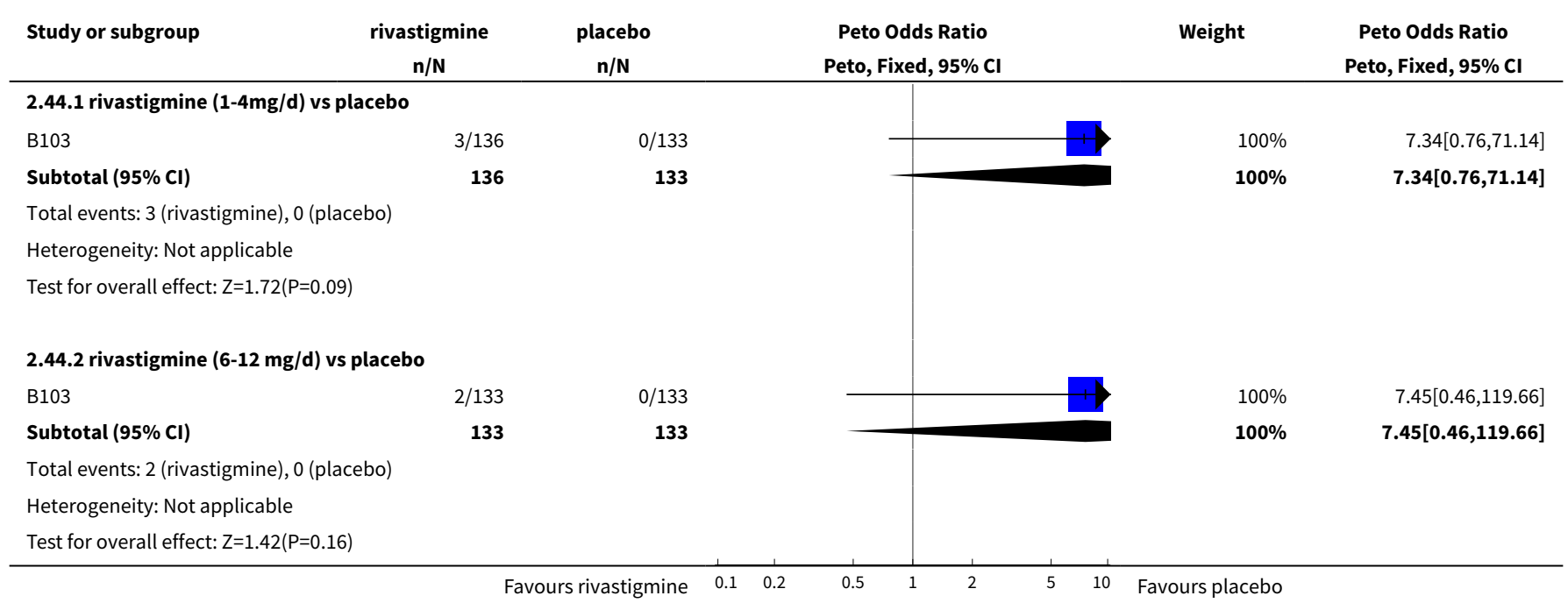


Analysis 2.45. Comparison 2 Rivastigmine oral capsules (1 to $4 \mathrm{mg} /$ day or 6 to $12 \mathrm{mg} /$ day in two divided doses) versus placebo, Outcome 45 deaths before end of treatment at 26 weeks.

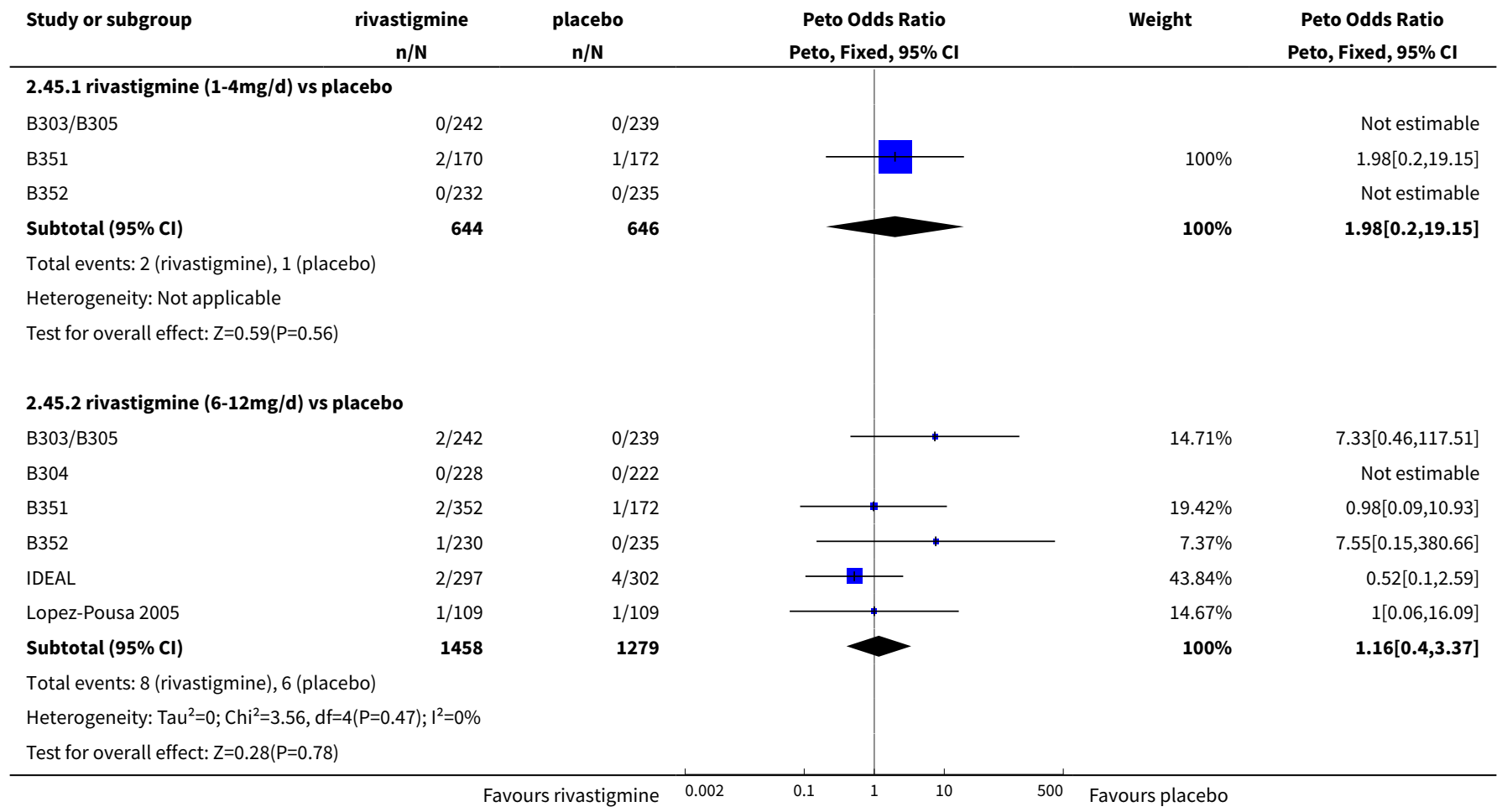

\section{Analysis 2.46. Comparison 2 Rivastigmine oral capsules ( 1 to $4 \mathrm{mg} /$ day or 6 to $12 \mathrm{mg} /$ day in two divided doses) versus placebo, Outcome 46 CIBIC-Plus (no change or worse at 12 weeks) OC.}

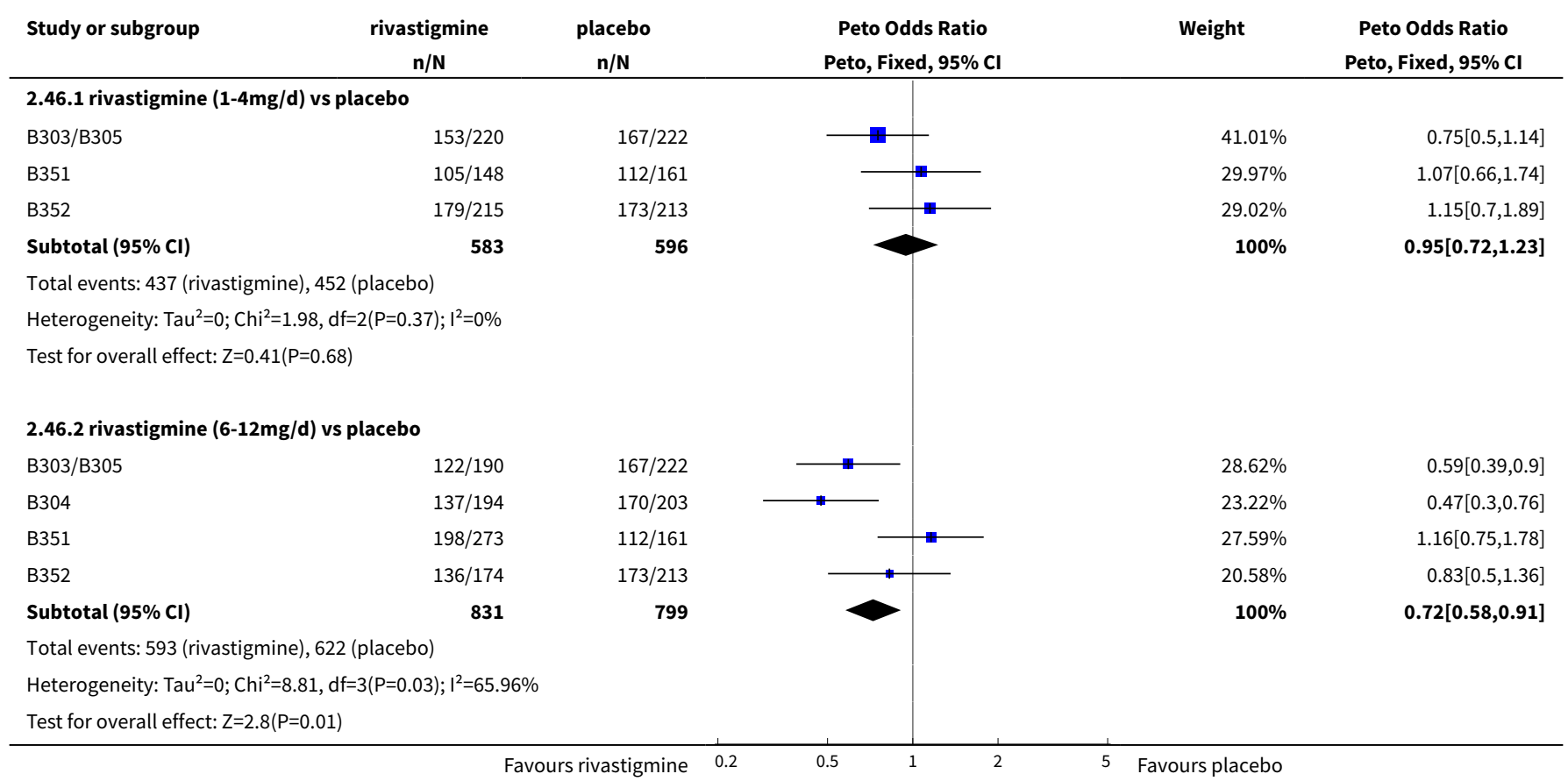




\section{Analysis 2.47. Comparison 2 Rivastigmine oral capsules ( 1 to $4 \mathrm{mg} /$ day or 6 to $12 \mathrm{mg} /$ day in two divided doses) versus placebo, Outcome 47 CIBIC-Plus (no change or worse at 26 weeks) OC.}

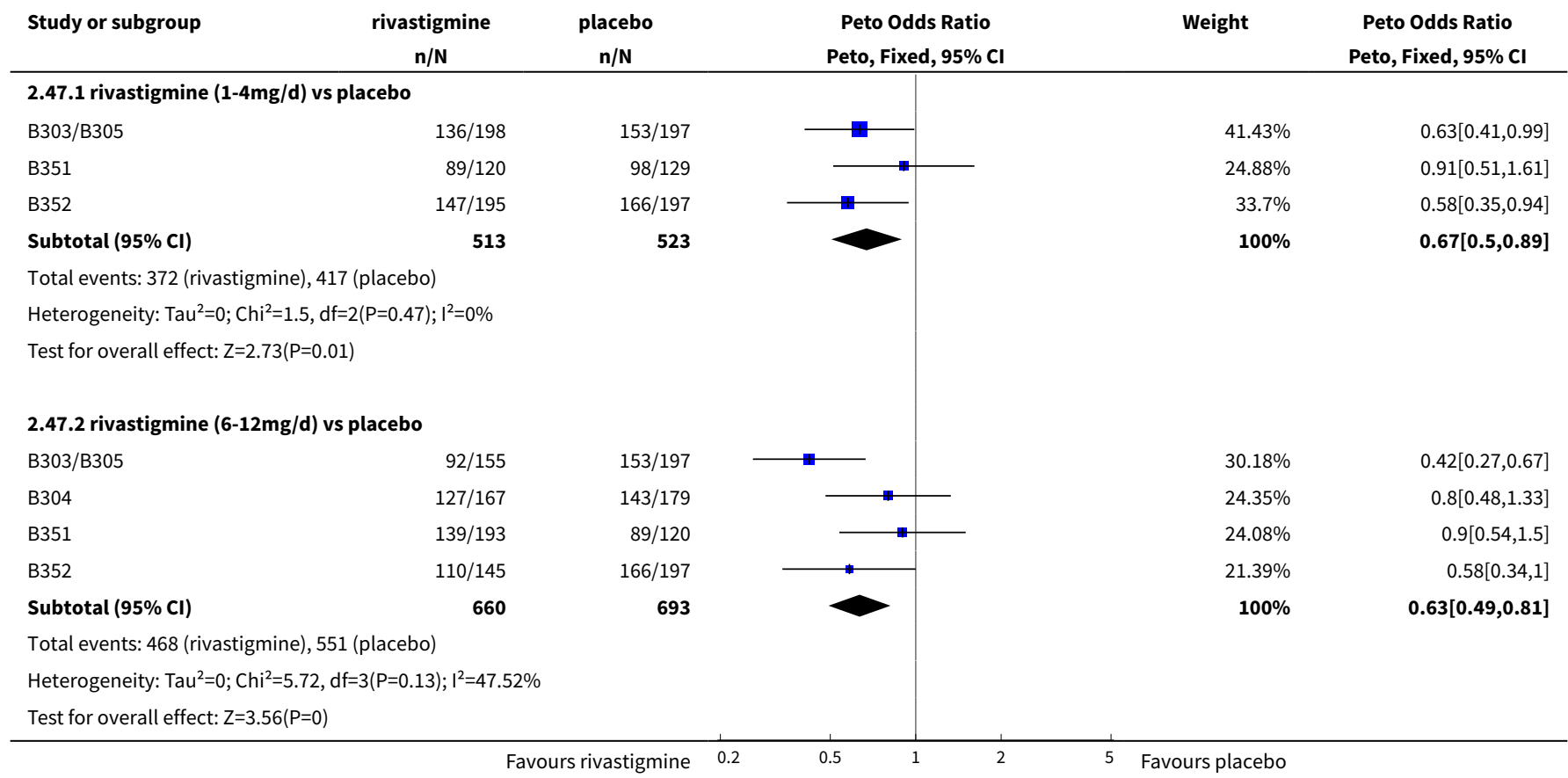

Analysis 2.48. Comparison 2 Rivastigmine oral capsules (1 to $4 \mathrm{mg} /$ day or 6 to $12 \mathrm{mg} /$ day in two divided doses) versus placebo, Outcome 48 CIBIC-Plus (no change or worse at 12 weeks) OC+RDO.

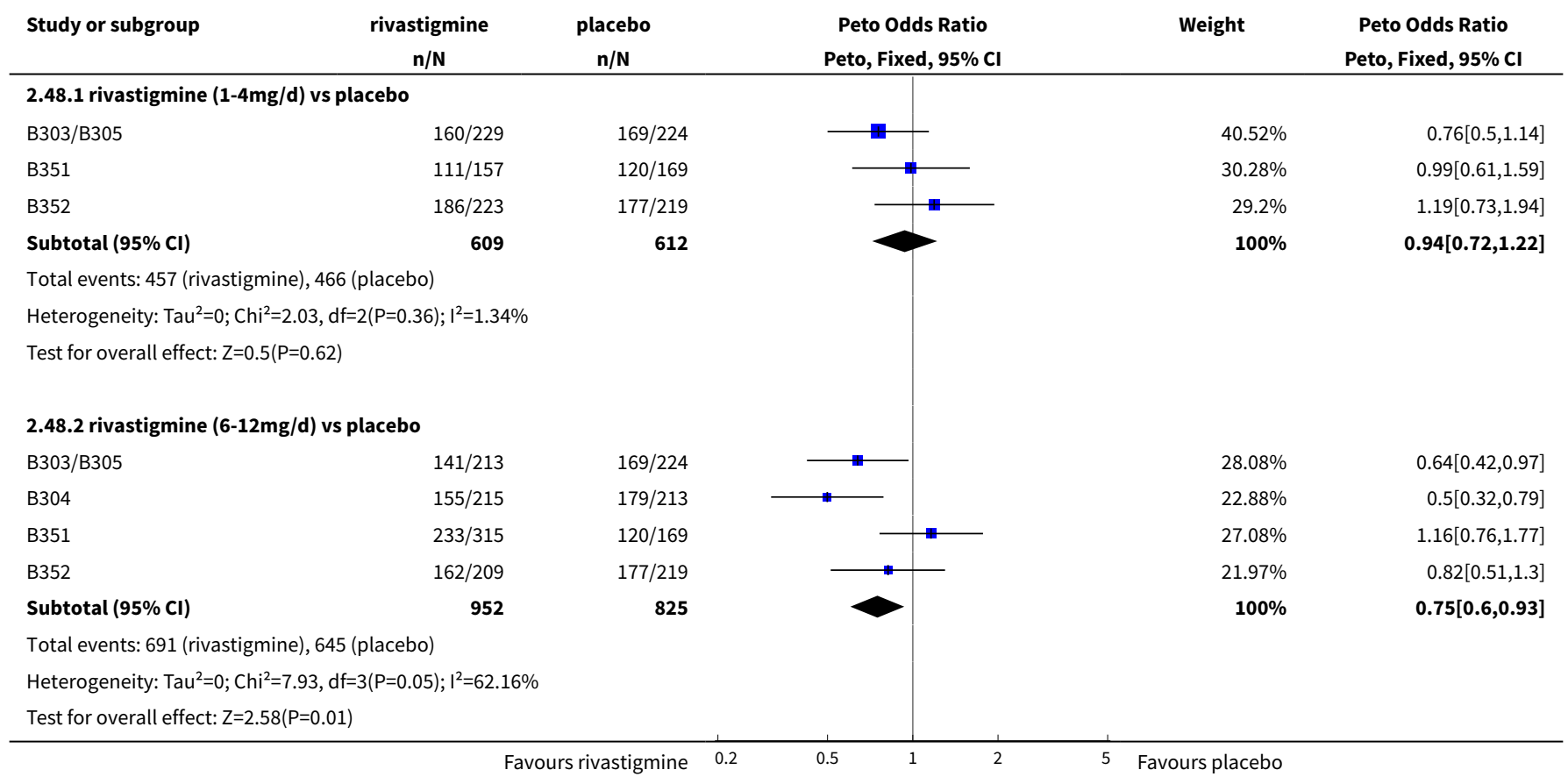


Analysis 2.49. Comparison 2 Rivastigmine oral capsules ( 1 to $4 \mathrm{mg} /$ day or 6 to $12 \mathrm{mg} /$ day in two divided doses) versus placebo, Outcome 49 CIBIC-Plus (no change or worse at 26 weeks) OC+RDO.

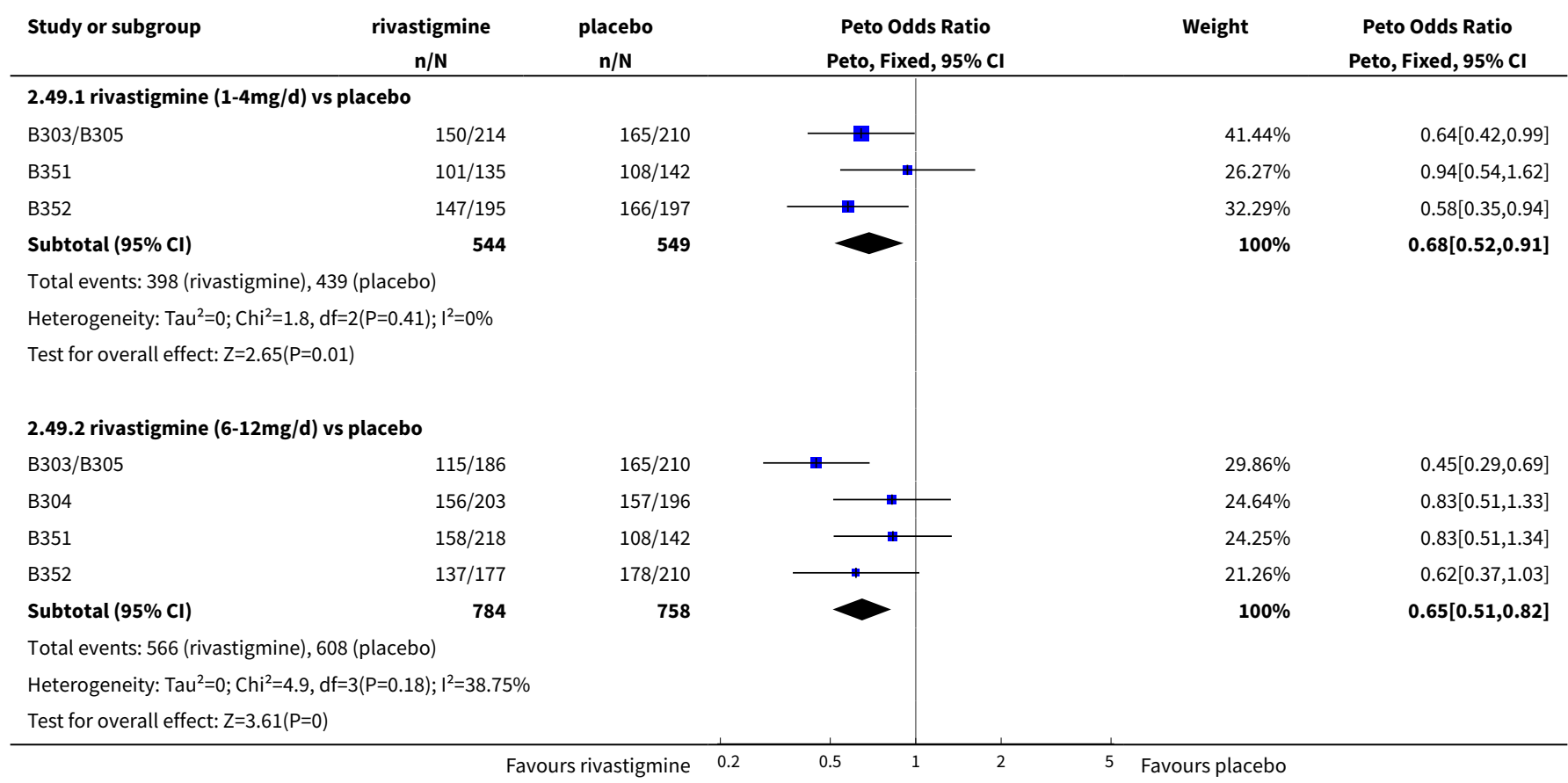

Analysis 2.50. Comparison 2 Rivastigmine oral capsules (1 to $4 \mathrm{mg} /$ day or 6 to $12 \mathrm{mg} /$ day in two divided doses) versus placebo, Outcome 50 CIBIC-Plus (no change or worse at 12 weeks) ALL+OC.

\begin{tabular}{|c|c|c|c|c|c|}
\hline Study or subgroup & $\begin{array}{c}\text { rivastigmine } \\
\mathrm{n} / \mathrm{N}\end{array}$ & $\begin{array}{c}\text { placebo } \\
n / N\end{array}$ & $\begin{array}{c}\text { Peto Odds Ratio } \\
\text { Peto, Fixed, } 95 \% \mathrm{Cl}\end{array}$ & Weight & $\begin{array}{c}\text { Peto Odds Ratio } \\
\text { Peto, Fixed, } 95 \% \mathrm{Cl}\end{array}$ \\
\hline \multicolumn{6}{|c|}{ 2.50.1 rivastigmine $(1-4 \mathrm{mg} / \mathrm{d})$ vs placebo } \\
\hline B303/B305 & $175 / 242$ & $183 / 238$ & 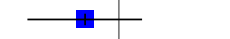 & $40.95 \%$ & $0.79[0.52,1.18]$ \\
\hline B351 & $132 / 175$ & $122 / 171$ & 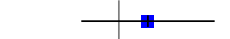 & $30.41 \%$ & $1.23[0.77,1.98]$ \\
\hline B352 & $197 / 233$ & $194 / 234$ & & $28.64 \%$ & $1.13[0.69,1.84]$ \\
\hline Subtotal $(95 \% \mathrm{Cl})$ & 650 & 643 & & $100 \%$ & $1[0.77,1.3]$ \\
\hline \multicolumn{6}{|c|}{ Heterogeneity: $\mathrm{Tau}^{2}=0 ; \mathrm{Chi}^{2}=2.29, \mathrm{df}=2(\mathrm{P}=0.32) ; \mathrm{I}^{2}=12.69 \%$} \\
\hline \multicolumn{6}{|c|}{ Test for overall effect: $Z=0.01(P=1)$} \\
\hline \multicolumn{6}{|c|}{2.50 .2 rivastigmine $(6-12 \mathrm{mg} / \mathrm{d})$ vs placebo } \\
\hline B303/B305 & $174 / 242$ & $183 / 238$ & $\longrightarrow$ & $29.36 \%$ & $0.77[0.51,1.16]$ \\
\hline B304 & $171 / 228$ & $187 / 220$ & - & $23.08 \%$ & $0.54[0.34,0.85]$ \\
\hline B352 & $193 / 231$ & $194 / 234$ & & $20.84 \%$ & $1.05[0.64,1.7]$ \\
\hline Subtotal $(95 \% \mathrm{Cl})$ & 1054 & 863 & & $100 \%$ & $0.9[0.72,1.13]$ \\
\hline \multicolumn{6}{|c|}{ Total events: 816 (rivastigmine), 686 (placebo) } \\
\hline \multicolumn{6}{|c|}{ Heterogeneity: $\mathrm{Tau}^{2}=0 ; \mathrm{Chi}^{2}=11.25, \mathrm{df}=3(\mathrm{P}=0.01) ; \mathrm{I}^{2}=73.34 \%$} \\
\hline \multicolumn{6}{|c|}{ Test for overall effect: $Z=0.89(P=0.37)$} \\
\hline
\end{tabular}


Analysis 2.51. Comparison 2 Rivastigmine oral capsules ( 1 to $4 \mathrm{mg} /$ day or 6 to $12 \mathrm{mg} /$ day in two divided doses) versus placebo, Outcome 51 CIBIC-Plus (no change or worse at 26 weeks) ALL+OC.

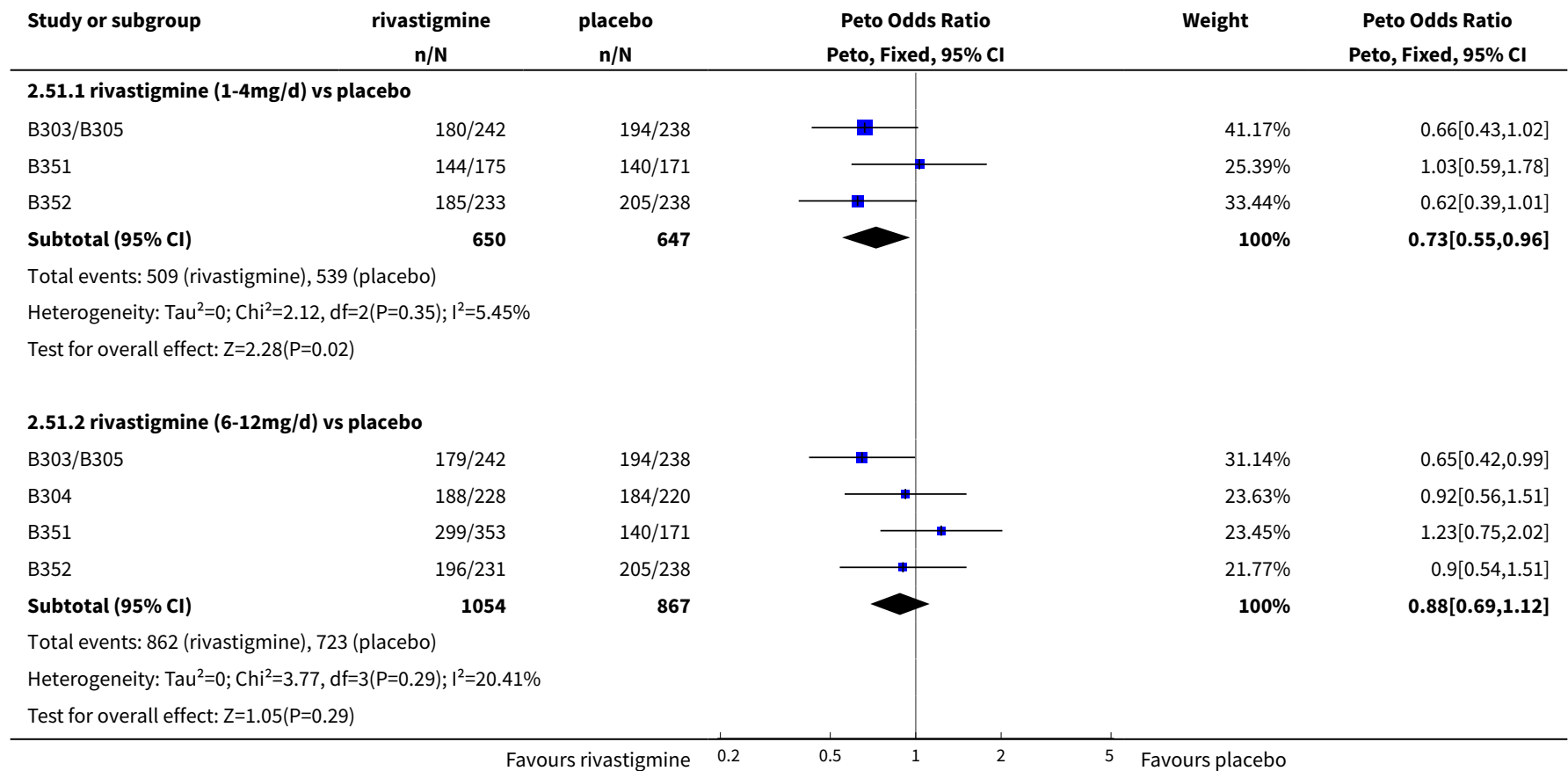

\section{Analysis 2.52. Comparison 2 Rivastigmine oral capsules ( 1 to $4 \mathrm{mg} /$ day or 6 to $12 \mathrm{mg} /$ day in two divided doses) versus placebo, Outcome 52 ADAS-Cog (change from baseline at 12 weeks) OC.}

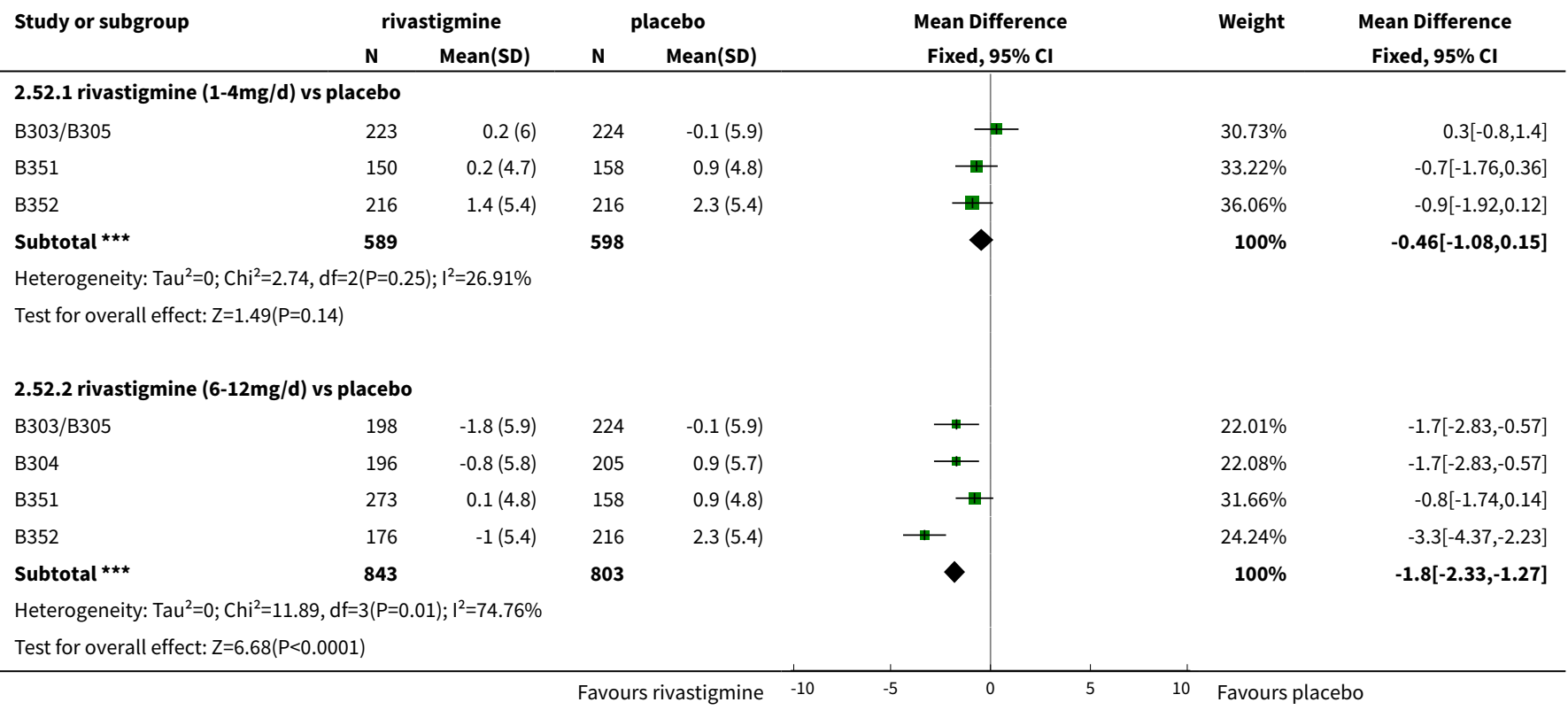


Analysis 2.53. Comparison 2 Rivastigmine oral capsules ( 1 to $4 \mathrm{mg} /$ day or 6 to $12 \mathrm{mg} /$ day in two divided doses) versus placebo, Outcome 53 ADAS-Cog (change from baseline at 26 weeks) OC.

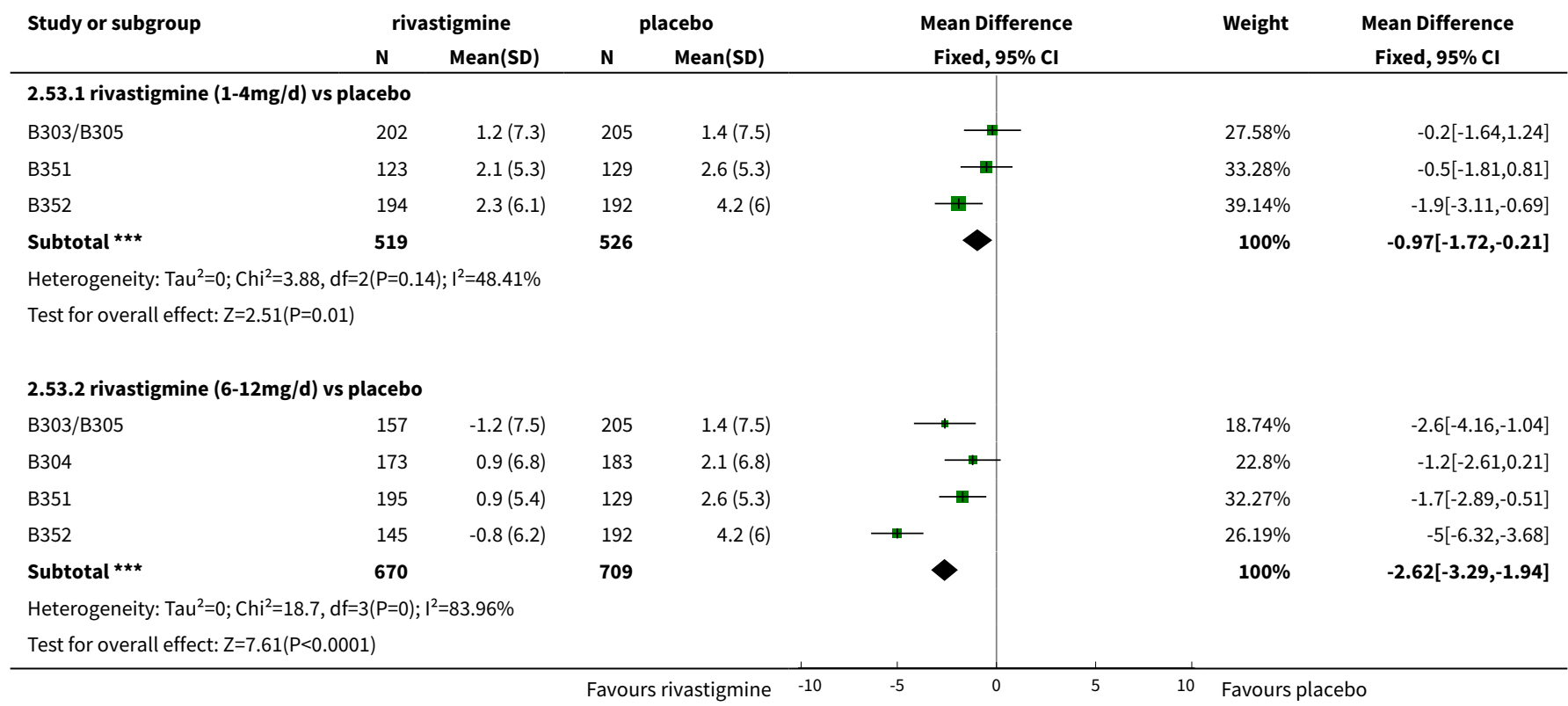

Analysis 2.54. Comparison 2 Rivastigmine oral capsules (1 to $4 \mathrm{mg} / \mathrm{day}$ or 6 to $12 \mathrm{mg} / \mathrm{day}$ in two divided doses) versus placebo, Outcome 54 ADAS-Cog (change from baseline at 12 weeks) OC+RDO.

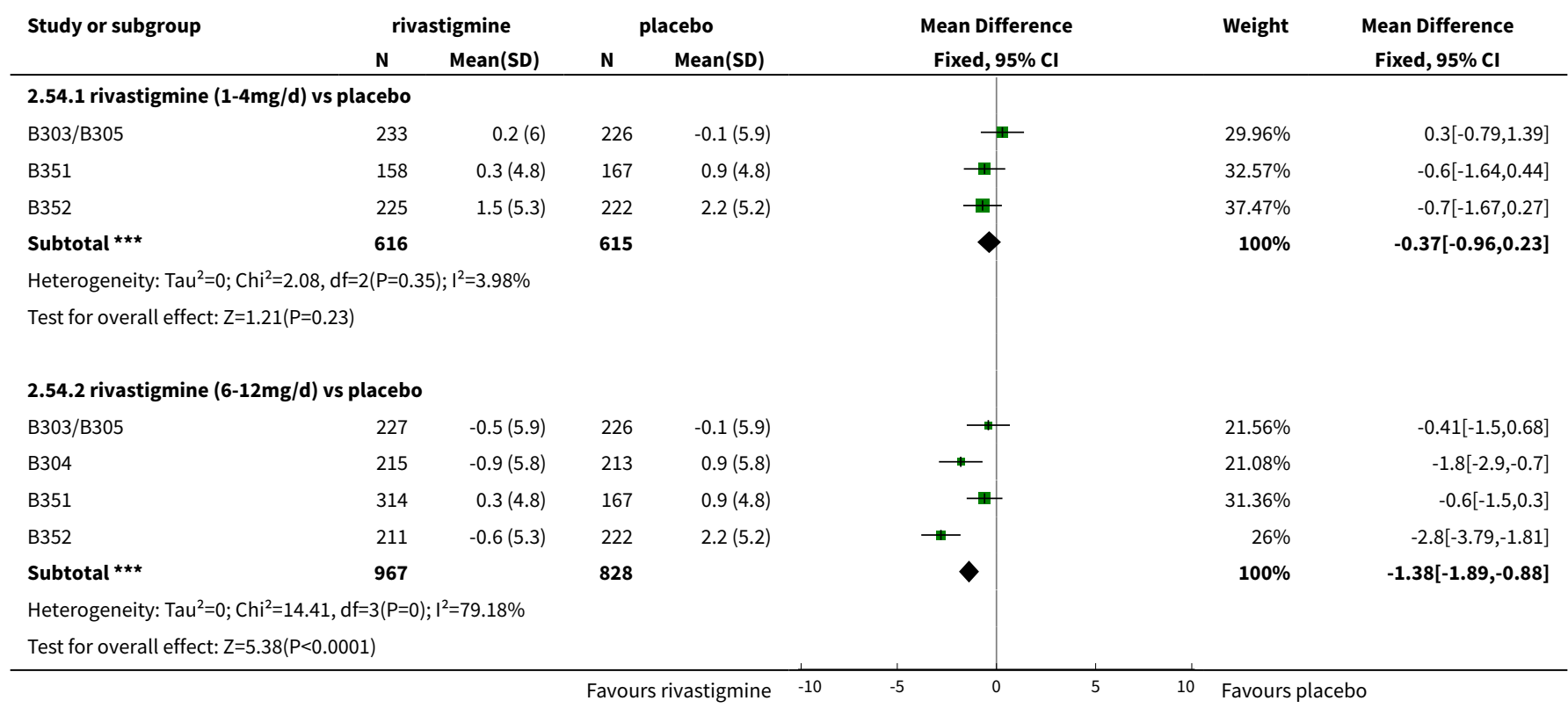


Analysis 2.55. Comparison 2 Rivastigmine oral capsules (1 to $4 \mathrm{mg} /$ day or 6 to $12 \mathrm{mg} /$ day in two divided doses) versus placebo, Outcome 55 ADAS- $\operatorname{Cog}$ (change from baseline at 26 weeks) OC+RDO.

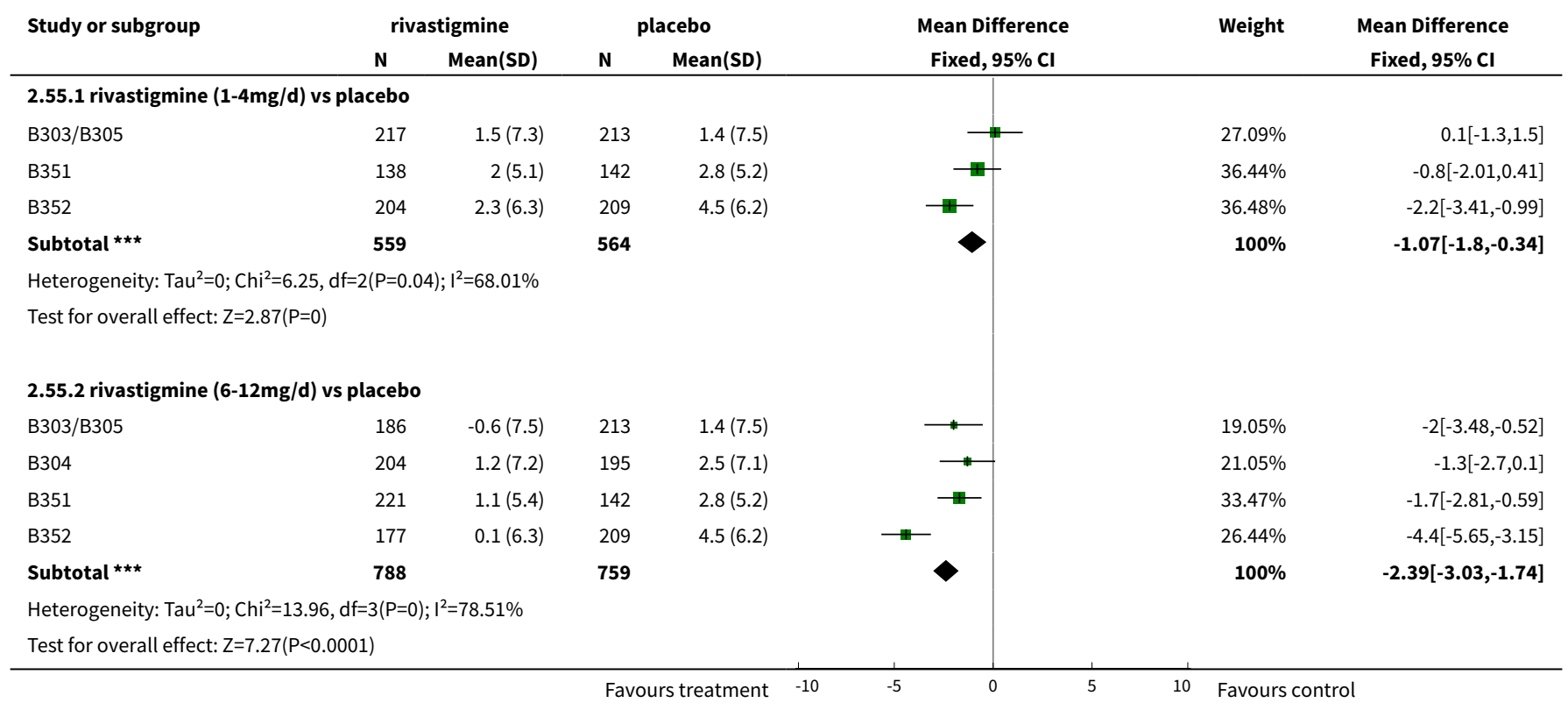

\section{Comparison 3. Rivastigmine $20 \mathrm{~cm}^{2}$ patch ( $17.4 \mathrm{mg} /$ day) versus placebo}

\begin{tabular}{|c|c|c|c|c|}
\hline Outcome or subgroup title & $\begin{array}{l}\text { No. of } \\
\text { studies }\end{array}$ & $\begin{array}{l}\text { No. of } \\
\text { partici- } \\
\text { pants }\end{array}$ & Statistical method & Effect size \\
\hline $\begin{array}{l}1 \text { ADAS-Cog (change from baseline at } 24 \text { weeks) } \\
\text { ITT }\end{array}$ & 1 & 543 & Mean Difference (IV, Fixed, 95\% CI) & $-2.6[-3.72,-1.48]$ \\
\hline 2 TMT-A (change from baseline at 24 weeks) ITT & 1 & 496 & Mean Difference (IV, Fixed, 95\% CI) & $\begin{array}{l}-14.2[-24.11 \\
-4.29]\end{array}$ \\
\hline $\begin{array}{l}3 \text { clock drawing (change from baseline at } 24 \\
\text { weeks) ITT }\end{array}$ & 1 & 520 & Mean Difference (IV, Fixed, 95\% CI) & $0.2[-0.34,0.74]$ \\
\hline 4 MMSE (change from baseline at 24 weeks) ITT & 1 & 543 & Mean Difference (IV, Fixed, 95\% CI) & $0.90[0.32,1.48]$ \\
\hline $\begin{array}{l}5 \text { ADCS-ADL (change from baseline at } 24 \\
\text { weeks) ITT }\end{array}$ & 1 & 544 & Mean Difference (IV, Fixed, 95\% CI) & $2.3[0.52,4.08]$ \\
\hline $\begin{array}{l}6 \mathrm{NPI}-12 \text { (change from baseline at } 24 \text { weeks) } \\
\text { ITT }\end{array}$ & 1 & 544 & Mean Difference (IV, Fixed, 95\% CI) & $-0.60[-2.88,1.68]$ \\
\hline $\begin{array}{l}7 \text { withdrawals before end of treatment at } 24 \\
\text { weeks }\end{array}$ & 1 & 605 & Odds Ratio (M-H, Fixed, 95\% Cl) & $1.90[1.22,2.97]$ \\
\hline 8 at least one adverse event by 24 weeks & 1 & 605 & Odds Ratio (M-H, Fixed, 95\% Cl) & $2.28[1.64,3.16]$ \\
\hline $\begin{array}{l}9 \text { withdrawals due to an adverse event before } \\
\text { end of treatment at } 24 \text { weeks }\end{array}$ & 1 & 605 & Odds Ratio (M-H, Fixed, 95\% Cl) & $1.80[0.93,3.46]$ \\
\hline
\end{tabular}




\begin{tabular}{|c|c|c|c|c|}
\hline Outcome or subgroup title & $\begin{array}{l}\text { No. of } \\
\text { studies }\end{array}$ & $\begin{array}{l}\text { No. of } \\
\text { partici- } \\
\text { pants }\end{array}$ & Statistical method & Effect size \\
\hline $\begin{array}{l}10 \text { at least one adverse event of dizziness by } 24 \\
\text { weeks }\end{array}$ & 1 & 605 & Odds Ratio (M-H, Fixed, 95\% Cl) & $3.14[1.31,7.50]$ \\
\hline $\begin{array}{l}11 \text { at least one adverse event of nausea by } 24 \\
\text { weeks }\end{array}$ & 1 & 605 & Odds Ratio (M-H, Fixed, 95\% Cl) & $5.12[2.85,9.22]$ \\
\hline $\begin{array}{l}12 \text { at least one adverse event of vomiting by } 24 \\
\text { weeks }\end{array}$ & 1 & 605 & Odds Ratio (M-H, Fixed, 95\% Cl) & $6.77[3.38,13.53]$ \\
\hline $\begin{array}{l}13 \text { at least one adverse event of weight de- } \\
\text { crease by } 24 \text { weeks }\end{array}$ & 1 & 605 & Odds Ratio (M-H, Fixed, 95\% Cl) & $6.12[2.09,17.92]$ \\
\hline $\begin{array}{l}14 \text { at least one adverse event of decreased ap- } \\
\text { petite by } 24 \text { weeks }\end{array}$ & 1 & 605 & Odds Ratio (M-H, Fixed, 95\% Cl) & $5.19[1.49,18.12]$ \\
\hline $\begin{array}{l}15 \text { at least one adverse event of headache by } \\
24 \text { weeks }\end{array}$ & 1 & 605 & Odds Ratio (M-H, Fixed, 95\% Cl) & $2.66[0.94,7.56]$ \\
\hline $\begin{array}{l}16 \text { at least one adverse event of asthenia by } 24 \\
\text { weeks }\end{array}$ & 1 & 605 & Odds Ratio (M-H, Fixed, 95\% Cl) & $3.05[0.82,11.38]$ \\
\hline 17 deaths before end of treatment at 24 weeks & 1 & 605 & Odds Ratio (M-H, Fixed, 95\% Cl) & $1.67[0.40,7.06]$ \\
\hline $\begin{array}{l}18 \mathrm{NPI}-\mathrm{D} \text { carer distress scale (change from } \\
\text { baseline at } 24 \text { weeks) ITT }\end{array}$ & 1 & 544 & Mean Difference (IV, Fixed, 95\% CI) & $0.0[-1.07,1.07]$ \\
\hline
\end{tabular}

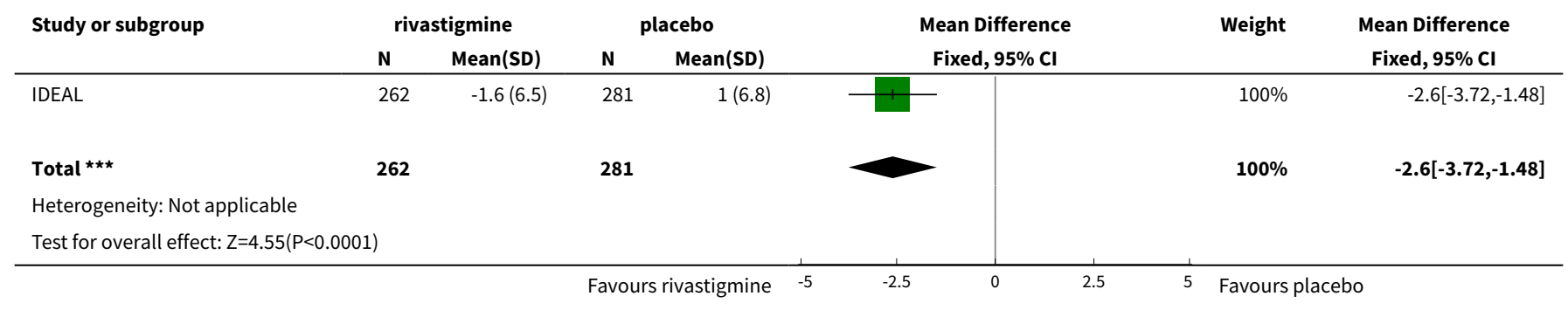

Analysis 3.2. Comparison 3 Rivastigmine $20 \mathrm{~cm}^{2}$ patch ( $17.4 \mathrm{mg} /$ day) versus placebo, Outcome 2 TMT-A (change from baseline at 24 weeks) ITT.

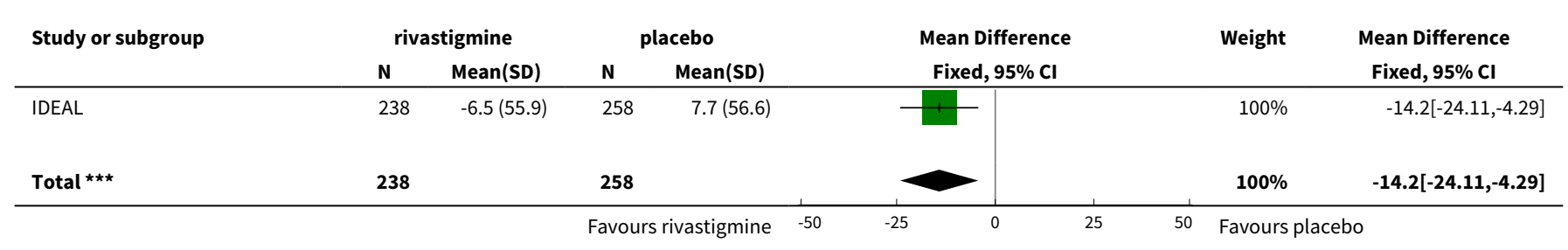




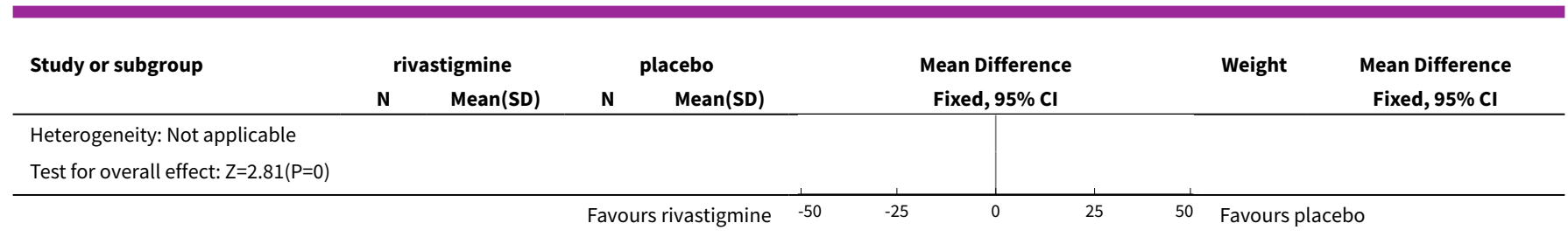

Analysis 3.3. Comparison 3 Rivastigmine $20 \mathrm{~cm}^{2}$ patch $(17.4 \mathrm{mg} /$ day) versus placebo, Outcome 3 clock drawing (change from baseline at 24 weeks) ITT.

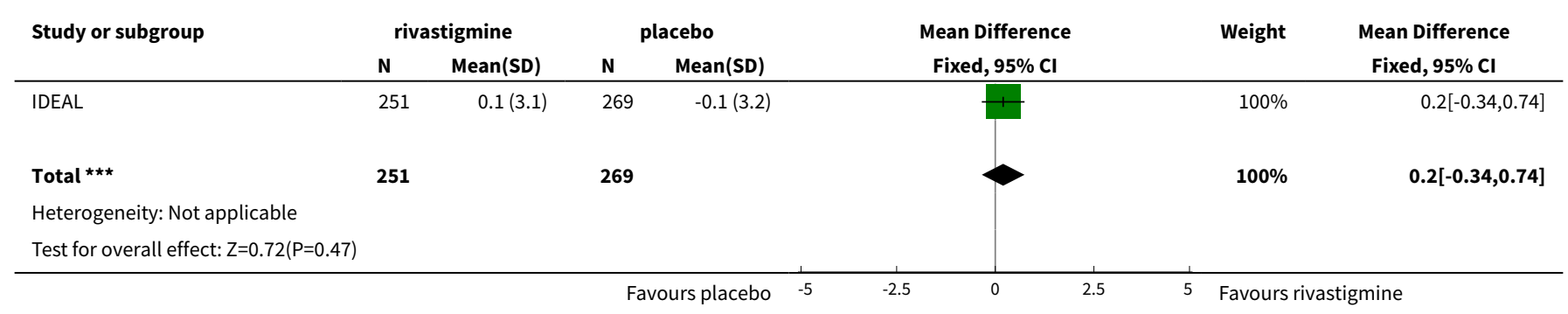

Analysis 3.4. Comparison 3 Rivastigmine $20 \mathrm{~cm}^{2}$ patch $(17.4 \mathrm{mg} /$ day) versus placebo, Outcome 4 MMSE (change from baseline at 24 weeks) ITT.

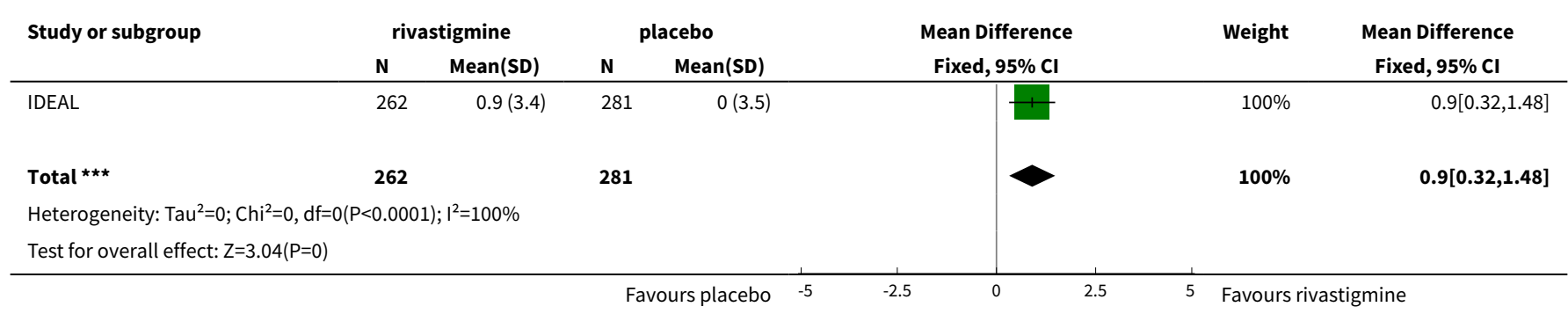

Analysis 3.5. Comparison 3 Rivastigmine $20 \mathrm{~cm}^{2}$ patch ( $17.4 \mathrm{mg} /$ day) versus placebo, Outcome 5 ADCS-ADL (change from baseline at 24 weeks) ITT.

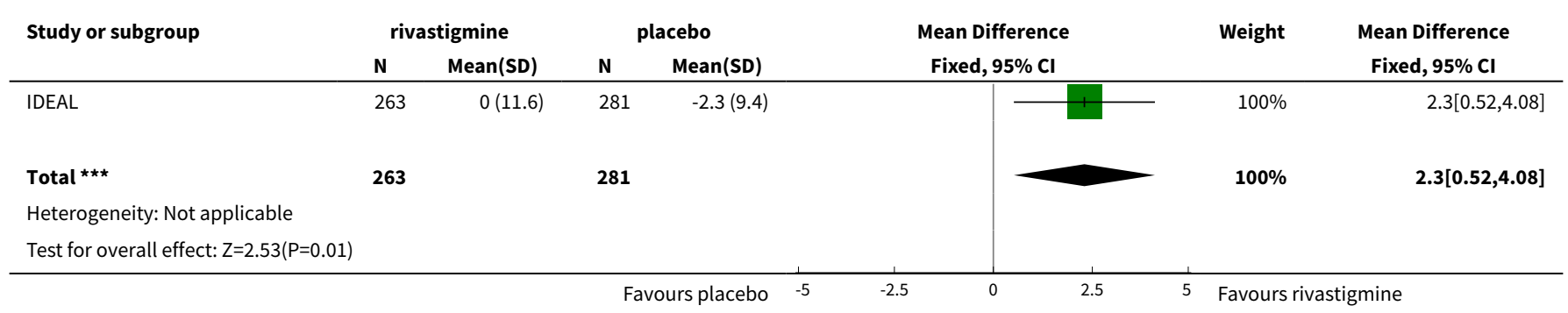


Analysis 3.6. Comparison 3 Rivastigmine $20 \mathrm{~cm}^{2}$ patch (17.4 $\left.\mathrm{mg} / \mathrm{day}\right)$ versus placebo, Outcome 6 NPI-12 (change from baseline at 24 weeks) ITT.

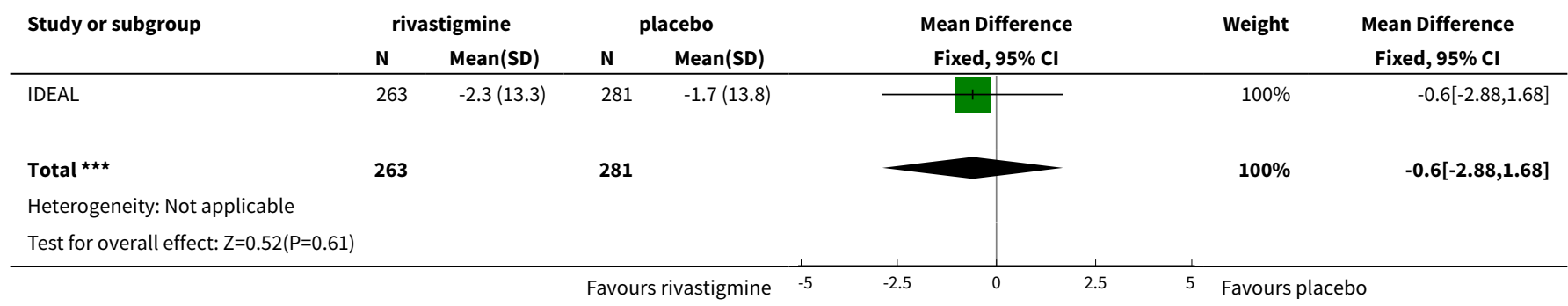

Analysis 3.7. Comparison 3 Rivastigmine $20 \mathrm{~cm}^{2}$ patch $(17.4 \mathrm{mg} /$ day) versus placebo, Outcome 7 withdrawals before end of treatment at 24 weeks.

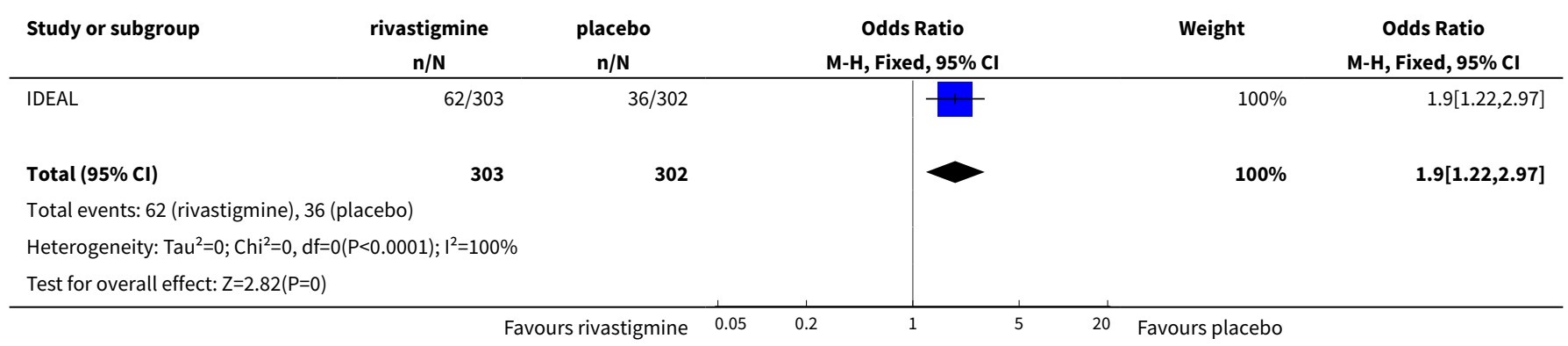

Analysis 3.8. Comparison 3 Rivastigmine $20 \mathrm{~cm}^{2}$ patch $(17.4 \mathrm{mg} /$ day) versus placebo, Outcome 8 at least one adverse event by 24 weeks.

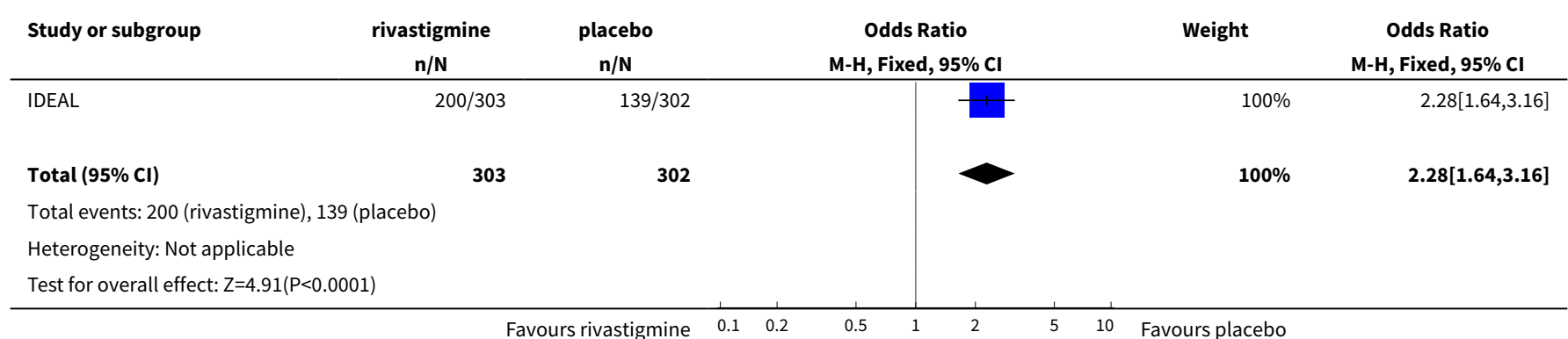

Analysis 3.9. Comparison 3 Rivastigmine $20 \mathrm{~cm}^{2}$ patch (17.4 $\mathrm{mg} /$ day) versus placebo, Outcome 9 withdrawals due to an adverse event before end of treatment at 24 weeks.

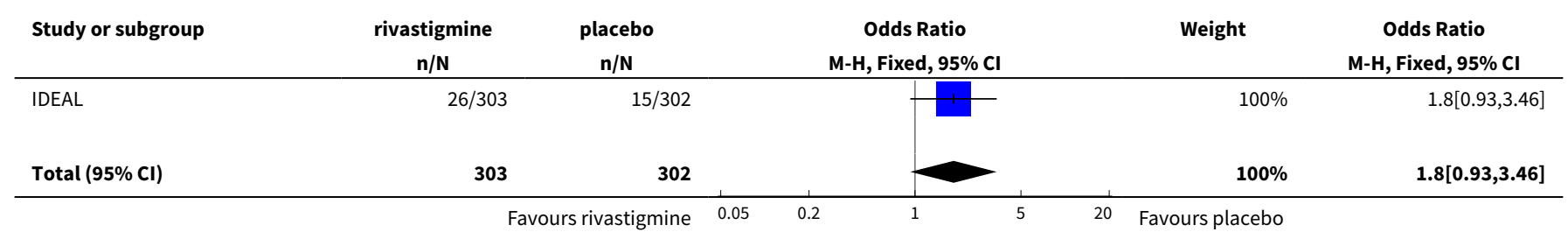




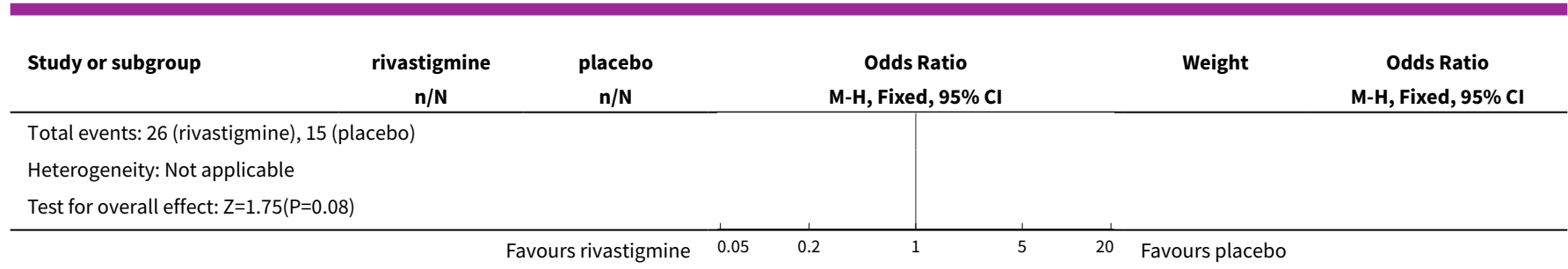

Analysis 3.10. Comparison 3 Rivastigmine $20 \mathrm{~cm}^{2}$ patch (17.4 mg/day) versus placebo, Outcome 10 at least one adverse event of dizziness by 24 weeks.

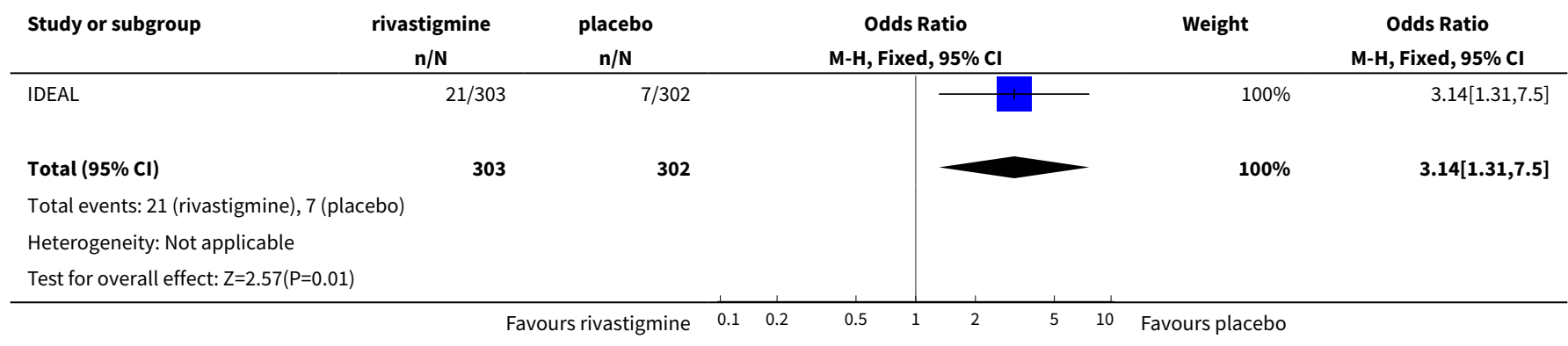

Analysis 3.11 . Comparison 3 Rivastigmine $20 \mathrm{~cm}^{2}$ patch ( $17.4 \mathrm{mg} /$ day) versus placebo, Outcome 11 at least one adverse event of nausea by 24 weeks.

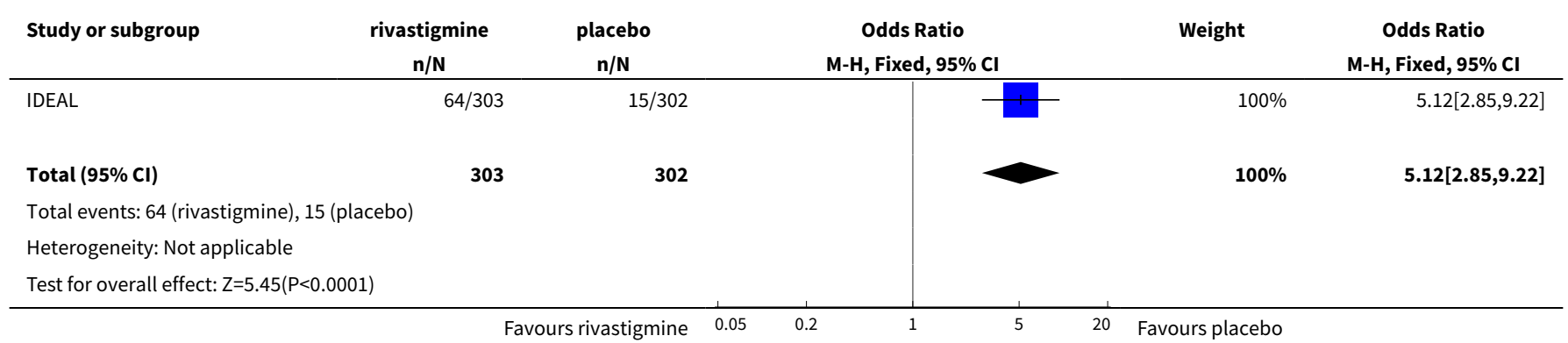

Analysis 3.12. Comparison 3 Rivastigmine $20 \mathrm{~cm}^{2}$ patch $(17.4 \mathrm{mg} /$ day $)$ versus placebo, Outcome 12 at least one adverse event of vomiting by 24 weeks.

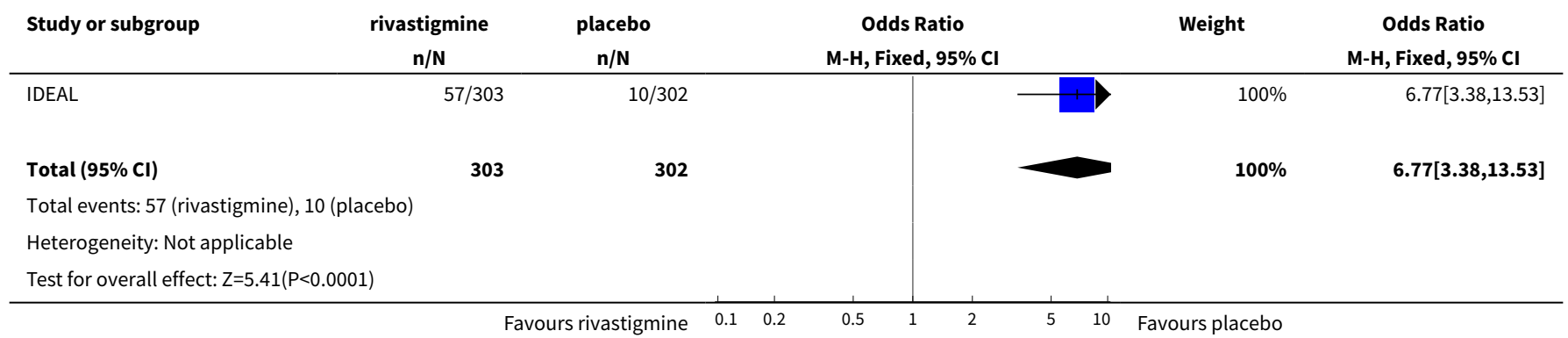


Analysis 3.13. Comparison 3 Rivastigmine $20 \mathrm{~cm}^{2}$ patch (17.4 $\mathrm{mg} /$ day) versus placebo, Outcome 13 at least one adverse event of weight decrease by 24 weeks.

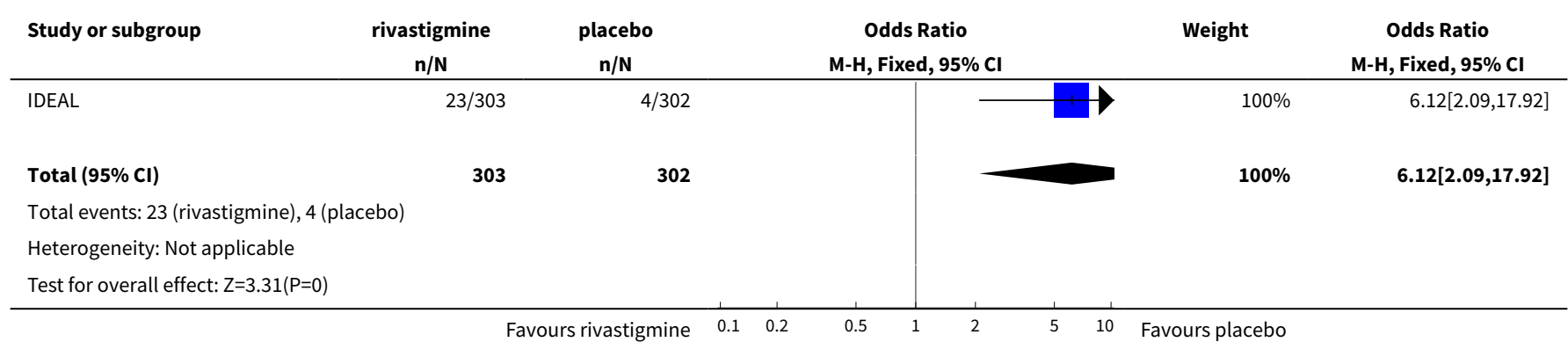

Analysis 3.14. Comparison 3 Rivastigmine $20 \mathrm{~cm}^{2}$ patch (17.4 mg/day) versus placebo, Outcome 14 at least one adverse event of decreased appetite by 24 weeks.

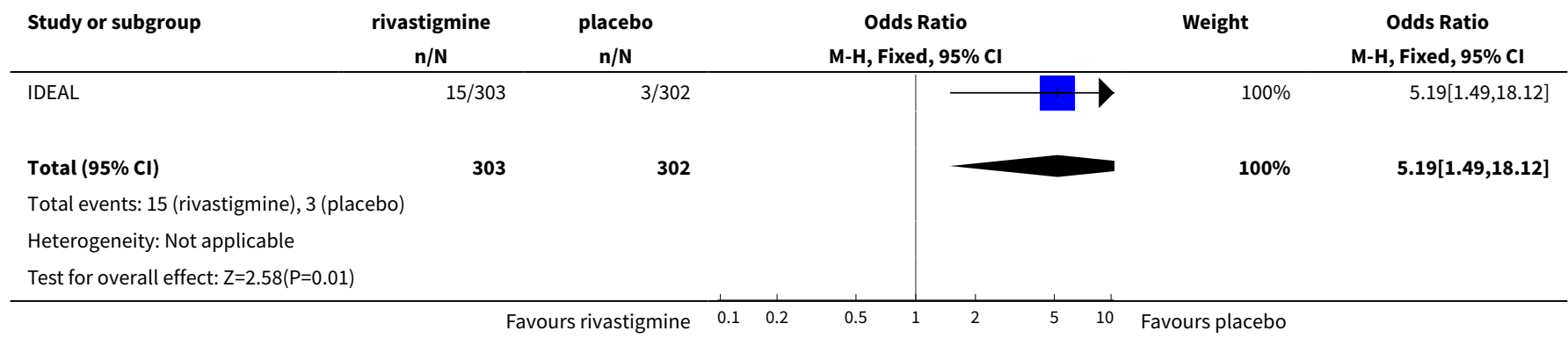

Analysis 3.15. Comparison 3 Rivastigmine $20 \mathrm{~cm}^{2}$ patch (17.4 $\mathrm{mg} /$ day) versus placebo, Outcome 15 at least one adverse event of headache by 24 weeks.

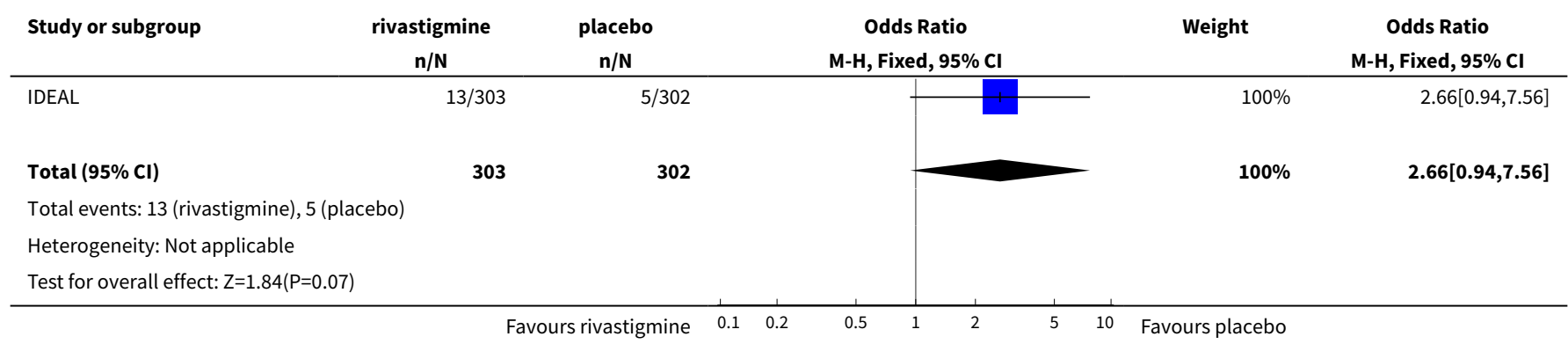

Analysis 3.16. Comparison 3 Rivastigmine $20 \mathrm{~cm}^{2}$ patch (17.4 $\left.\mathrm{mg} / \mathrm{day}\right)$ versus placebo, Outcome 16 at least one adverse event of asthenia by 24 weeks.

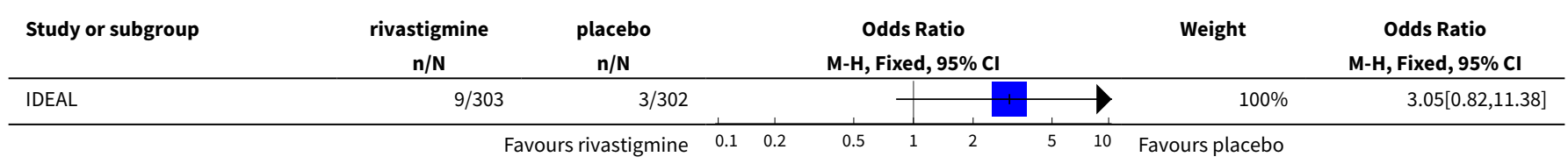




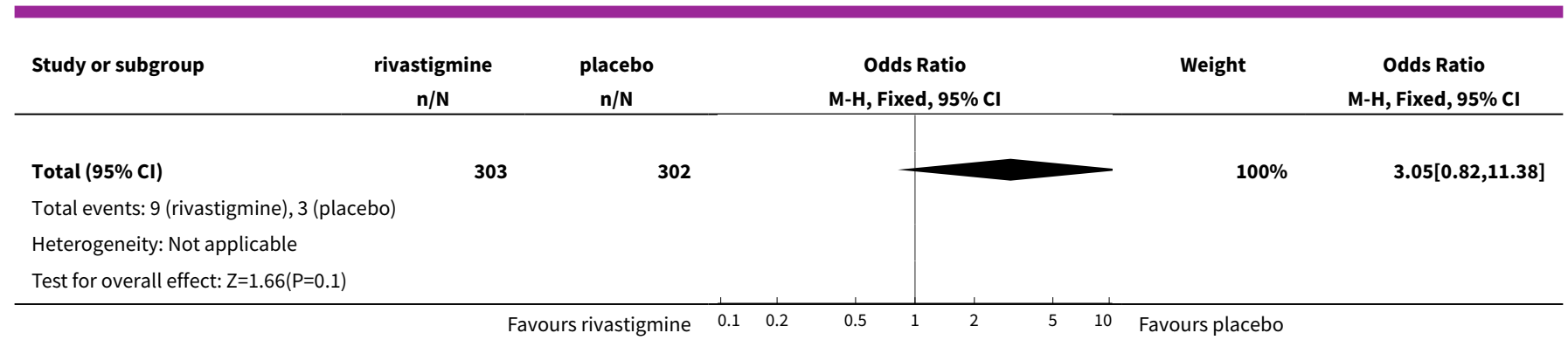

Analysis 3.17. Comparison 3 Rivastigmine $20 \mathrm{~cm}^{2}$ patch $(17.4 \mathrm{mg} /$ day) versus placebo, Outcome 17 deaths before end of treatment at 24 weeks.

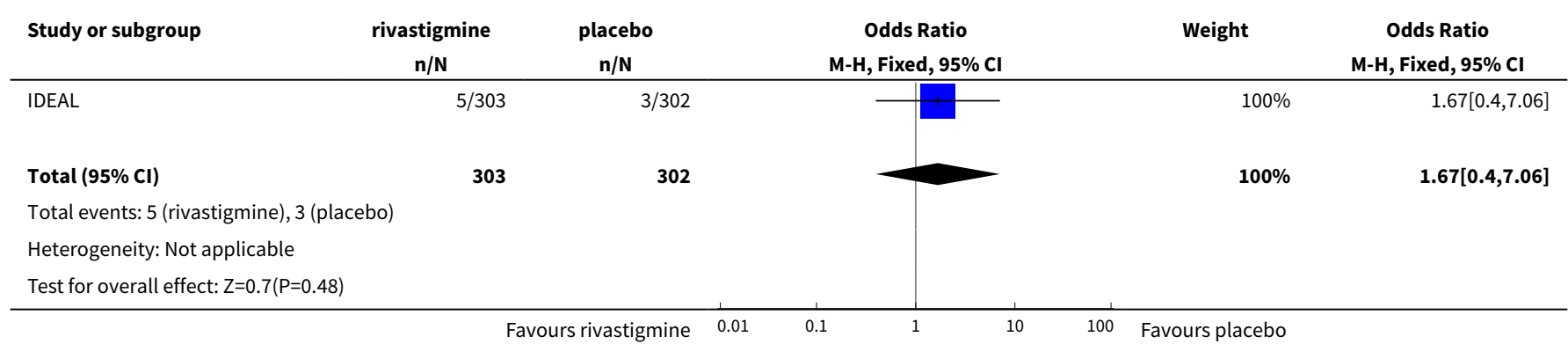

Analysis 3.18. Comparison 3 Rivastigmine $20 \mathrm{~cm}^{2}$ patch (17.4 $\mathrm{mg} /$ day) versus placebo, Outcome 18 NPI-D carer distress scale (change from baseline at 24 weeks) ITT.

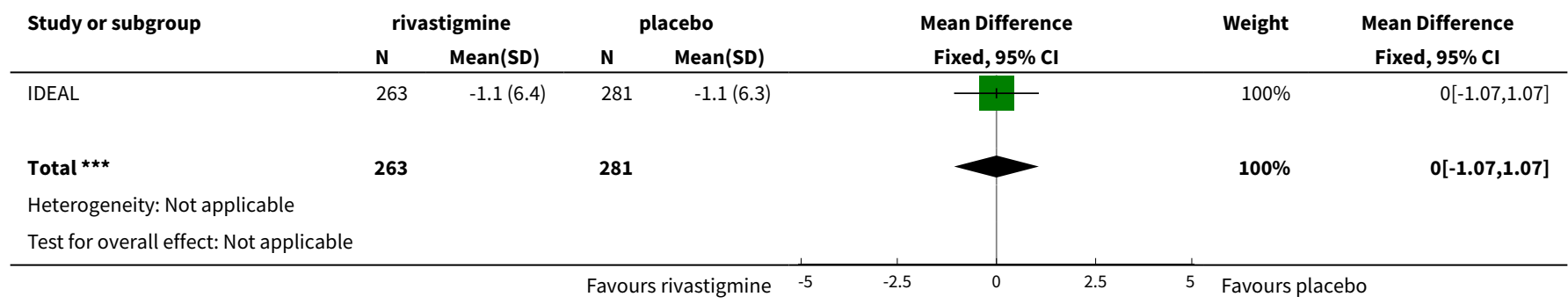

\section{Comparison 4. Rivastigmine $10 \mathrm{~cm}^{2}$ patch ( $9.5 \mathrm{mg} /$ day) versus placebo}

\begin{tabular}{|c|c|c|c|c|}
\hline Outcome or subgroup title & $\begin{array}{l}\text { No. of } \\
\text { studies }\end{array}$ & $\begin{array}{l}\text { No. of } \\
\text { partici- } \\
\text { pants }\end{array}$ & Statistical method & Effect size \\
\hline $\begin{array}{l}1 \text { ADAS-Cog (change from baseline at } 24 \text { weeks) } \\
\text { ITT }\end{array}$ & 2 & 1062 & $\begin{array}{l}\text { Mean Difference (IV, Fixed, 95\% } \\
\text { CI) }\end{array}$ & $\begin{array}{l}-1.35[-2.03 \\
-0.66]\end{array}$ \\
\hline 2 MMSE (change from baseline at 24 weeks) ITT & 2 & 1028 & $\begin{array}{l}\text { Mean Difference (IV, Fixed, 95\% } \\
\mathrm{CI})\end{array}$ & $0.64[0.26,1.02]$ \\
\hline $\begin{array}{l}3 \text { clock drawing (change from baseline at } 24 \\
\text { weeks) ITT }\end{array}$ & 1 & 514 & $\begin{array}{l}\text { Mean Difference (IV, Fixed, 95\% } \\
\mathrm{Cl})\end{array}$ & $0.4[-0.17,0.97]$ \\
\hline
\end{tabular}

Rivastigmine for Alzheimer's disease (Review) 


\begin{tabular}{|c|c|c|c|c|}
\hline Outcome or subgroup title & $\begin{array}{l}\text { No. of } \\
\text { studies }\end{array}$ & $\begin{array}{l}\text { No. of } \\
\text { partici- } \\
\text { pants }\end{array}$ & Statistical method & Effect size \\
\hline 4 TMT-A (change from baseline at 24 weeks) ITT & 1 & 499 & $\begin{array}{l}\text { Mean Difference (IV, Fixed, 95\% } \\
\mathrm{CI})\end{array}$ & $\begin{array}{l}-20.0[-29.80 \\
-10.20]\end{array}$ \\
\hline $\begin{array}{l}5 \text { Mental Function Impairment MENFIS (change } \\
\text { from baseline at } 24 \text { weeks) ITT }\end{array}$ & 1 & 537 & $\begin{array}{l}\text { Mean Difference (IV, Fixed, 95\% } \\
\mathrm{CI})\end{array}$ & $\begin{array}{l}-1.30[-2.32 \\
-0.28]\end{array}$ \\
\hline $\begin{array}{l}6 \text { ADCS-ADL (change from baseline at } 24 \text { weeks) } \\
\text { ITT }\end{array}$ & 1 & 528 & $\begin{array}{l}\text { Mean Difference (IV, Fixed, 95\% } \\
\mathrm{Cl} \text { ) }\end{array}$ & $2.20[0.62,3.78]$ \\
\hline $\begin{array}{l}7 \text { Disability Assessment for Dementia (DAD) } \\
\text { (change from baseline at } 24 \text { weeks) ITT }\end{array}$ & 1 & 536 & $\begin{array}{l}\text { Mean Difference (IV, Fixed, 95\% } \\
\mathrm{Cl} \text { ) }\end{array}$ & $2.30[0.34,4.26]$ \\
\hline $\begin{array}{l}8 \text { BEHAVE-AD (change from baseline at } 24 \\
\text { weeks) ITT }\end{array}$ & 1 & 537 & $\begin{array}{l}\text { Mean Difference (IV, Fixed, 95\% } \\
\mathrm{CI})\end{array}$ & $-0.20[-0.92,0.52]$ \\
\hline 9 NPI-12 (change from baseline at 24 weeks) ITT & 1 & 529 & $\begin{array}{l}\text { Mean Difference (IV, Fixed, 95\% } \\
\mathrm{CI})\end{array}$ & $0.0[-2.16,2.16]$ \\
\hline $\begin{array}{l}10 \text { Clinical Global Impression (no change or } \\
\text { worse at } 24 \text { weeks) }\end{array}$ & 2 & 1063 & Odds Ratio (M-H, Fixed, 95\% Cl) & $0.77[0.58,1.02]$ \\
\hline $\begin{array}{l}11 \text { withdrawals before end of treatment at } 24 \\
\text { weeks }\end{array}$ & 2 & 1170 & Odds Ratio (M-H, Fixed, 95\% Cl) & $1.67[1.23,2.26]$ \\
\hline 12 at least one adverse event by 24 weeks & 2 & 1460 & Odds Ratio (M-H, Fixed, 95\% Cl) & $1.63[1.29,2.06]$ \\
\hline $\begin{array}{l}13 \text { withdrawals due to an adverse event before } \\
\text { end of treatment at } 24 \text { weeks }\end{array}$ & 2 & 1170 & Odds Ratio (M-H, Fixed, 95\% CI) & $1.84[1.20,2.82]$ \\
\hline $\begin{array}{l}14 \text { at least one adverse event of application site } \\
\text { erythema by } 24 \text { weeks }\end{array}$ & 1 & 573 & Odds Ratio (M-H, Fixed, 95\% CI) & $2.73[1.87,3.98]$ \\
\hline $\begin{array}{l}15 \text { at least one adverse event of application site } \\
\text { pruritis by } 24 \text { weeks }\end{array}$ & 1 & 573 & Odds Ratio (M-H, Fixed, 95\% Cl) & $1.97[1.36,2.86]$ \\
\hline $\begin{array}{l}16 \text { at least one adverse event of application site } \\
\text { edema by } 24 \text { weeks }\end{array}$ & 1 & 573 & Odds Ratio (M-H, Fixed, 95\% Cl) & $4.83[2.09,11.15]$ \\
\hline $\begin{array}{l}17 \text { at least one adverse event application site ex- } \\
\text { foliation by } 24 \text { weeks }\end{array}$ & 1 & 573 & Odds Ratio (M-H, Fixed, 95\% Cl) & $2.81[0.88,8.93]$ \\
\hline $\begin{array}{l}18 \text { at least one adverse event of dermatitis con- } \\
\text { tact by } 24 \text { weeks }\end{array}$ & 1 & 573 & Odds Ratio (M-H, Fixed, 95\% CI) & $1.91[1.24,2.94]$ \\
\hline $\begin{array}{l}19 \text { at least one adverse event of nasopharyngitis } \\
\text { by } 24 \text { weeks }\end{array}$ & 1 & 573 & Odds Ratio (M-H, Fixed, 95\% CI) & $1.03[0.62,1.73]$ \\
\hline $\begin{array}{l}20 \text { at least one adverse event of nausea by } 24 \\
\text { weeks }\end{array}$ & 2 & 1166 & Odds Ratio (M-H, Fixed, 95\% CI) & $1.80[1.07,3.02]$ \\
\hline $\begin{array}{l}21 \text { at least one adverse event of vomiting by } 24 \\
\text { weeks }\end{array}$ & 2 & 1166 & Odds Ratio (M-H, Fixed, 95\% Cl) & $2.06[1.20,3.53]$ \\
\hline
\end{tabular}




\begin{tabular}{|c|c|c|c|c|}
\hline Outcome or subgroup title & $\begin{array}{l}\text { No. of } \\
\text { studies }\end{array}$ & $\begin{array}{l}\text { No. of } \\
\text { partici- } \\
\text { pants }\end{array}$ & Statistical method & Effect size \\
\hline $\begin{array}{l}22 \text { at least one adverse event of diarrhoea by } 24 \\
\text { weeks }\end{array}$ & 1 & 593 & Odds Ratio (M-H, Fixed, 95\% Cl) & $1.93[0.87,4.24]$ \\
\hline $\begin{array}{l}23 \text { at least one adverse event of weight decrease } \\
\text { by } 24 \text { weeks }\end{array}$ & 1 & 593 & Odds Ratio (M-H, Fixed, 95\% Cl) & $2.11[0.63,7.07]$ \\
\hline $\begin{array}{l}24 \text { at least one adverse event of dizziness by } 24 \\
\text { weeks }\end{array}$ & 1 & 593 & Odds Ratio (M-H, Fixed, 95\% Cl) & $1.04[0.36,3.00]$ \\
\hline $\begin{array}{l}25 \text { at least one adverse event of decreased ap- } \\
\text { petite by } 24 \text { weeks }\end{array}$ & 1 & 593 & Odds Ratio (M-H, Fixed, 95\% Cl) & $0.69[0.11,4.16]$ \\
\hline $\begin{array}{l}26 \text { at least one adverse event of headache by } 24 \\
\text { weeks }\end{array}$ & 1 & 593 & Odds Ratio (M-H, Fixed, 95\% Cl) & $2.11[0.71,6.26]$ \\
\hline $\begin{array}{l}27 \text { at least one adverse event of asthenia by } 24 \\
\text { weeks }\end{array}$ & 1 & 593 & Odds Ratio (M-H, Fixed, 95\% Cl) & $1.74[0.41,7.36]$ \\
\hline 28 deaths before end of treatment at 24 weeks & 2 & 1170 & Odds Ratio (M-H, Fixed, 95\% Cl) & $1.02[0.28,3.81]$ \\
\hline $\begin{array}{l}29 \text { NPI-D carer distress scale (change from base- } \\
\text { line at } 24 \text { weeks) ITT }\end{array}$ & 1 & 529 & $\begin{array}{l}\text { Mean Difference (IV, Fixed, 95\% } \\
\text { CI) }\end{array}$ & $0.10[-0.91,1.11]$ \\
\hline
\end{tabular}

\section{Analysis 4.1. Comparison 4 Rivastigmine $10 \mathrm{~cm}^{2}$ patch $(9.5 \mathrm{mg} /$ day) versus} placebo, Outcome 1 ADAS-Cog (change from baseline at 24 weeks) ITT.

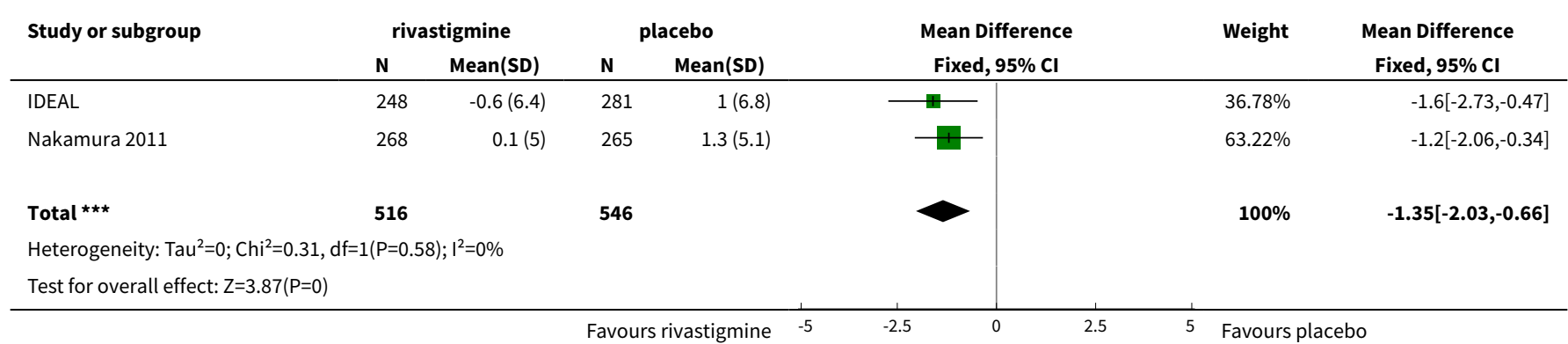

Analysis 4.2. Comparison 4 Rivastigmine $10 \mathrm{~cm}^{2}$ patch $(9.5 \mathrm{mg} /$ day $)$ versus placebo, Outcome 2 MMSE (change from baseline at 24 weeks) ITT.

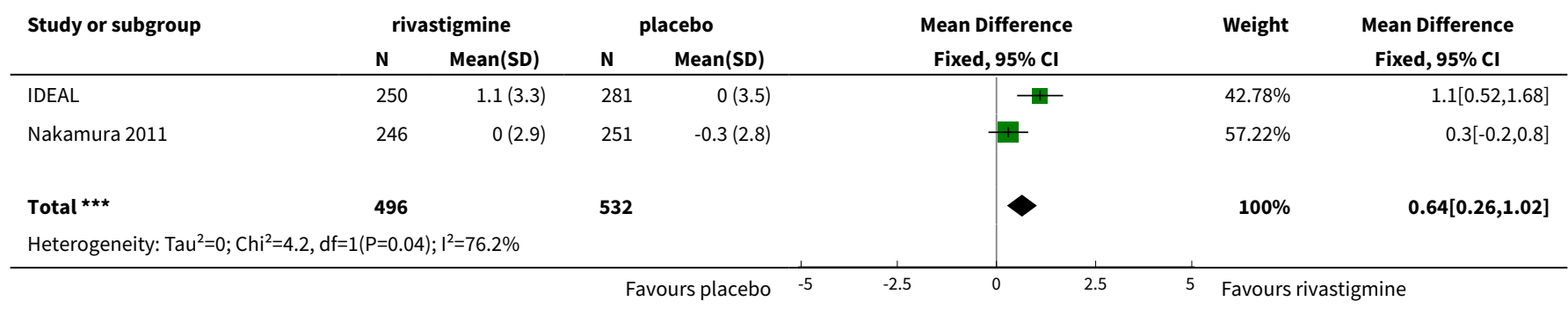




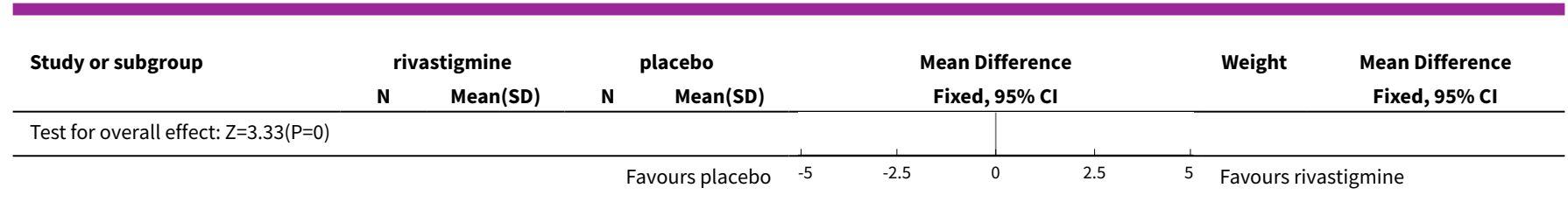

Analysis 4.3. Comparison 4 Rivastigmine $10 \mathrm{~cm}^{2}$ patch $(9.5 \mathrm{mg} /$ day) versus placebo, Outcome 3 clock drawing (change from baseline at 24 weeks) ITT.

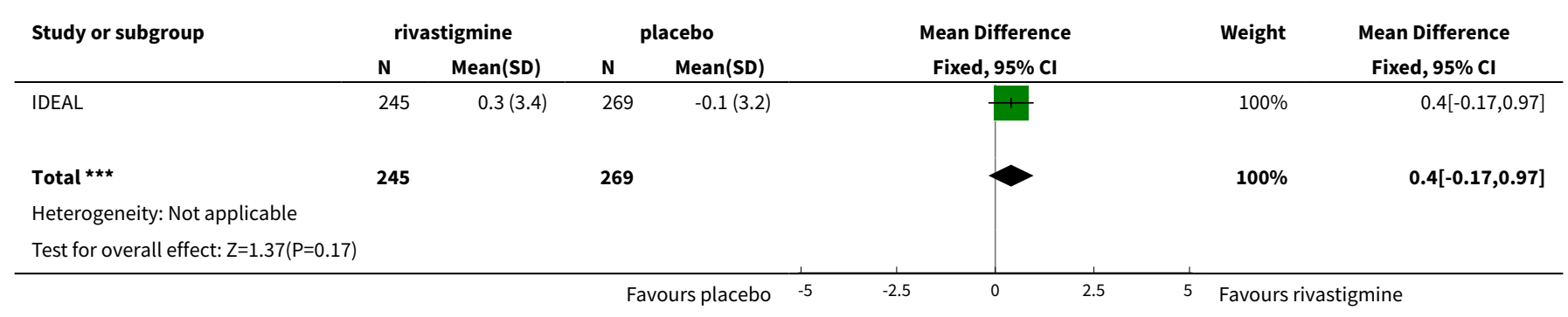

Analysis 4.4. Comparison 4 Rivastigmine $10 \mathrm{~cm}^{2}$ patch $(9.5 \mathrm{mg} /$ day) versus placebo, Outcome 4 TMT-A (change from baseline at 24 weeks) ITT.

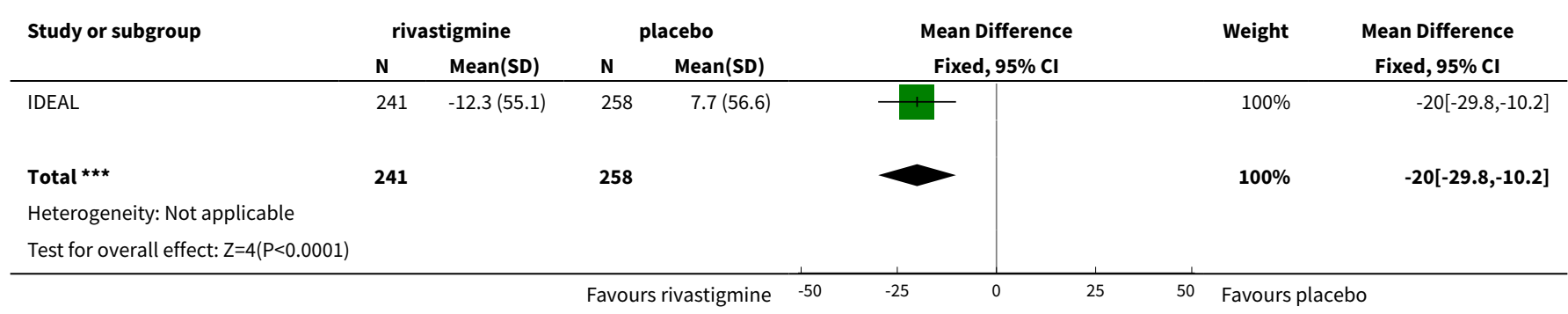

Analysis 4.5. Comparison 4 Rivastigmine $10 \mathrm{~cm}^{2}$ patch $(9.5 \mathrm{mg} /$ day $)$ versus placebo, Outcome 5 Mental Function Impairment MENFIS (change from baseline at 24 weeks) ITT.

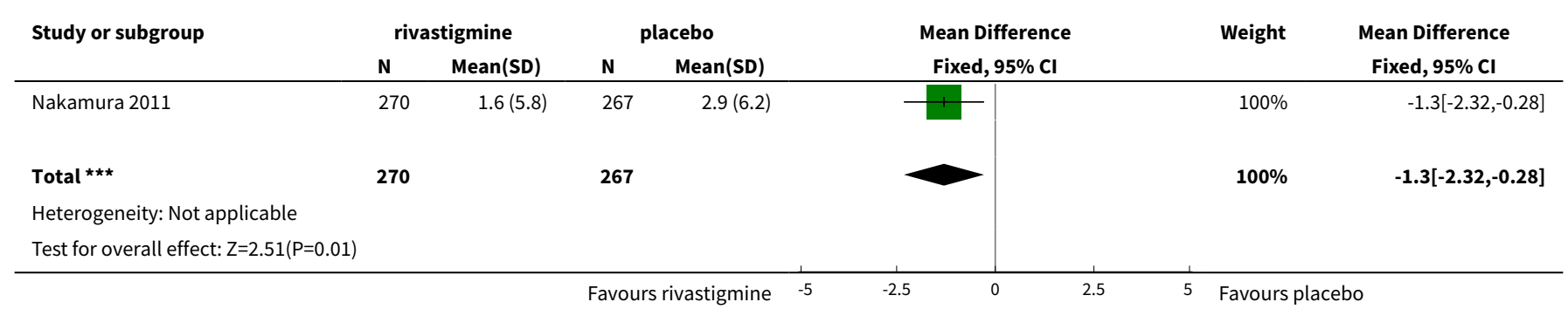


Analysis 4.6. Comparison 4 Rivastigmine $10 \mathrm{~cm}^{2}$ patch $(9.5 \mathrm{mg} /$ day) versus placebo, Outcome 6 ADCS-ADL (change from baseline at 24 weeks) ITT.

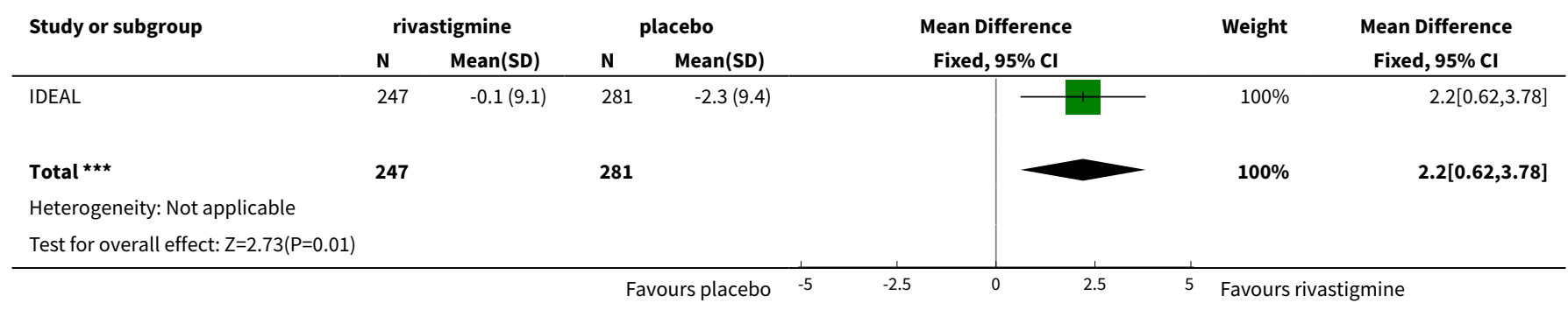

Analysis 4.7. Comparison 4 Rivastigmine $10 \mathrm{~cm}^{2}$ patch $(9.5 \mathrm{mg} /$ day $)$ versus placebo, Outcome 7 Disability Assessment for Dementia (DAD) (change from baseline at 24 weeks) ITT.

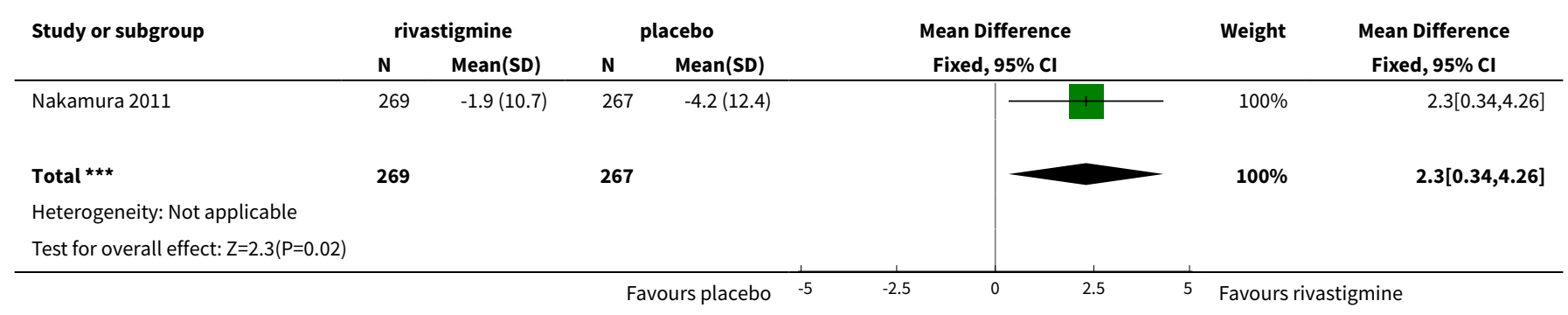

Analysis 4.8. Comparison 4 Rivastigmine $10 \mathrm{~cm}^{2}$ patch $(9.5 \mathrm{mg} /$ day $)$ versus placebo, Outcome 8 BEHAVE-AD (change from baseline at 24 weeks) ITT.

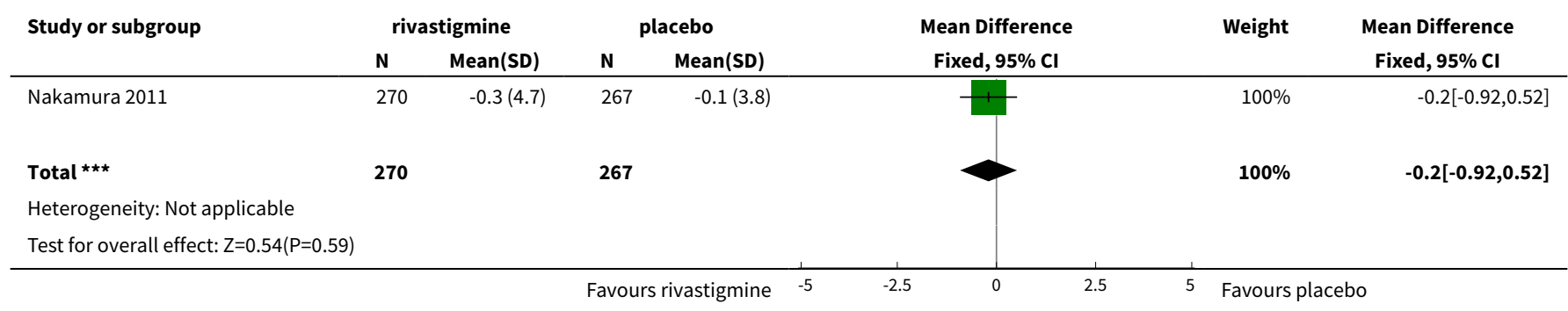

Analysis 4.9. Comparison 4 Rivastigmine $10 \mathrm{~cm}^{2}$ patch $(9.5 \mathrm{mg} /$ day) versus placebo, Outcome 9 NPI-12 (change from baseline at 24 weeks) ITT.

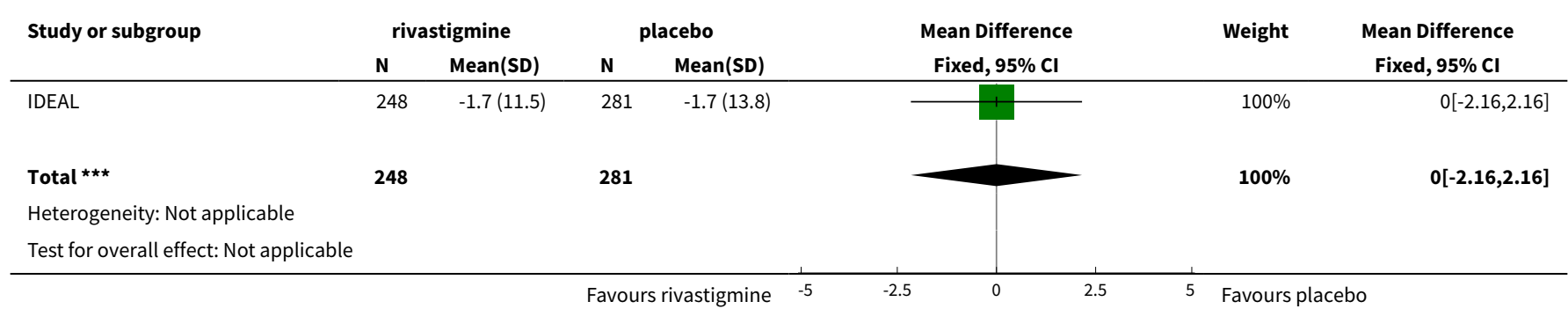


Analysis 4.10. Comparison 4 Rivastigmine $10 \mathrm{~cm}^{2}$ patch $(9.5 \mathrm{mg} /$ day $)$ versus placebo, Outcome 10 Clinical Global Impression (no change or worse at 24 weeks).

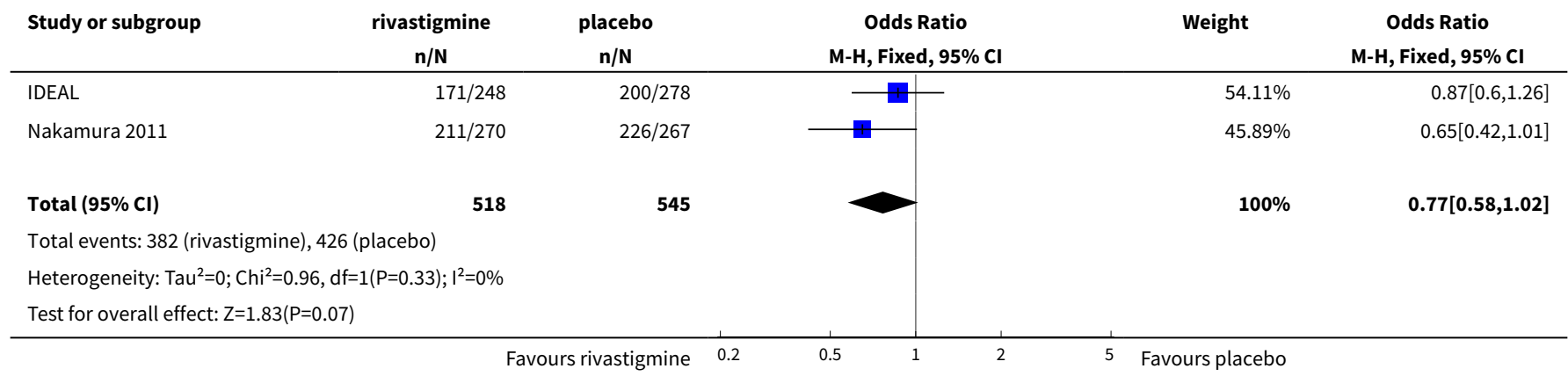

Analysis 4.11. Comparison 4 Rivastigmine $10 \mathrm{~cm}^{2}$ patch $(9.5 \mathrm{mg} / \mathrm{day})$ versus placebo, Outcome 11 withdrawals before end of treatment at 24 weeks.

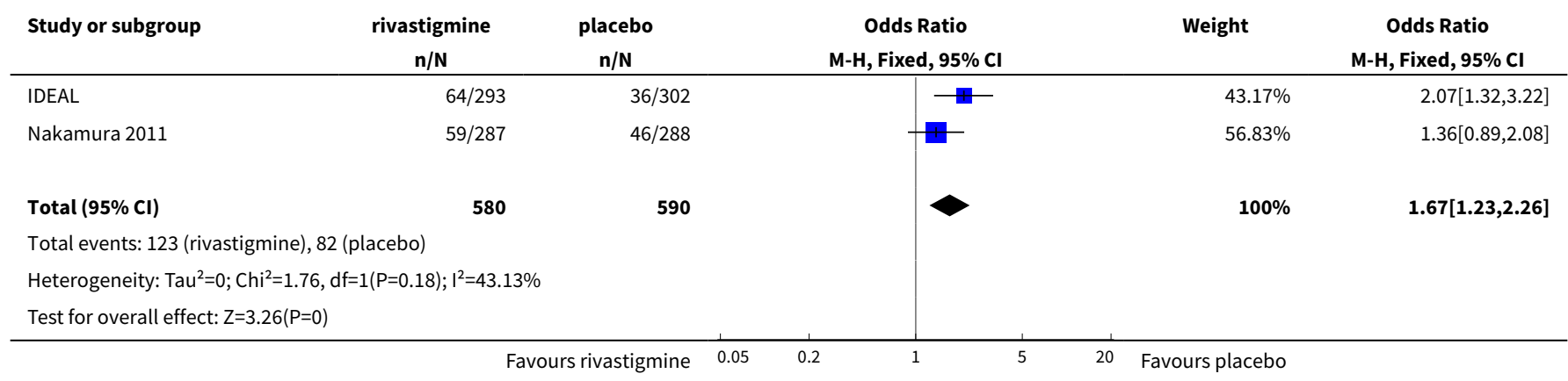

Analysis 4.12. Comparison 4 Rivastigmine $10 \mathrm{~cm}^{2}$ patch $(9.5 \mathrm{mg} /$ day $)$ versus placebo, Outcome 12 at least one adverse event by 24 weeks.

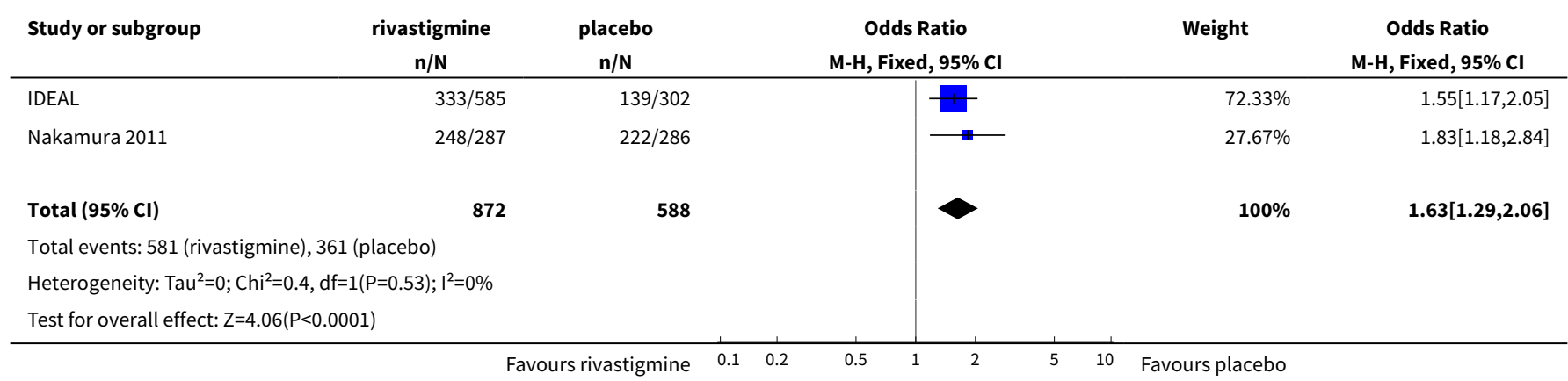


Analysis 4.13. Comparison 4 Rivastigmine $10 \mathrm{~cm}^{2}$ patch $(9.5 \mathrm{mg} /$ day) versus placebo, Outcome 13 withdrawals due to an adverse event before end of treatment at 24 weeks.

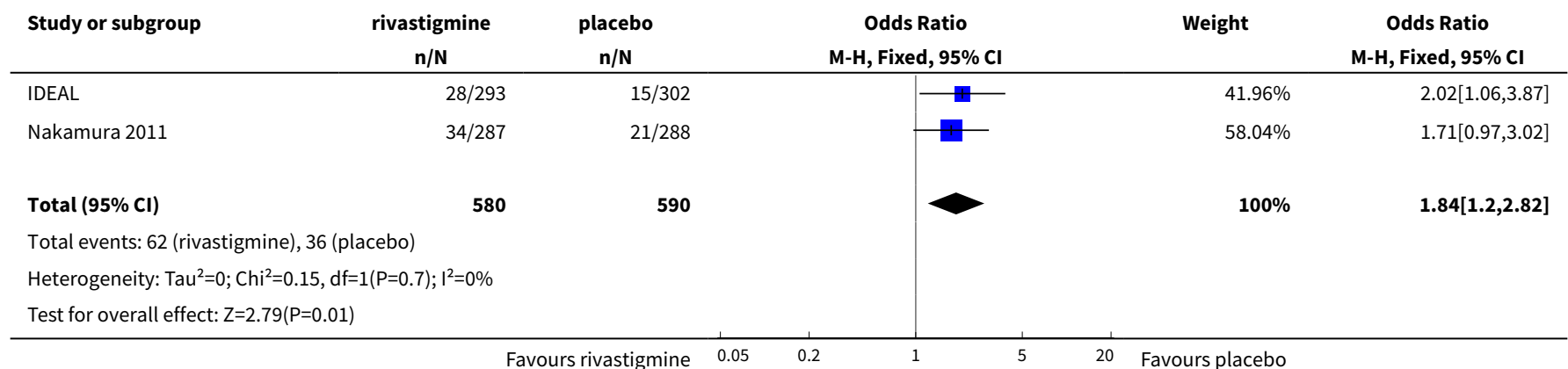

Analysis 4.14. Comparison 4 Rivastigmine $10 \mathrm{~cm}^{2}$ patch $(9.5 \mathrm{mg} /$ day) versus placebo, Outcome 14 at least one adverse event of application site erythema by 24 weeks.

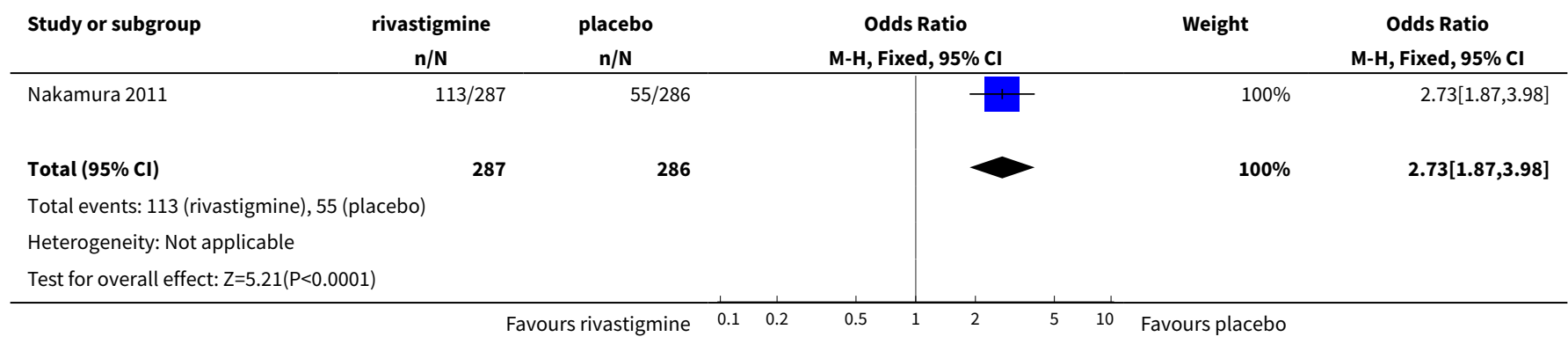

Analysis 4.15. Comparison 4 Rivastigmine $10 \mathrm{~cm}^{2}$ patch $(9.5 \mathrm{mg} /$ day) versus placebo, Outcome 15 at least one adverse event of application site pruritis by 24 weeks.

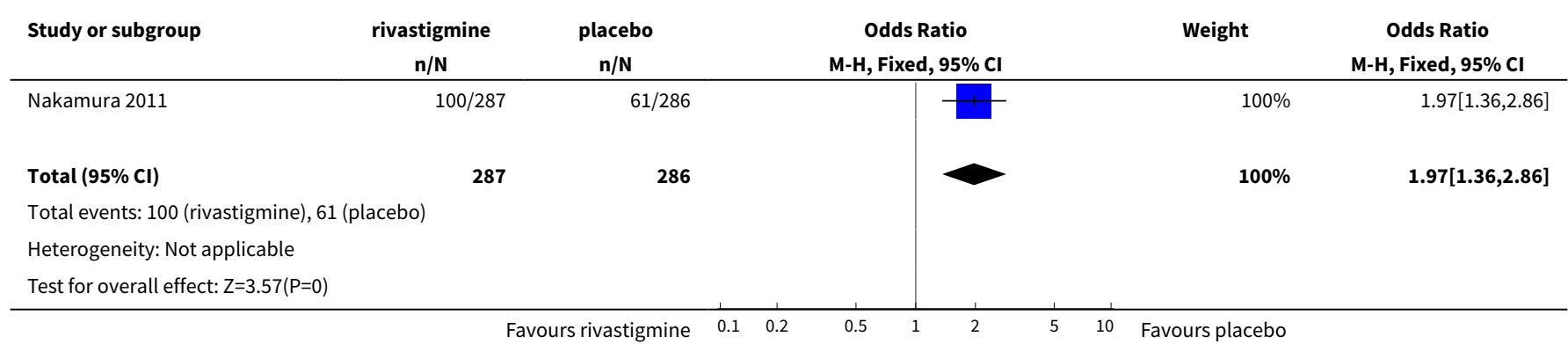

Analysis 4.16. Comparison 4 Rivastigmine $10 \mathrm{~cm}^{2}$ patch $(9.5 \mathrm{mg} /$ day) versus placebo, Outcome 16 at least one adverse event of application site edema by 24 weeks.

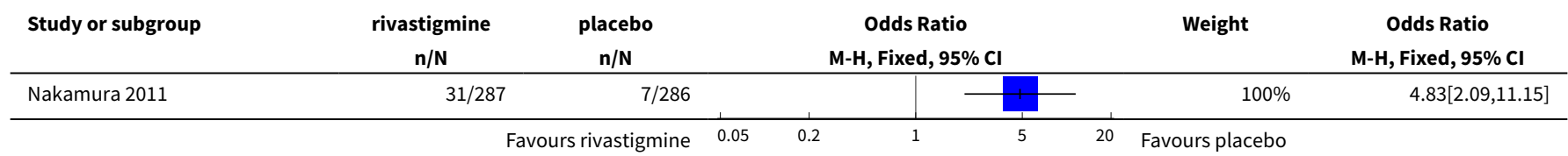




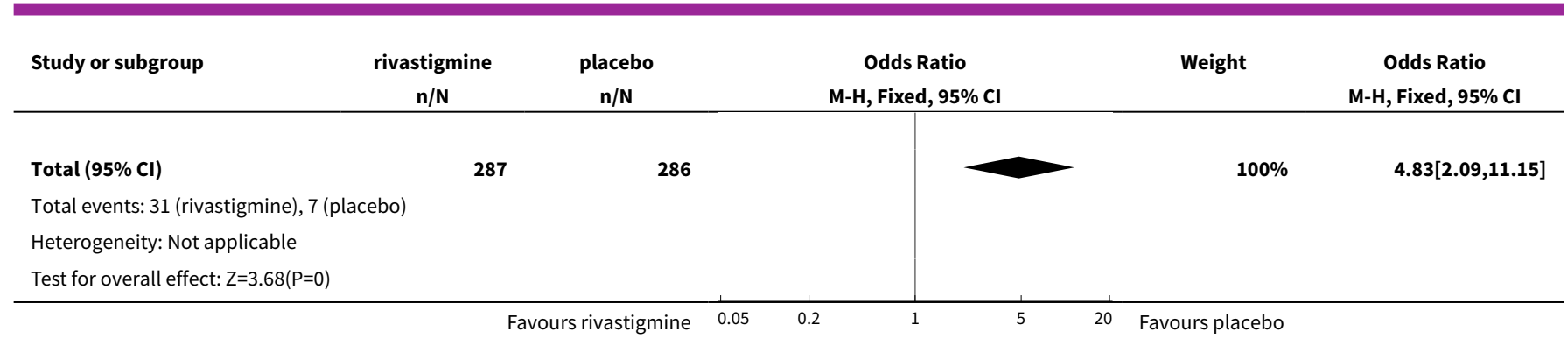

Analysis 4.17. Comparison 4 Rivastigmine $10 \mathrm{~cm}^{2}$ patch $(9.5 \mathrm{mg} /$ day $)$ versus placebo, Outcome 17 at least one adverse event application site exfoliation by 24 weeks.

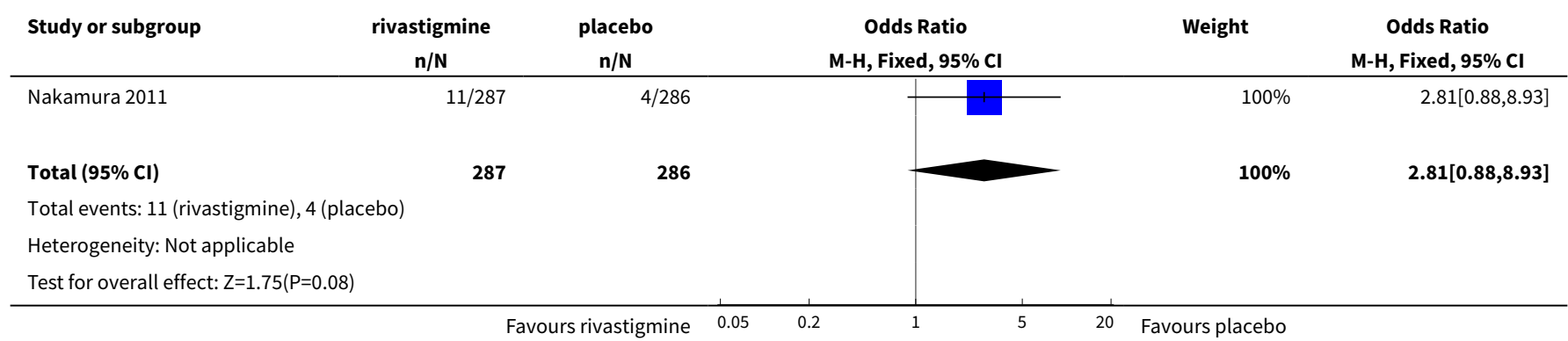

Analysis 4.18. Comparison 4 Rivastigmine $10 \mathrm{~cm}^{2}$ patch $(9.5 \mathrm{mg} /$ day $)$ versus placebo, Outcome 18 at least one adverse event of dermatitis contact by 24 weeks.

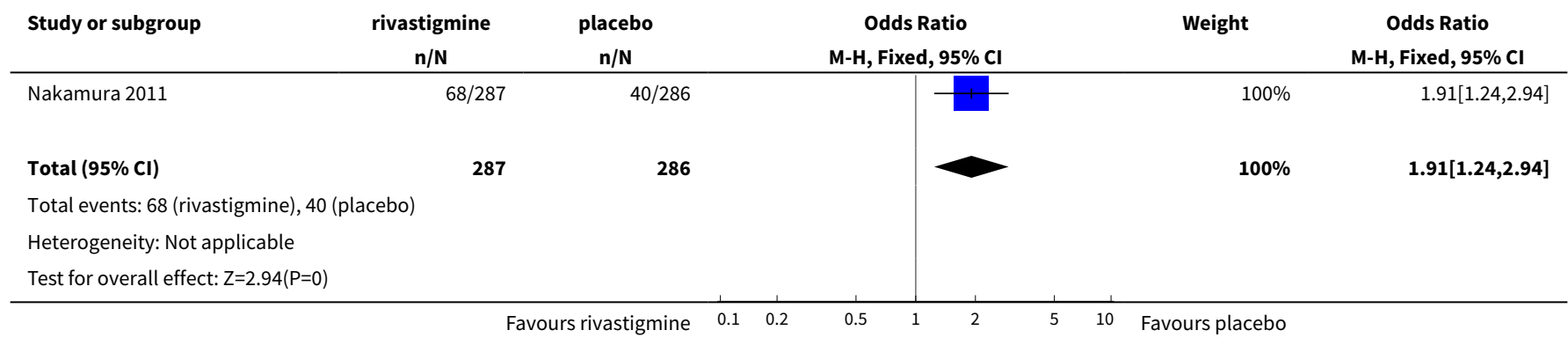

Analysis 4.19. Comparison 4 Rivastigmine $10 \mathrm{~cm}^{2}$ patch $(9.5 \mathrm{mg} /$ day) versus placebo, Outcome 19 at least one adverse event of nasopharyngitis by 24 weeks.

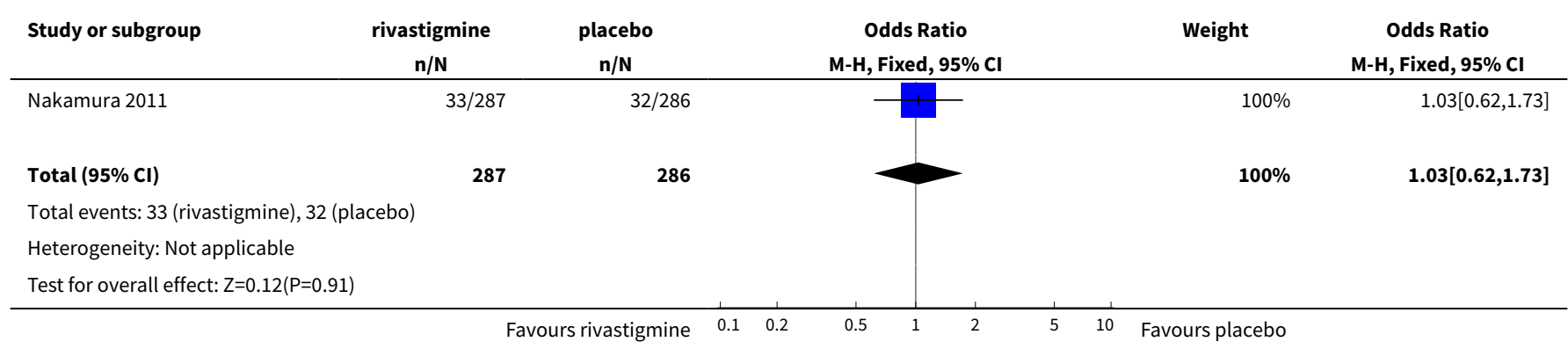


Analysis 4.20. Comparison 4 Rivastigmine $10 \mathrm{~cm}^{2}$ patch $(9.5 \mathrm{mg} / \mathrm{day})$ versus placebo, Outcome 20 at least one adverse event of nausea by 24 weeks.

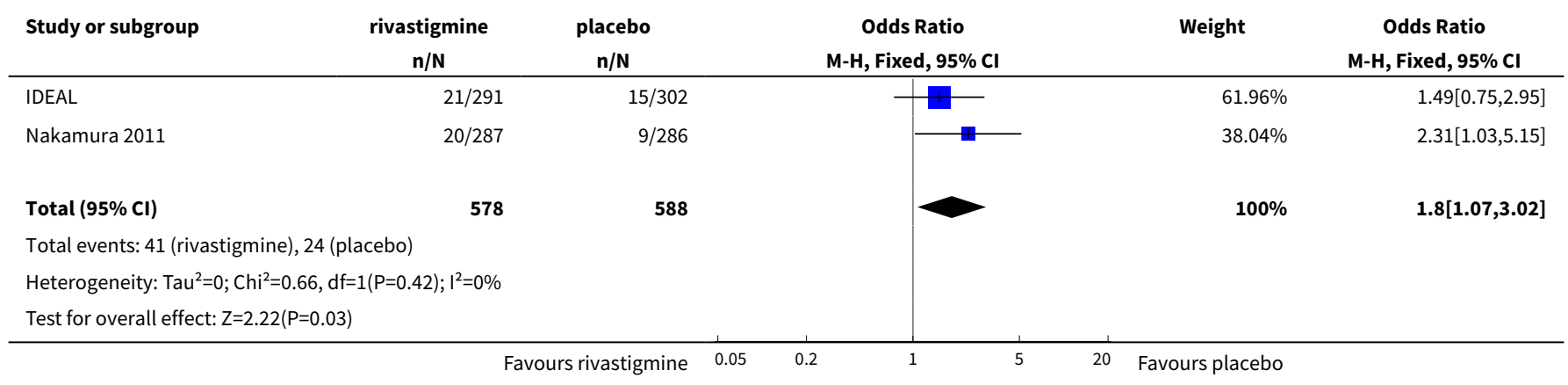

Analysis 4.21. Comparison 4 Rivastigmine $10 \mathrm{~cm}^{2}$ patch $(9.5 \mathrm{mg} / \mathrm{day})$ versus placebo, Outcome 21 at least one adverse event of vomiting by 24 weeks.

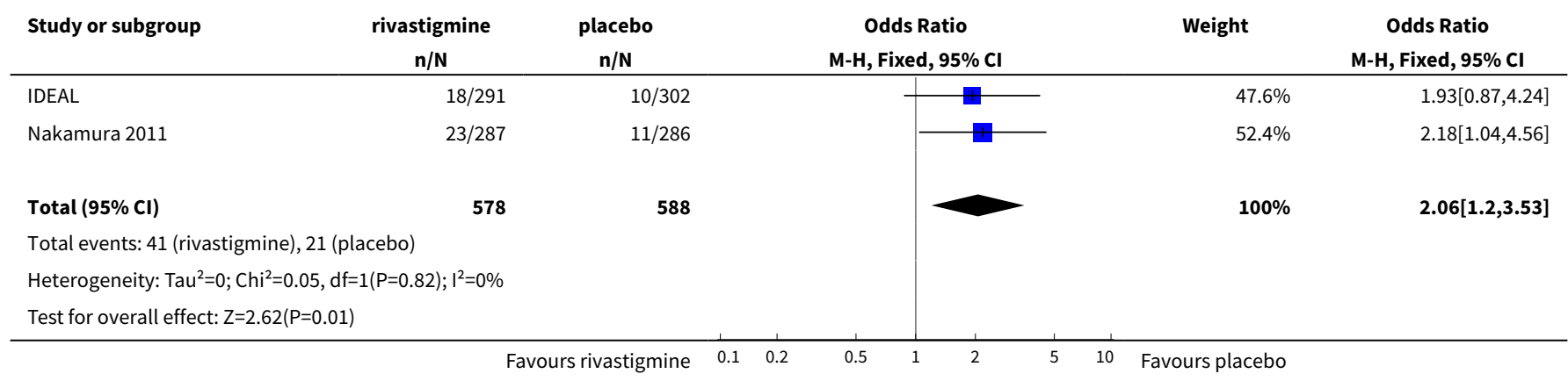

Analysis 4.22. Comparison 4 Rivastigmine $10 \mathrm{~cm}^{2}$ patch $(9.5 \mathrm{mg} /$ day $)$ versus placebo, Outcome 22 at least one adverse event of diarrhoea by 24 weeks.

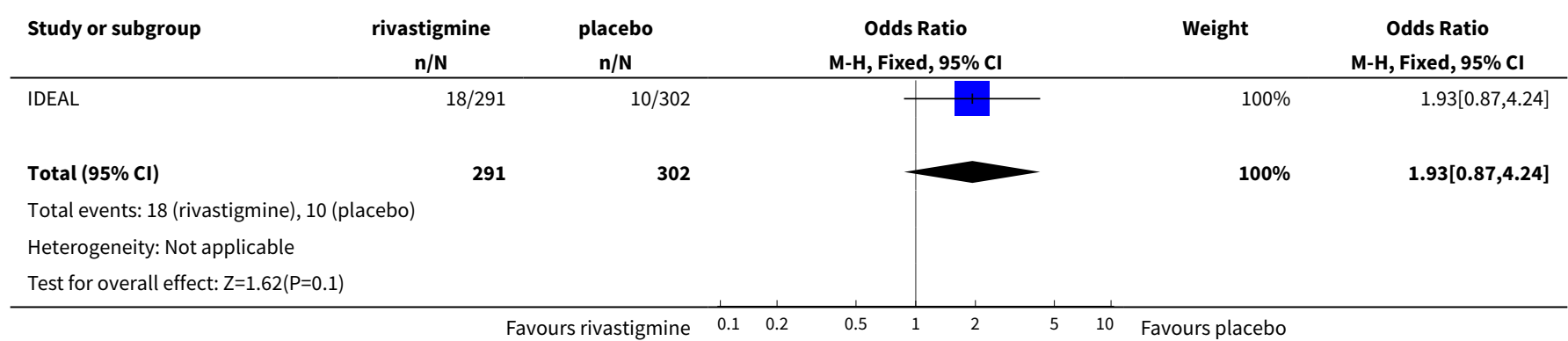


Analysis 4.23. Comparison 4 Rivastigmine $10 \mathrm{~cm}^{2}$ patch $(9.5 \mathrm{mg} /$ day) versus placebo, Outcome 23 at least one adverse event of weight decrease by 24 weeks.

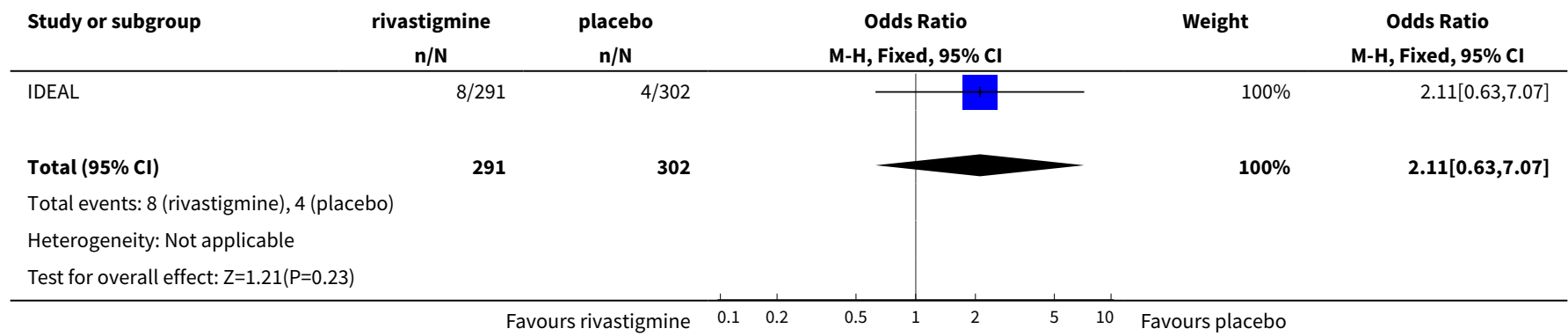

Analysis 4.24. Comparison 4 Rivastigmine $10 \mathrm{~cm}^{2}$ patch $(9.5 \mathrm{mg} /$ day $)$ versus placebo, Outcome 24 at least one adverse event of dizziness by 24 weeks.

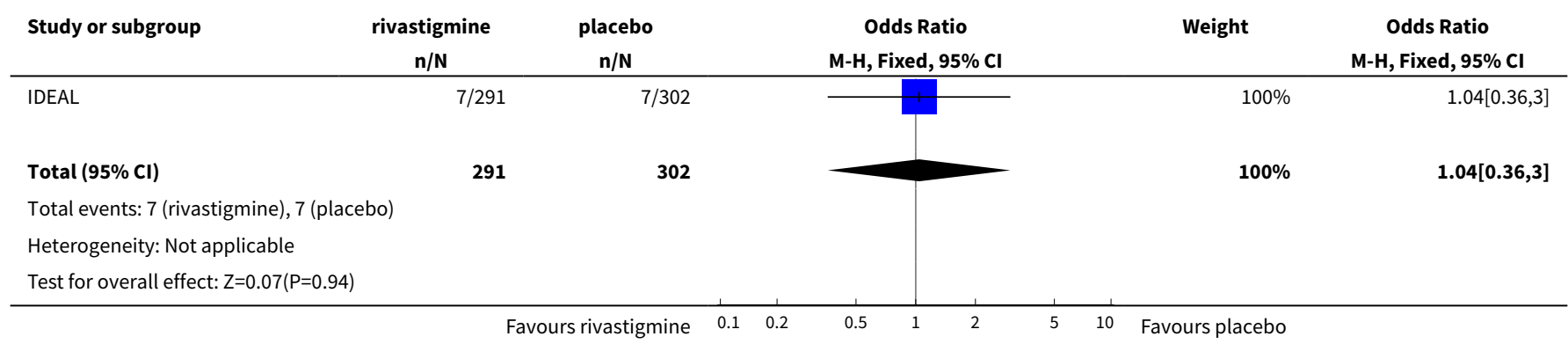

Analysis 4.25. Comparison 4 Rivastigmine $10 \mathrm{~cm}^{2}$ patch $(9.5 \mathrm{mg} /$ day) versus placebo, Outcome 25 at least one adverse event of decreased appetite by 24 weeks.

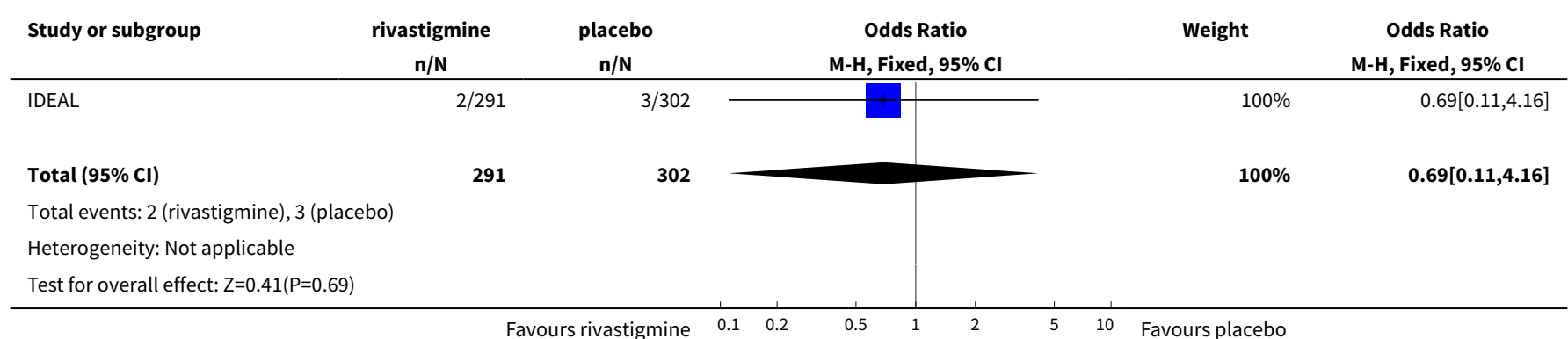

Analysis 4.26. Comparison 4 Rivastigmine $10 \mathrm{~cm}^{2}$ patch $(9.5 \mathrm{mg} /$ day) versus placebo, Outcome 26 at least one adverse event of headache by 24 weeks.

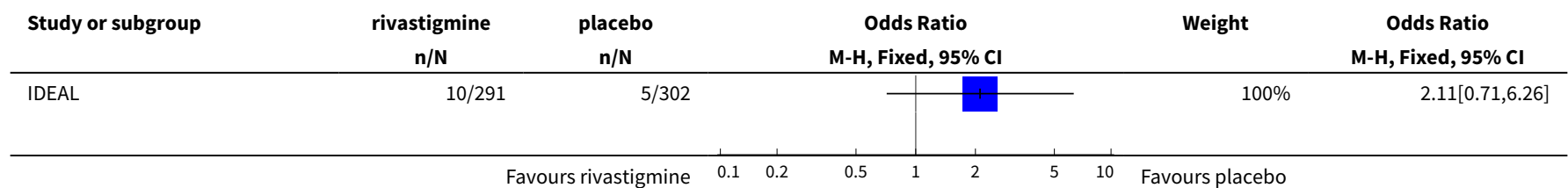




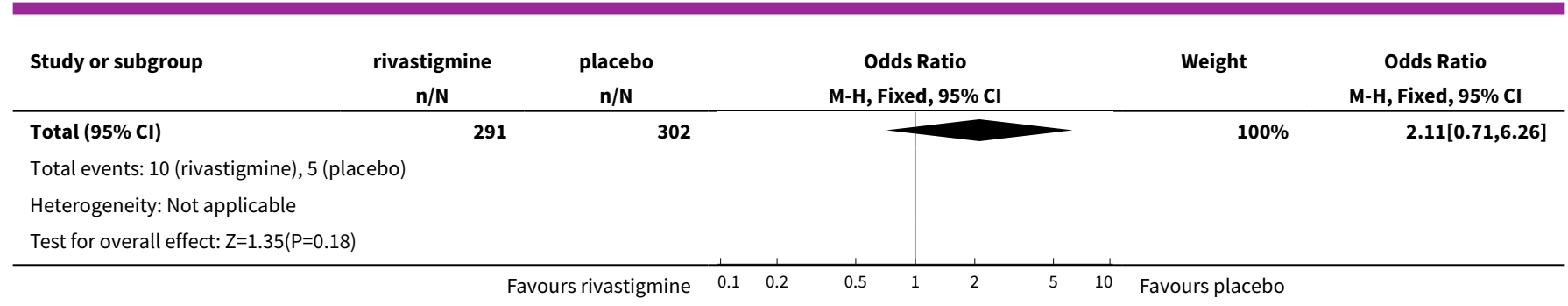

Analysis 4.27. Comparison 4 Rivastigmine $10 \mathrm{~cm}^{2}$ patch $(9.5 \mathrm{mg} /$ day $)$ versus placebo, Outcome 27 at least one adverse event of asthenia by 24 weeks.

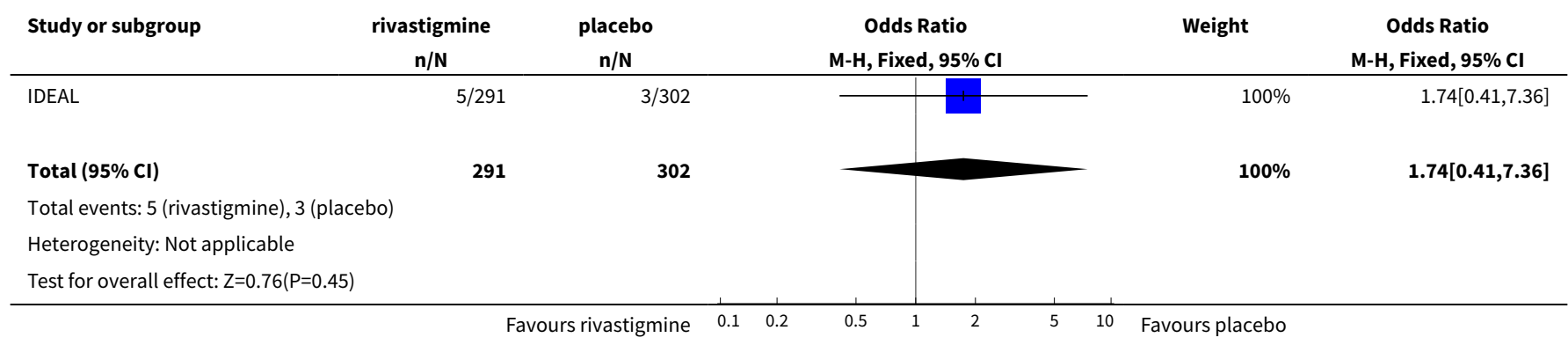

Analysis 4.28. Comparison 4 Rivastigmine $10 \mathrm{~cm}^{2}$ patch $(9.5 \mathrm{mg} /$ day $)$ versus placebo, Outcome 28 deaths before end of treatment at 24 weeks.

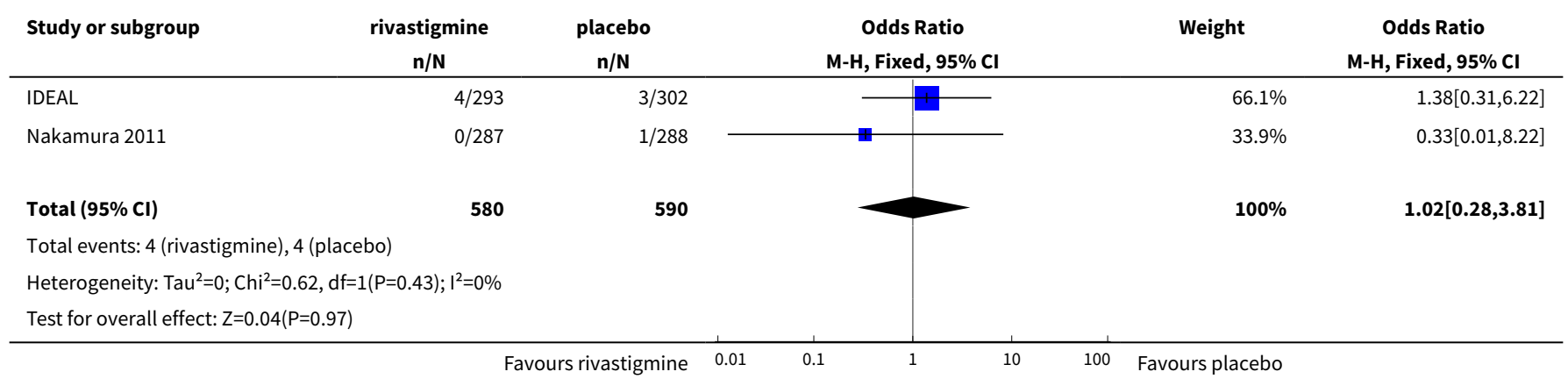

Analysis 4.29. Comparison 4 Rivastigmine $10 \mathrm{~cm}^{2}$ patch $(9.5 \mathrm{mg} /$ day $)$ versus placebo, Outcome 29 NPI-D carer distress scale (change from baseline at 24 weeks) ITT.

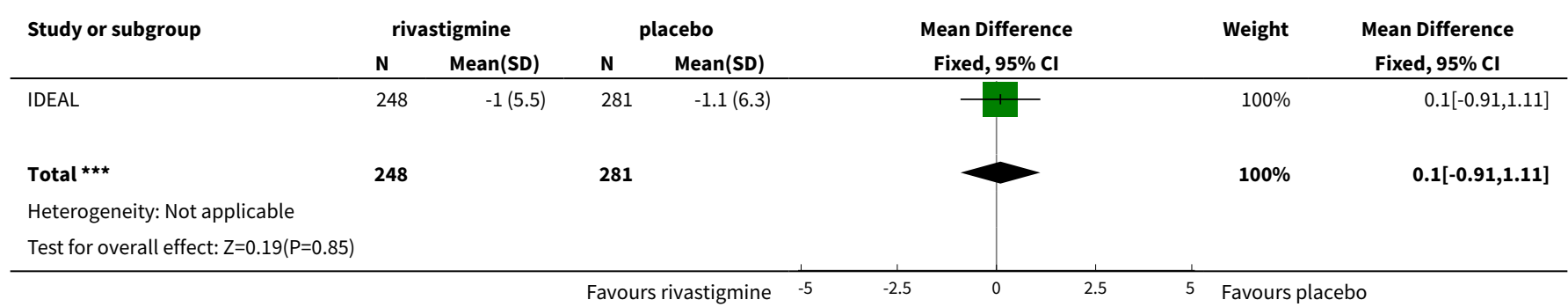




\section{Comparison 5. Rivastigmine $5 \mathrm{~cm}^{2}$ patch ( $4.6 \mathrm{mg} /$ day) versus placebo}

\begin{tabular}{|c|c|c|c|c|}
\hline Outcome or subgroup title & $\begin{array}{l}\text { No. of } \\
\text { studies }\end{array}$ & $\begin{array}{l}\text { No. of } \\
\text { partici- } \\
\text { pants }\end{array}$ & Statistical method & Effect size \\
\hline $\begin{array}{l}1 \text { ADAS-J Cog (change from baseline at } 24 \text { weeks) } \\
\text { ITT }\end{array}$ & 1 & 531 & $\begin{array}{l}\text { Mean Difference (IV, Fixed, 95\% } \\
\mathrm{Cl} \text { ) }\end{array}$ & $-0.8[-1.62,0.02]$ \\
\hline 2 MMSE (change from baseline at 24 weeks) ITT & 1 & 487 & $\begin{array}{l}\text { Mean Difference (IV, Fixed, 95\% } \\
\mathrm{Cl} \text { ) }\end{array}$ & $0.0[-0.52,0.52]$ \\
\hline $\begin{array}{l}3 \text { Mental Function Impairment MENFIS (change } \\
\text { from baseline at } 24 \text { weeks) ITT }\end{array}$ & 1 & 536 & $\begin{array}{l}\text { Mean Difference (IV, Fixed, 95\% } \\
\mathrm{CI})\end{array}$ & $\begin{array}{l}-0.70[-1.72 \\
0.32]\end{array}$ \\
\hline $\begin{array}{l}4 \text { Disability Assessment for Dementia (DAD) } \\
\text { (change from baseline at } 24 \text { weeks) ITT }\end{array}$ & 1 & 536 & $\begin{array}{l}\text { Mean Difference (IV, Fixed, 95\% } \\
\mathrm{CI})\end{array}$ & $\begin{array}{l}1.20[-0.73 \\
3.13]\end{array}$ \\
\hline 5 CIBIC-Plus J (no change or worse at 24 weeks) ITT & 1 & 536 & Odds Ratio (M-H, Fixed, 95\% Cl) & $0.67[0.43,1.05]$ \\
\hline $\begin{array}{l}6 \text { BEHAVE-AD (change from baseline at } 24 \text { weeks) } \\
\text { ITT }\end{array}$ & 1 & 536 & $\begin{array}{l}\text { Mean Difference (IV, Fixed, 95\% } \\
\mathrm{CI})\end{array}$ & $0.0[-0.67,0.67]$ \\
\hline 7 withdrawals before end of treatment at 24 weeks & 1 & 572 & Odds Ratio (M-H, Fixed, 95\% Cl) & $1.53[1.01,2.33]$ \\
\hline 8 at least one adverse event by 24 weeks & 1 & 568 & Odds Ratio (M-H, Fixed, 95\% Cl) & $1.80[1.16,2.78]$ \\
\hline $\begin{array}{l}9 \text { withdrawals due to an adverse event before end } \\
\text { of treatment at } 24 \text { weeks }\end{array}$ & 1 & 572 & Odds Ratio (M-H, Fixed, 95\% Cl) & $1.96[1.12,3.44]$ \\
\hline $\begin{array}{l}10 \text { at least one adverse event of application site } \\
\text { erythema by } 24 \text { weeks }\end{array}$ & 1 & 568 & Odds Ratio (M-H, Fixed, 95\% Cl) & $2.53[1.73,3.70]$ \\
\hline $\begin{array}{l}11 \text { at least one adverse event of application site } \\
\text { pruritis by } 24 \text { weeks }\end{array}$ & 1 & 568 & Odds Ratio (M-H, Fixed, 95\% Cl) & $1.79[1.23,2.60]$ \\
\hline $\begin{array}{l}12 \text { at least one adverse event of application site } \\
\text { edema by } 24 \text { weeks }\end{array}$ & 1 & 568 & Odds Ratio (M-H, Fixed, 95\% Cl) & $\begin{array}{l}5.65[2.46 \\
12.94]\end{array}$ \\
\hline $\begin{array}{l}13 \text { at least one adverse event application site exfo- } \\
\text { liation by } 24 \text { weeks }\end{array}$ & 1 & 568 & Odds Ratio (M-H, Fixed, 95\% Cl) & $\begin{array}{l}3.68[1.20 \\
11.33]\end{array}$ \\
\hline $\begin{array}{l}14 \text { at least one adverse event of dermatitis contact } \\
\text { by } 24 \text { weeks }\end{array}$ & 1 & 568 & Odds Ratio (M-H, Fixed, 95\% Cl) & $1.99[1.30,3.06]$ \\
\hline $\begin{array}{l}15 \text { at least one adverse event of nasopharyngitis by } \\
24 \text { weeks }\end{array}$ & 1 & 568 & Odds Ratio (M-H, Fixed, 95\% Cl) & $0.67[0.38,1.19]$ \\
\hline $\begin{array}{l}16 \text { at least one adverse event of nausea by } 24 \\
\text { weeks }\end{array}$ & 1 & 568 & Odds Ratio (M-H, Fixed, 95\% Cl) & $0.33[0.09,1.24]$ \\
\hline $\begin{array}{l}17 \text { at least one adverse event of vomiting by } 24 \\
\text { weeks }\end{array}$ & 1 & 568 & Odds Ratio (M-H, Fixed, 95\% Cl) & $1.01[0.43,2.38]$ \\
\hline 18 deaths before end of treatment at 24 weeks & 1 & 572 & Odds Ratio (M-H, Fixed, 95\% Cl) & $\begin{array}{l}1.01[0.06 \\
16.29]\end{array}$ \\
\hline
\end{tabular}


Analysis 5.1. Comparison 5 Rivastigmine $5 \mathrm{~cm}^{2}$ patch $(4.6 \mathrm{mg} / \mathrm{day})$ versus placebo, Outcome 1 ADAS-J Cog (change from baseline at 24 weeks) ITT.

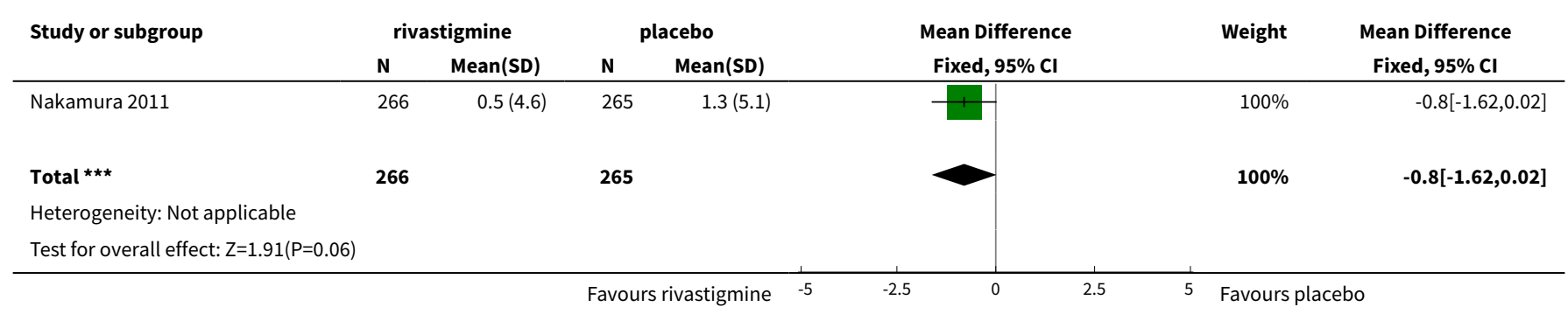

Analysis 5.2. Comparison 5 Rivastigmine $5 \mathrm{~cm}^{2}$ patch $(4.6 \mathrm{mg} /$ day) versus placebo, Outcome 2 MMSE (change from baseline at 24 weeks) ITT.

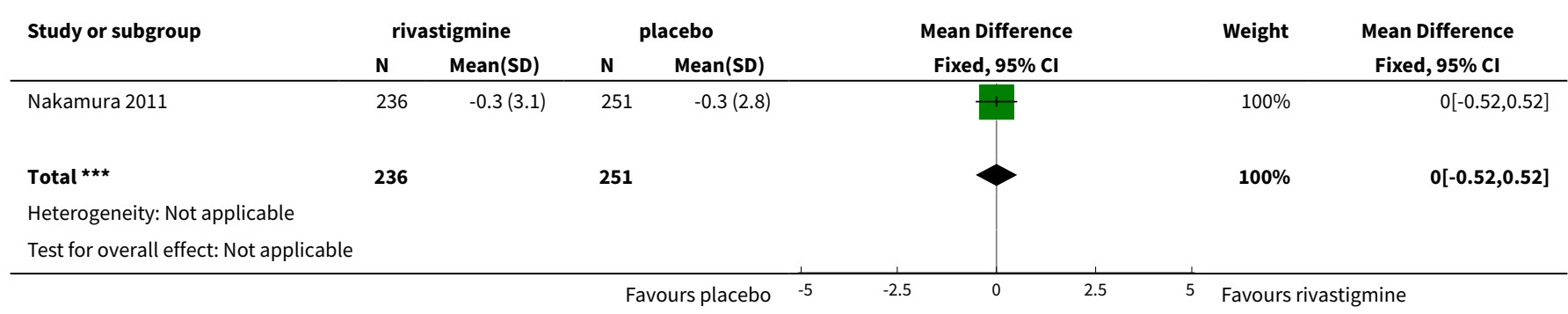

Analysis 5.3. Comparison 5 Rivastigmine $5 \mathrm{~cm}^{2}$ patch ( $4.6 \mathrm{mg} /$ day) versus placebo, Outcome 3 Mental Function Impairment MENFIS (change from baseline at 24 weeks) ITT.

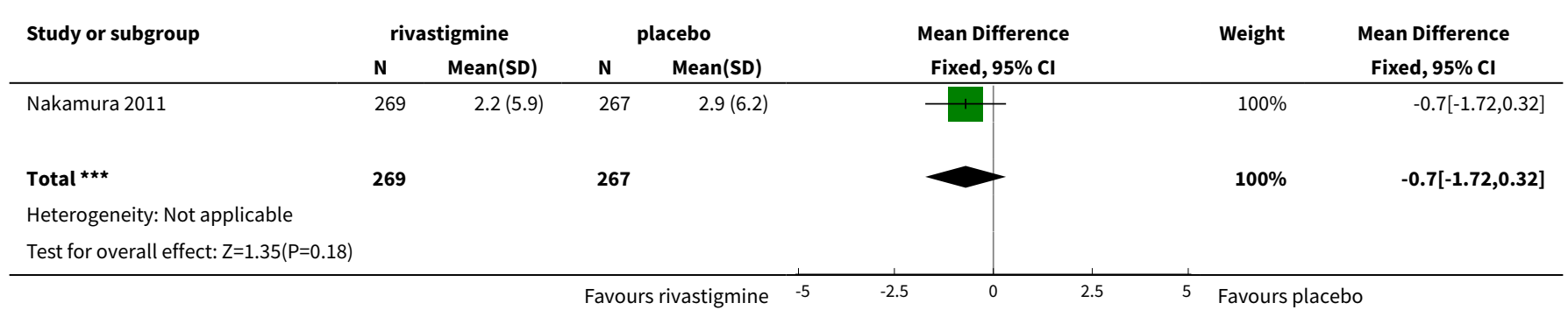

Analysis 5.4. Comparison 5 Rivastigmine $5 \mathrm{~cm}^{2}$ patch ( $4.6 \mathrm{mg} /$ day) versus placebo, Outcome 4 Disability Assessment for Dementia (DAD) (change from baseline at 24 weeks) ITT.

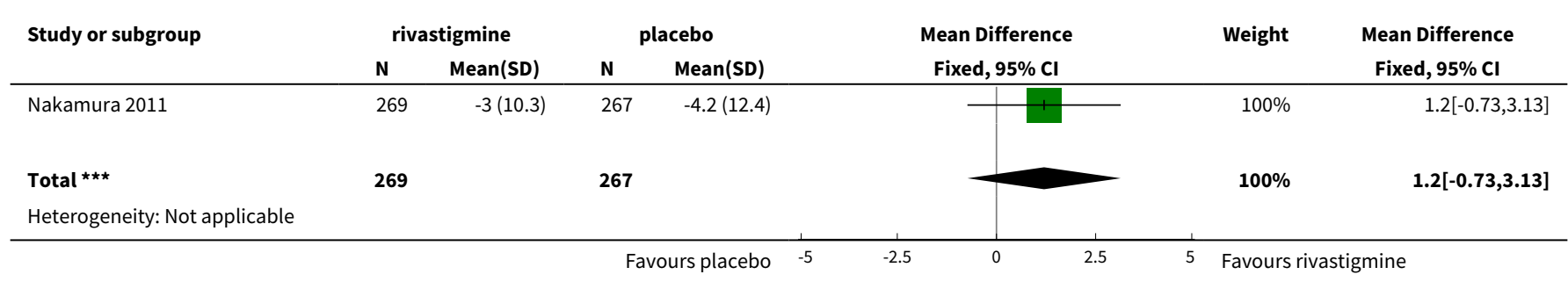




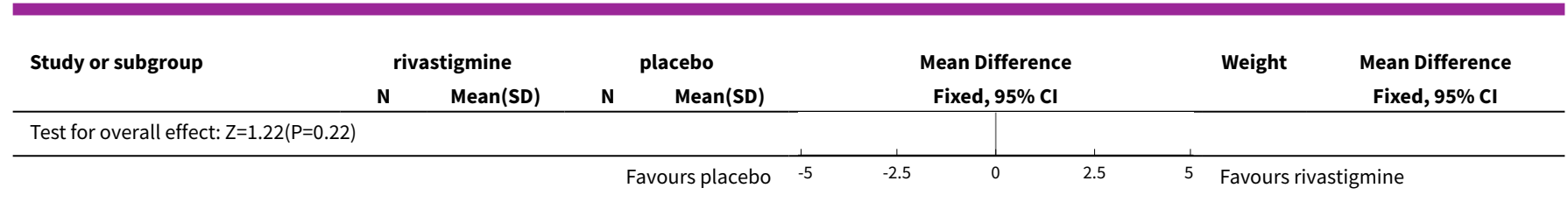

Analysis 5.5. Comparison 5 Rivastigmine $5 \mathrm{~cm}^{2}$ patch $(4.6 \mathrm{mg} / \mathrm{day})$ versus placebo, Outcome 5 CIBIC-Plus J (no change or worse at 24 weeks) ITT.

\begin{tabular}{|c|c|c|c|c|c|}
\hline Study or subgroup & $\begin{array}{c}\text { rivastigmine } \\
n / N\end{array}$ & $\begin{array}{c}\text { placebo } \\
n / N\end{array}$ & $\begin{array}{c}\text { Odds Ratio } \\
\text { M-H, Fixed, 95\% Cl }\end{array}$ & Weight & $\begin{array}{c}\text { Odds Ratio } \\
\text { M-H, Fixed, } 95 \% \mathrm{Cl}\end{array}$ \\
\hline Nakamura 2011 & $212 / 269$ & $226 / 267$ & & $100 \%$ & $0.67[0.43,1.05]$ \\
\hline Total $(95 \% \mathrm{Cl})$ & 269 & 267 & & $100 \%$ & $0.67[0.43,1.05]$ \\
\hline \multicolumn{6}{|c|}{ Total events: 212 (rivastigmine), 226 (placebo) } \\
\hline \multicolumn{6}{|c|}{ Heterogeneity: Not applicable } \\
\hline \multicolumn{6}{|c|}{ Test for overall effect: $Z=1.74(P=0.08)$} \\
\hline
\end{tabular}

Analysis 5.6. Comparison 5 Rivastigmine $5 \mathrm{~cm}^{2}$ patch $(4.6 \mathrm{mg} /$ day) versus placebo, Outcome 6 BEHAVE-AD (change from baseline at 24 weeks) ITT.

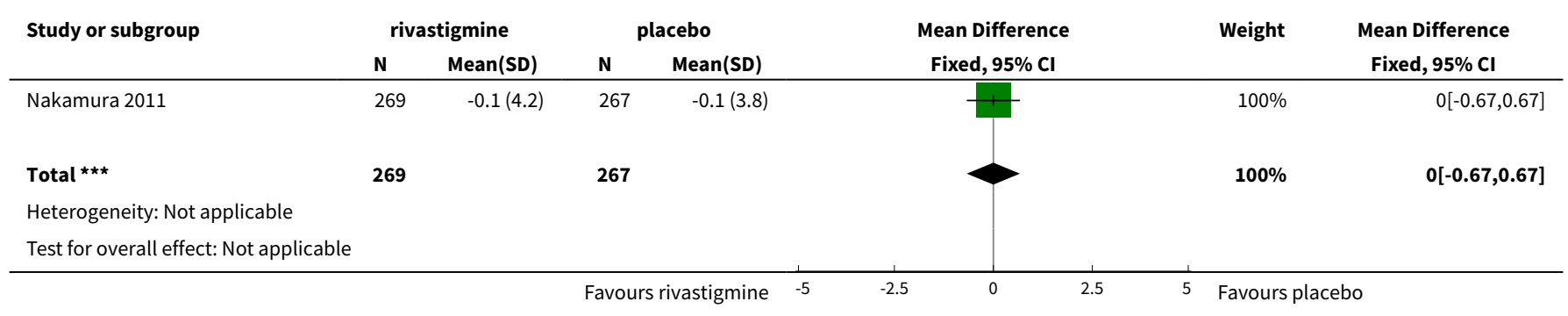

Analysis 5.7. Comparison 5 Rivastigmine $5 \mathrm{~cm}^{2}$ patch $(4.6 \mathrm{mg} /$ day) versus placebo, Outcome 7 withdrawals before end of treatment at 24 weeks.

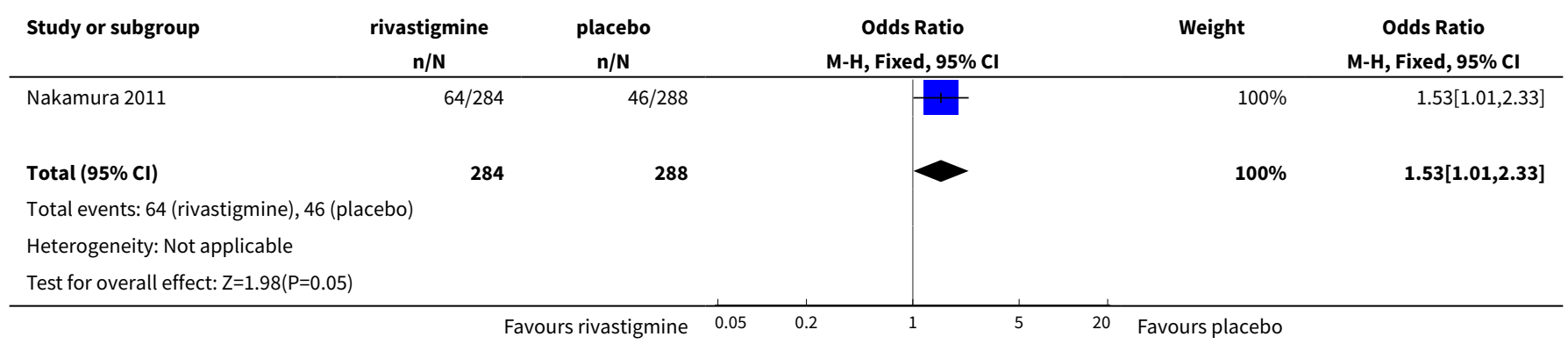


Analysis 5.8. Comparison 5 Rivastigmine $5 \mathrm{~cm}^{2}$ patch $(4.6 \mathrm{mg} /$ day) versus placebo, Outcome 8 at least one adverse event by 24 weeks.

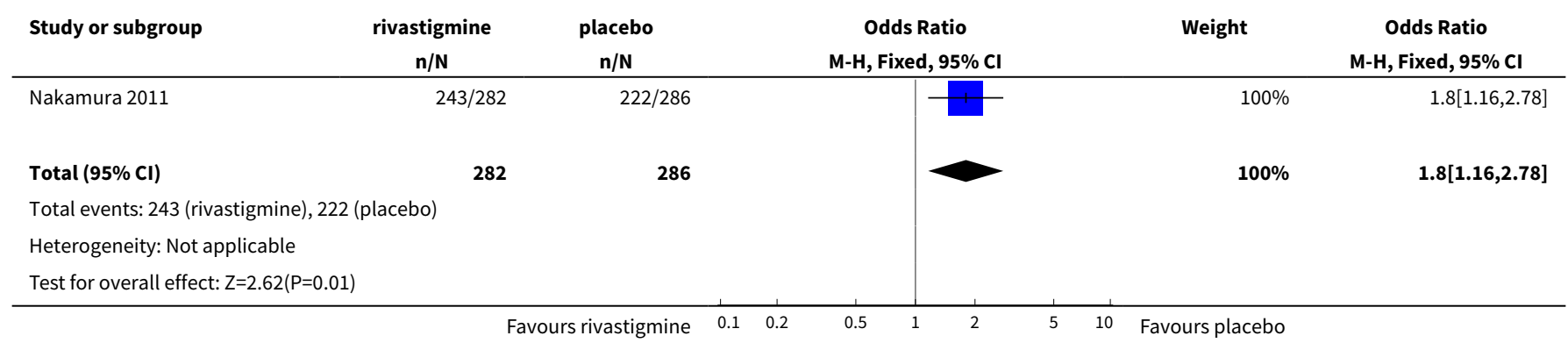

Analysis 5.9. Comparison 5 Rivastigmine $5 \mathrm{~cm}^{2}$ patch ( $4.6 \mathrm{mg} /$ day) versus placebo, Outcome 9 withdrawals due to an adverse event before end of treatment at 24 weeks.

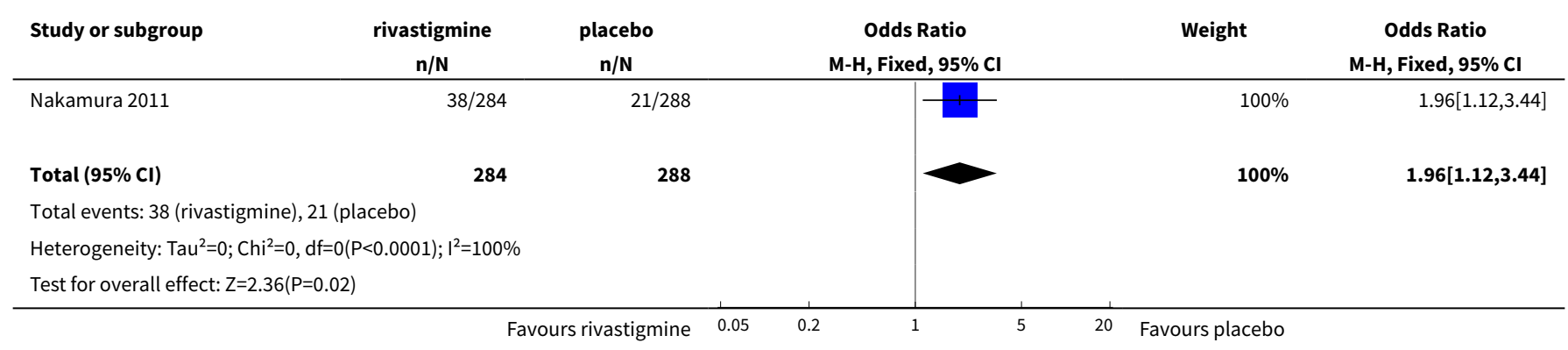

Analysis 5.10. Comparison 5 Rivastigmine $5 \mathrm{~cm}^{2}$ patch $(4.6 \mathrm{mg} /$ day $)$ versus placebo, Outcome 10 at least one adverse event of application site erythema by 24 weeks.

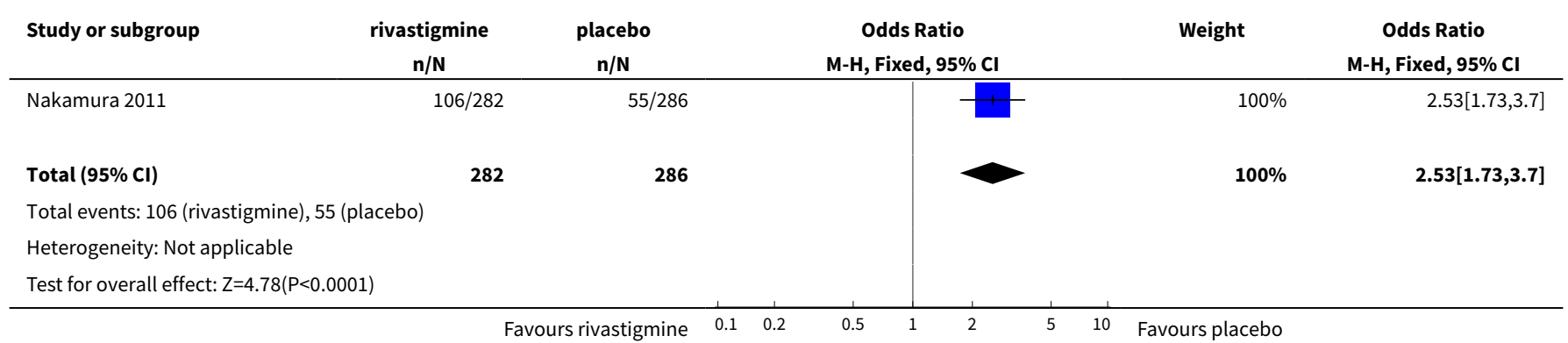

Analysis 5.11. Comparison 5 Rivastigmine $5 \mathrm{~cm}^{2}$ patch $(4.6 \mathrm{mg} /$ day) versus placebo, Outcome 11 at least one adverse event of application site pruritis by 24 weeks.

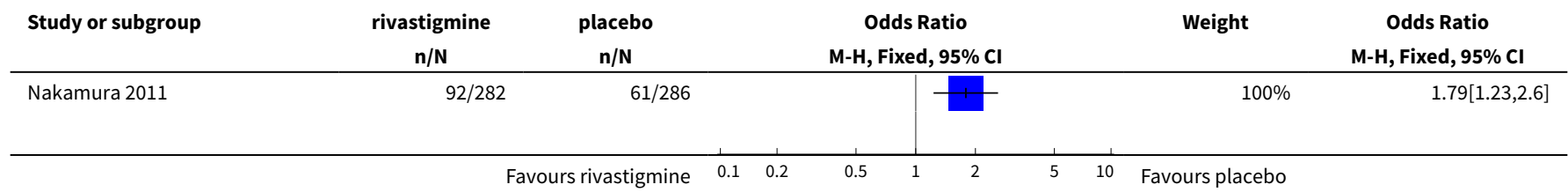




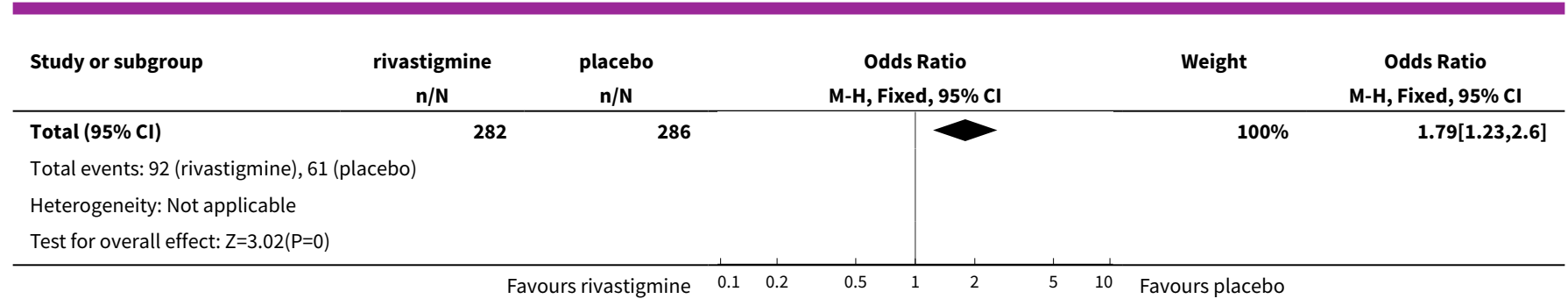

Analysis 5.12. Comparison 5 Rivastigmine $5 \mathrm{~cm}^{2}$ patch ( $4.6 \mathrm{mg} /$ day) versus placebo, Outcome 12 at least one adverse event of application site edema by 24 weeks.

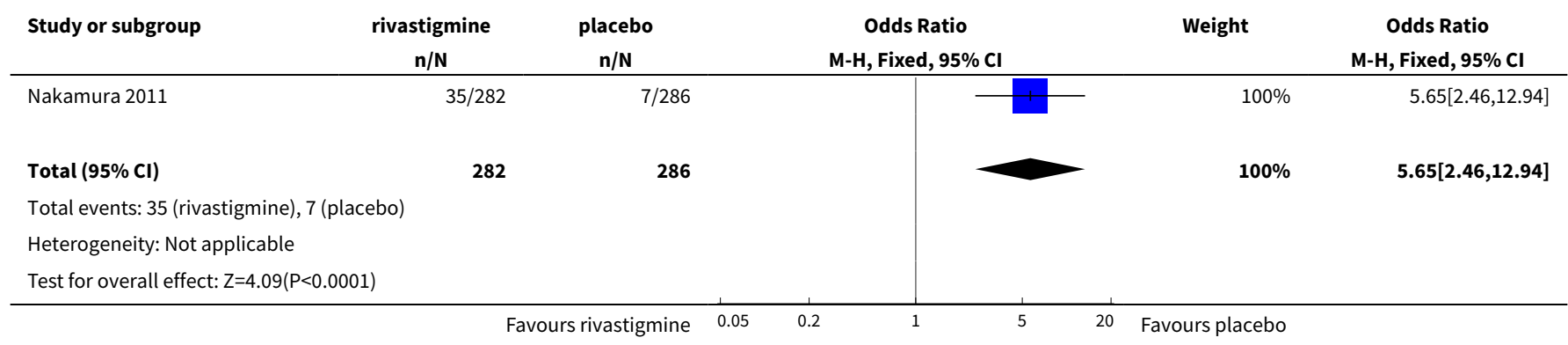

Analysis 5.13. Comparison 5 Rivastigmine $5 \mathrm{~cm}^{2}$ patch $(4.6 \mathrm{mg} /$ day) versus placebo, Outcome 13 at least one adverse event application site exfoliation by 24 weeks.

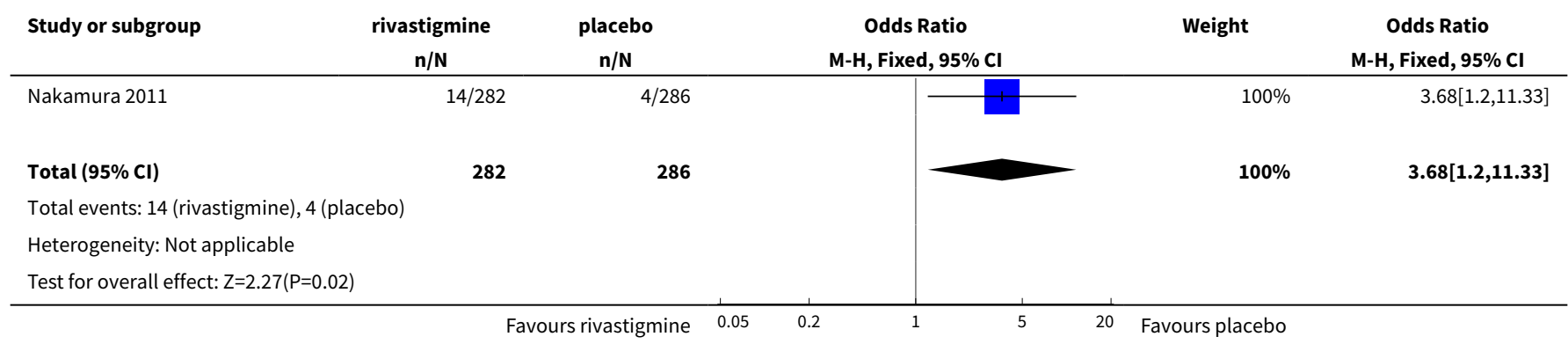

Analysis 5.14. Comparison 5 Rivastigmine $5 \mathrm{~cm}^{2}$ patch ( $4.6 \mathrm{mg} /$ day) versus placebo, Outcome 14 at least one adverse event of dermatitis contact by 24 weeks.

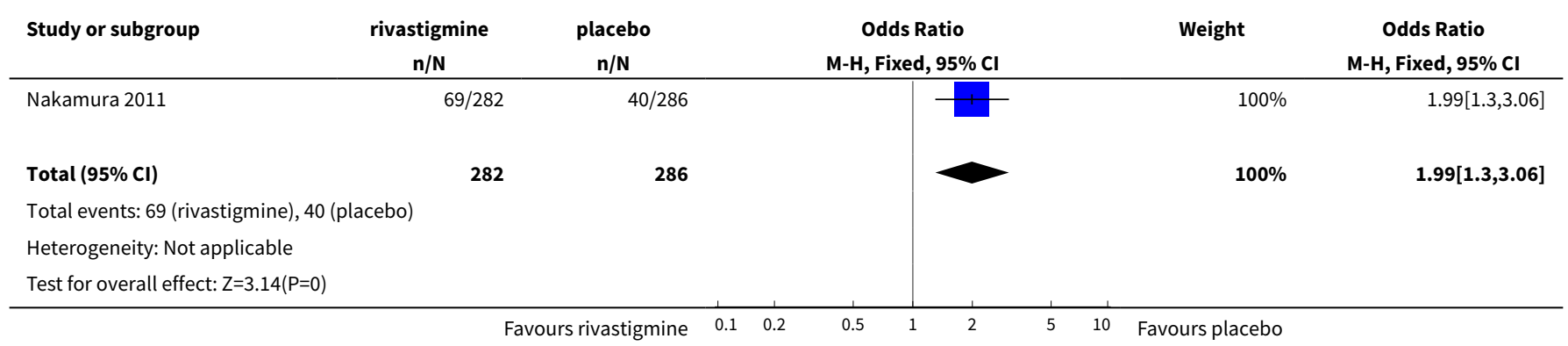


Analysis 5.15. Comparison 5 Rivastigmine $5 \mathrm{~cm}^{2}$ patch $(4.6 \mathrm{mg} /$ day) versus placebo, Outcome 15 at least one adverse event of nasopharyngitis by 24 weeks.

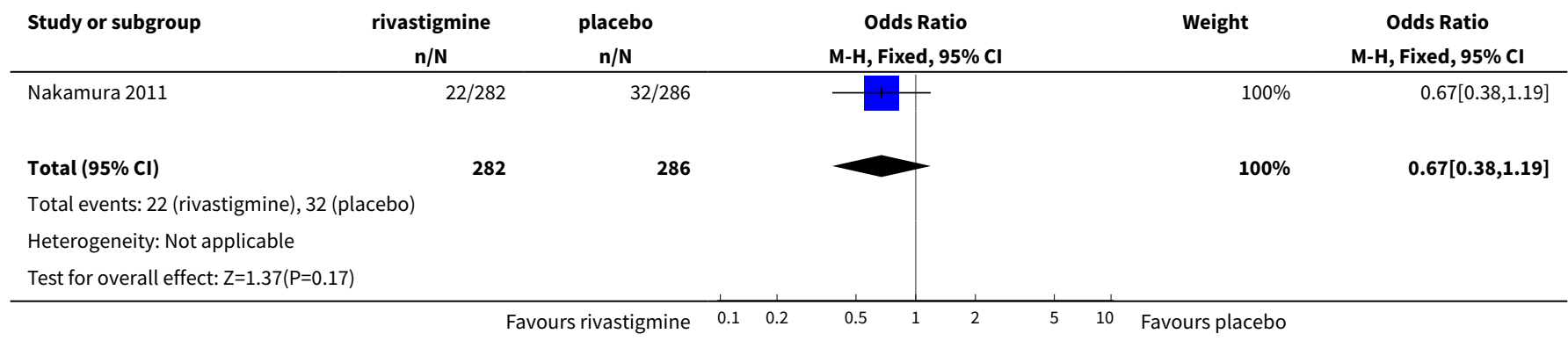

Analysis 5.16. Comparison 5 Rivastigmine $5 \mathrm{~cm}^{2}$ patch $(4.6 \mathrm{mg} /$ day) versus placebo, Outcome 16 at least one adverse event of nausea by 24 weeks.

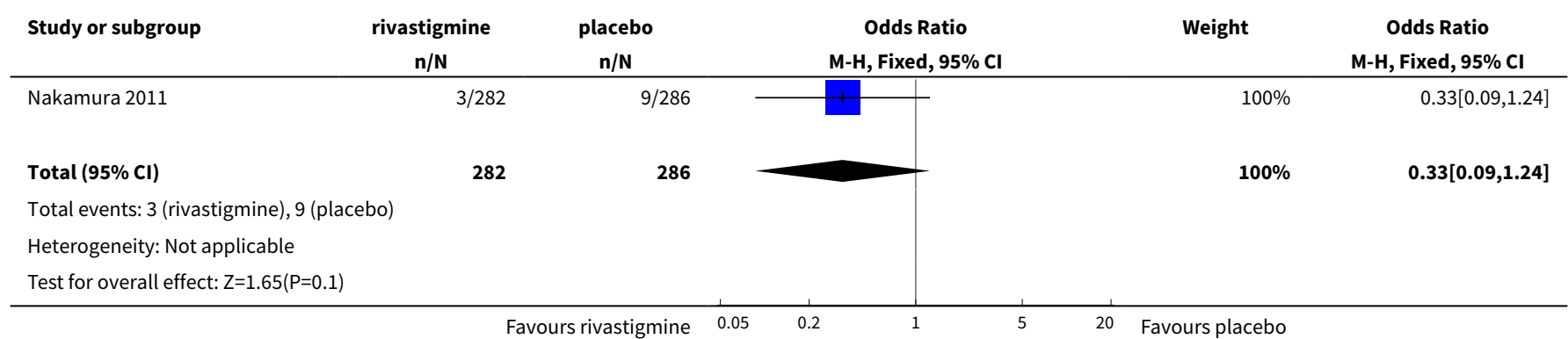

Analysis 5.17. Comparison 5 Rivastigmine $5 \mathrm{~cm}^{2}$ patch $(4.6 \mathrm{mg} /$ day) versus placebo, Outcome 17 at least one adverse event of vomiting by 24 weeks.

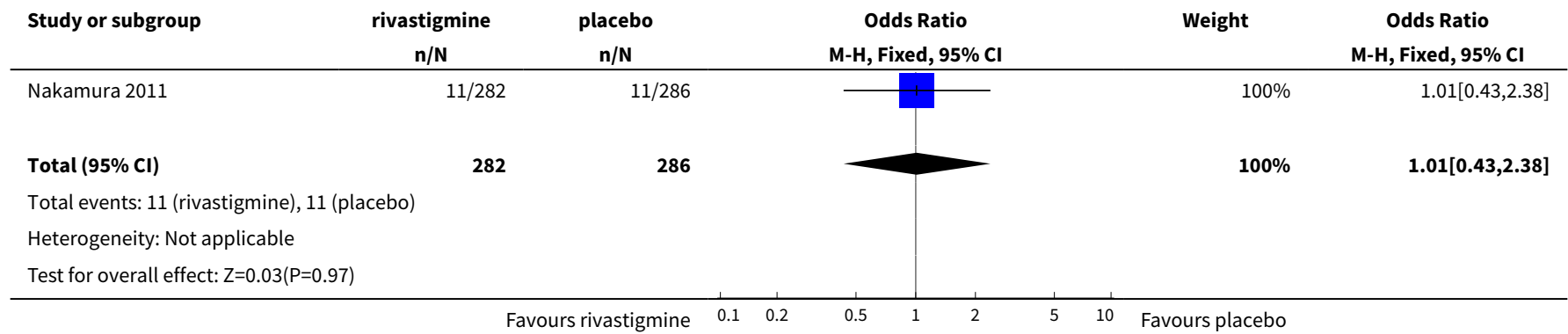

Analysis 5.18. Comparison 5 Rivastigmine $5 \mathrm{~cm}^{2}$ patch ( $4.6 \mathrm{mg} /$ day) versus placebo, Outcome 18 deaths before end of treatment at 24 weeks.

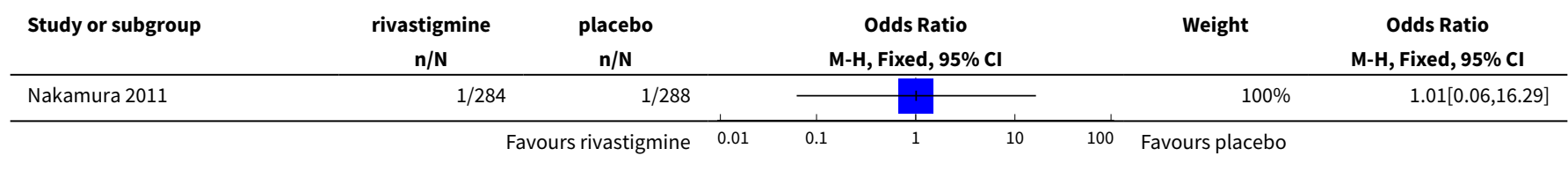




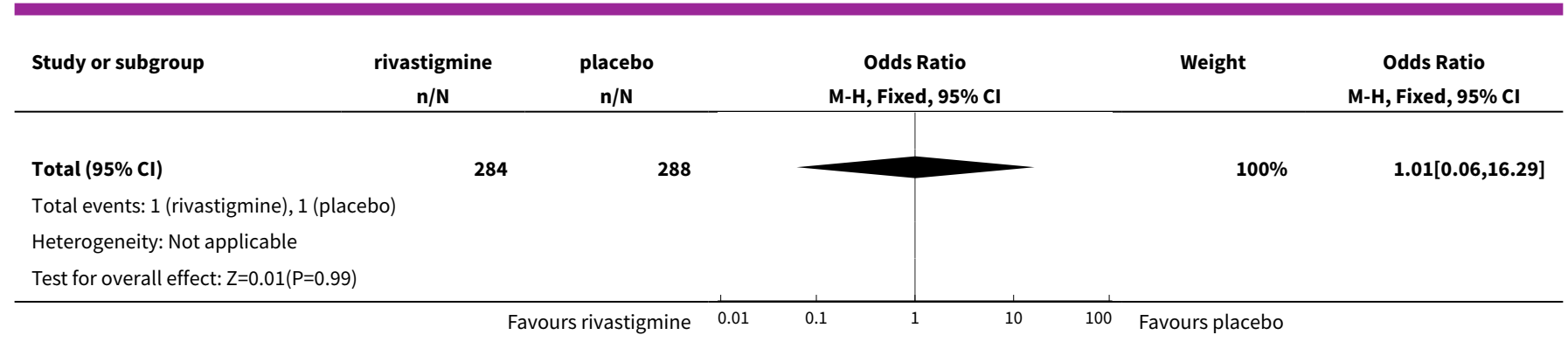

Comparison 6. Rivastigmine $10 \mathrm{~cm}^{2}$ patch ( $9.5 \mathrm{mg} /$ day) versus rivastigmine capsules ( 6 to $12 \mathrm{mg} /$ day in two divided doses)

\begin{tabular}{|c|c|c|c|c|}
\hline Outcome or subgroup title & $\begin{array}{l}\text { No. of } \\
\text { studies }\end{array}$ & $\begin{array}{l}\text { No. of } \\
\text { partici- } \\
\text { pants }\end{array}$ & Statistical method & Effect size \\
\hline $\begin{array}{l}1 \text { ADAS-Cog (change from baseline at } 24 \text { weeks) } \\
\text { ITT }\end{array}$ & 1 & 501 & Mean Difference (IV, Fixed, 95\% CI) & $0.0[-1.10,1.10]$ \\
\hline 2 MMSE (change from baseline at 24 weeks) ITT & 1 & 506 & Mean Difference (IV, Fixed, 95\% CI) & $0.30[-0.27,0.87]$ \\
\hline $\begin{array}{l}3 \text { clock drawing (change from baseline at } 24 \\
\text { weeks) ITT }\end{array}$ & 1 & 491 & Mean Difference (IV, Fixed, 95\% CI) & $0.10[-0.46,0.66]$ \\
\hline 4 TMT-A (change from baseline at 24 weeks) ITT & 1 & 481 & Mean Difference (IV, Fixed, 95\% CI) & $\begin{array}{l}-2.60[-13.48 \\
8.28]\end{array}$ \\
\hline $\begin{array}{l}5 \text { ADCS-ADL (change from baseline at } 24 \\
\text { weeks) ITT }\end{array}$ & 1 & 501 & Mean Difference (IV, Fixed, 95\% CI) & $0.40[-1.23,2.03]$ \\
\hline $\begin{array}{l}6 \text { Clinical Global Impression (no change or } \\
\text { worse at } 24 \text { weeks) }\end{array}$ & 1 & 501 & Odds Ratio (M-H, Fixed, 95\% Cl) & $1.27[0.88,1.84]$ \\
\hline $\begin{array}{l}7 \mathrm{NPI}-12 \text { (change from baseline at } 24 \text { weeks) } \\
\text { ITT }\end{array}$ & 1 & 501 & Mean Difference (IV, Fixed, 95\% CI) & $0.50[-1.55,2.55]$ \\
\hline $\begin{array}{l}8 \text { withdrawals before end of treatment at } 24 \\
\text { weeks }\end{array}$ & 1 & 590 & Odds Ratio (M-H, Fixed, 95\% Cl) & $1.04[0.70,1.54]$ \\
\hline 9 at least one adverse event by 24 weeks & 1 & 585 & Odds Ratio (M-H, Fixed, 95\% Cl) & $0.59[0.43,0.82]$ \\
\hline $\begin{array}{l}10 \text { withdrawals due to an adverse event before } \\
\text { end of treatment at } 24 \text { weeks }\end{array}$ & 1 & 590 & Odds Ratio (M-H, Fixed, 95\% Cl) & $1.20[0.68,2.13]$ \\
\hline $\begin{array}{l}11 \text { at least one adverse event of nausea by } 24 \\
\text { weeks }\end{array}$ & 1 & 585 & Odds Ratio (M-H, Fixed, 95\% Cl) & $0.26[0.15,0.43]$ \\
\hline $\begin{array}{l}12 \text { at least one adverse event of vomiting by } 24 \\
\text { weeks }\end{array}$ & 1 & 585 & Odds Ratio (M-H, Fixed, 95\% Cl) & $0.32[0.18,0.57]$ \\
\hline $\begin{array}{l}13 \text { at least one adverse event of diarrhoea by } \\
24 \text { weeks }\end{array}$ & 1 & 585 & Odds Ratio (M-H, Fixed, 95\% Cl) & $1.15[0.57,2.29]$ \\
\hline $\begin{array}{l}14 \text { at least one adverse event of weight de- } \\
\text { crease by } 24 \text { weeks }\end{array}$ & 1 & 585 & Odds Ratio (M-H, Fixed, 95\% Cl) & $0.49[0.21,1.17]$ \\
\hline
\end{tabular}




\begin{tabular}{llllll}
\hline Outcome or subgroup title & $\begin{array}{l}\text { No. of } \\
\text { studies }\end{array}$ & $\begin{array}{l}\text { No. of } \\
\text { partici- } \\
\text { pants }\end{array}$ & Statistical method & Effect size \\
\hline $\begin{array}{l}15 \text { at least one adverse event of dizziness by } 24 \\
\text { weeks }\end{array}$ & 1 & 585 & Odds Ratio (M-H, Fixed, 95\% Cl) & $0.30[0.13,0.72]$ \\
\hline $\begin{array}{l}16 \text { at least one adverse event of decreased ap- } \\
\text { petite by 24 weeks }\end{array}$ & 1 & 585 & Odds Ratio (M-H, Fixed, 95\% Cl) & $0.16[0.04,0.73]$ \\
\hline $\begin{array}{l}17 \text { at least one adverse event of headache by } \\
24 \text { weeks }\end{array}$ & 1 & 585 & Odds Ratio (M-H, Fixed, 95\% Cl) & $0.55[0.25,1.20]$ \\
\hline $\begin{array}{l}18 \text { at least one adverse event of asthenia by 24 } \\
\text { weeks }\end{array}$ & 1 & 585 & Odds Ratio (M-H, Fixed, 95\% Cl) & $0.28[0.10,0.78]$ \\
\hline $\begin{array}{l}19 \text { deaths before end of treatment at 24 weeks } \\
+30 \text { days }\end{array}$ & 1 & 590 & Odds Ratio (M-H, Fixed, 95\% Cl) & $2.56[0.49,13.31]$ \\
\hline $\begin{array}{l}20 \text { NPl-D carer distress scale (change from } \\
\text { baseline at 24 weeks) ITT }\end{array}$ & 1 & 501 & Mean Difference (IV, Fixed, 95\% Cl) & $0.10[-0.96,1.16]$ \\
\hline
\end{tabular}

Analysis 6.1. Comparison 6 Rivastigmine $10 \mathrm{~cm}^{2}$ patch $(9.5 \mathrm{mg} / \mathrm{day})$ versus rivastigmine capsules (6 to $12 \mathrm{mg} /$ day in two divided doses), Outcome 1 ADAS-Cog (change from baseline at 24 weeks) ITT.

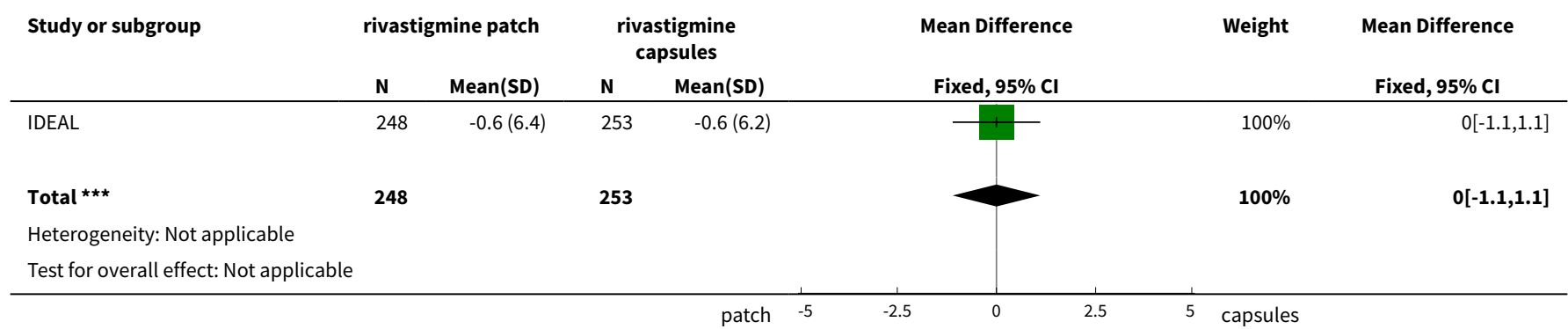

Analysis 6.2. Comparison 6 Rivastigmine $10 \mathrm{~cm}^{2}$ patch $(9.5 \mathrm{mg} /$ day) versus rivastigmine capsules ( 6 to $12 \mathrm{mg} /$ day in two divided doses), Outcome 2 MMSE (change from baseline at 24 weeks) ITT.

\begin{tabular}{|c|c|c|c|c|c|c|c|}
\hline \multirow[t]{2}{*}{ Study or subgroup } & \multicolumn{2}{|c|}{ rivastigmine patch } & \multicolumn{2}{|c|}{$\begin{array}{c}\text { rivastigmine } \\
\text { capsules }\end{array}$} & \multirow{2}{*}{$\begin{array}{c}\text { Mean Difference } \\
\text { Fixed, } 95 \% \mathrm{Cl}\end{array}$} & \multirow[t]{2}{*}{ Weight } & \multirow{2}{*}{$\begin{array}{l}\text { Mean Difference } \\
\text { Fixed, } 95 \% \mathrm{Cl}\end{array}$} \\
\hline & $\mathbf{N}$ & Mean(SD) & $\mathbf{N}$ & $\operatorname{Mean}(S D)$ & & & \\
\hline IDEAL & 250 & $1.1(3.3)$ & 256 & $0.8(3.2)$ & & $100 \%$ & $0.3[-0.27,0.87]$ \\
\hline 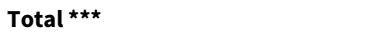 & 250 & & 256 & & & $100 \%$ & $0.3[-0.27,0.87]$ \\
\hline \multicolumn{8}{|l|}{ Heterogeneity: Not applicable } \\
\hline & & & & patch -5 & -2.5 & 5 capsules & \\
\hline
\end{tabular}


Analysis 6.3. Comparison 6 Rivastigmine $10 \mathrm{~cm}^{2}$ patch $(9.5 \mathrm{mg} /$ day) versus rivastigmine capsules $(6$ to $12 \mathrm{mg}$ /day in two divided doses), Outcome 3 clock drawing (change from baseline at 24 weeks) ITT.

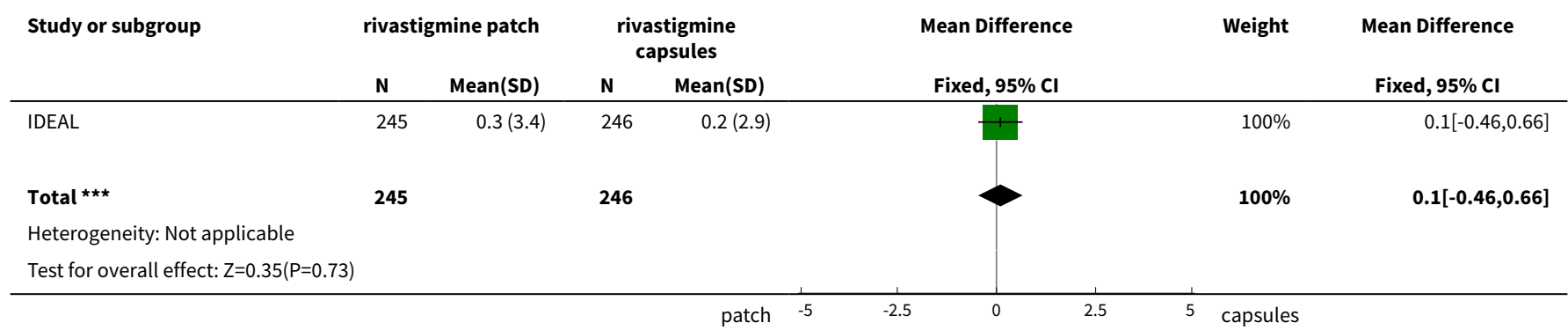

Analysis 6.4. Comparison 6 Rivastigmine $10 \mathrm{~cm}^{2}$ patch $(9.5 \mathrm{mg} /$ day) versus rivastigmine capsules ( 6 to $12 \mathrm{mg}$ /day in two divided doses), Outcome 4 TMT-A (change from baseline at 24 weeks) ITT.

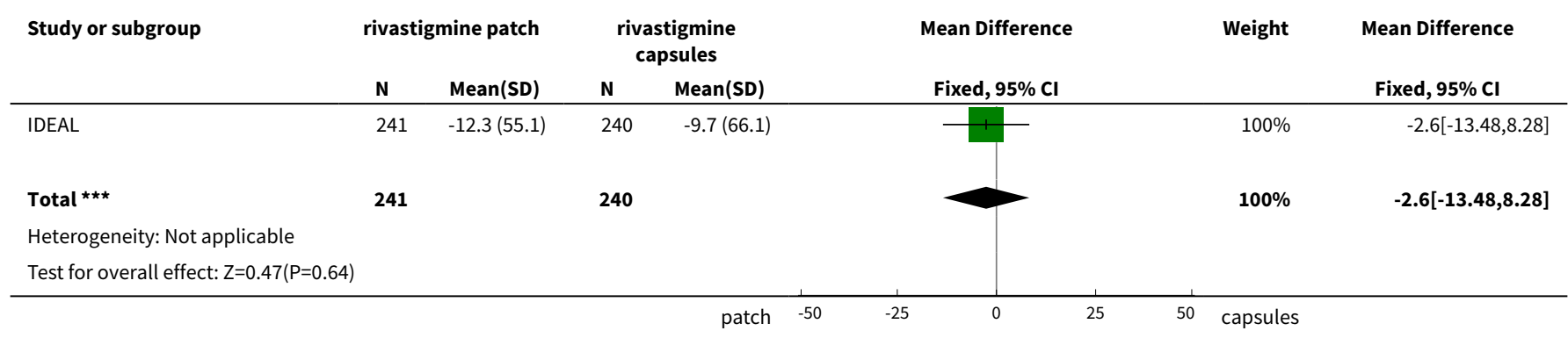

Analysis 6.5. Comparison 6 Rivastigmine $10 \mathrm{~cm}^{2}$ patch $(9.5 \mathrm{mg} /$ day $)$ versus rivastigmine capsules ( 6 to $12 \mathrm{mg}$ /day in two divided doses), Outcome 5 ADCS-ADL (change from baseline at 24 weeks) ITT.

\begin{tabular}{|c|c|c|c|c|c|c|c|}
\hline \multirow[t]{2}{*}{ Study or subgroup } & \multicolumn{2}{|c|}{ rivastigmine patch } & \multicolumn{2}{|c|}{$\begin{array}{l}\text { rivastigmine } \\
\text { capsules }\end{array}$} & \multirow{2}{*}{$\begin{array}{c}\text { Mean Difference } \\
\text { Fixed, 95\% Cl } \\
\end{array}$} & \multirow[t]{2}{*}{ Weight } & \multirow{2}{*}{$\begin{array}{c}\text { Mean Difference } \\
\text { Fixed, } 95 \% \mathrm{Cl} \\
\end{array}$} \\
\hline & $\mathbf{N}$ & Mean(SD) & $\mathbf{N}$ & Mean(SD) & & & \\
\hline IDEAL & 247 & $-0.1(9.1)$ & 254 & $-0.5(9.5)$ & 1 & $100 \%$ & $0.4[-1.23,2.03]$ \\
\hline Total ${ }^{\star \star \star}$ & 247 & & 254 & & & $100 \%$ & $0.4[-1.23,2.03]$ \\
\hline \multicolumn{8}{|c|}{ Heterogeneity: $\operatorname{Tau}^{2}=0 ; \mathrm{Chi}^{2}=0, \mathrm{df}=0(\mathrm{P}<0.0001) ; \mathrm{I}^{2}=100 \%$} \\
\hline
\end{tabular}

Analysis 6.6. Comparison 6 Rivastigmine $10 \mathrm{~cm}^{2}$ patch $(9.5 \mathrm{mg} /$ day) versus rivastigmine capsules ( 6 to $12 \mathrm{mg} /$ day in two divided doses), Outcome 6 Clinical Global Impression (no change or worse at 24 weeks).

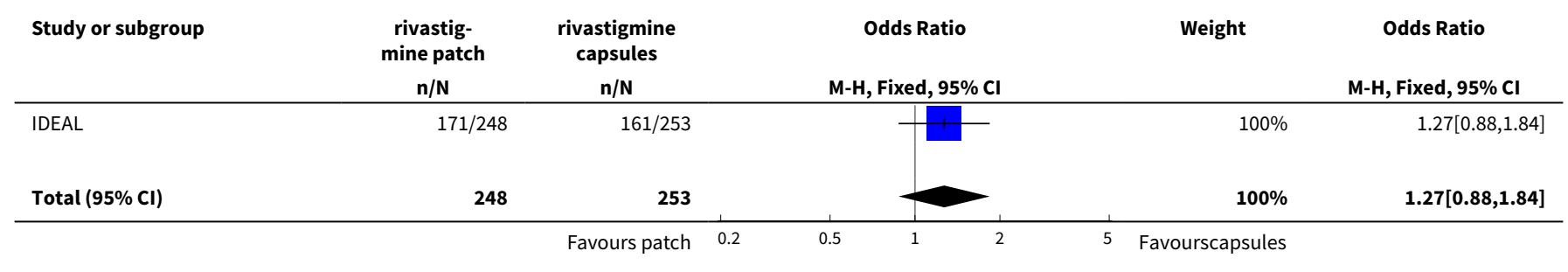




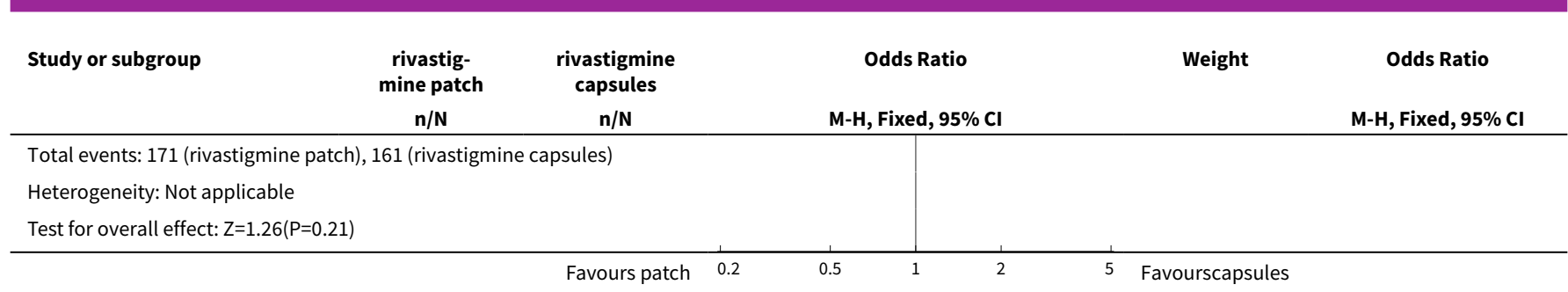

Analysis 6.7. Comparison 6 Rivastigmine $10 \mathrm{~cm}^{2}$ patch $(9.5 \mathrm{mg} /$ day $)$ versus rivastigmine capsules ( 6 to $12 \mathrm{mg} /$ day in two divided doses), Outcome $7 \mathrm{NPI}-12$ (change from baseline at 24 weeks) ITT.

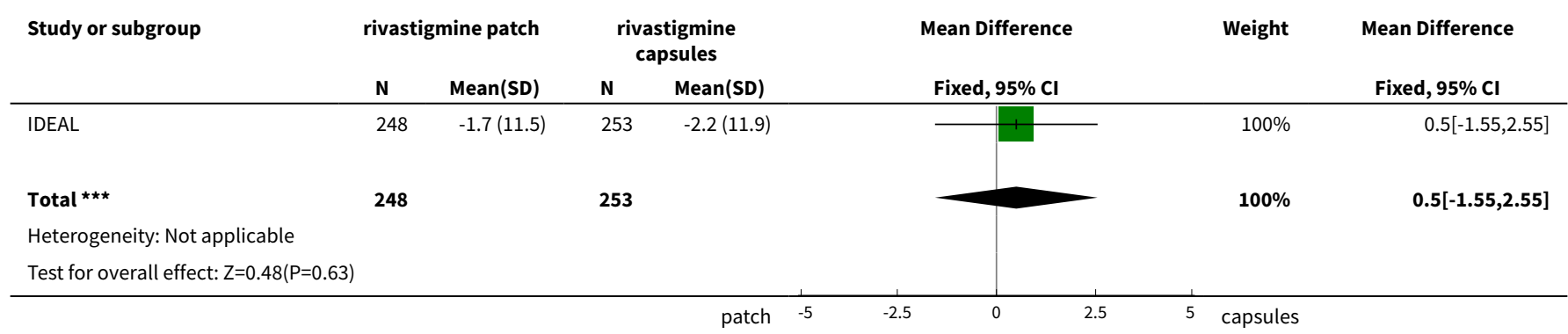

Analysis 6.8. Comparison 6 Rivastigmine $10 \mathrm{~cm}^{2}$ patch $(9.5 \mathrm{mg} /$ day) versus rivastigmine capsules ( 6 to $12 \mathrm{mg} /$ day in two divided doses), Outcome 8 withdrawals before end of treatment at 24 weeks.

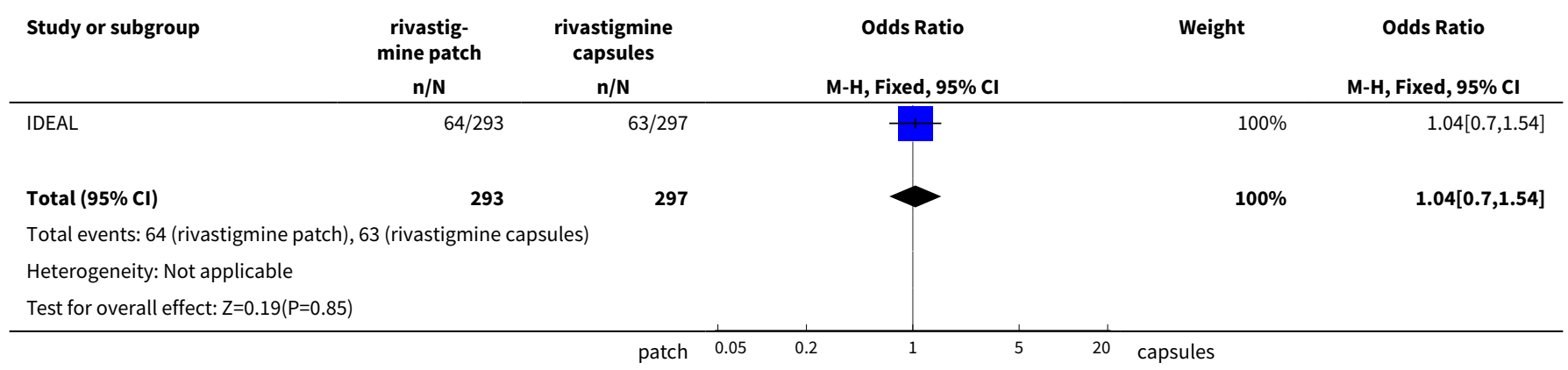

Analysis 6.9. Comparison 6 Rivastigmine $10 \mathrm{~cm}^{2}$ patch $(9.5 \mathrm{mg} /$ day) versus rivastigmine capsules ( 6 to $12 \mathrm{mg} /$ day in two divided doses), Outcome 9 at least one adverse event by 24 weeks.

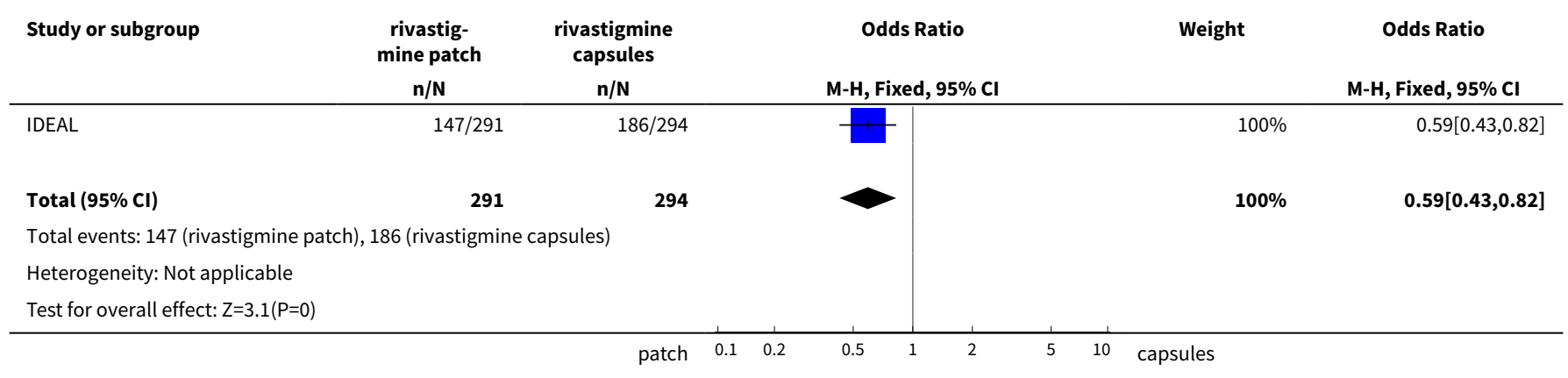


Analysis 6.10. Comparison 6 Rivastigmine $10 \mathrm{~cm}^{2}$ patch $(9.5 \mathrm{mg} /$ day) versus rivastigmine capsules (6 to $12 \mathrm{mg} /$ day in two divided doses), Outcome 10 withdrawals due to an adverse event before end of treatment at 24 weeks.

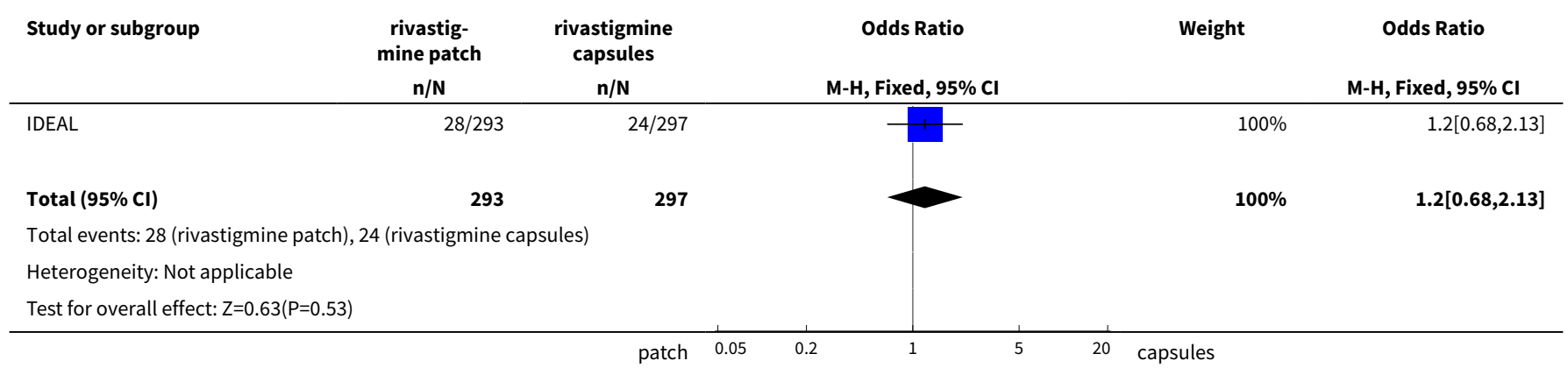

Analysis 6.11 . Comparison 6 Rivastigmine $10 \mathrm{~cm}^{2}$ patch $(9.5 \mathrm{mg} /$ day) versus rivastigmine capsules ( 6 to $12 \mathrm{mg} /$ day in two divided doses), Outcome 11 at least one adverse event of nausea by 24 weeks.

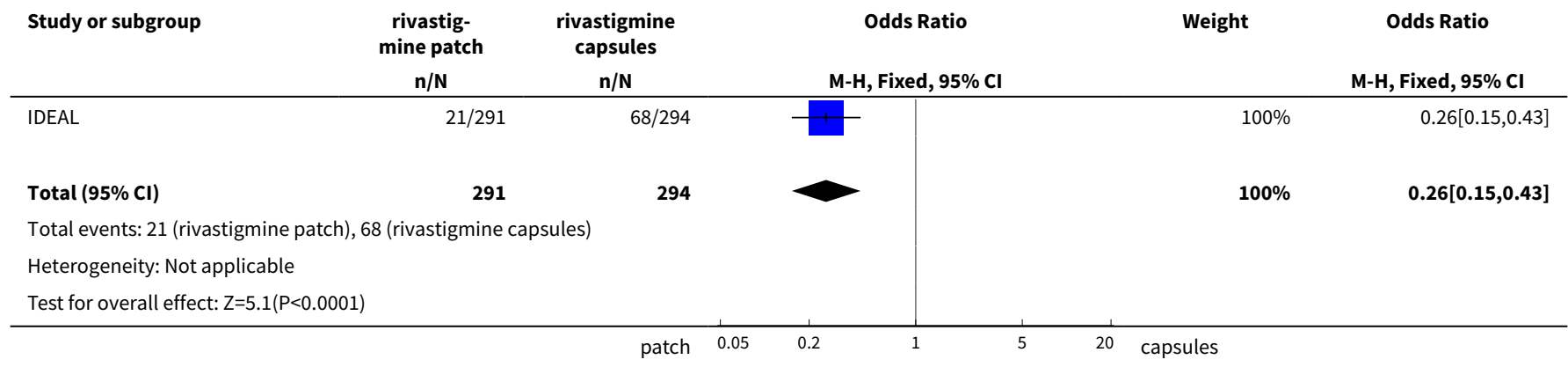

Analysis 6.12. Comparison 6 Rivastigmine $10 \mathrm{~cm}^{2}$ patch $(9.5 \mathrm{mg} /$ day) versus rivastigmine capsules $(6$ to $12 \mathrm{mg}$ /day in two divided doses), Outcome 12 at least one adverse event of vomiting by 24 weeks.

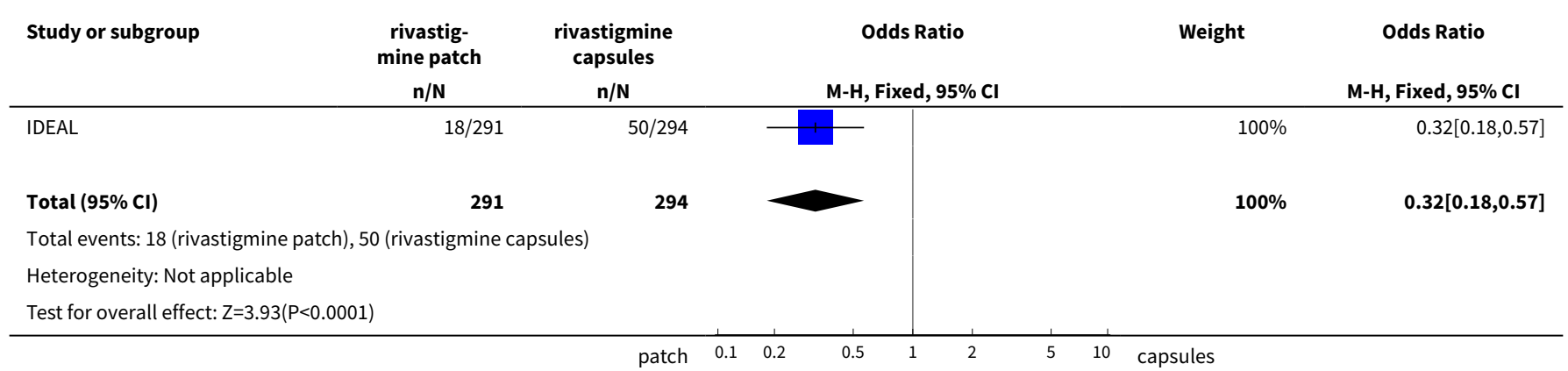


Analysis 6.13. Comparison 6 Rivastigmine $10 \mathrm{~cm}^{2}$ patch $(9.5 \mathrm{mg} /$ day) versus rivastigmine capsules (6 to $12 \mathrm{mg}$ /day in two divided doses), Outcome 13 at least one adverse event of diarrhoea by 24 weeks.

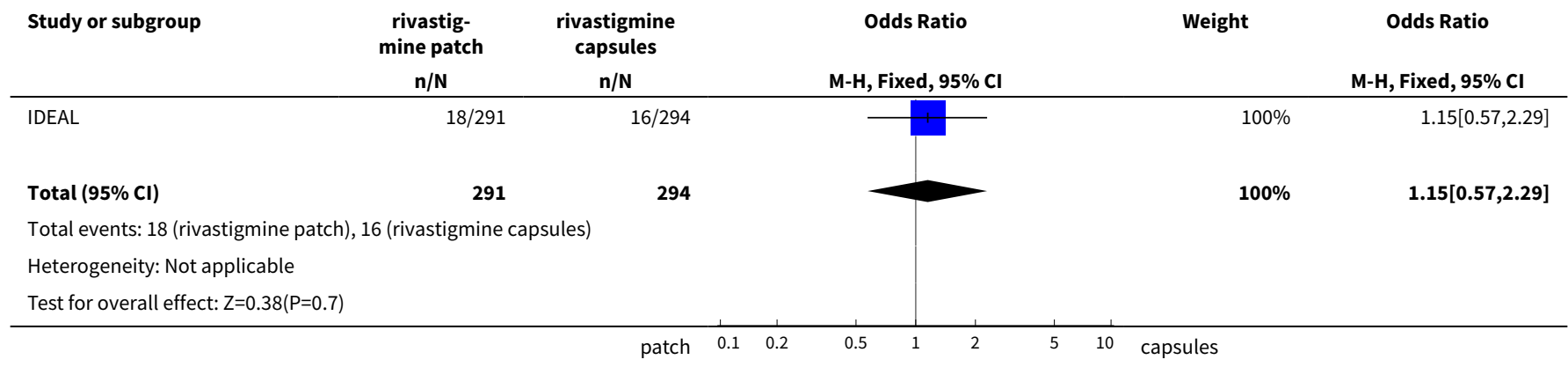

Analysis 6.14. Comparison 6 Rivastigmine $10 \mathrm{~cm}^{2}$ patch $(9.5 \mathrm{mg} /$ day) versus rivastigmine capsules (6 to $12 \mathrm{mg} /$ day in two divided doses), Outcome 14 at least one adverse event of weight decrease by 24 weeks.

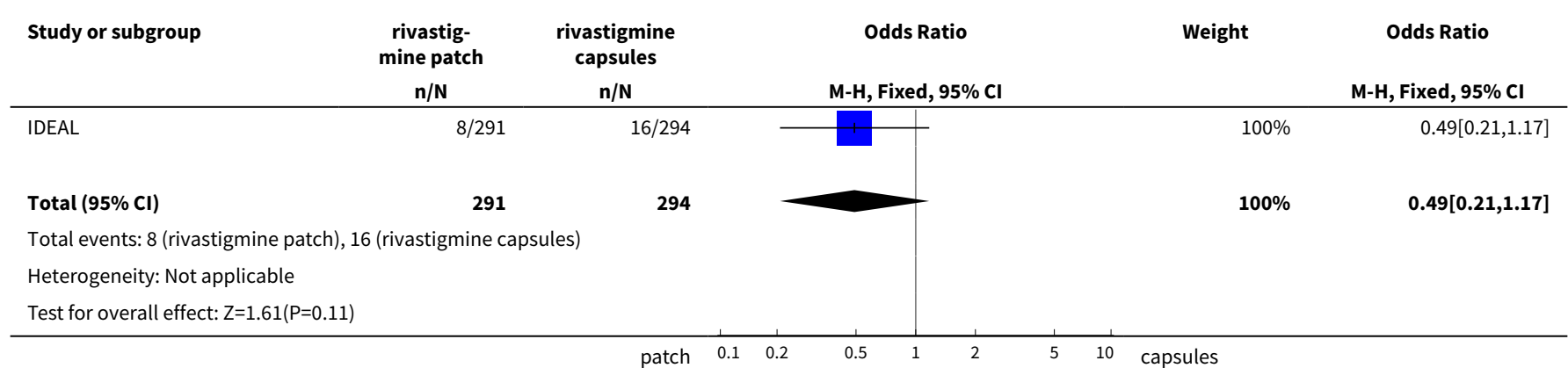

Analysis 6.15. Comparison 6 Rivastigmine $10 \mathrm{~cm}^{2}$ patch $(9.5 \mathrm{mg} /$ day) versus rivastigmine capsules ( 6 to $12 \mathrm{mg}$ /day in two divided doses), Outcome 15 at least one adverse event of dizziness by 24 weeks.

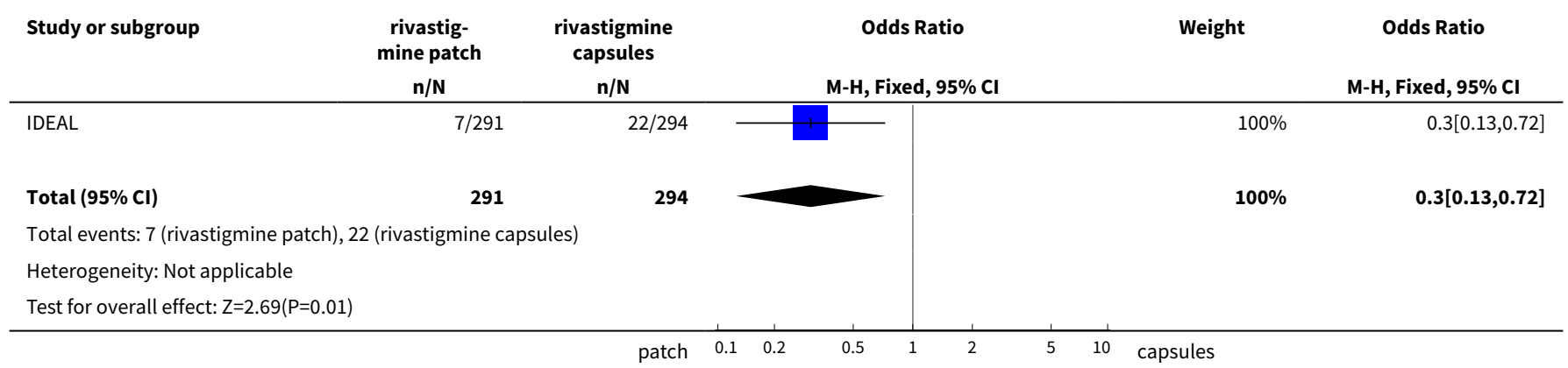


Analysis 6.16. Comparison 6 Rivastigmine $10 \mathrm{~cm}^{2}$ patch $(9.5 \mathrm{mg} /$ day) versus rivastigmine capsules (6 to 12 $\mathrm{mg} /$ day in two divided doses), Outcome 16 at least one adverse event of decreased appetite by 24 weeks.

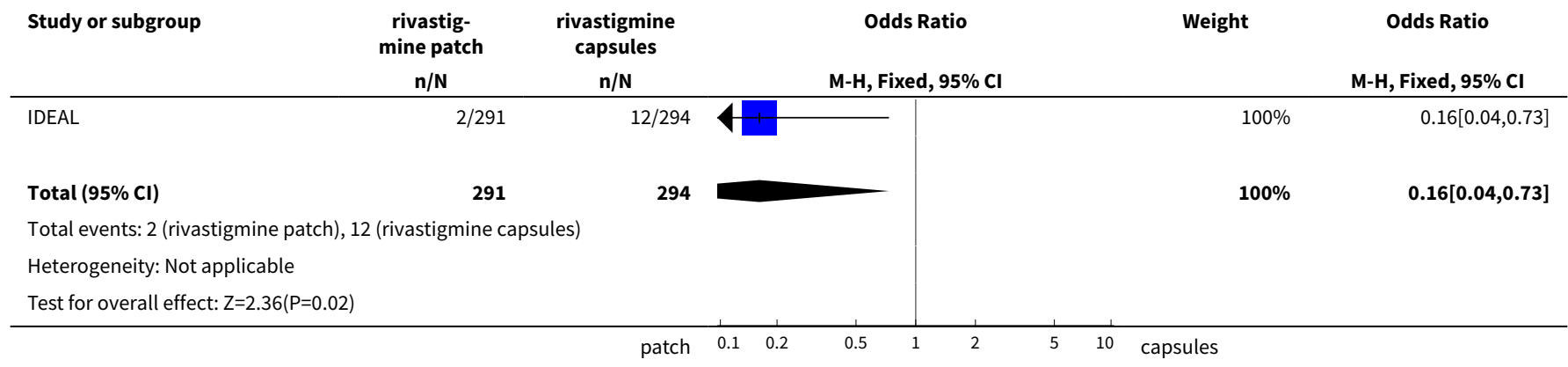

Analysis 6.17. Comparison 6 Rivastigmine $10 \mathrm{~cm}^{2}$ patch $(9.5 \mathrm{mg} /$ day) versus rivastigmine capsules $(6$ to $12 \mathrm{mg}$ /day in two divided doses), Outcome 17 at least one adverse event of headache by 24 weeks.

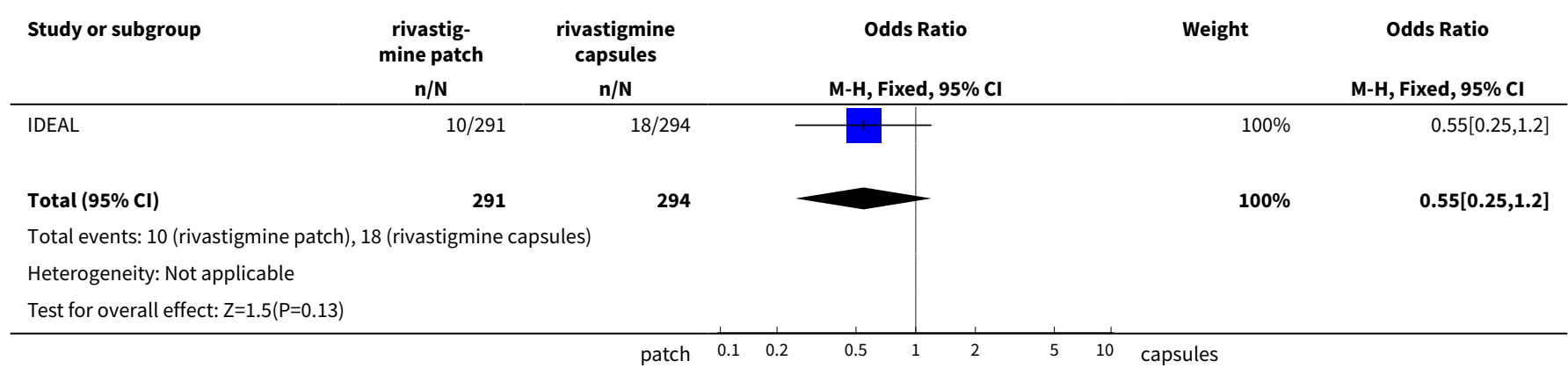

Analysis 6.18. Comparison 6 Rivastigmine $10 \mathrm{~cm}^{2}$ patch $(9.5 \mathrm{mg} /$ day) versus rivastigmine capsules ( 6 to $12 \mathrm{mg}$ /day in two divided doses), Outcome 18 at least one adverse event of asthenia by 24 weeks.

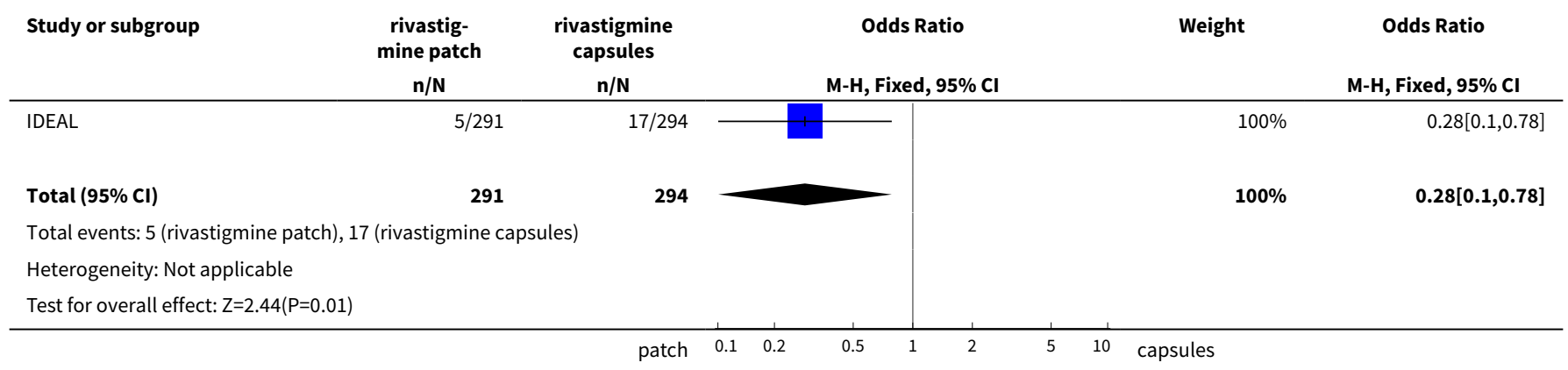


Analysis 6.19. Comparison 6 Rivastigmine $10 \mathrm{~cm}^{2}$ patch $(9.5 \mathrm{mg} /$ day) versus rivastigmine capsules (6 to $12 \mathrm{mg}$ /day in two divided doses), Outcome 19 deaths before end of treatment at 24 weeks +30 days.

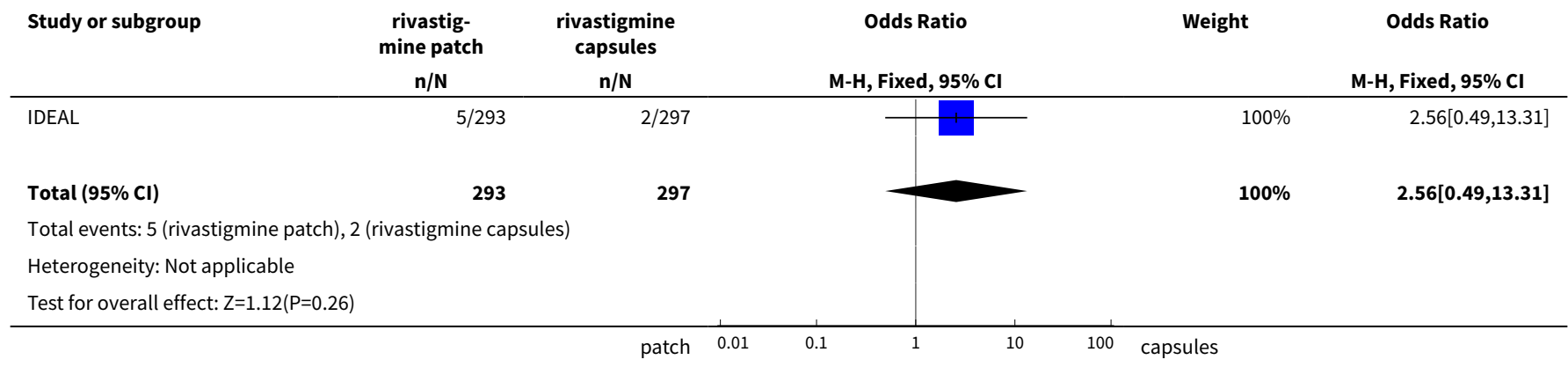

Analysis 6.20. Comparison 6 Rivastigmine $10 \mathrm{~cm}^{2}$ patch $(9.5 \mathrm{mg} /$ day) versus rivastigmine capsules (6 to 12 $\mathrm{mg} /$ day in two divided doses), Outcome 20 NPI-D carer distress scale (change from baseline at 24 weeks) ITT.

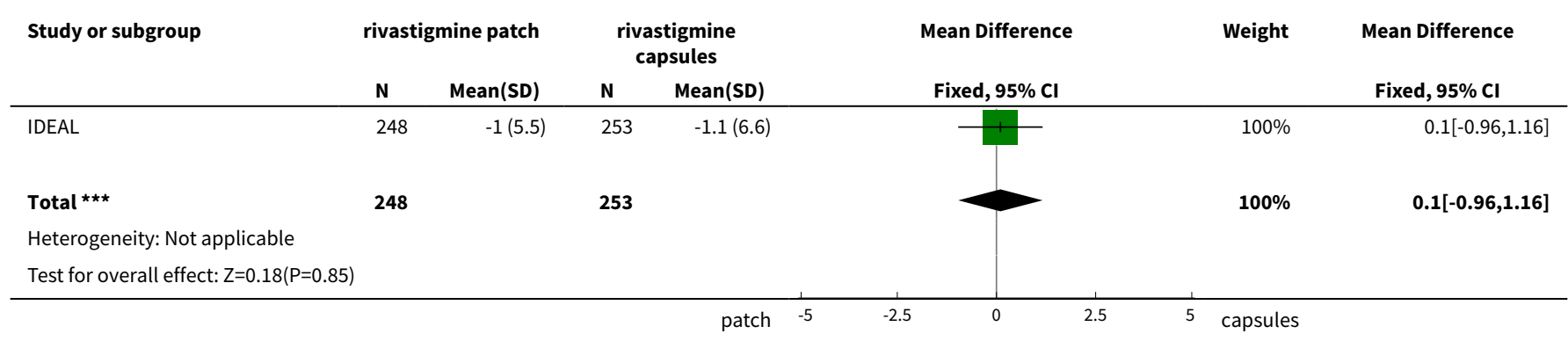

\section{ADDITIONAL TABLES}




\begin{tabular}{|c|c|c|c|c|c|c|c|c|}
\hline Study & $\begin{array}{l}\text { Duration } \\
\text { (weeks) }\end{array}$ & $\begin{array}{l}\text { Partici- } \\
\text { pants }\end{array}$ & $\begin{array}{l}\text { Mean age } \\
\text { (SD) }\end{array}$ & $\%$ males & $\begin{array}{l}\text { Mean MMSE } \\
\text { (SD) }\end{array}$ & country & $\begin{array}{l}\text { Number of } \\
\text { centres }\end{array}$ & Treatment groups \\
\hline \multicolumn{9}{|c|}{ Oral (different doses versus placebo ) } \\
\hline $\begin{array}{l}\text { B103 } \\
\text { (Phase } \\
\text { II) }\end{array}$ & 13 & 402 & 69.4 & 44 & - & Europe & 54 & $\begin{array}{l}\text { 1. } 4 \mathrm{mg} / \text { day b.i.d } \\
\text { 2. } 6 \mathrm{mg} / \text { day b.i.d } \\
\text { 3. placebo }\end{array}$ \\
\hline $\begin{array}{l}\text { B104 } \\
\text { (Phase } \\
\text { II) }\end{array}$ & 18 & 114 & $71.2(7.5)$ & 39 & $19.5(3.7)$ & $\begin{array}{l}\text { Belgium, } \\
\text { France, } \\
\text { UK, Nor- } \\
\text { way, } \\
\text { Canada }\end{array}$ & 11 & $\begin{array}{l}\text { 1. } 6 \text { to } 12 \mathrm{mg} / \text { day b.i.d. } \\
\text { 2. } 6 \text { to } 12 \mathrm{mg} / \text { day t.i.d } \\
\text { 3. placebo }\end{array}$ \\
\hline $\begin{array}{l}\text { B303/ } \\
\text { B305* } \\
\text { (Phase } \\
\text { III) }\end{array}$ & 26 & 725 & $72.0(8.1)$ & 41 & $20.0(4.5)$ & $\begin{array}{l}\text { France, } \\
\text { Germany, } \\
\text { Austria, } \\
\text { Switzer- } \\
\text { land, } \\
\text { Canada, } \\
\text { USA }\end{array}$ & 44 & $\begin{array}{l}\text { 1. } 1 \text { to } 4 \mathrm{mg} \text { b.i.d } \\
\text { 2. } 6 \text { to } 12 \mathrm{mg} / \text { day b.i.d., placebo }\end{array}$ \\
\hline $\begin{array}{l}\text { B304* } \\
\text { (Phase } \\
\text { III) }\end{array}$ & 26 & 677 & $71.4(8.2)$ & 41 & $18.5(4.5)$ & $\begin{array}{l}\text { UK, Ire- } \\
\text { land, Aus- } \\
\text { tralia, } \\
\text { Canada, } \\
\text { RSA, Italy }\end{array}$ & 37 & $\begin{array}{l}\text { 1. } 2 \text { to } 12 \mathrm{mg} / \text { day b.i.d. } \\
\text { 2. } 2 \text { to } 12 \mathrm{mg} / \text { day t.i.d. } \\
\text { 3. placebo }\end{array}$ \\
\hline $\begin{array}{l}\text { B351* } \\
\text { (Phase } \\
\text { III) }\end{array}$ & 26 & 702 & $74.1(8.3)$ & 44 & $20.0(4.4)$ & USA & 14 & $\begin{array}{l}\text { 1. } 3 \mathrm{mg} / \text { day t.i.d } \\
\text { 2. } 6 \mathrm{mg} / \text { day t.i.d } \\
\text { 3. } 9 \mathrm{mg} / \text { day b.i.d } \\
\text { 4. placebo }\end{array}$ \\
\hline $\begin{array}{l}\text { B352* } \\
\text { (Phase } \\
\text { III) }\end{array}$ & 26 & 699 & $74.5(7.4)$ & 39 & $19.7(4.5)$ & USA & 22 & $\begin{array}{l}\text { 1. } 1 \text { to } 4 \mathrm{mg} \text { per day b.i.d } \\
\text { 2. } 6 \text { to } 12 \mathrm{mg} / \text { day b.i.d. } \\
\text { 3. placebo }\end{array}$ \\
\hline $\begin{array}{l}\text { Ballard } \\
2005\end{array}$ & 26 & 93 & $83.8(7.7)$ & 20 & - & UK & - & $\begin{array}{l}\text { 1. } 6 \text { to } 12 \mathrm{mg} / \text { day b.i.d } \\
\text { 2. placebo }\end{array}$ \\
\hline
\end{tabular}




\begin{tabular}{|c|c|c|c|c|c|c|c|c|}
\hline $\begin{array}{l}\text { Karaman } \\
2005^{\star}\end{array}$ & 52 & 44 & 73.8 & 45 & 12.2 & Turkey & 1 & $\begin{array}{l}\text { 1. } 6 \text { to } 12 \mathrm{mg} / \text { day b.i.d. } \\
\text { 2. placebo }\end{array}$ \\
\hline $\begin{array}{l}\text { Lopez- } \\
\text { Pousa } \\
2005^{\star}\end{array}$ & 26 & 218 & 77.6 & 23 & 8.8 & Spain & 21 & $\begin{array}{l}\text { 1. } 6 \text { to } 12 \mathrm{mg} / \text { day b.i.d. } \\
\text { 2. placebo }\end{array}$ \\
\hline $\begin{array}{l}\text { Mowla } \\
2007\end{array}$ & 12 & 122 & 69.2 & 46 & $16.1(4.0)$ & Iran & - & $\begin{array}{l}\text { 1. } 6 \text { to } 12 \mathrm{mg} / \text { day b.i.d. } \\
\text { 2. placebo }\end{array}$ \\
\hline Tai 2000 & 26 & 80 & - & - & - & Taiwan & - & $\begin{array}{l}\text { 1. } 3 \text { to } 6 \mathrm{mg} / \text { day b.i.d. } \\
\text { 2. placebo }\end{array}$ \\
\hline \multicolumn{9}{|c|}{ Oral and patches } \\
\hline $\begin{array}{l}\text { IDEAL* } \\
\text { (Phase } \\
\text { III) }\end{array}$ & 24 & 1195 & $73.3(7.8)$ & 33 & $16.5(3.0)$ & $\begin{array}{l}\text { North, } \\
\text { Central } \\
\text { and South } \\
\text { America, } \\
\text { Asia, Eu- } \\
\text { rope }\end{array}$ & 100 & $\begin{array}{l}\text { 1. patch } 9.5 \mathrm{mg} / \text { day } \\
\text { 2. patch } 17.4 \mathrm{mg} / \text { day } \\
\text { 3. capsules } 6 \text { to } 12 \mathrm{mg} / \text { day b.i.d. } \\
\text { 4. placebo }\end{array}$ \\
\hline \multicolumn{9}{|l|}{ Patches } \\
\hline $\begin{array}{l}\text { Naka- } \\
\text { mura } \\
2011\end{array}$ & 24 & 859 & $74.6(7.2)$ & 31.7 & $16.6(3.0)$ & Japan & multicentre & $\begin{array}{l}\text { 1. patch } 4.6 \mathrm{mg} / \text { day } \\
\text { 2. patch } 9.5 \mathrm{mg} / \text { day } \\
\text { 3. placebo }\end{array}$ \\
\hline
\end{tabular}

* These studies met the inclusion criteria of the main analysis comparing rivastigmine at the therapeutic doses versus placebo. b.i.d = bis in die in Latin, this means that a medication is taken two times a day, dividing the total daily dose into two doses.

t.i.d = ter in die in Latin, this means that a medication is taken three times a day, dividing the total daily dose into three doses.

MMSE = Mini-Mental Health State Examination. The score range from 0 ( severe impairment) to 30 (normal). 
Table 2. Objectives of included studies

\begin{tabular}{ll}
\hline Study & Objective \\
\hline B103 & $\begin{array}{l}\text { To assess the short term (3 months) symptomatic efficacy and tolerability of rivastigmine } 4 \text { and } 6 \\
\mathrm{mg} / \text { day compared with placebo in patients with AD }\end{array}$ \\
\hline B104 & $\begin{array}{l}\text { Primary: to determine the maximum tolerated dose (MTD) of rivastigmine in patients with mild to } \\
\text { moderate dementia of the Alzheimer type (DAT) }\end{array}$
\end{tabular}

Secondary: to determine - a) whether tolerability is different when the drug is administered twice daily (b.i.d.) or three times daily (t.i.d.) - b) if nausea and vomiting, associated with cholinesterase inhibition, can be controlled with antiemetics thereby increasing the MTD, and - c) to assess the efficacy of rivastigmine at its MTD in comparison with that of placebo in the treatment of DAT daily and 6 to $12 \mathrm{mg}$ daily) versus placebo over a 26 week treatment period as assessed by two primary measures of outcome; change from baseline in ADAS-Cog score and the CIBIC-Plus score at week 26

Primary 2: to evaluate the safety of the study medication as assessed by incidence of adverse events, clinical laboratory evaluations, vital signs, ECG recordings, and the results of physical examination made at baseline and throughout the study

Secondary: to assess dose-efficacy and dose-safety relationships for rivastigmine

Primary: to evaluate the efficacy and safety of individual highest well-tolerated doses (range 6 to 12 $\mathrm{mg}$ daily) of rivastigmine given b.i.d. or t.i.d. for 26 weeks compared with placebo in the therapy of patients with probable Alzheimer's disease

Secondary: to compare the twice daily and three times daily dosing regimens with respect to efficacy and safety to evaluate changes in activities of daily living (ADL) and placebo for 26 weeks of treatment

Secondary: to assess the dose-efficacy and dose-safety relationships for rivastigmine

Tertiary: to explore the pharmacokinetics of rivastigmine at doses of 3, 6 and $9 \mathrm{mg}$ daily

Primary: to evaluate the efficacy and safety of two non-overlapping dose ranges of rivastigmine (1 to $4 \mathrm{mg}$ daily and 6 to $12 \mathrm{mg}$ daily) and placebo for 26 weeks of treatment

Secondary: to assess the dose-efficacy and dose-safety relationships of rivastigmine. To investigate the relationship between plasma concentrations of rivastigmine and efficacy and safety

Tertiary: to explore the pharmacokinetics of rivastigmine at doses of 1 to 4 and 6 to $12 \mathrm{mg}$ daily

IDEAL

To compare the efficacy,safety and tolerability of a novel rivastigmine transdermal patch with conventional rivastigmine capsules and placebo in patients with $A D$

Karaman 2005

To evaluate the efficacy of rivastigmine for a period of 12 months in patients with advanced moderate $A D$

Lopez-Pousa 2005

To evaluate the safety and efficacy of rivastigmine in patients with more advanced $A D$ 
Table 2. Objectives of included studies (Continued)

Ballard 2005

Tai 2000
To determine whether rivastigmine was better than placebo for agitation and cognition

To evaluate the safety and efficacy of Exelon compared with placebo in patients with probable Alzheimer's disease who had dementia ranging from mild to moderate degree

Nakamura 2011

To evaluate the efficacy, safety, and tolerability of the $5 \mathrm{~cm}^{2}$ (9 mg loading dose, $4.6 \mathrm{mg} / 24 \mathrm{~h}$ delivery rate) and $10 \mathrm{~cm}^{2}$ (18 $\mathrm{mg}$ loading dose, $9.5 \mathrm{mg} /$ day delivery rate) rivastigmine patch in Japanese patients with $A D$ 


\begin{tabular}{|c|c|c|c|c|c|c|c|c|c|c|}
\hline $\begin{array}{l}\text { Time treatment group } \\
\text { (weeks) }\end{array}$ & B103 & B104 & $\begin{array}{l}\text { B303 } \\
\text { B305 }\end{array}$ & B304 & B351 & B352 & IDEAL & $\begin{array}{l}\text { Kara- } \\
\text { man }\end{array}$ & $\begin{array}{l}\text { Lopez- } \\
\text { Pousa }\end{array}$ & $\begin{array}{l}\text { Naka- } \\
\text { mura }\end{array}$ \\
\hline $\begin{array}{l}10 \quad \text { low b.i.d. } \\
\text { to } \\
12\end{array}$ & 4 & - & 3.8 & - & 2.9 & 3.6 & & & & \\
\hline medium b.i.d. & 6 & - & - & - & 5.7 & - & & & & \\
\hline high b.i.d. & - & 9.6 & 10.4 & 9.5 & 8.8 & 10.1 & & 6.1 & & \\
\hline high t.i.d. & - & 10.2 & - & 9.7 & - & - & & & & \\
\hline $26 \quad$ low b.i.d. & - & - & 3.7 & - & 2.8 & 3.5 & & & & \\
\hline medium b.i.d. & - & - & - & - & 5.7 & - & & & & \\
\hline high b.i.d. & - & - & 10.4 & 9.3 & 8.5 & 9.7 & 9.7 & 8.3 & 9.8 & \\
\hline high t.i.d. & - & - & - & 9.6 & - & - & & & & \\
\hline low patch & & & & & & & & & & 4.6 \\
\hline medium patch & & & & & & & 9.5 & & & 9.5 \\
\hline high patch & & & & & & & 16.5 & & & \\
\hline 48 medium patch & & & & & & & & & & \\
\hline high patch & & & & & & & & & & \\
\hline 52 high b.i.d. & & & & & & & & 10.7 & & \\
\hline
\end{tabular}

Exact doses not available for B103, Ballard 2005, Tai 2000, Mowla 2007.

Table 4. Measured outcomes

\begin{tabular}{llll}
\hline Outcomes assessed & Cognitive function & $\begin{array}{l}\text { Activities of daily } \\
\text { llving }\end{array}$ & $\begin{array}{l}\text { Behav- } \\
\text { ioural } \\
\text { symp- } \\
\text { toms }\end{array}$
\end{tabular}




\begin{tabular}{|c|c|c|c|c|c|c|c|c|c|}
\hline Study & ADAS-Cog & MMSE & Others & PDS & Others & & CIBIC-Plus & Others & \\
\hline B103 & & $x$ & OE, TMT, NOSGER, DSST, VRT & & & & & CGIC & \\
\hline B104 & $x$ & & Wechsler psychometric tests, NOSGER & & & & $x$ & & \\
\hline B303/B305 & $x$ & $\mathrm{x}$ & ADAS-CogA & $x$ & CAS & & $x$ & GDS & \\
\hline B304 & $x$ & $x$ & ADAS-CogA & $x$ & CAS & & $x$ & GDS & \\
\hline B351 & $x$ & $x$ & ADAS-CogA & $x$ & CAS & & $x$ & GDS & \\
\hline B352 & $x$ & $x$ & ADAS-CogA & $x$ & CAS & & $x$ & GDS & \\
\hline Ballard 2005 & & & SIB & & & CMAI & & & \\
\hline Karaman 2005 & $x$ & $x$ & & $x$ & $\begin{array}{l}\text { ACDS- } \\
A D L \\
D A D\end{array}$ & & $x$ & GDS & \\
\hline IDEAL & $x$ & $x$ & CLOCK DRAWING, TMT & & $\begin{array}{l}\text { ACDS- } \\
\text { ADL }\end{array}$ & NPI-12 & & $\begin{array}{l}\text { AD- } \\
\text { CS-CGIC }\end{array}$ & \\
\hline Lopez-Pousa 2005 & & $x$ & SIB, BLESSED DEMENTIA SCALE & & $\begin{array}{l}\text { ACDS- } \\
\text { ADL }\end{array}$ & $\begin{array}{l}\text { NPI-10, } \\
\text { NPI-4 }\end{array}$ & & $\begin{array}{l}\text { GDS } \\
\text { AD- } \\
\text { CS-CGIC }\end{array}$ & \\
\hline Mowla 2007 & & & WMS-III, & & $A D L$ & & & CGI & $\begin{array}{l}\text { Hamilton } \\
\text { score }\end{array}$ \\
\hline Tai 2000 & & $x$ & NPT & & & & $x$ & GDS & \\
\hline Nakamura 2011 & $x$ & $\mathrm{x}$ & MENFIS & & DAD & $\begin{array}{l}\text { BE- } \\
\text { HAVE-AD }\end{array}$ & $x$ & & \\
\hline
\end{tabular}

$x$ indicated that the study measured this outcome.

The full names of these scales and their properties are described in Types of outcome measures. 
Table 5. Comparison of different methods of dealing with missing values

\begin{tabular}{llllll}
\hline Time & popu- & ri- & place- \\
point & lation & vastig- \\
mine & $n$ & & $\begin{array}{l}\text { prob- } \\
\text { ability } \\
\text { level }\end{array}$ & $\begin{array}{l}95 \% \text { confidence } \\
\text { limits }\end{array}$
\end{tabular}

\section{1 to $4 \mathrm{mg}$ daily versus placebo, ADAS-Cog measured as change from baseline}

\begin{tabular}{|c|c|c|c|c|c|c|}
\hline \multirow{3}{*}{$\begin{array}{l}12 \\
\text { weeks }\end{array}$} & ITT & 650 & 643 & favours rivastigmine WMD -0.31 & 0.30 & $-0.87,0.25$ \\
\hline & OC & 589 & 598 & favours rivastigmine WMD -0.46 & 0.14 & $-1.08,0.15$ \\
\hline & $\begin{array}{l}\mathrm{RDO}+ \\
\mathrm{OC}\end{array}$ & 616 & 615 & favours rivastigmine WMD -0.37 & 0.20 & $-0.96,0.23$ \\
\hline \multirow{3}{*}{$\begin{array}{l}18 \\
\text { weeks }\end{array}$} & ITT & 650 & 643 & favours rivastigmine WMD -1.07 & 0.0004 & $-1.66,-0.48$ \\
\hline & OC & 558 & 552 & favours rivastigmine WMD -1.19 & 0.0005 & $-1.86,-0.52$ \\
\hline & $\begin{array}{l}\mathrm{RDO}+ \\
\mathrm{OC}\end{array}$ & 573 & 572 & favours rivastigmine WMD -1.33 & 0.00008 & $-1.99,-0.67$ \\
\hline \multirow{3}{*}{$\begin{array}{l}26 \\
\text { weeks }\end{array}$} & ITT & 650 & 644 & favours rivastigmine WMD -0.84 & 0.01 & $-1.48,-0.19$ \\
\hline & OC & 519 & 526 & favours rivastigmine WMD -0.96 & 0.01 & $-1.72,-0.21$ \\
\hline & $\begin{array}{l}\mathrm{RDO}+ \\
\mathrm{OC}\end{array}$ & 559 & 564 & favours rivastigmine WMD -1.07 & 0.004 & $-1.80,-0.34$ \\
\hline
\end{tabular}

\section{6 to $12 \mathrm{mg}$ daily versus placebo, ADAS-Cog measured as change from baseline}

\begin{tabular}{lllllll}
\hline 12 & ITT & 1054 & 863 & favours rivastigmine WMD -1.49 & $<0.00001$ & $-1.96,-1.01$ \\
\cline { 2 - 7 } & OC & 843 & 803 & favours rivastigmine WMD -1.80 & $<0.00001$ & $-2.33,-1.27$ \\
\cline { 2 - 7 } \\
$\begin{array}{llllll}\text { RDO }+ \\
\text { OC }\end{array}$ & & 867 & 828 & favours rivastigmine WMD -1.38 & $<0.00001$ & $-1.89,-0.88$ \\
\hline
\end{tabular}

\section{6 to $12 \mathrm{mg}$ daily versus placebo, ADAS-Cog measured as change from baseline}

\begin{tabular}{|c|c|c|c|c|c|c|}
\hline \multirow{3}{*}{$\begin{array}{l}18 \\
\text { weeks }\end{array}$} & ITT & 1054 & 863 & favours rivastigmine WMD -1.79 & $<0.00001$ & $-2.30,-1.29$ \\
\hline & $\mathrm{OC}$ & 732 & 742 & favours rivastigmine WMD -2.36 & $<0.00001$ & $-2.96,-1.76$ \\
\hline & $\begin{array}{l}\mathrm{RDO}+ \\
\mathrm{OC}\end{array}$ & 837 & 772 & favours rivastigmine WMD -2.12 & $<0.00001$ & $-2.69,-1.55$ \\
\hline \multirow{3}{*}{$\begin{array}{l}26 \\
\text { weeks }\end{array}$} & ITT & 1054 & 863 & favours rivastigmine WMD -2.09 & $<0.00001$ & $-2.65,-1.54$ \\
\hline & $\mathrm{OC}$ & 670 & 709 & favours rivastigmine WMD -2.62 & $<0.00001$ & $-3.29,-1.94$ \\
\hline & $\begin{array}{l}\mathrm{RDO}+ \\
\mathrm{OC}\end{array}$ & 788 & 759 & favours rivastigmine WMD -2.39 & $<0.00001$ & $-3.03,-1.74$ \\
\hline
\end{tabular}

1 to $4 \mathrm{mg}$ daily versus placebo, CIBIC-Plus measured as no change or worse 
Table 5. Comparison of different methods of dealing with missing values (Continued)

\begin{tabular}{|c|c|c|c|c|c|c|}
\hline \multirow[t]{3}{*}{$\begin{array}{l}12 \\
\text { weeks }\end{array}$} & ITT & 608 & 612 & $\begin{array}{l}\text { favours rivastigmine } \\
\text { Peto OR } 0.93\end{array}$ & 0.60 & $0.72,1.21$ \\
\hline & OC & 583 & 596 & $\begin{array}{l}\text { favours rivastigmine } \\
\text { Peto OR } 0.95\end{array}$ & 0.70 & $0.72,1.23$ \\
\hline & $\begin{array}{l}\mathrm{RDO}+ \\
\mathrm{OC}\end{array}$ & 609 & 612 & $\begin{array}{l}\text { favours rivastigmine } \\
\text { Peto OR } 0.94\end{array}$ & 0.60 & $0.72,1.22$ \\
\hline \multirow[t]{3}{*}{$\begin{array}{l}18 \\
\text { weeks }\end{array}$} & ITT & 614 & 620 & $\begin{array}{l}\text { favours rivastigmine } \\
\text { Peto OR } 0.98\end{array}$ & 0.90 & $0.75,1.26$ \\
\hline & $O C$ & 556 & 554 & $\begin{array}{l}\text { favours placebo } \\
\text { Peto OR } 1.04\end{array}$ & 0.80 & $0.80,1.37$ \\
\hline & $\begin{array}{l}\mathrm{RDO}+ \\
\mathrm{OC}\end{array}$ & 570 & 576 & $\begin{array}{l}\text { favours placebo } \\
\text { Peto OR } 1.02\end{array}$ & 0.90 & $0.78,1.34$ \\
\hline \multirow[t]{3}{*}{$\begin{array}{l}26 \\
\text { weeks }\end{array}$} & ITT & 614 & 623 & $\begin{array}{l}\text { favours rivastigmine } \\
\text { Peto OR } 0.71\end{array}$ & 0.01 & $0.55,0.93$ \\
\hline & OC & 513 & 523 & $\begin{array}{l}\text { favours rivastigmine } \\
\text { Peto OR } 0.67\end{array}$ & 0.006 & $0.50,0.89$ \\
\hline & $\begin{array}{l}\mathrm{RDO}+ \\
\mathrm{OC}\end{array}$ & 544 & 549 & $\begin{array}{l}\text { favours rivastigmine } \\
\text { Peto OR } 0.68\end{array}$ & 0.008 & $0.52,0.91$ \\
\hline
\end{tabular}

1 to $4 \mathrm{mg}$ daily versus placebo, CIBIC-Plus measured as no change or worse

\begin{tabular}{|c|c|c|c|c|c|c|}
\hline \multirow[t]{4}{*}{$\begin{array}{l}12 \\
\text { weeks }\end{array}$} & ITT & 950 & 825 & $\begin{array}{l}\text { favours rivastigmine } \\
\text { Peto OR } 0.74\end{array}$ & 0.008 & $0.60,0.92$ \\
\hline & $\mathrm{OC}$ & 831 & 799 & favours rivastigmine & 0.005 & $0.58,0.91$ \\
\hline & & & & Peto OR 0.72 & & \\
\hline & $\begin{array}{l}\mathrm{RDO}+ \\
\mathrm{OC}\end{array}$ & 952 & 825 & $\begin{array}{l}\text { favours rivastigmine } \\
\text { Peto OR } 0.75\end{array}$ & 0.01 & $0.60,0.93$ \\
\hline \multirow{5}{*}{$\begin{array}{l}18 \\
\text { weeks }\end{array}$} & ITT & 970 & 835 & favours rivastigmine & 0.06 & $0.65,1.01$ \\
\hline & & & & Peto OR 0.81 & & \\
\hline & $\mathrm{OC}$ & 720 & 741 & favours rivastigmine & 0.005 & $0.57,0.91$ \\
\hline & & & & Peto OR 0.72 & & \\
\hline & $\begin{array}{l}\mathrm{RDO}+ \\
\mathrm{OC}\end{array}$ & 820 & 772 & $\begin{array}{l}\text { favours rivastigmine } \\
\text { Peto OR } 0.77\end{array}$ & 0.02 & $0.62,0.97$ \\
\hline
\end{tabular}


Table 5. Comparison of different methods of dealing with missing values (Continued)

\begin{tabular}{|c|c|c|c|c|c|c|}
\hline $\begin{array}{l}26 \\
\text { weeks }\end{array}$ & ITT & 973 & 839 & $\begin{array}{l}\text { favours rivastigmine } \\
\text { Peto OR } 0.68\end{array}$ & 0.0007 & $0.55,0.85$ \\
\hline & $\mathrm{OC}$ & 660 & 693 & $\begin{array}{l}\text { favours rivastigmine } \\
\text { Peto OR } 0.63\end{array}$ & 0.0004 & $0.49,0.81$ \\
\hline & $\begin{array}{l}\mathrm{RDO}+ \\
\mathrm{OC}\end{array}$ & 784 & 758 & $\begin{array}{l}\text { favours rivastigmine } \\
\text { Peto OR } 0.65\end{array}$ & 0.0003 & $0.51,0.82$ \\
\hline
\end{tabular}

The results for two outcomes, ADAS-Cog and CBIC at 12, 18 and 26 weeks, have been pooled for 3 studies, B303/B305, B351. B352. These studies reported results for 3 populations, intention-to-treat (ITT), completers (OC), and completers + retrieved dropout (RDO + OC). The table reports the results of the meta-analyses for 2 comparisons ( 1 to $4 \mathrm{mg}$ daily versus placebo and 6 to $12 \mathrm{mg} / \mathrm{day}$ versus placebo) for the 3 populations at the 3 time points.

\section{APPENDICES}

Appendix 1. Searches: February 2013, January 2014, March 2015

\begin{tabular}{lll}
\hline Source & Search strategy retrieved
\end{tabular}

\section{ALOIS (www.medi- rivastigmine OR "SDZ ENA 713" OR exelon cine.ox.ac.uk/alois)}

[Searched on 02 March 2015; up-todate: 01 March 2015]
Feb 2013:

Jan 2014: 5

March 2015: 17

Feb 2013: 299

Jan 2014: 144

$$
\begin{aligned}
& \text { 2. MEDLINE In- } \\
& \text { process and other } \\
& \text { non-indexed cita- } \\
& \text { tions and MEDLINE } \\
& \text { Feb 2013: 1950- } \\
& \text { present (OvidSP) } \\
& \text { Jan 2014: 1950- } \\
& \text { present [24 January } \\
& \text { 2014] (OvidSP) } \\
& \text { 1. exp Dementia/ } \\
& \text { 2. Delirium, Dementia, Amnestic, Cognitive Disorders/ } \\
& \text { 3. dement }{ }^{\star} \cdot \mathrm{mp} \text {. } \\
& \text { 4. alzheimer*.mp. } \\
& \text { 5. ("organic brain disease" or "organic brain syndrome").mp. } \\
& \text { 6. "benign senescent forgetfulness".mp. } \\
& \text { 7. (cerebr } \left.{ }^{\star} \text { adj2 deteriorat }{ }^{\star}\right) \cdot m p \text {. } \\
& \text { 8. } \left.\text { (cerebral }^{\star} \text { adj2 insufficient }{ }^{\star}\right) \cdot \mathrm{mp} \text {. } \\
& \text { 9. or/1-8 } \\
& \text { 10. Rivastigmin }{ }^{\star} . \mathrm{ti}, \mathrm{ab} \text {. } \\
& \text { 11. exelon }{ }^{\star} . t i, a b \text {. } \\
& \text { 12. (ENA or "SDZ ENA 713").ti,ab. } \\
& \text { 13. *Cholinesterase Inhibitors/ } \\
& \text { 14. or } / 10-13
\end{aligned}
$$


(Continued)

15. 9 and 14

16. controlled trial.pt.

17. controlled clinical trial.pt.

18. ab.

19. placebo.ab.

20. drug therapy.fs.

21. randomly.ab.

22. trial.ab.

23. groups.ab.

24. or $/ 16-23$

25. (animals not (humans and animals)).sh.

26. 24 not 25

27. 15 and 26

28. $\left(2011^{\star}\right.$ or $2012^{\star}$ or $\left.2013^{\star}\right)$.ed.

29. 27 and 28

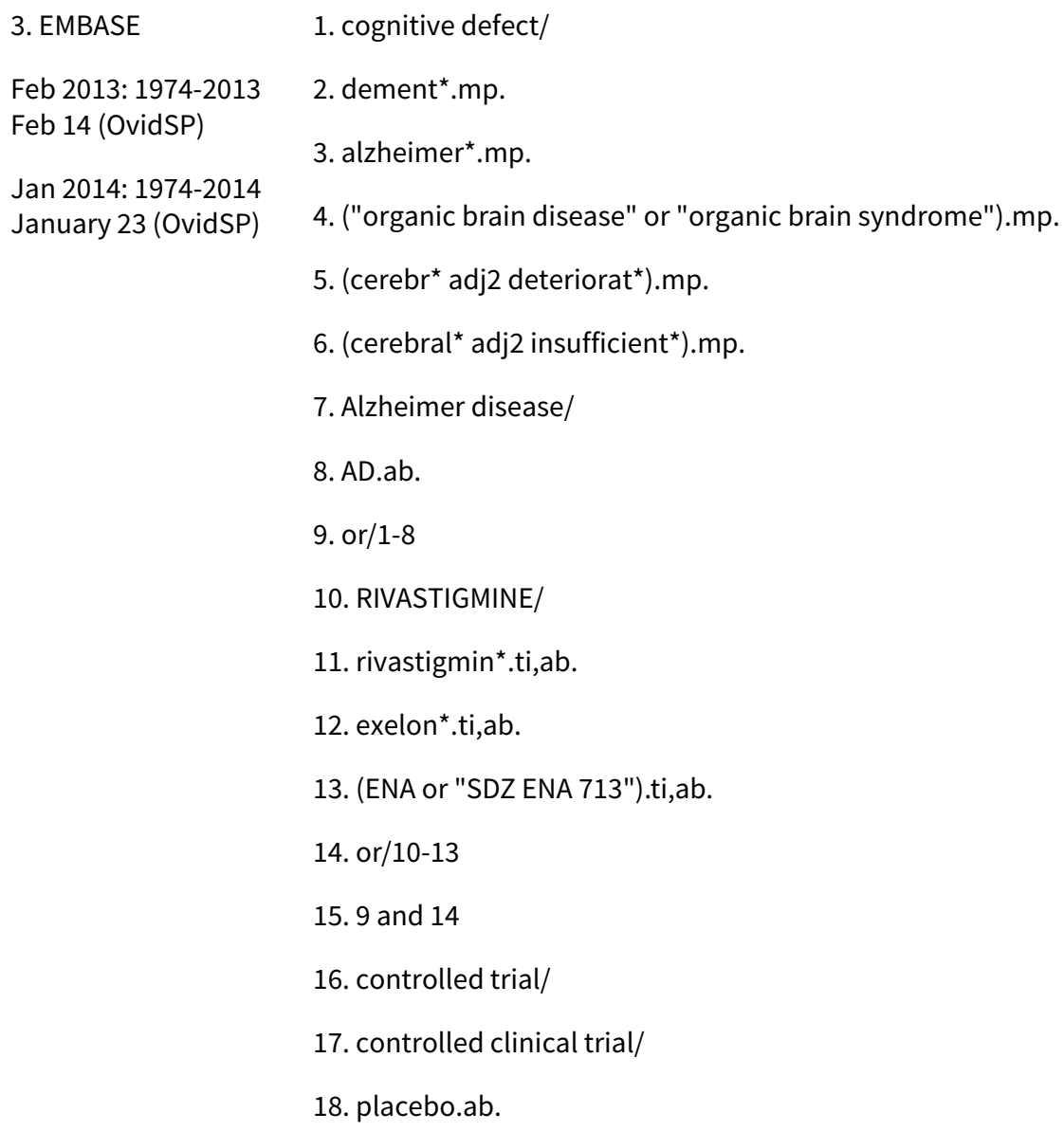


(Continued)

19. randomly.ab.

20. trial.ab.

21. ("double-blind*" or "double-mask*").ti,ab.

22. or $/ 16-21$

23. 15 and 22

24. $\left(2011^{\star}\right.$ or $2012^{\star}$ or $\left.2013^{\star}\right)$.em.

25. 23 and 24

\begin{tabular}{|c|c|}
\hline 4. PsycINFO & 1. alzheimer ${ }^{\star} . \mathrm{mp}$. \\
\hline Feb 2013: 1806-Feb- & 2. ("organic brain disease" or "orga \\
\hline $\begin{array}{l}\text { ruary week } 22013 \\
\text { (OvidSP) }\end{array}$ & 3. $\left(\right.$ cerebr $^{\star}$ adj2 deteriorat $\left.{ }^{\star}\right) \cdot \mathrm{mp}$. \\
\hline \multirow{11}{*}{$\begin{array}{l}\text { Jan 2014: 1806-Jan- } \\
\text { uary week } 32014 \\
\text { (OvidSP) }\end{array}$} & 4. $\left(\right.$ cerebral $^{\star}$ adj2 insufficient $\left.^{\star}\right) \cdot \mathrm{mp}$ \\
\hline & 5. Alzheimer's Disease/ \\
\hline & 6. AD.ab. \\
\hline & 7. or/1-6 \\
\hline & 8. rivastigmin ${ }^{\star} . t i, a b$. \\
\hline & 9. exelon ${ }^{\star} . t i, a b$. \\
\hline & 10. (ENA or "SDZ ENA 713").ti,ab. \\
\hline & 11. or/8-10 \\
\hline & 12. 7 and 11 \\
\hline & 13. $\left(2011^{\star}\right.$ or $2012^{\star}$ or $\left.2013^{\star}\right)$.up. \\
\hline & 14. 12 and 13 \\
\hline
\end{tabular}

Feb 2013: 56

Feb 2013: 1806-Feb-

ganic brain syndrome").mp.

Jan 2014: 28 ruary week 22013

(OvidSP)

uary week 32014

5. CINAHL (EBSCO-

Feb 2013: 50

host)

Feb 2013: all dates

to February week 1

S1 (MH "Dementia+")

S2 (MH "Delirium") or (MH "Delirium, Dementia, Amnestic, Cognitive Disorders")

2013

S3 (MH "Wernicke's Encephalopathy")

S4 TX dement*

S5 TX alzheimer*

S6 TX lewy* N2 bod*

S7 TX deliri ${ }^{*}$

S8 TX chronic N2 cerebrovascular

S9 TX "organic brain disease" or "organic brain syndrome"

S10 TX "normal pressure hydrocephalus" and "shunt*" 
S11 TX "benign senescent forgetfulness"

S12 TX cerebr ${ }^{\star}$ N2 deteriorat*

S13 TX cerebral ${ }^{*}$ N2 insufficient ${ }^{*}$

S14 TX pick* N2 disease

S15 TX creutzfeldt or jcd or cjd

S16 TX huntington*

S17 TX binswanger*

S18 TX korsako*

$\mathrm{S} 19 \mathrm{~S} 1$ or $\mathrm{S} 2$ or $\mathrm{S} 3$ or $\mathrm{S} 4$ or $\mathrm{S} 5$ or $\mathrm{S} 6$ or $\mathrm{S} 7$ or $\mathrm{S} 8$ or $\mathrm{S} 9$ or $\mathrm{S} 10$ or $\mathrm{S} 11$ or $\mathrm{S} 12$ or $\mathrm{S} 13$ or $\mathrm{S} 14$ or $\mathrm{S} 15$ or $\mathrm{S} 16$ or $\mathrm{S} 17$ or $\mathrm{S} 18$

S20 TX "cognit* impair*"

S21 TX "cognit* defect*"

S22 (MH "Cognition Disorders+")

$\mathrm{S} 23 \mathrm{TX} \mathrm{MCl}$

S24 TX ACMI

S25 TX ARCD

S26 TX SMC

S27 TX CIND

S28 TX BSF

S29 TX AAMI

S30 AB MD

S31 AB LCD

S32 AB QD OR "questionable dementia"

S33 TX AACD

S34 TX MNCD

S35 TX "N-MCl" or "A-MCl" or "M-MCI"

S36 TX "preclinical AD"

S37 TX "pre-clinical AD"

S38 TX "preclinical alzheimer" " or "pre-clinical alzheimer"

S39 TX aMCI OR MCla

S40 TX "CDR 0.5" or "clinical dementia rating scale 0.5 "

S41 TX "GDS 3" OR "stage 3 GDS"

S42 TX "global deterioration scale" AND "stage 3"

S43 TX "Benign senescent forgetfulness"

S44 TX "mild neurocognit* disorder*" 
S45 TX prodrom* N2 dement*

S46 TX "age-related symptom*"

S47 TX cognit* N2 deficit*

S48 TX cognit* N2 deteriorat*

S49 TX cognit* N2 declin*

S50 TX cognit* N2 degenerat*

S51 TX cognit* N2 complain*

S52 TX cognit* N2 disturb*

S53 TX cognit* N2 disorder*

S54 TX memory N2 episod* or TX memory N2 los* or TX memory N2 impair* or TX memory N2 complain*

S55 TX memory N2 disturb* or TX memory N2 disorder ${ }^{\star}$ or TX cerebr ${ }^{\star}$ N2 impair ${ }^{\star}$ or TX cerebr* N2 los*

S56 TX cerebr ${ }^{\star}$ N2 complain* or TX cerebr ${ }^{\star}$ N2 deteriorat* or TX cerebr $^{\star}$ N2 disorder ${ }^{\star}$ or TX cerebr* N2 disturb*

S57 TX mental ${ }^{\star}$ N2 declin ${ }^{\star}$ or TX mental ${ }^{*}$ N2 los $^{\star}$ or TX mental ${ }^{\star}$ N2 impair ${ }^{\star}$ or TX mental ${ }^{*} \mathrm{~N} 2$ deteriorat $^{\star}$

S58 TX "pre-clinical dementia" or TX "preclinical dementia"

$\mathrm{S} 59 \mathrm{~S} 20$ or $\mathrm{S} 21$ or $\mathrm{S} 22$ or $\mathrm{S} 23$ or $\mathrm{S} 24$ or $\mathrm{S} 25$ or $\mathrm{S} 26$ or $\mathrm{S} 27$ or $\mathrm{S} 28$ or $\mathrm{S} 29$ or S30 or S31 or S32 or S33 or S34 or S35 or S36 or S37 or S38 or S39 or S40 or S41 or S42 or S43 or $\mathrm{S} 44$ or $\mathrm{S} 45$ or $\mathrm{S} 46$ or $\mathrm{S} 47$ or $\mathrm{S} 48$ or $\mathrm{S} 49$ or $\mathrm{S} 50$ or $\mathrm{S} 51$ or $\mathrm{S} 52$ or $\mathrm{S} 53$ or $\mathrm{S} 54$ or $\mathrm{S} 55$ or S56 or S57 or S58

S60 S19 or S59

6. Web of Science and conference proceedings

Feb 2013: 1950 to

Feb 142013

Jan 2014: 1950 to

Jan 242014
Topic $=\left(\right.$ dement $^{\star}$ OR alzheimer ${ }^{\star}$ OR "lewy bod ${ }^{\star}$ " OR DLB OR "vascular cognitive impairment ${ }^{\star}$ " OR FTD OF FTLD OR "cerebrovascular insufficienc*") AND Topic=(rivastigmin * OR exelon OR "SDZ ENA 713") AND Topic=(random* OR placebo OR "double-blind*" OR trial OR RCT OR CCT) AND Year Published=(2011-2013)

Timespan=All Years. Databases=SCI-EXPANDED, SSCI, A\&HCI, CPCI-S, CPCI-SSH.
Feb 2013: 102

Jan 2014: 54

\section{LILACS (BIREME) \\ Feb 2013: all dates to \\ 14 February 2013 \\ Jan 2014: all dates to \\ 24 January 2014}

rivastigmine OR rivastigmine OR "SDZ ENA 713" OR exelon [Words]

Feb 2013: 9

\begin{tabular}{|c|c|}
\hline 8. CENTRAL (The & \#1 MeSH descriptor: [Dementia] explode all trees \\
\hline & \#2 MeSH descriptor: [Delirium] this term only \\
\hline $\begin{array}{l}\text { Feb 2013: Issue } 4 \text { of } \\
\text { 12, } 2013\end{array}$ & \#3 MeSH descriptor: [Wernicke Encephalopathy] this term only \\
\hline $\begin{array}{l}\text { Jan 2014: Issue } 1 \text { of } \\
12,2014\end{array}$ & $\begin{array}{l}\text { \#4 MeSH descriptor: [Delirium, Dementia, Amnestic, Cognitive Disorders] this term } \\
\text { only }\end{array}$ \\
\hline
\end{tabular}

Rivastigmine for Alzheimer's disease (Review)

Feb 2013: 7

Jan 2014: 12 
(Continued)

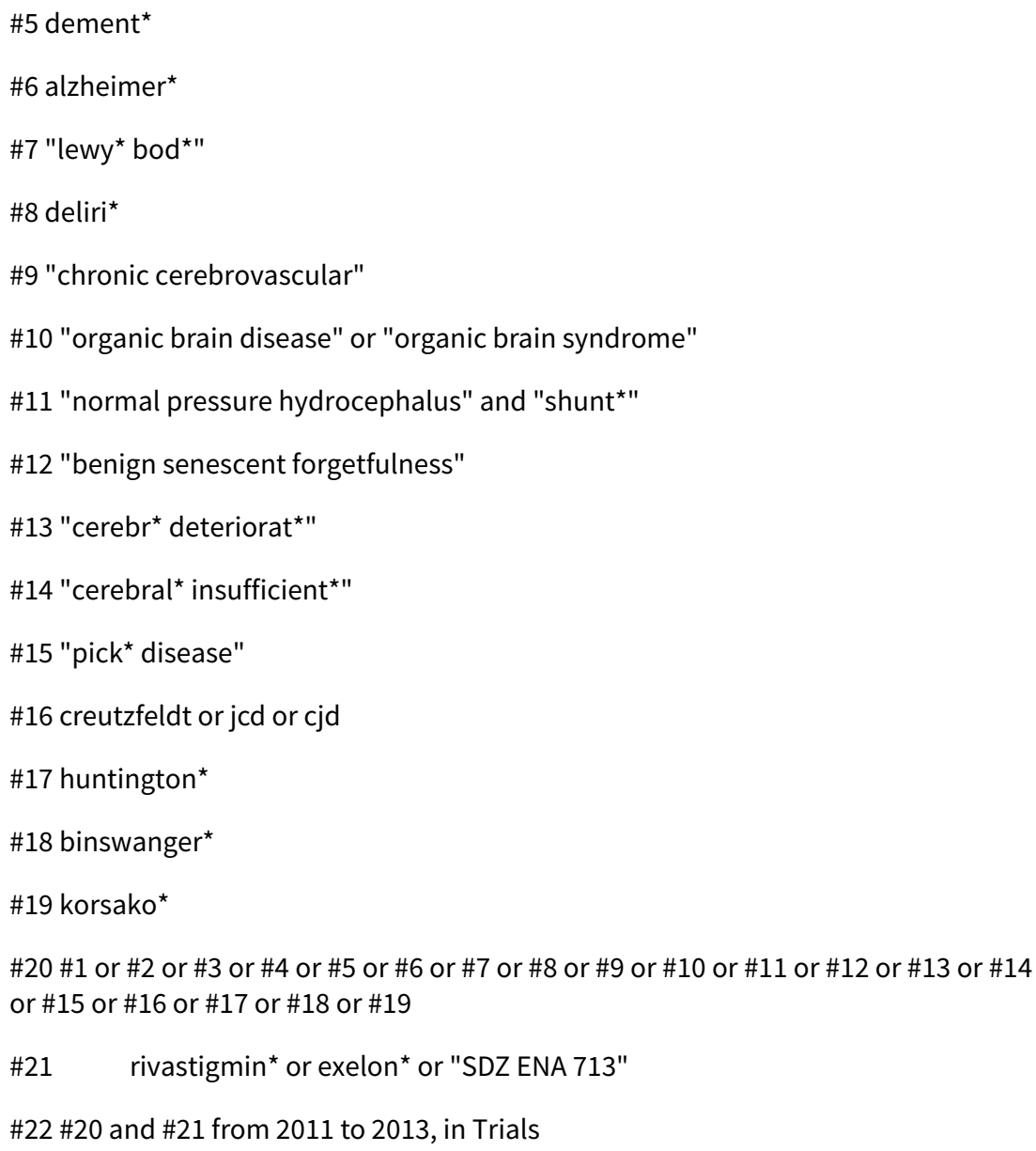

9. Clinicaltrials.gov (www.clinicaltrials.gov) rivastigmine OR exelon OR "SDZ ENA 713" | Interventional Studies | dementia OR alzheimer OR alzheimers OR lewy OR vascular cognitive impairment | Adult, Senior | received from $01 / 01 / 2011$ to $02 / 15 / 2013$

Feb 2013: 16

- all dates
10. ICTRP Search
Portal (http://
apps.who.int/tri-
alsearch) [includes:
Australian New
Zealand Clinical Tri-
als Registry; Clinical-
Trilas.gov; ISRCTN;
Chinese Clinical Tri-
al Registry; Clinical
Trials Registry - In-
dia; Clinical Research
Information Service
- Republic of Korea;
German Clinical Tri-
als Register; Iranian
Registry of Clinical
Trials; Japan Primary
Registries Network;
Pan African Clinical
Trial Registry; Sri

Advanced search: (rivastigmine OR exelon OR "SDZ ENA 713" | Interventional Stud-

Feb 2013: 136

ies) AND (received from 01/01/2011 to 02/15/2013)

Jan 2014: 2 


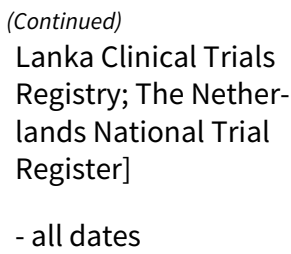

\section{Appendix 2. Update search: February 2011}

\begin{tabular}{lll}
\hline Source & Search strategy Hits retrieved
\end{tabular}

\begin{tabular}{ll}
$\begin{array}{l}\text { 1. ALOIS (www.medi- } \\
\text { cine.ox.ac.uk/alois) }\end{array}$ & $\begin{array}{l}\text { Advanced search: Study design: RCT AND Health status: Alzheimer AND Intervention: } \\
\text { rivastigmine }\end{array}$ \\
\hline
\end{tabular}

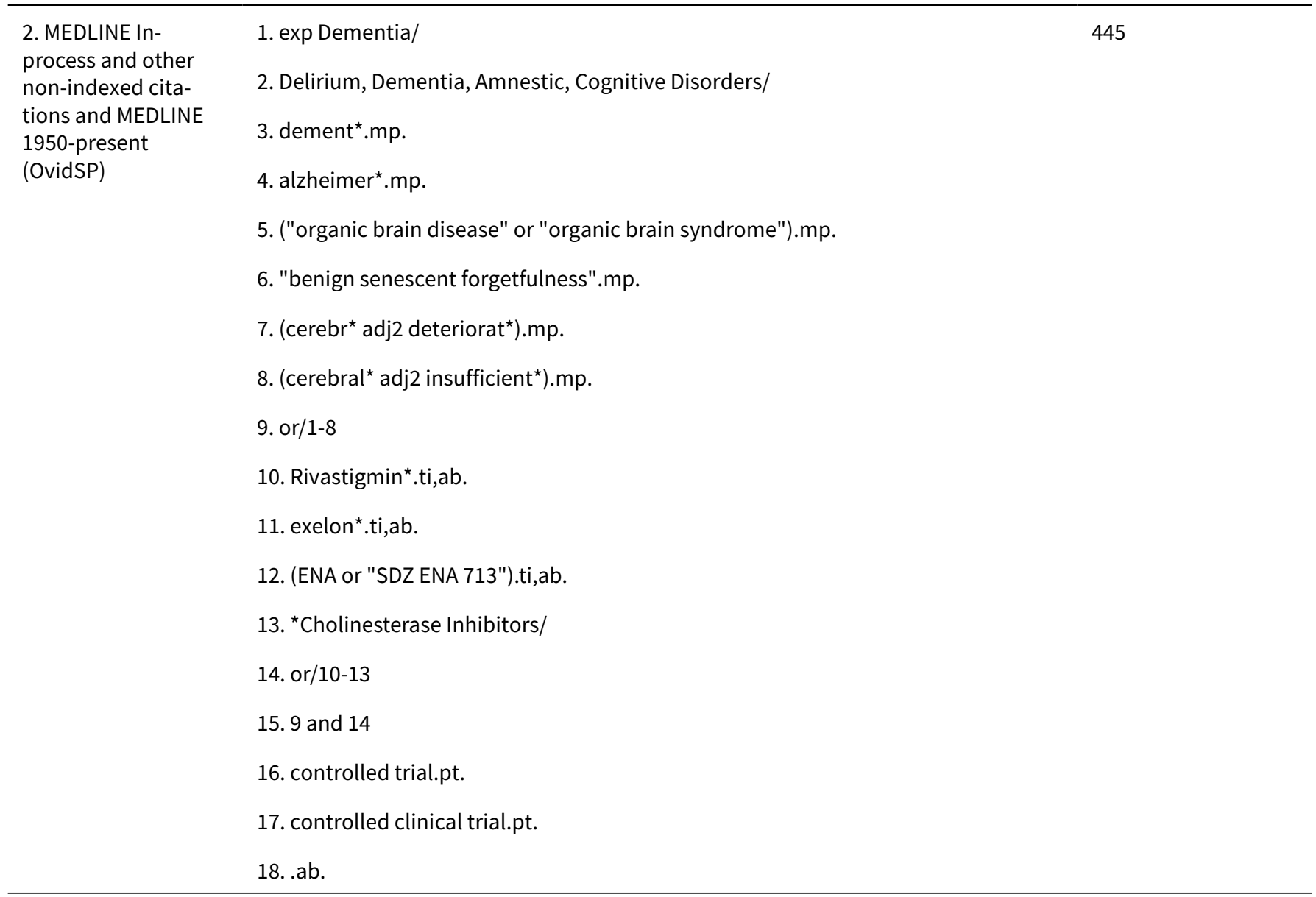


(Continued)

19. placebo.ab.

20. drug therapy.fs.

21. randomly.ab.

22. trial.ab.

23. groups.ab.

24. or/16-23

25. (animals not (humans and animals)).sh.

26. 24 not 25

27. 15 and 26

28. $\left(2008^{\star}\right.$ or $2009^{\star}$ or $2010^{\star}$ or $\left.2011^{\star}\right)$.ed.

29. 27 and 28

1980-2011 week 6

2. dement*.mp.

(OvidSP)

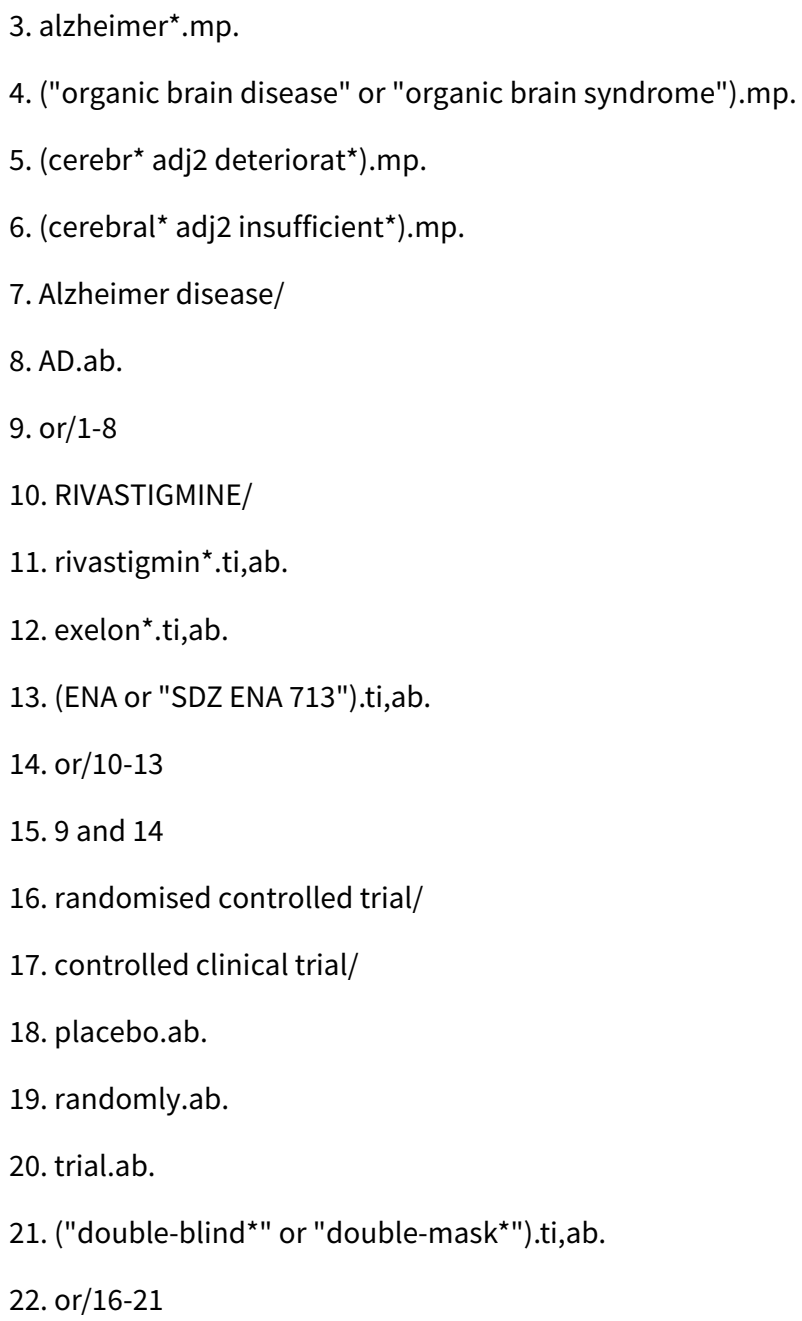


(Continued)

23. 15 and 22

24. $\left(2008^{\star}\right.$ or $2009^{\star}$ or $2010^{\star}$ or $\left.2011^{\star}\right)$.em.

25.23 and 24
4. PsycINFO
1. alzheimer ${ }^{\star} . \mathrm{mp}$.
2. ("organic brain disease" or "organic brain syndrome").mp.
22011 (OvidSP)
3. (cerebr ${ }^{\star}$ adj2 deteriorat $\left.{ }^{\star}\right) \cdot \mathrm{mp}$.
4. (cerebral $^{\star}$ adj2 insufficient $\left.{ }^{\star}\right) \cdot \mathrm{mp}$.
5. Alzheimer's Disease/
6. AD.ab.
7. or/1-6
8. rivastigmin ${ }^{\star} . t i, a b$.
9. exelon ${ }^{\star} . t i, a b$.
10. (ENA or "SDZ ENA 713").ti,ab.
11. or $/ 8-10$
12. 7 and 11
13. $\left(2008^{\star}\right.$ or $2009^{\star}$ or $2010^{\star}$ or $\left.2011^{\star}\right)$.up.
14. 12 and 13

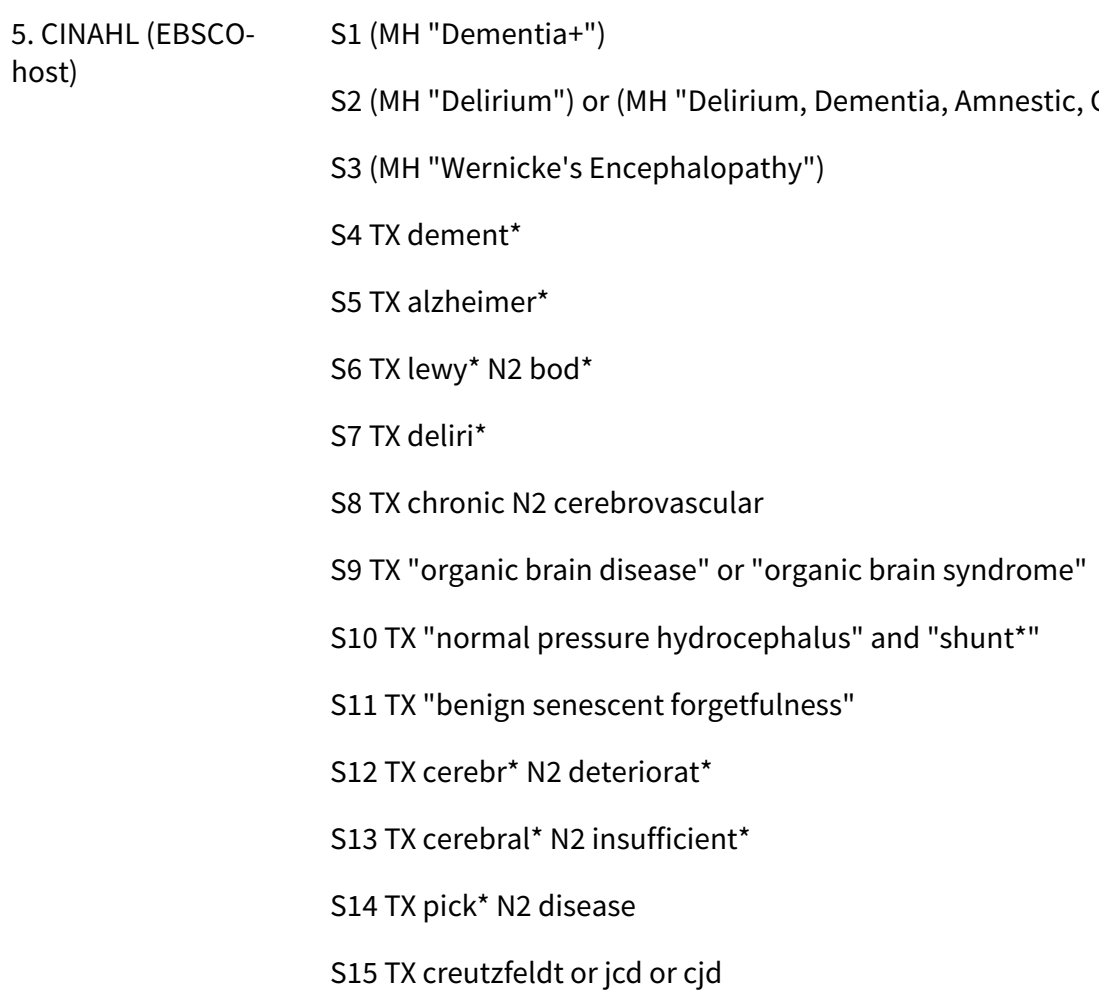

S3 (MH "Wernicke's Encephalopathy")

S4 TX dement*

S5 TX alzheimer*

S6 TX lewy* N2 bod*

S7 TX deliri ${ }^{*}$

S8 TX chronic N2 cerebrovascular

S9 TX "organic brain disease" or "organic brain syndrome"

S10 TX "normal pressure hydrocephalus" and "shunt*"

S11 TX "benign senescent forgetfulness"

S12 TX cerebr ${ }^{\star}$ N2 deteriorat*

S13 TX cerebral ${ }^{*}$ N2 insufficient ${ }^{*}$

S14 TX pick* N2 disease

S15 TX creutzfeldt or jcd or cjd

S2 (MH "Delirium") or (MH "Delirium, Dementia, Amnestic, Cognitive Disorders") 


\section{S16 TX huntington* \\ S17 TX binswanger* \\ S18 TX korsako*}

$\mathrm{S} 19 \mathrm{~S} 1$ or $\mathrm{S} 2$ or $\mathrm{S} 3$ or $\mathrm{S} 4$ or $\mathrm{S} 5$ or $\mathrm{S} 6$ or $\mathrm{S} 7$ or $\mathrm{S} 8$ or $\mathrm{S} 9$ or $\mathrm{S} 10$ or $\mathrm{S} 11$ or $\mathrm{S} 12$ or $\mathrm{S} 13$ or $\mathrm{S} 14$ or $\mathrm{S} 15$ or $\mathrm{S} 16$ or $\mathrm{S} 17$ or $\mathrm{S} 18$

S20 TX "cognit* impair*"

S21 TX "cognit* defect*"

S22 (MH "Cognition Disorders+")

S23 TX MCI

S24 TX ACMI

S25 TX ARCD

S26 TX SMC

S27 TX CIND

S28 TX BSF

S29 TX AAMI

S30 AB MD

S31 AB LCD

S32 AB QD OR "questionable dementia"

S33 TX AACD

S34 TX MNCD

S35 TX "N-MCI" or "A-MCI" or "M-MCI"

S36 TX "preclinical AD"

S37 TX "pre-clinical AD"

S38 TX "preclinical alzheimer*" or "pre-clinical alzheimer*"

\section{S39 TX aMCI OR MCla}

S40 TX "CDR 0.5 " or "clinical dementia rating scale 0.5 "

S41 TX "GDS 3" OR "stage 3 GDS"

S42 TX "global deterioration scale" AND "stage 3"

S43 TX "Benign senescent forgetfulness"

S44 TX "mild neurocognit* disorder"

S45 TX prodrom* N2 dement*

S46 TX "age-related symptom*"

S47 TX cognit* N2 deficit*

S48 TX cognit* N2 deteriorat*

S49 TX cognit* N2 declin* 
(Continued)

\section{S50 TX cognit* N2 degenerat* \\ S51 TX cognit* N2 complain* \\ S52 TX cognit* N2 disturb* \\ S53 TX cognit * N2 disorder*}

S54 TX memory N2 episod* or TX memory N2 los* or TX memory N2 impair* or TX memory N2 complain*

S55 TX memory N2 disturb* or TX memory N2 disorder ${ }^{\star}$ or TX cerebr ${ }^{\star}$ N2 impair ${ }^{\star}$ or TX cerebr* N2 los*

S56 TX cerebr ${ }^{\star}$ N2 complain* or TX cerebr ${ }^{\star}$ N2 deteriorat ${ }^{*}$ or TX cerebr ${ }^{\star}$ N2 disorder* or TX cerebr* N2 disturb*

S57 TX mental ${ }^{\star}$ N2 declin* or TX mental ${ }^{\star}$ N2 los $^{\star}$ or TX mental ${ }^{\star}$ N2 impair* or TX mental ${ }^{*} \mathrm{~N} 2$ deteriorat $^{\star}$

S58 TX "pre-clinical dementia" or TX "preclinical dementia"

$\mathrm{S} 59 \mathrm{~S} 20$ or S21 or S22 or S23 or S24 or S25 or S26 or S27 or S28 or S29 or S30 or S31 or $\mathrm{S} 32$ or $\mathrm{S} 33$ or $\mathrm{S} 34$ or $\mathrm{S} 35$ or $\mathrm{S} 36$ or $\mathrm{S} 37$ or $\mathrm{S} 38$ or $\mathrm{S} 39$ or $\mathrm{S} 40$ or $\mathrm{S} 41$ or $\mathrm{S} 42$ or $\mathrm{S} 43$ or $\mathrm{S} 44$ or $\mathrm{S} 45$ or $\mathrm{S} 46$ or $\mathrm{S} 47$ or $\mathrm{S} 48$ or $\mathrm{S} 49$ or $\mathrm{S} 50$ or $\mathrm{S} 51$ or $\mathrm{S} 52$ or $\mathrm{S} 53$ or $\mathrm{S} 54$ or $\mathrm{S} 55$ or S56 or S57 or S58

S60 S19 or S59
6. ISI Web of Knowl- edge - all databas- es [includes: Web of Science (1945- present); BIOSIS Pre- views (1926-present); MEDLINE (1950- present); Journal Ci- tation Reports]

Topic=(rivastigmine OR exelon OR ena OR "SDZ ENA 713") AND Topic=(alzheimer* OR AD OR "ADD") AND Topic=(random* OR placebo OR trial OR "double-blind*") AND Year Published $=(2008-2011)$

\begin{tabular}{lll}
\hline 7. LILACS (BIREME) & rivastigmine OR exelon & 7 \\
\hline $\begin{array}{l}\text { 8. CENTRAL (The } \\
\text { Sochrane Library) (Is- }\end{array}$ & $\# 1$ MeSH descriptor Dementia explode all trees & 40 \\
sue Oct 2010) & $\# 2$ MeSH descriptor Delirium, this term only \\
& $\# 3$ MeSH descriptor Wernicke Encephalopathy, this term only \\
& $\# 4$ MeSH descriptor Delirium, Dementia, Amnestic, Cognitive Disorders, this term \\
& only \\
& $\# 5$ dement ${ }^{\star}$ \\
& $\# 6$ alzheimer* \\
& $\# 7$ "lewy* bod*" \\
& $\# 8$ deliri ${ }^{\star}$ \\
& $\# 9$ "chronic cerebrovascular" \\
& $\# 10$ "organic brain disease" or "organic brain syndrome" \\
& $\# 11$ "normal pressure hydrocephalus" and "shunt"
\end{tabular}


(Continued)

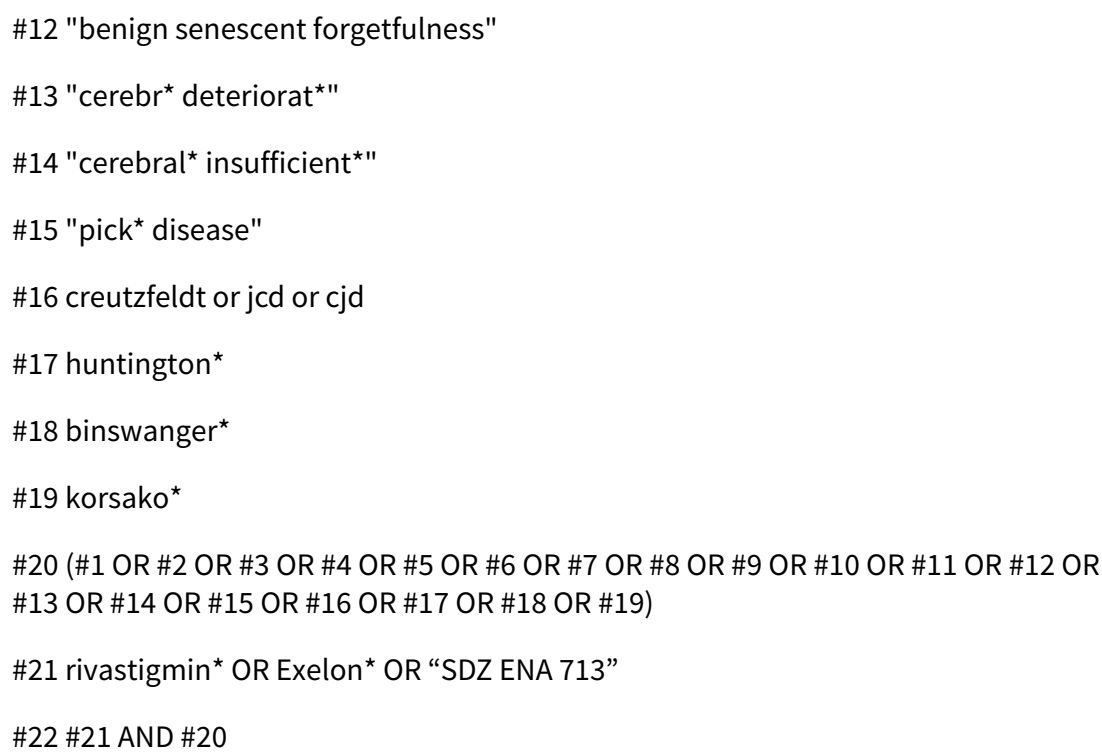

$\begin{array}{lll}\text { 9. Clinicaltrials.gov } & \begin{array}{l}\text { Advanced search: Intervention: rivastigmine OR Exelon OR "SDZ ENA 713” AND Con- } \\ \text { (www.clinicaltrial- }\end{array} & 18 \\ & \text { dition: Alzheimer OR Alzheimer's OR ad OR dementia OR alzheimers } & \end{array}$
10. ICTRP Search Portal (http:// apps.who.int/tri- alsearch) [includes: Australian New Zealand Clinical Tri- als Registry; Clinical- Trilas.gov; ISRCTN; Chinese Clinical Tri- al Registry; Clinical Trials Registry - In- dia; Clinical Research Information Service - Republic of Korea; German Clinical Tri- als Register; Iranian Registry of Clinical Trials; Japan Primary Registries Network; Pan African Clinical Trial Registry; Sri Lanka Clinical Trials Registry; The Nether- lands National Trial Register]

\section{(Alzheimer OR Alzheimer's OR ad OR dementia OR alzheimers) AND (rivastigmine OR 5 Exelon) AND (2008-2011)}


WHAT'S NEW

\begin{tabular}{lll}
\hline Date & Event & Description \\
\hline 2 March 2020 & Amended & One word changed/corrected in PLS \\
\hline
\end{tabular}

\section{HISTOR Y}

Protocol first published: Issue 3, 1998

Review first published: Issue 3, 1998

\begin{tabular}{|c|c|c|}
\hline Date & Event & Description \\
\hline 10 September 2015 & Amended & $\begin{array}{l}\text { Third author added (previously omitted in error); Implications for } \\
\text { research section edited to remove incorrect text. }\end{array}$ \\
\hline 10 September 2015 & $\begin{array}{l}\text { New citation required but conclusions } \\
\text { have not changed }\end{array}$ & $\begin{array}{l}\text { Third author added (previously omitted in error); Implications for } \\
\text { research section edited to remove incorrect text. }\end{array}$ \\
\hline 2 March 2015 & New search has been performed & $\begin{array}{l}\text { A pre-publication search was run for this review on } 2 \text { March } 2015 . \\
\text { All results were assessed and no new studies were identified }\end{array}$ \\
\hline 2 March 2015 & $\begin{array}{l}\text { New citation required but conclusions } \\
\text { have not changed }\end{array}$ & Conclusions unchanged \\
\hline 24 January 2014 & New search has been performed & $\begin{array}{l}\text { An update search was performed for this review on } 24 \text { January } \\
2014 .\end{array}$ \\
\hline 15 February 2013 & New search has been performed & $\begin{array}{l}\text { A pre-publication search was performed for this review on } 15 \\
\text { February } 2013\end{array}$ \\
\hline 10 May 2011 & New search has been performed & $\begin{array}{l}\text { An update search was performed for this review on } 16 \text { February } \\
2011\end{array}$ \\
\hline 24 March 2009 & Amended & Table 1 and Discussion have been amended \\
\hline 18 December 2008 & New search has been performed & Update searches were run in March 2008 \\
\hline 4 September 2008 & $\begin{array}{l}\text { New citation required and conclusions } \\
\text { have changed }\end{array}$ & $\begin{array}{l}\text { An update search was performed on } 27 \text { March 2008. Two new } \\
\text { studies have been included, IDEAL and Mowla } 2007 .\end{array}$ \\
\hline \multirow[t]{2}{*}{15 June 2006} & New search has been performed & $\begin{array}{l}\text { Update 2006. Two new trials in more severe dementia, Karaman } \\
2005 \text { and Lopez-Pousa 2005, were included. }\end{array}$ \\
\hline & & $\begin{array}{l}\text { We have contacted the authors of Karaman } 2005 \text { for clarification } \\
\text { of their unusual drop out rates and unusually small standard de- } \\
\text { viations of outcome measures before drawing firm conclusions } \\
\text { from the data, but have not received a reply. }\end{array}$ \\
\hline 30 August 2000 & $\begin{array}{l}\text { New citation required and conclusions } \\
\text { have changed }\end{array}$ & Substantive amendment \\
\hline
\end{tabular}




\section{CONTRIBUTIONS OF AUTHORS}

This updated review was prepared by J Birks and J Grimley Evans. V lakovidou and M Tsolaki made contributions to the original review.

Contact editor: Frans Verhey.

Consumer editor: Mervyn Richardson.

The review has been peer reviewed anonymously.

The 2014 update was undertaken by J Birks.

\section{DECLARATIONS OF INTEREST}

None known

\section{SOURCES OF SUPPORT}

\section{Internal sources}

- No sources of support supplied

\section{External sources}

- NIHR, UK.

This review update was supported by the National Institute for Health Research, via a Cochrane Programme Grant to the Cochrane Dementia and Cognitive Improvement group. The views and opinions expressed therein are those of the authors and do not necessarily reflect those of the Systematic Reviews Programme, NIHR, NHS or the Department of Health

\section{DIFFERENCES BETWEEN PROTOCOLANDREVIEW}

In the 2014 update of the review, the results were reorganised to focus on currently recommended doses. The main analysis was done for the 26 week period and seven outcomes were prioritised for meta-analysis. The other analyses done in earlier versions are retained in the appendix.

The risk of bias assessment of individual studies was also expanded for this update, with additional assessments on blinding, selective reporting and other biases carried out.

\section{NOTES}

\section{Update 2014}

Additional studies were included: Mowla 2007, Nakamura 2011

\section{Update 2005}

One new trial, Ballard 2005, met the inclusion criteria for the review but its results could not be included in the analyses. There were substantial losses from the trial, and of concern was the elimination of those participants with low baseline scores from the analyses.

November 2003: following an update search, one additional trial, Tai 2000, was added. There is only limited information available about this trial. It appears to be an independent trial carried out in Taiwan. No results could be used from Tai 2000.

The review authors dealt with the consumer editor and peer reviewer comments.

\section{N DEX TERMS}

\section{Medical Subject Headings (MeSH)}

Alzheimer Disease [*drug therapy]; Caregivers [psychology]; Cholinesterase Inhibitors [*administration \& dosage] [adverse effects]; Cognition Disorders [drug therapy]; Drug Administration Schedule; Phenylcarbamates [*administration \& dosage] [adverse effects]; Randomized Controlled Trials as Topic; Rivastigmine; Severity of Illness Index

\section{MeSH check words}

Humans 